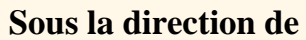 Marcel Fournier, Yves Gingras et Othmar Keel
}

Marcel Fournier, sociologue, département de sociologie, Université de Montréal, Yves Gingras, département de sociologie de l’UQAM,

Otmar Keel, historien, département d’Histoire, Université de Montréal.

(1987)

\section{Sciences et médecine au Québec. \\ Perspectives sociohistoriques}

Un document produit en version numérique par Jean-Marie Tremblay, bénévole, professeur de sociologie au Cégep de Chicoutimi

Courriel: jmt_sociologue@videotron.ca

Site web: http://pages.infinit.net/sociojmt

Dans le cadre de la collection: "Les classiques des sciences sociales"

Site web: http://classiques.uqac.ca/

Une collection développée en collaboration avec la Bibliothèque Paul-Émile-Boulet de l'Université du Québec à Chicoutimi

Site web: http://bibliotheque.uqac.ca/ 


\section{Politique d'utilisation de la bibliothèque des Classiques}

Toute reproduction et rediffusion de nos fichiers est interdite, même avec la mention de leur provenance, sans l'autorisation formelle, écrite, du fondateur des Classiques des sciences sociales, Jean-Marie Tremblay, sociologue.

Les fichiers des Classiques des sciences sociales ne peuvent sans autorisation formelle:

- être hébergés (en fichier ou page web, en totalité ou en partie) sur un serveur autre que celui des Classiques.

- servir de base de travail à un autre fichier modifié ensuite par tout autre moyen (couleur, police, mise en page, extraits, support, etc...),

Les fichiers (.html, .doc, .pdf., .rtf, .jpg, .gif) disponibles sur le site Les Classiques des sciences sociales sont la propriété des Classiques des sciences sociales, un organisme à but non lucratif composé exclusivement de bénévoles.

Ils sont disponibles pour une utilisation intellectuelle et personnelle et, en aucun cas, commerciale. Toute utilisation à des fins commerciales des fichiers sur ce site est strictement interdite et toute rediffusion est également strictement interdite.

L'accès à notre travail est libre et gratuit à tous les utilisateurs. C'est notre mission.

Jean-Marie Tremblay, sociologue

Fondateur et Président-directeur général, LES CLASSIQUES DES SCIENCES SOCIALES. 
Cette édition électronique a été réalisée par Jean-Marie Tremblay, bénévole, professeur de sociologie au Cégep de Chicoutimi à partir de :

Sous la direction de Marcel FOURNIER, Yves GINGRAS et Otmar KEEL,

Sciences et médecine au Québec. Perspectives sociohistoriques.

Québec : IQRC (Institut québécois de recherche sur la culture), 1987, 210 pp.

Marcel Fournier [sociologue, département de sociologie, Université de Montréal]; Yves Gingras, département de sociologie de l’UQAM; Otmar Keel [historien, département d’Histoire, Université de Montréal].

[Les auteurs nous ont autorisé, le 29 septembre 2008, conjointement avec la permission du directeur général des Presses de l’Université Laval, M. Denis Dion, la diffusion de ce livre dans Les Classiques des sciences sociales.]

8. Courriels denis.dion@pul.ulaval.ca, marcel.fournier@umontreal.ca, otkeel@yahoo.fr et gingras.yves@uqam.ca.

URL : http://www.pulaval.com/

Polices de caractères utilisée :

Pour le texte: Times New Roman, 12 points.

Pour les citations : Times New Roman, 12 points.

Pour les notes de bas de page : Times New Roman, 12 points.

Édition électronique réalisée avec le traitement de textes Microsoft Word 2001 pour Macintosh.

Mise en page sur papier format : LETTRE (US letter), 8.5'’ x 11'’)

Édition numérique réalisée le 14 janvier 2009 à Chicoutimi, Ville de Saguenay, province de Québec, Canada. 


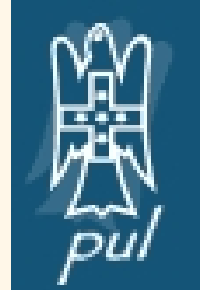

Nous voulons remercier la direction des Éditions des Presses de l'Université Laval et de l'IQRC de nous avoir donné son autorisation, conjointement avec celle de MM. Marcel Fournier, Yves Gingras et Othmar Keel, de diffuser le texte intégral de ce livre, Sciences et médecine au Québec. Perspectives sociohistoriques, dans Les Classiques des sciences sociales.

Merci de votre confiance en nous et longue vie aux Presses de l’Université Laval et de l’IQRC (Institut québécois de recherche sur la culture).

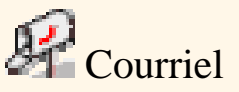

marcel.fournier@umontreal.ca, otkeel@yahoo.fr et gingras.yves@uqam.ca.

Merci à l'éditeur :

M. Denis Dion, dir. gén., Éditions des PUL et de l’IQRC :

Courriel :

denis.dion@pul.ulaval.ca

URL : http://www.pulaval.com/

Merci,

Jean-Marie Tremblay, sociologue.

Fondateur et PDG, Les Classiques des sciences sociales. 14 janvier 2009. 
Sous la direction de

Marcel FOURNIER, Yves GINGRAS et Otmar KEEL,

Sciences et médecine au Québec.

Perspectives sociohistoriques.

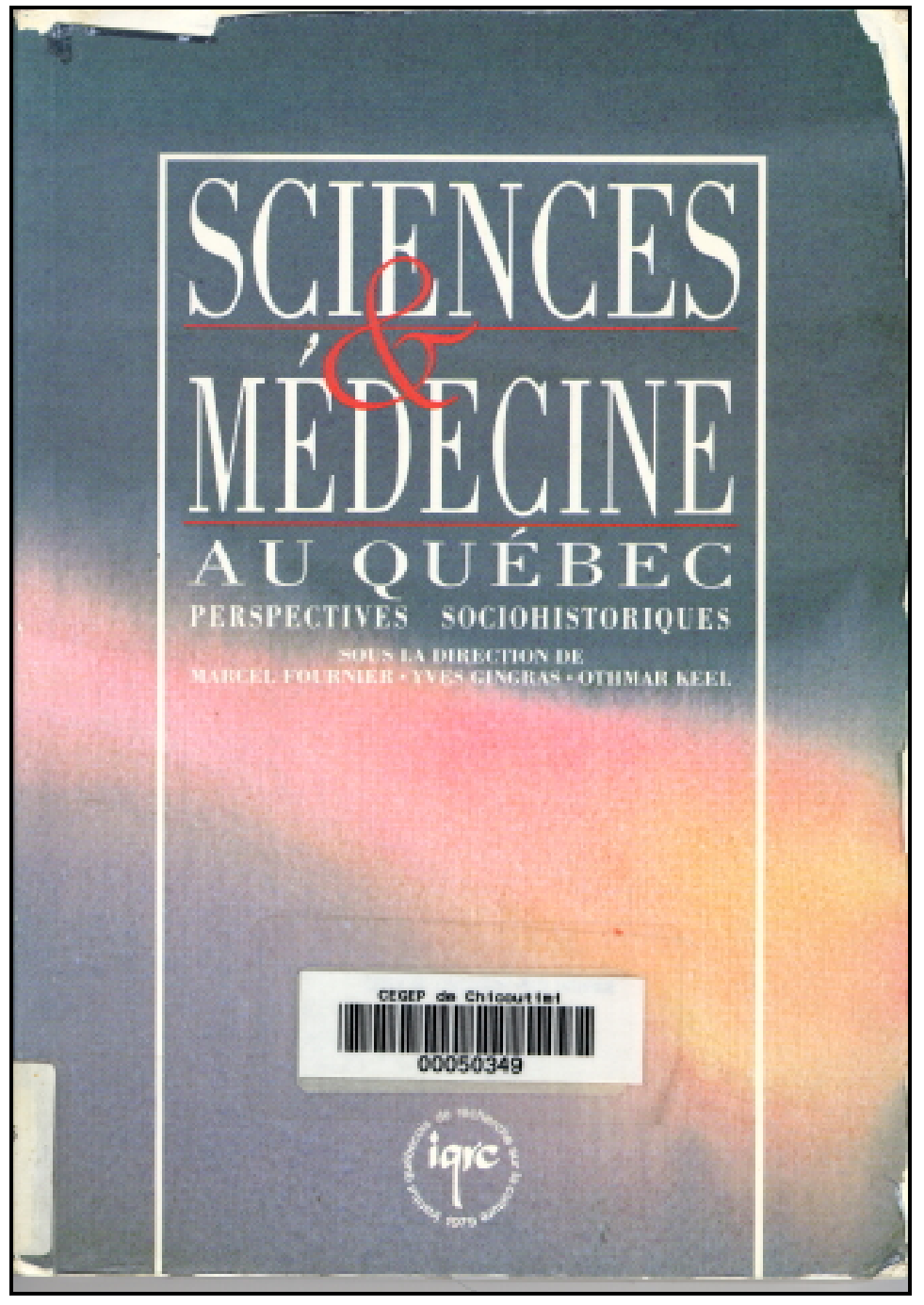

Québec : IQRC (Institut québécois de recherche sur la culture), 1987, 210 pp. 


\section{Table des matières}

Quatrième de couverture

$\underline{\text { Remerciements }}$

$\underline{\text { Collaborateurs }}$

Marcel Fournier, Yves Gingras et Othmar Keel, “Introduction.”

Chapitre 1. Robert Gagnon, "Les discours sur l'enseignement pratique au canada français, 1850-1900.”

Chapitre 2. Richard A. Jarrell, "L'ultramontanisme et la science au Canada français."

Chapitre 3. Yves Gingras, "La réception des rayons $\mathrm{X}$ au Québec : radiographie des pratiques scientifiques."

Chapitre 4. Michael Farley, Peter Keating et Othmar Keel, "La vaccination à Montréal dans la seconde moitié du 19e siècle : pratiques, obstacles et résistances."

Chapitre 5. George Weisz, “Origines géographiques et lieux de pratique des diplômés en médecine au Québec de 1834 à 1939.”

Chapitre 6. Marcel Fournier, “Entre l'hôpital et l'université : l'Institut du cancer de Montréal.” 
Sciences et médecine au Québec.

Perspectives sociohistoriques

\section{QUATRIÈME DE COUVERTURE}

$\underline{\text { Retour à la table des matières }}$

Face aux nombreux discours que suscite aujourd'hui le développement rapide de la science et de la technologie, le présent volume offre, en raison de la perspective sociohistorique adoptée, le moyen d'une indispensable prise de distance. Pour la période qui va de la fin du XIXe siècle aux années 1960, les auteurs ont réuni des études originales qui mettent en lumière, la spécificité du développement des sciences et de la médecine au Québec.

Les sciences et la médecine moderne au Québec ont une histoire riche et complexe dont ne rend pas compte la problématique évolutionniste du « retard ». Les études rassemblées ici vont au-delà des simples survols et proposent une analyse rigoureuse de divers aspects du processus d'institutionnalisation de l'activité scientifique: attitudes des classes dirigeantes et du clergé envers les sciences, position des sciences dans l'enseignement, conditions d'implantation de la vaccination à Montréal, réaction des scientifiques face à la découverte des rayons $\mathrm{X}$. rôle des institutions universitaires dans la formation des médecins et stratégie des chercheurs dans les centres de recherche biomédicale. 
Sciences et médecine au Québec.

Perspectives sociohistoriques

\section{REMERCIEMENTS}

$\underline{\text { Retour à la table des matières }}$

Il nous fait plaisir de remercier l'Université de Montréal et l'Université du Québec à Montréal pour leur contribution aux frais de traduction des textes de MM. Richard A. Jarrell et George Weisz. 
Sciences et médecine au Québec.

Perspectives sociohistoriques

\section{Collaborateurs}

$\underline{\text { Retour à la table des matières }}$

Michael Farley Sciences, technologie et communications, ministère des Affaires extérieures, Canada

Marcel Fournier Professeur, Département de sociologie, Université de Montréal

Robert Gagnon Département de sociologie, Université de Montréal

Yves Gingras $\quad$ Professeur, Département de sociologie, Université du Québec à Montréal

Richard A. Jarrell Professeur, Department of Natural Science, Atkinson College, York University

Peter Keating Chercheur, Department of the History of Science, Harvard University

Othmar Keel Professeur, Département d'histoire, Université de Montréal

George Weisz Professeur, Humanities and Social Studies of Medicine, McGill University 
Sciences et médecine au Québec.

Perspectives sociohistoriques

\section{INTRODUCTION}

par Marcel Fournier, Yves Gingras et Othmar Keel

Respectivement professeurs, Département de sociologie, Université de Montréal, Département de sociologie, Université du Québec à Montréal et Département d’histoire, Université de Montréal.

$\underline{\text { Retour à la table des matières }}$

Dans sa préface à l'étude de Raymond Duchesne, La science et le pouvoir au Québec, publiée en 1978, Fernand Dumont constatait que l'histoire des sciences était une «parente pauvre » de l'histoire de la culture québécoise ${ }^{1}$. La même observation aurait pu être faite pour la sociologie des sciences. Il faut attendre en effet le début des années 1970 pour que soient introduits dans les programmes universitaires des cours d'histoire et de sociologie des sciences et que se multiplient les recherches et les publications dans ces domaines. Au Canada, cette croissance a entraîné la création en 1976 du « newsletter » History of Science and Technology in Canada Bulletin, devenu revue savante en 1981.

L'apparition de ces nouvelles préoccupations intellectuelles n'est pas, il faut le reconnaître, indépendante d'une prise de conscience de l'enjeu social, politique et économique que représente le développement des activités scientifiques (enseignement et recherche). Au cours des deux dernières décennies, l'action même des gouvernements témoigne de l'importance de ce «nouvel » enjeu : création en 1966 du Conseil des sciences du Canada, mise sur pied en 1968 à

1 Raymond Duchesne, La science et le pouvoir au Québec (1920-1965), Québec, Éditeur officiel, 1978. 
Ottawa d'un Comité du Sénat dirigé par Maurice Lamontagne, chargé d'enquêter sur la politique scientifique canadienne et organisation en 1971 d'un ministère d'État aux Sciences et à la Technologie; au Québec, en 1982, création d'un ministère de la Science et de la Technologie à la suite de l'élaboration, en 1980, d'une Politique québécoise de la recherche scientifique.

Au moment même où la société québécoise cherche à tourner une page de son histoire et à prendre le "virage technologique », se manifestent ici et là divers signes d'inquiétude, et aussi des attitudes critiques dont certaines expriment un vague sentiment antiscientifique. Centrales nucléaires et lignes hydroélectriques dans les champs, robots dans les usines et micro-ordinateurs dans les maisons, voilà des symboles de la nouvelle «force » que représente le couple sciencetechnologie, et dont on craint une perte de contrôle dans un futur pas si lointain.

Face aux controverses que suscite le développement des sciences, quelle que soit notre attitude, positive ou négative, enthousiaste ou désenchantée, l'histoire et la sociologie nous offrent les moyens d'une indispensable prise de distance : la science est certes un "facteur de changement », une "force productive », diront certains, mais son action s'exerce dans des contextes qui, par les ressources économiques, politiques et culturelles mobilisées, lui donnent une orientation et une signification particulières.

Au Québec, l'émergence au début des années 1920 d'une première génération de scientifiques professionnels francophones avait suscité un certain intérêt pour des questions de l'histoire des sciences. Cependant, il s'agissait moins d'étudier de façon rigoureuse les origines d'une tradition scientifique canadienne-française que de chercher dans le passé des "précurseurs » et aussi des explications à ce que plusieurs percevaient alors comme un développement tardif d'institutions et de vocations scientifiques chez les Canadiens français. C'est du moins l'impression que donne la comparaison des deux milieux anglophone et francophone de l'époque. Ces interrogations s'ajoutaient d'ailleurs à celles plus globales sur le rôle des Canadiens français dans le développement économique de la province de Québec. Ainsi engagés dans des débats publics, les scientifiques de la première heure comme le frère Marie-Victorin, Léon Lortie, Adrien Pouliot et Jacques Rousseau, pour n'en nommer que quelques-uns, se sont affirmés non seulement comme les défenseurs de la science mais aussi comme les historiens et les sociologues de leur propre activité intellectuelle. Dans le mouvement même où ils 
s'impliquaient dans l'organisation de laboratoires et la mise sur pied de sociétés savantes ou d'associations scientifiques telle l'Association canadienne-française pour l'avancement des sciences (ACFAS), ces scientifiques espéraient acquérir, sur les plans local et national, une légitimité culturelle, en s'inventant en quelque sorte une tradition glorieuse remontant jusqu'à la Nouvelle-France.

Parallèlement à cette activité d'historien, les pionniers des années 1920 firent aussi prendre conscience aux Canadiens français de leur position dominée dans le système scientifique canadien. Élève et disciple du frère Marie-Victorin et, pendant de longues années, secrétaire de l'ACFAS, Jacques Rousseau se préoccupait, au début des années 1930, de la situation de la formation scientifique du Canada français : sur la base d'une analyse de la carrière des diplômés de la Faculté des sciences de l'Université de Montréal, entre 1920 et 1930, celui-ci constatait l'absence de diplômés à des postes dans les services scientifiques provinciaux et fédéraux ou dans l'industrie ${ }^{2}$. Dix ans plus tard, un autre professeur, Georges Baril, formulait la même conclusion : le principal débouché pour les diplômés en sciences demeure l'enseignement ${ }^{3}$. La thématique de ces scientifiques et de ces professeurs en sciences était celle du «salut par l'éducation ». Pour sa part, Adrien Pouliot, professeur de mathématiques à l'École de chimie de l'Université Laval, lançait à la toute fin des années 1920 un cri d'alarme dans une série d'articles «Les sciences dans l'enseignement classique » qui, publiés dans la revue L'Enseignement secondaire, eurent un impact considérable dans les milieux de l'enseignement ${ }^{4}$. L'un de ses collègues, Cyrias Ouellet, adoptait aussi le style pamphlétaire pour dénoncer les déficiences de la culture de la classe supérieure francophone et pour présenter la science comme un «antidote à nos maladies 5 ». Vingt ans plus tard, il publiait une première esquisse de l'histoire des sciences et de l'état de la recherche au Canada français,

2 Jacques Rousseau, "Les sciences pures chez les Canadiens français », Opinions, vol. III, no 3, juillet 1932, p. 8-10.

3 Georges Baril, «La Faculté des sciences: vingtième anniversaire de sa fondation ", Annales de l'ACFAS, vol. VII, 1941, p. 217-218.

4 Voir l'article de F. Descarries-Bélanger, M. Fournier et L. Maheu, « Le frère Marie-Victorin et les petites sciences", Recherches sociographiques, vol. XX, no 1, janvier-avril 1979, p. 7-39.

5 Cyrias Ouellet, «Les sciences dans l'éducation », Les idées, vol. VIII, nos 1-2, juillet-août 1938, p. 62-63. 
esquisse qui pendant longtemps allait demeurer la principale référence dans le domaine ${ }^{6}$.

Au sein de cette génération de scientifiques, Léon Lortie, de l'Université de Montréal, est celui qui, après avoir été actif dans le mouvement de « défense de la science » et avoir occupé des postes administratifs au sein de l'Université et ailleurs, développa un intérêt soutenu pour l'histoire de la science au Canada au point d'en faire une spécialité. On lui confia en 1949 la tâche de rédiger le chapitre consacré aux sciences dans le recueil d'études spéciales pour la Commission royale d'enquête sur l'avancement des arts, des lettres et des sciences au Canada ${ }^{7}$. Lortie écrira aussi plusieurs articles sur divers aspects de la trame scientifique de l'histoire du Canada et entreprendra à la fin de sa carrière universitaire une histoire, demeurée inachevée, de l'Université de Montréal et de l'École Polytechnique ${ }^{8}$.

Les scientifiques se sont donc préoccupés de présenter et d'analyser euxmêmes le développement de leurs disciplines. En médecine, la situation est identique: la première génération d'historiens de la médecine est en effet composée presque uniquement de médecins. Signalons entre autres, History of Medicine in the Province of Quebec (Montréal, 1932), de Maude Abbot de l'Université McGill, la biographie de Michel Sarrazin, chirurgien de la NouvelleFrance, Michel Sarrazin, sa vie, ses travaux et son temps (Lévis, 1927), pour laquelle Arthur Vallée de l'Université Laval obtint en 1928 le Prix David, et les nombreux travaux du docteur Léo Parizeau de Montréal, l'un des animateurs de la Société de biologie et de l'ACFAS ${ }^{9}$.

6 La vie des sciences au Canada français, Québec, ministère des Affaires culturelles, 1964.

7 Léon Lortie, «Les sciences », dans Les arts, lettres et sciences au Canada, 1949-1951, Ottawa, Imprimeur de Sa Majesté le Roi, 1951, p. 289-300. L'un de ses collègues, le mathématicien Abel Gauthier signe le chapitre sur les mathématiques.

8 Par exemple : Léon Lortie, «La trame scientifique de l'histoire du Canada », dans Les pionniers de la science canadienne, Toronto, University of Toronto Press, 1966, p. 3-35 ; «Les débuts de l'ère scientifique », dans Léon Lortie et Adrien Pouliot, éd., Deux sources du présent, Société royale du Canada, University of Toronto Press, 1960, p. 90-104.

9 Par exemple, Léo Parizeau, «Le centenaire de la fondation du Journal de médecine de Québec », Union médicale du Canada, vol. 55, 1926, p. 1-7, «Et 
En histoire de la médecine, la recherche connut dans les années d'après-guerre un essor considérable avec la formation de la Société canadienne d'histoire de la médecine à l'Université Laval en 1950. Tout aussi bien historiens que médecins, les membres de cette société publièrent plus d'une centaine de travaux pendant les premières vingt-cinq années ${ }^{10}$. Au fil des ans, ces scientifiques et ces médecinshistoriens firent graduellement place à des chercheurs formés dans les sciences humaines et sociales et préoccupés de réunir d'une manière plus systématique et plus critique les diverses données disponibles.

L'histoire des sciences et de la médecine demeure cependant longtemps marginale dans le champ des recherches historiques qui, à partir des années 1950, connaît une forte expansion. Dans son étude récente sur « La modernisation de l'historiographie et l'émergence de l'histoire sociale », l'historien Fernand Ouellet ne consacre qu'un court paragraphe à l'histoire des sciences et de la technologie, indice à la fois du développement récent de ce domaine de recherche et du fait que ses praticiens ne sont pas encore vraiment intégrés à la communauté des historiens ${ }^{11}$. Cependant, le développement de l'histoire sociale facilite la

avant l'ACFAS, il y eut la SPASLAC », Annales de l'ACFAS, vol. IX, 1943, p. 186-188.

10 Sur l'histoire de cette société, voir S. Leblond, «La société canadienne d'histoire de la médecine », Les cahiers des dix, no 39, 1974, p. 189-220. Les membres les plus actifs sont en histoire, A. Roy, J.-C. Bonenfant, L. Lacoursière et A. Drolet, et en médecine, C.-A. Gauthier, S. Leblond, E. Garnaud et C. Vézina. Parmi les publications importantes, il faut souligner celles de l'Histoire de la Faculté de médecine de Lavai par C.-M. Boissonnault (Québec, 1953), l'« Histoire de la société médicale de Québec » par C.-A. Gauthier (Laval médical, 1943, p. 62-121) et les nombreux textes de Leblond ( «a médecine dans la province de Québec avant 1847 », Cahiers des dix, no 35, 1970, p. 69-95 ; "La profession médicale sous l'Union », Cahiers des dix, no 38, 1973, p. 165-203). À l'occasion de son vingtième anniversaire, la Société canadienne d'histoire de la médecine a publié un volume intitulé Trois siècles de médecine québécoise, Cahiers d'histoire, no 22 ; La société historique du Québec, Québec, 1970.

11 Fernand Ouellet, "La modernisation de l'historiographie et l'émergence de l'histoire sociale ", Recherches sociographiques, vol. XXVI, nos 1-2, 1985, p. 11-83. Pour une revue des travaux récents consacrés à l'histoire des sciences, voir Raymond Duchesne, « Historiographie des sciences et des techniques au 
rencontre de ces deux groupes et de leurs domaines de recherche de sorte qu'un bon nombre de textes récents, dont ceux réunis ici, complètent les travaux plus généraux consacrés à l'histoire et à la sociologie de la culture savante. Cette approche résolument sociale tient compte non seulement des individus mais aussi des institutions de production et de diffusion des connaissances: histoire des livres et de l'imprimerie ${ }^{12}$, histoire des institutions d'enseignement secondaire et supérieur, etc. ${ }^{13}$. En sociologie, un déplacement similaire s'opère, permettant l'émergence d'une sociologie, d'abord des sciences humaines et sociales ${ }^{14}$, puis des sciences elles-mêmes ${ }^{15}$. Des thèses récentes intègrent d'ailleurs les aspects historiques et sociologiques pour rendre compte du développement de disciplines et d'institutions canadiennes et québécoises 16 .

Canada », Revue d'histoire d'Amérique française, vol. XXXV, 1986, p. 193216.

12 Voir Y. Lamonde, L'imprimerie au Québec, 19e-20e siècles, Québec, IQRC, 1983.

13 Par exemple les travaux de C. Galarneau : «L'enseignement des sciences au Québec et Jérôme Demers, 1765-1835 », Revue de l'Université d'Ottawa, 1977, p. 84-94 ; Les collèges classiques au Canada français, Montréal, Fides, 1978. Du côté anglophone, il faut souligner les volumes de S.B. Frost, McGill University, for the Advancement of Learning, vol. 1, 1801-1895, et vol. II, 1895-1971, Montréal, McGill/Queen's University Press, 1980 et 1984.

14 Voir Jean-Charles Falardeau, L'essor des sciences sociales au Canada français, Québec, ministère des Affaires culturelles, 1964; numéro de Recherches sociographiques, vol. XV, nos 2-3, mai-août 1974, «La sociologie au Québec »; Marcel Fournier, "L'institutionnalisation des sciences sociales au Québec », Sociologie et sociétés, vol. V, no 1, mai 1973, p. 27-59; "Édouard Montpetit et l'université moderne ou l'échec d'une génération », Revue d'histoire d'Amérique française, vol. 36, no 1, juin 1982, p. 3-31.

15 M. Fournier, L. Maheu et al., « Le champ scientifique québécois », Sociologie et sociétés, vol. VII, no 1, 1975, p. 119-132 ; M. Fournier et L. Maheu, "Nationalisme et nationalisation du champ scientifique québécois", Sociologie et sociétés, vol. VII, no 2, 1975, p. 89-114; F. DescarriesBélanger, M. Fournier et L. Maheu, « Le frère Marie-Victorin et les petites sciences », Recherches sociographiques, vol. XX, no 1, janvier-avril 1979, p. 8-39.

16 Voir par exemple, Yves Gingras, Les physiciens canadiens : généalogie d'un groupe social (1850-1950), Ph.D., Université de Montréal, 1984 ; Raymond Duchesne, Sciences, culture savante et pouvoir politique, Ph.D., Université de Montréal, 1984 ; Francine Descarries-Bélanger, Production des savoirs 
Si l'on voulait caractériser les divers travaux québécois récents, on pourrait dire qu'ils ont porté moins sur le contenu des sciences que sur les conditions institutionnelles et socio-politiques de leur développement ${ }^{17}$. D'ailleurs, pour la médecine aussi, plusieurs des travaux récents ont pour objet les institutions médicales proprement dites - hôpitaux et asiles, rapports entre ces institutions et l'assistance sociale 18 - ainsi que la mise en place de l'administration de la santé publique, la médicalisation de la société et la profession médicale ${ }^{19}$. On a enfin

spécialisés et développement de la science au Québec, Ph.D. Université de Montréal, 1984 ; Peter Keating, L"Institutionnalisation de la psychiatrie au Québec : 1800-1914, Ph.D. Université de Montréal, 1986.

17 Parmi les exceptions, on peut souligner les travaux de Roger Krohn, professeur au Département de sociologie de l'Université McGill.

18 Voir par exemple, M. D'Allaire, L'Hôpital général de Québec, 1692-1766 (Montréal, 1971) ; F. Harvey et R. Samuel, Matériel pour une sociologie des maladies mentales au Québec, Cahiers de l'ISSH, Québec, 1974 ; A. Paradis, Essais pour une préhistoire de la psychiatrie au Canada (1800-1885), Recherches et théories, no 15, Trois-Rivières, 1977 ; J.-R. Porter, « L'Hôpital général de Québec et le soin des aliénés (1717-1845) », La société canadienne d'histoire de l'Église catholique, no 44, 1977, p. 23-55; G. Poulin, L'assistance sociale dans la province de Québec, 1608-1951, Commission royale d'enquête sur les problèmes constitutionnels, 1955, Annexe 2; S. Mongeau, Évolution de l'assistance au Québec: une étude historique de diverses modalités d'assistance au Québec de la colonie à nos jours, Montréal, 1967 ; J.-Y. Rivard et al., L'évolution des services de santé et des modes de distribution de soins au Québec, Annexe II de la Commission d'enquête sur la santé et le bien-être social, Québec, 1970 ; A. Dupont, Les relations entre l'Église et l'État sous Louis-Alexandre Taschereau, 19201936, Montréal, 1972 ; J.-L. Roy, La marche des Québécois, Montréal, 1976 ; H. Stalwick, Asylum Administration in Canada Before Confederation, thèse de doctorat, Université de Londres, 1969.

19 Par exemple: B. Tunis, The Médical Profession in Lower Canada: Its Evolution as a Social Group, 1788-1838, Research Essay, Carleton University, Department of History, 1979 ; J. Bernier, « François Blanchet et le mouvement réformiste en médecine au début du XIXe siècle ", Revue d'histoire de l'Amérique française, no 34, 1980, p. 223-224 ; «Vers un nouvel ordre médical : les origines de la corporation des médecins et chirurgiens du Québec », Recherches sociographiques, vol. XXII, no 2, 198 1, p. 307-330. "Le corps médical québécois à la fin du XVIIIe siècle » dans C.-G. Roland, (éd.), Health, Disease and Medicine : Essays in Canadian History, Toronto, 1982 ; J. Bernier, « La standardisation des études médicales et la consolidation de la profession dans la deuxième moitié du XIXe siècle ", Revue d'histoire de l'Amérique française, vol. 37, no 1, 1983, p. 51-66 ; C. Pierre-Deschênes, 
voulu analyser le développement de la médecine dans la perspective d'une histoire sociale de la classe ouvrière 20 ou dans celle d'une sociologie historique globale du Québec 21.

Dans une perspective socio-historique, le phénomène le plus important est sans aucun doute celui de l'institutionnalisation de l'activité scientifique, c'est-àdire l'acquisition pour cette activité d'une véritable légitimité culturelle et, pour ceux qui l'exercent, d'un statut social et d'une position institutionnelle (postes, instruments, subventions, etc.). Plongeant ses racines dans la seconde moitié du XIXe siècle, et stimulé au tournant des années 1920, ce processus ne se réalise pleinement, au Québec, qu'au lendemain de la Seconde Guerre mondiale. Plusieurs facteurs ont été invoqués pour expliquer les particularités de ce développement: faible intérêt des classes dirigeantes, opposition de certaines fractions du clergé, formation scolaire inadéquate, etc.

Sensibles à ces diverses questions et convaincus qu'il fallait aller au-delà des simples survols et construire une image plus précise, plus nuancée du

"Santé publique et organisation de la profession médicale au Québec, 18701918 », Revue d'histoire de l'Amérique française, vol. 35, no 3, 1981, p. 355375. M. Farley, Oth. Keel et C. Limoges, "Les commencements de l'administration montréalaise de la santé publique », HSTC Bulletin : Journal of the History of Canadian Science Technology and Medicine, no 20, 1982, p. 24-46, no 21, 1982, p. 85-109 ; Oth. Keel et P. Keating : « Autour du Journal de médecine de Québec: programme scientifique et programme de médicalisation », dans R.A. Jarrell et N. Ball (eds.) : Critical Issues in the History of Canadian Science, Technology and Medicine, Ottawa, HSTC Publications, 1983, p. 101-134.

20 T. Copp, The Anatomy of Poverty: The Condition of the Working Class in Montreal, 1897-1929, Toronto, 1974. Voir aussi les mémoires de M. Tétrault, L'état de santé des Montréalais, de 1880 à 1914, Mémoire de maîtrise, Université de Montréal, 1979 et de C. Pierre-Deschênes, La tuberculose au début du XIXe siècle : problème social et réponse réformiste, mémoire de maîtrise, Département d'histoire, UQAM, 1980.

21 J.-C. Robert, Montréal 1821-1871: aspects de l'urbanisation, thèse de doctorat de 3e cycle, École des hautes études en sciences sociales, Paris, 1977 ; P. -A. Linteau, Histoire de la ville de Maisonneuve, thèse de Ph.D., Université de Montréal, 1975, chap. 11, p. 317-337. Parmi les travaux plus proprement sociologiques consacrés à la médecine et àla santé, il faut souligner: M. Renaud et L. Bozzini, Médecine et société. Les années 80, Montréal, Éd. A. St-Martin, 1981. 
développement des sciences au Québec, nous avons, en septembre 1982, constitué à l'Université de Montréal un groupe de discussion sur l'histoire et la sociologie des sciences et réuni des chercheurs d'horizons disciplinaires et d'affiliation institutionnelle différents. L'intention générale était d'animer la vie intellectuelle du milieu universitaire en ce domaine en créant un lieu d'échange et de discussion. Plus spécifiquement, les objectifs étaient de fournir une évaluation critique des travaux récents, dont ceux-là mêmes des chercheurs, professeurs et étudiants diplômés, qui participaient au séminaire. Fruit de ce travail collectif de réflexion et de discussion, le présent ouvrage respecte toutefois la diversité des préoccupations et des perspectives de chacun des participants, tout en offrant un éclairage nouveau sur des problèmes importants du développement des sciences et de la médecine au Québec.

Les textes de Robert Gagnon et Richard Jarrell, qui portent sur la seconde moitié du XIXe siècle, fournissent un complément nécessaire aux travaux de Jean-Paul Bernard sur Les Rouges 22 et de Nadia F. Eid 23 sur les ultramontains en présentant une analyse, pour l'un, de l'importance accordée par l'élite libérale à l'enseignement pratique, et pour l'autre, de la place de la science dans le discours ultramontain. Bien que le clergé ne se soit pas oppose en principe, contrairement à ce que l'on pense souvent, à l'enseignement des sciences en général et des sciences appliquées en particulier, il semble bien que par son monopole sur l'enseignement secondaire et universitaire et par sa conception de la science comme complément de culture, il ait constitué dans les faits un frein au développement de la science comme activité de recherche et comme force de production. Ensemble, ces deux textes montrent bien comment un ralentissement du développement scientifique, au moins au niveau de l'enseignement secondaire et universitaire, fut en quelque sorte l'effet pervers résultant du conflit entre des groupes sociaux, le clergé ne pouvant accéder aux demandes des réformateurs (laïcs pour la plupart), sans remettre en cause son monopole sur le système d'enseignement.

22 Jean-Paul Bernard, Les Rouges. Libéralisme, nationalisme et anticléricalisme au milieu du XIXe siècle, Montréal, P.U.Q., 1971.

23 Nadia F. Eid, Le clergé et le pouvoir politique au Québec, Montréal, Hurtubise, HMH, 1978. 
À la fois la position marginale des sciences dans le système d'enseignement et la formation générale des professeurs de sciences (choisis parmi le clergé) renforcent la dimension culturelle du rapport que des générations de Canadiens français ont entretenu avec la science. Ce rapport contraste avec celui que manifestent, au tournant du siècle, des chercheurs et des professeurs d'une institution telle que l'Université McGill. Dans son texte, Yves Gingras montre que l'attitude prise face aux rayons $\mathrm{X}$ varie selon les institutions universitaires, francophones ou anglophones, en fonction même des différences de formation et de pratiques scientifiques: Laval et McGill s'opposeraient comme la culture générale s'oppose à l'esprit scientifique et comme la salle de conférence s'oppose au laboratoire. Ainsi, en abandonnant la problématique du retard (implicitement évolutionniste), l'analyse de l'auteur cherche plutôt à mettre en évidence les conditions sociales et institutionnelles qui ont favorisé l'émergence de pratiques différentes, à Laval et à McGill, à l'égard des objets scientifiques.

Dans leur texte, Michael Farley, Peter Keating et Othmar Keel se penchent aussi sur la seconde moitié du XIXe siècle, mais du point de vue d'une histoire sociale et scientifique de la médecine. Plus précisément, ils se proposent d'analyser la constitution de l'autorité sociale et culturelle de la médecine à travers l'étude de la mise en application de l'une des premières mesures sanitaires, celle de la vaccination antivariolique, qui a suscité une série de problèmes à Montréal. À la fois par son objet et par sa perspective, cette étude fournit une contribution originale à une analyse socio-historique de l'activité scientifique du Québec. En effet, on n'avait pas étudié jusqu'ici le contexte global des débuts d'une politique de santé et de médicalisation dans lequel s'inscrit la mise en pratique d'un programme de vaccination. Les auteurs comblent cette lacune en faisant une étude des conditions dans lesquelles ce programme a été organisé et mis progressivement en œuvre, ce qui permet de mieux comprendre les obstacles scientifiques, techniques, administratifs, sociaux et politiques que ce programme a rencontrés. Jusqu'ici, on avait considéré que ces résistances à la vaccination provenaient de l'ignorance et des préjugés religieux de la population francophone. Or, la découverte scientifique de la vaccination et la diffusion de cette pratique se sont heurtées àdes résistances considérables dans la plupart des pays, et notamment en Angleterre. À partir d'une telle approche comparative, les auteurs proposent une nouvelle analyse de la mise en place de la vaccination à Montréal 
ainsi que des résistances et des obstacles rencontrés lors de l'application de cette mesure.

Pour sa part, Georges Weisz s'intéresse aussi à l'histoire de la médecine, sous l'angle d'une sociologie historique des institutions d'enseignement supérieur et pour une période beaucoup plus longue (de la seconde moitié du XIXe siècle à la Seconde Guerre mondiale). Partant de l'idée que la composition du corps étudiant est révélatrice non seulement du caractère général de l'enseignement dispensé dans une institution donnée, mais aussi de la stratégie de développement de cette institution, Weisz analyse l'évolution des provenances géographiques des étudiants en médecine au Québec durant la période 1834-1939. Il est le premier à entreprendre une description exhaustive des origines régionales et de l'évolution de la population des étudiants en médecine du Québec. L'analyse de telles données suggère de nouvelles hypothèses de travail sur les stratégies conduites par les institutions en question. Ce qui ressort de l'analyse, c'est le caractère absolument différent des trois Facultés de médecine en ce qui a trait au recrutement. Ce qu'on appelle l'excellence scientifique de l'Université McGill reposait en partie sur son intégration dans un réseau universitaire d'élite en Amérique du Nord, tandis que l'enseignement à la Faculté de médecine de l'Université Laval était avant tout adapté à un recrutement largement rural.

Tout comme les études précédentes, celle de Marcel Fournier adopte une perspective socio-historique pour analyser les activités d'un groupe de recherche scientifique situé entre l'hôpital et l'université : l'Institut du cancer de Montréal, de l'après-Seconde Guerre au début des années 1980. Contrairement à diverses études de laboratoires qui se limitent à la dynamique interne ou à l'organisation des groupes de recherche, cette monographie met en évidence les contraintes et les problèmes rencontrés par l'Institut à divers moments de son histoire et les stratégies élaborées par ses directeurs et ses chercheurs pour demeurer compétitifs dans le champ de la recherche sur le cancer tout en tirant avantage de l'inconvénient que peut représenter le fait d'exercer une pratique scientifique dans le contexte économique et linguistique du Québec.

En plus d'aborder des disciplines et des époques différentes, l'ensemble des textes réunis ici mettent en évidence l'idée suivante: une meilleure compréhension du développement scientifique québécois devrait non seulement faire place au contexte spécifique qui définit les limites des différentes pratiques 
possibles, mais aussi tenir compte du rapport que divers groupes ou institutions entretiennent avec des milieux extérieurs tant canadiens qu'internationaux. Il est rare qu'un champ scientifique soit strictement délimité par les frontières nationales ; une juste appréciation de son développement doit prendre en compte des effets qui du point de vue national peuvent apparaître « externes », mais qui font bel et bien partie du système scientifique par les contraintes qu'ils imposent et par les stratégies qu'ils dictent, du moins en partie, aux acteurs.

À un autre niveau, ce volume se veut une contribution à une sociologie historique du développement scientifique, approche qui devrait se substituer aux analyses trop générales qui prêtent d'emblée aux groupes sociaux des mentalités « traditionnelles » pour expliquer leur « retard» ou «pragmatiques » pour expliquer leur dynamisme 24 . Nonobstant le caractère trop souvent tautologique de telles explications, elles sont toujours implicitement évolutionnistes et, par leur globalité même, ne rendent jamais compte de la spécificité et de la localité des facteurs déterminants du développement social, pourtant clairement mis en évidence par de nombreuses études récentes ${ }^{25}$. Il convient donc beaucoup mieux d'aborder les questions de développement scientifique en termes de spécificités : spécificité de fonctionnement de divers milieux scientifiques et spécificité des fonctions sociales, politiques et économiques que remplit l'activité de recherche et d'enseignement dans un milieu social donné.

24 Pour un exemple récent de cette approche, voir Yakov M. Rabkin et J. Ann Levi-Lloyd, "Technology and Two Cultures: One Hundred Years of Engineering Education in Montreal », Minerva, vol. 22, no 1, printemps 1984, p. 67-95.

25 Voir par exemple, Barry Barnes and Steven Shapin (eds.), Natural Order. Historical Studies of Scientific Culture, London, Sage Publications, 1979. 
Sciences et médecine au Québec.

Perspectives sociohistoriques

\section{Chapitre I \\ Les discours sur l'enseignement pratique au canada français, 1850-1900}

par Robert Gagnon

Département de sociologie, Université de Montréal

$\underline{\text { Retour à la table des matières }}$

On a beaucoup écrit sur le « retard économique du Québec » et sur l'infériorité économique des Canadiens français. Dès le XIXe siècle, journalistes et essayistes, politiciens et hommes de lettres ont tenu des discours sur les raisons et les facteurs qui ont engendré ou encouragé cet état de choses. Étienne Parent, L.-O. David et Léon Gérin, pour ne nommer que ceux-là, ont tenté d'expliquer, à leur façon, ce problème. Dans la première moitié du XXe siècle, d'autres prirent la relève et contribuèrent à gonfler le volume des écrits sur ce sujet. Édouard Montpetit, E. Minville, E. Bouchette et $\mathrm{O}$. Asselin proposèrent, tour à tour, d'autres thèses pour rendre compte de l'infériorité économique de leurs compatriotes. Plus près de nous, historiens, sociologues et économistes se sont penchés sur le même problème. Équipés de concepts empruntés au champ des sciences sociales, ils ont cherché à donner une explication plus rigoureuse en replaçant le problème dans une perspective historique ${ }^{26}$.

26 R. Durocher et P.-A. Linteau, Le «retard» du Québec et l'infériorité économique des Canadiens français, Montréal, Boréal Express, 1971, p. 7-8. 
Il n'en demeure pas moins que l'explication du «retard économique du Québec », qu'elle soit celle des universitaires ou des penseurs témoins du phénomène, consiste toujours à privilégier soit le facteur économique, c'est-à-dire le rythme et le type d'industrialisation du Québec, la dépendance économique de la bourgeoisie canadienne-française, etc., soit le facteur culturel, à savoir : un système d'éducation qui ne correspond pas aux réalités économiques, une idéologie conservatrice véhiculée par l'Église qui encourage la vocation paysanne des Canadiens français, etc.

Notre intention n'est pas ici de trancher la question du « retard économique du Québec ». Nous voulons plutôt tenter d'éclaircir un aspect précis de ce problème. En prenant pour objet les discours sur l'enseignement pratique dans la deuxième moitié du XIXe siècle, nous essaierons de comprendre et d'expliquer pourquoi et comment des agents dans le champ social se sont soudainement opposés au système d'éducation supérieur traditionnel qui était voué surtout à la formation des membres des professions libérales et contrôlé en grande partie par les autorités ecclésiastiques. En stigmatisant ce type d'éducation (qu'ils perçoivent, entre autres, comme une des causes de l'infériorité économique des Canadiens français), ces agents se font les promoteurs d'un enseignement plus pratique (basé sur des connaissances scientifiques et techniques), jugé d'autant plus nécessaire qu'il remplit une fonction sociale et économique. Sans chercher à minimiser les facteurs économiques qui sont, à notre avis, déterminants, puisqu'ils imposent des rapports de force entre les différents groupes sociaux (ces facteurs ont d'ailleurs été amplement analysés jusqu'ici), nous proposons une analyse complémentaire qui renvoie à une lutte de pouvoir entre deux groupes sociaux pour le monopole de l'autorité dans le domaine de l'éducation au Québec.

$\mathrm{Si}$, comme l'affirme Fernand Dumont ${ }^{27}$, on ne peut manquer de repérer, à l'époque entre la petite bourgeoisie professionnelle et le clergé des conflits de classe, c'est peut-être dans le champ de l'éducation que les luttes entre ces deux groupements se sont révélées les plus lourdes de conséquences. À cause même de l'importance idéologique des enjeux (les institutions scolaires étant des instances privilégiées de production idéologique et sociale), il nous a paru crucial d'analyser

27 F. Dumont, Idéologie au Canada français 1850-1900, Québec, P.U.L., 1971, p. 150. 
les différents discours des porte-parole de la petite bourgeoisie professionnelle, qui cherchaient à imposer comme légitime une représentation de ce qu'est ou devrait être le système d'éducation au Québec. Ces discours ont réussi à regrouper et à mobiliser autour des mêmes thèmes, des politiciens du Parti conservateur et du Parti libéral, plus tard du Parti national, des éducateurs laïcs et des journalistes de la presse laïque. Pourtant, en raison de la conjoncture historique et de la ferme volonté du clergé de ne pas laisser échapper une parcelle de son autorité dans le domaine de l'éducation, les revendications qu'un certain travail collectif avait unifiées ne parviendront pas à aboutir.

Plusieurs auteurs ont analysé les luttes dans le champ social entre les élites laïques, composées en grande partie par des membres des professions libérales, et le clergé au XIXe siècle. Ils ont contribué, par le fait même, à expliquer comment la volonté de certains membres de cette petite bourgeoisie de promouvoir l'institutionnalisation des sciences appliquées avait été freinée par une conjoncture défavorable ${ }^{28}$.

Cependant, cette littérature consacrée à l'analyse des tensions entre le clergé et le pouvoir politique en matière d'éducation, ne s'est pas attardée à préciser le caractère indissociablement idéologique et politique du discours sur la science, les sciences appliquées et l'enseignement pratique qui prend forme au cours du XIXe siècle. Pour comprendre la force qu'acquiert ce discours, il faut tout d'abord rappeler les changements économiques qui transforment le Québec à cette époque. C'est alors que l'idéologie du libéralisme économique gagne de plus en plus de membres de la petite bourgeoisie professionnelle francophone. Puisant à même les lieux communs générés par cette idéologie, qui vont de l'encombrement des professions libérales à la pénurie d'ingénieurs et d'industriels, en passant par le poids relatif de l'éducation dans le développement économique, plusieurs membres de ce groupe social construisent un discours réclamant une éducation pratique qui, par sa définition même, s'oppose à l'éducation classique. Beaucoup plus qu'une simple réforme dans le domaine de l'éducation, c'est la mise en place

28 J.-P. Bernard, Les Rouges, Montréal, P.U.Q., 1971 ; N. Eid, Le clergé et le pouvoir politique au Québec, Montréal, Hurtubise, 1978 ; M. Hamelin, Les premières années du parlementarisme québécois: 1867-1878, Québec, P.U.L., 1974; J.-P. Charland, Histoire de l'enseignement technique et professionnel, Québec, IQRC, 1982. 
d'une autre filière de l'enseignement secondaire, et par là, d'un autre système de reproduction des agents qui est revendiquée.

\section{LES CONDITIONS D'ÉMERGENCE D'UN DISCOURS}

Comme l'ont souligné Jean Hamelin et Yves Roby ${ }^{29}$, la création d'une économie de marché ne se fait pas sans douleur. À partir des années 1850 et surtout 1860, l'amélioration des techniques agricoles, la spécialisation des fermes et la mécanisation induisent des transferts de population. L'avènement des chemins de fer ouvre des régions à la colonisation et à l'échange des biens, des hommes et des idées. De plus, la révolution industrielle du XIXe siècle ne favorise pas le Québec qui n'a ni charbon, ni marché assez grand pour encourager les investissements dans le secteur industriel. Économiquement et socialement, le Québec, de 1851 à 1896, se métamorphose alors radicalement. Le processus d'industrialisation est bien illustré par les statistiques suivantes : la valeur de la productivité du secteur secondaire passe alors de 2 millions\$ en 1851 à $157474000 \$$ en 1896, soit une augmentation de $7,578 \%{ }^{30}$.

L'idéologie montante, comme l'ont fait remarquer Durocher, Linteau et Robert ${ }^{31}$, est alors celle du libéralisme économique. Idéologie de la classe bourgeoise, elle met l'accent sur l'individu plutôt que sur la collectivité et surtout, elle perçoit le progrès de la société comme la somme des réussites individuelles. Le progrès est alors vu comme nécessaire et bénéfique, l'éducation comme un moyen de le réaliser. Bien sûr, par le contrôle qu'elle exerce sur l'économie québécoise, c'est la bourgeoisie anglophone qui exprime cette réalité nouvelle

29 J. Hamelin et Y. Roby, Histoire économique du Québec 1851-1896, Montréal, Fides, 1971, p. 262.

30 Ibid., p. 262.

31 R. Durocher, P.-A. Linteau et J.-C. Robert, Histoire du Québec contemporain, Montréal, Boréal Express, 1979, p. 308-309. 
avec le plus d'énergie. Cependant, plusieurs membres de la petite bourgeoisie professionnelle francophone partagent aussi cette idéologie 32 .

On connaît, par ailleurs, le rôle important qu'a joué le clergé dans le champ de l'éducation au Bas-Canada. L'échec des insurrections de 1837 ébranle fortement les représentants de la bourgeoisie parlementaire du Bas-Canada. L'Église profite alors de l'effondrement du mouvement nationaliste laïc pour imposer à la collectivité canadienne-française sa définition de la société qui est, avant tout, cléricale et fondée sur un nationalisme catholique ${ }^{33}$. L'ascension du clergé, dans les années 1840 et 1850, est fulgurante ${ }^{34}$. Dans le monde de l'éducation, l'Église se réserve tout d'abord l'enseignement secondaire. Les collèges classiques ont alors comme fonction de préparer des prêtres et de former une élite intellectuelle composée de membres des professions libérales, de journalistes et d'hommes politiques ${ }^{35}$. En 1852, l'enseignement supérieur universitaire est inauguré avec la création de l'Université Laval, mise sur pied et dirigée par le clergé qui s'assure ainsi du contrôle de ce nouveau secteur de l'enseignement. En somme, la conjoncture des années 1840 favorise l'Église catholique qui consolide sa position dominante non seulement dans le système d'éducation mais dans l'ensemble de la société québécoise 36 .

Cependant, dès 1850, certaines élites laïques canadiennes-françaises contestent les pouvoirs croissants du clergé dans le monde de l'éducation. Beaucoup, par exemple, affirment qu'il faut faire quelque chose pour améliorer un système qu'ils jugent inadapté aux nouvelles réalités économiques. L'encombrement des professions libérales est alors un thème fréquemment évoqué

32 Par petite bourgeoisie professionnelle, nous désignons le groupe social dont les membres font partie des professions libérales. Leur nombre augmente plus rapidement que celui de la population de la province tout au long du XIXe siècle. Aux médecins, notaires et avocats viennent aussi s'ajouter les journalistes, hommes politiques et certains éducateurs. L'instance scolaire privilégiée de production et de reproduction de ce groupe est sans contredit le collège classique.

33 R. Heap, L'Église, l'État et l'éducation au Québec : 1875-1898, mémoire de maîtrise, Université McGill, 1978, p. 28.

34 Ibid., p. 29-30.

35 C. Galarneau, Les collèges classiques au Canada français, Montréal, Fides, 1978, p. 25.

36 R. Heap, op. cit., p. 32. 
pour critiquer la formation dispensée dans les collèges. Ce sont les Rouges qui véhiculent avec le plus d'enthousiasme ces jugements, reflets indiscutables de l'influence grandissante de l'idéologie du libéralisme économique sur une fraction de la classe dominante au Canada français. Dans le domaine de l'éducation, ils revendiquent avec force un pouvoir accru de l'État. Ils exigent des réformes scolaires qu'ils jugent essentielles au progrès de la société canadienne-française. Un éditorial du journal rougiste Le Pays mentionne ainsi que « les amis du progrès ont beau demander à ce que l'enseignement de nos collèges soit conforme à la pratique du siècle [...] on répond que les directeurs de nos collèges sont les maîtres de diriger ces institutions comme ils l'entendent 37 ». Cette contestation du monopole de l'autorité religieuse en matière d'éducation s'appuie, en grande partie, sur le fait que l'on constate dans les collèges une surabondance de grec et de latin ainsi que des lacunes en algèbre et en chimie ${ }^{38}$.

Ces demandes de réformes, exigées à grand bruit par l'intelligentsia rougiste, n'émanent pas exclusivement de ce parti politique. D'autres membres de la petite bourgeoisie revendiquent aussi un enseignement plus pratique adapté à la nouvelle conjoncture économique. P.-J.-O. Chauveau, dans son premier rapport annuel comme surintendant de l'Instruction publique, en 1855, reprend les mots de son prédécesseur J.-B. Meilleur, et affirme: «aujourd'hui, il faut des modifications pour donner au système tout le développement dont il est susceptible, pour le mettre au niveau des progrès qui ont été faits, et pour donner à l'enseignement ce haut caractère d'utilité et de perfection, vers lequel doit tendre tout système d'instruction nationale 39 ». Conscient de l'importance du rôle de l'État dans le secteur de l'éducation, Chauveau a conscience également qu'un processus économique est en train de bouleverser le Canada-Uni. Toujours en accord avec l'esprit du libéralisme économique, il propose des réformes qui favorisent l'enseignement agricole, commercial et industriel, en souhaitant que « le Bas-Canada pourra bientôt devenir ce que la nature elle-même a voulu qu'il fût, un pays aussi manufacturier qu'agricole 40 ».

37 Le Pays, 13 et 25 décembre 1855, cité par J.-P. Bernard, op. cit., p. 127.

38 J.-P. Bernard, op. cit., p. 127.

39 Rapport du surintendant de l'Éducation du Bas-Canada pour l'année 1855, p. 4.

40 Ibid., p. 12. 
Ainsi, à partir des années 1850, prend forme un discours qui conteste dans un premier temps le type d'éducation mis en place par l'Église et qui, dans un deuxième temps, propose des réformes dont la nature est inspirée en grande partie par l'idéologie du libéralisme économique. On peut dès lors supposer que l'intérêt considérable que rencontre la question des réformes scolaires, à partir du milieu du XIXe siècle, est directement lié à l'influence grandissante des idées libérales sur les élites laïques au Canada français. Le libéralisme économique pousse ainsi certains agents de ce groupe social, non seulement à renier leur formation humaniste, mais aussi à proposer un nouveau type de formation dans lequel les sciences appliquées, l'enseignement technique et les arts occupent une place privilégiée.

Avec ou sans les Rouges, bon nombre de représentants de ce groupe social, mobilisant le discours libéral, critiquent les prétentions du clergé au monopole de l'autorité en matière d'éducation. La conjoncture liée à la Confédération, à la création de la province de Québec, à l'émigration massive des Canadiens français vers les États-Unis et à l'accélération du processus d'industrialisation, crée d'ailleurs un climat propice à la remise en cause du système d'enseignement. Plusieurs éditorialistes ne manquent pas de se plaindre que «tout est à refaire dans notre système d'éducation », et « qu'il y a trop de collèges classiques ». Ils exigent également du gouvernement qu'il favorise « de manière toute spéciale les écoles industrielles et commerciales, qu'il fasse des sacrifices pour avoir des professeurs compétents 41 ». Ainsi, à travers un discours réclamant une éducation plus pratique où la science, en particulier la science appliquée, occuperait une place d'honneur, c'est une transformation radicale du système qui est exigée. Politiquement marqué, le discours qui prône « plus de physique, de mécanique, de technologie » et «moins de grec et de latin » a cela de particulier qu'il s'accompagne toujours d'une condamnation du système éducatif existant, d'un exposé sur le rôle de l'éducation comme facteur de développement économique et d'une exhortation à former un personnel enseignant compétent. Ces thèmes interdépendants jouent un rôle mobilisateur auprès des différents groupes composant la petite bourgeoisie canadienne-française. Libéraux, conservateurs, instituteurs laïcs, commerçants et membres des professions libérales sont tour à

41 L'Opinion publique, 5 février 1870. 
tour attirés par l'un ou l'autre de ces thèmes et ils approuvent un discours qui s'impose peu à peu comme allant de soi.

\section{DE L'ENCOMBREMENT DES PROFESSIONS LIBÉRALES À LA PÉNURIE DES INGÉNIEURS, ET DES INDUSTRIELS}

Nous avons signalé que dès les années 1850, le système d'éducation est fortement remis en question par les élites politiques. En 1867, à son retour d'un voyage en Europe et aux États-Unis, où il a été envoyé pour comparer les systèmes scolaires étrangers avec ceux du Canada et surtout du Québec, Chauveau est nommé premier ministre de la nouvelle province du Québec. Il prend en charge également un tout nouveau ministère, celui de l'Instruction publique. Il semble donc que les critiques qui, depuis plus de quinze ans, sont dirigées contre le système d'éducation, vont maintenant porter fruit et servir à réformer le système d'éducation franco-catholique. Il faut dire qu'il est devenu habituel, à cette époque, d'énumérer les lacunes du système d'enseignement offert à la jeunesse canadienne-française.

Si, comme nous le pensons, le discours sur l'importance des sciences appliquées et de l'enseignement technique s'inspire du libéralisme économique, on doit naturellement s'attendre à ce que les collèges classiques, principaux supports du système d'enseignement traditionnel, soient les cibles privilégiées des critiques. En fait, ces derniers dénoncent avec plus ou moins de force, selon les positions qu'ils occupent dans le champ social, la prolifération, le monopole ou encore l'inefficacité des collèges.

Bien entendu, de par ses liens « amicaux » avec le clergé ultramontain, c'est encore le gouvernement conservateur qui atténue le plus les reproches adressés aux institutions du clergé. Pourtant, malgré cette alliance, le ministre de l'Instruction publique et plusieurs de ses collègues ne manquent pas de contester le quasi-monopole des collèges classiques dans le secteur secondaire de l'enseignement. Ainsi, il est clair pour Chauveau qu'il faut favoriser la création d'établissements privilégiant un enseignement pratique au niveau secondaire. Nul doute, pour ce dernier, que l'enseignement secondaire dispensé exclusivement par 
les collèges classiques, ne peut répondre aux nouveaux besoins du Québec. Parlant des collèges classiques, il constate :

La province compte un assez grand nombre de ces institutions, trop peutêtre pour le chiffre de notre population, et si l'on ne perd pas de vue le besoin vital d'une éducation surtout pratique dans un jeune pays comme le nôtre ${ }^{42}$.

Son successeur, Gédéon Ouimet, aux titres de ministre de l'Instruction publique et de premier ministre, dévoile pour sa part les lacunes du système collégial, en ce qui a trait à l'éducation pratique, compte tenu des nouvelles réalités économiques du Québec. Il se demande, entre autres :

S'il ne serait pas possible d'apporter à notre système d'études collégiales quelques modifications devenues urgentes, par suite de la nouvelle position qu'il nous est faite par la Confédération. Les besoins de notre époque, d'ailleurs, ne sont pas les mêmes qu'autrefois et demandent des connaissances nouvelles. La France, l'Angleterre et plusieurs autres pays de l'Europe s'occupent beaucoup de cette question et ont déjà fait subir à l'ancien système d'études plusieurs changements nécessités par le nouvel état de la société et par les découvertes et les créations faites de nos jours dans les sciences, les arts et les industries. Il faut une instruction plus pratique : on ne saurait trop le répéter ${ }^{43}$.

Si deux premiers ministres conservateurs pensent qu'il faut briser le monopole des collèges classiques sur l'enseignement secondaire, on doit s'attendre aux mêmes conclusions de la part des libéraux. Ainsi, H.-G. Joly, député de Lotbinière, affirme en Chambre «qu'il est pénible de voir que, dans notre province, l'éducation pratique est entièrement sacrifiée à l'éducation classique ; nous avons un trop grand nombre de collèges où la jeunesse vient se bourrer de grec et de latin, ce qui fait que toutes les professions libérales sont encombrées 44 ».

Le Pays, le journal le plus libéral de l'époque, consacre en 1868 une série d'articles à la question de l'éducation. Ces articles sont un appel vibrant en faveur

42 Rapport du ministre de l'Instruction publique de la province de Québec pour l'année 1871-1872, p. viii.

43 Rapport du ministre de l'Instruction publique de la province de Québec pour l'année 1872-1873 et une partie de 1874, p. viii-ix.

44 Débats de l'Assemblée législative du Québec, (DALQ), H.-G. Joly, 16 janvier 1874. 
d'un enseignement axé davantage sur les sciences. Nous allons d'ailleurs revenir sur ces éditoriaux un peu plus loin, mais signalons tout de suite le bilan que dresse Le Pays sur le système d'éducation du Québec.

On projette en ce moment de faire un nouveau collège classique. Nous nous élevons de toute notre force contre ce moyen extra-surabondant de produire des inutilités. Le pays est inondé de collèges classiques, et non seulement le besoin ne se fait pas sentir d'en avoir d'autres, mais encore de convertir bon nombre de ceux qui existent en académies appropriées à notre position économique, à nos ressources, à notre avenir [...] C'est encore la jeunesse des collèges qui n'a pas d'avenir avec son bagage de latin mal appris, de français plus mal appris encore, de son ignorance de l'anglais et de toutes les branches d'instruction qui seules peuvent offrir des carrières avantageuses. Ce qu'il nous faut ce sont des ingénieurs, des géologues [...] Qu'il y ait des collèges classiques, c'est très bien, mais qu'ils n'existent que pour faire équilibre et non comme monopole [...] Nous voulons qu'il y ait à côté d'elle [éducation classique] des écoles pour les sciences et les arts qui absorbent aujourd'hui presque toute la vigueur intellectuelle des peuples civilisés 45 .

L.-O. David, dans son journal L'Opinion publique, constate pour sa part, que « les Canadiens français, après avoir été privés d'éducation, n'ont pas maintenant celle qui leur convient, celle qui peut les mettre en état d'occuper sur ce continent une position honorable 46 ». Bien entendu, l'éducation que souhaite David est d'un type qui accorde une place importante à l'enseignement des sciences appliquées.

Urgel-E. Archambault, fondateur de l'École Polytechnique de Montréal mais aussi principal de l'Académie commerciale du Plateau et grand défenseur de l'enseignement laïc, propage, dans un prospectus qu'il envoie aux directeurs des collèges pour les inciter à approuver la nouvelle École Polytechnique, un thème que l'on peut considérer comme récurrent à l'époque, à savoir, l'encombrement des professions libérales. Voici ce qu'il écrit :

On se plaint : la jeunesse canadienne n'a devant elle que la perspective des études légales ou médicales [...] Nos jeunes gens, après de longue études classiques, manquant des connaissances spéciales sur toutes ces choses (Chemin de fer, creusement des canaux, génie civil), se rejettent sur les

45 Le Pays, 20 juin 1868.

46 L'Opinion publique, 5 février 1870. Pour une analyse de la pensée de L.-O. David voir: Y.-F. Zoltvany, «L.-O. David et l'infériorité des Canadiens français », dans Recherches sociographiques, vol. X, nos 2-3, 1969, p. 426430. 
professions d'avocats, de notaires, de médecins. Cette école est, j'oserai dire, le seul moyen de désencombrer ces professions et de retenir notre jeunesse instruite au milieu de nous en lui offrant de nouvelles carrières 47.

Ce texte dessine les grandes lignes des critiques que l'on adresse au système d'enseignement en place à cette époque. Le dépouillement des journaux de la deuxième moitié du XIXe siècle révèle toute l'ampleur que prend cette remise en cause.

Il est important de signaler qu'au moment même où Chauveau reconnaît l'urgence de restructurer le système d'enseignement franco-catholique du Québec, en préconisant un enseignement plus pratique, qui répondrait «mieux » aux besoins nouveaux du pays, William Dawson, principal de l'Université McGill, tient le même discours chez ses compatriotes anglo-protestants. Revenant, lui aussi, d'un voyage en terre européenne, il tire les mêmes conclusions :

Jusqu'à présent force nous a été de nous contenter de cours académiques, ou des écoles nécessaires pour la médecine, le droit et la théologie. Quant aux hautes carrières industrielles, nos jeunes gens s'en trouvent à peu près exclus [...] Nous fondons des établissements manufacturiers de tout genre sans posséder une seule école où la jeunesse des deux sexes puisse apprendre la mécanique, la chimie appliquée, ou le dessin [...], nous n'avons aucune école spéciale pour former un ingénieur civil ou un arpenteur compétent [...] Avec des ressources minières qui ne sont pas surpassées par celles d'aucun pays du monde, nous n'avons pas une école où le jeune Canadien puisse s'instruire à fond sur la Science qui a pour objet l'exploitation des mines et la métallurgie ${ }^{48}$.

Tout comme Dawson, les promoteurs de l'enseignement des sciences appliquées chez les francophones ne manquent pas, eux aussi, de justifier leurs revendications en insistant sur la fonction essentielle d'une éducation pratique pour le développement économique du Québec.

47 Archives de l'École Polytechnique de Montréal.

48 Journal de l'Instruction publique, vol. XV, nos 1-2, 1871, p. 3. 


\section{ÉDUCATION ET DÉVELOPPEMENT ÉCONOMIQUE}

Sachant que la reconnaissance de la nécessité d'un enseignement pratique est une arme contre les prétentions du clergé au contrôle exclusif du domaine de l'éducation, on comprend mieux l'ardeur avec laquelle est débattue la question du poids relatif de l'éducation dans le développement économique. Le thème qui s'inspire le plus de l'idéologie du libéralisme économique est sans doute celui qui lie, dans un rapport de cause à effet, le système d'éducation et le développement économique. Surtout à partir de la fin des années 1860, la plupart de ceux qui prônent un enseignement pratique considèrent que l'infériorité matérielle des Canadiens français et le retard du Québec dans le développement économique résultent d'un système d'éducation inadéquat. Conséquemment, la transformation de ce système est alors perçue comme la panacée à tous les maux économiques de la province.

Ainsi, en 1872, le premier ministre du Québec, pour justifier l'importance d'établissements privilégiant l'enseignement des sciences pratiques, souligne que " c'est là que se forment tous les membres de cette classe moyenne qui est en quelque sorte l'âme vive d'une nation, et qui en fait la prospérité lorsqu'elle se montre à la hauteur de sa mission 49 ». Rappelons que depuis 1867, Chauveau fait de la création de fermes modèles et de l'enseignement de la science agricole dans les écoles normales, un objectif primordial pour le ministère de l'Instruction publique. Il dit d'ailleurs, en parlant des causes de l'émigration massive de ses compatriotes vers les États-Unis : « les deux principales sont toujours l'absence de manufactures qui fait que dans nos longs hivers, les enfants de nos cultivateurs se trouvent sans occupation et le manque de connaissances agricoles qui empêche notre agriculture de se développer comme il serait à désirer 50 ». On sait que Chauveau se préoccupe, en plus de l'enseignement des sciences agricoles, de

49 Rapport du ministre de l'Instruction publique de la province de Québec 18711872, p. viii.

50 Extrait du préambule du rapport du Comité permanent sur l'agriculture et la colonisation, cité dans Le Pays, 8 août 1868. 
l'enseignement des sciences appliquées. C'est cependant à son successeur G. Ouimet que revient l'honneur d'inaugurer l'École Polytechnique de Montréal. En 1873, l'année de la création de cette école de sciences appliquées, Ouimet justifie la nécessité de ce type d'enseignement, en déclarant :

Jusqu'ici, on ne s'est pas assez occupé d'écoles pratiques où l'industriel, le mécanicien, l'ingénieur, etc... pussent faire l'application des connaissances scientifiques qui le rattachent à la carrière qu'ils ont embrassée [...] Ce sont pourtant ces professions qui offrent aujourd'hui le plus d'avenir, et où la jeunesse pourra toujours se frayer une route, à mesure que les diverses branches d'industrie se multiplieront et qu'il faudra des hommes compétents pour les exploiter ${ }^{51}$.

Il va sans dire que dans ce genre de discours, la science en question n'est pratiquement jamais vue comme une partie du capital culturel nécessaire à l'honnête homme. Au contraire, cette science que l'on veut introduire dans les écoles est avant tout une science pratique qui a comme objectif ultime de préparer une partie de la jeunesse canadienne-française à « tirer parti des avantages et des richesses de notre pays et d'avoir la part qui nous appartient dans les travaux, les grandes entreprises commerciales et industrielles 52 ». D'ailleurs, l'éditorialiste du journal Le Pays est très explicite sur le type de sciences que l'on devrait retrouver dans les écoles qui enseignent les sciences et les arts. Dans un article paru au mois d'août 1868, on peut lire :

La mécanique, à part de ce qu'en savent par routine les menuisiers, les forgerons, etc.... n'est connue ici que des personnes venues d'outre-mer [...] Quelques notions de géométrie pratique et de dessin développeraient chez notre jeunesse le goût de faire autre chose que des avocats, des prêtres, des médecins ou des notaires, et bientôt on la verrait fréquenter des usines de tout genre, que nos pouvoirs d'eau créeront infailliblement au milieu de nous. On la verrait employée dans les travaux publics, dans la construction des chemins de fer, des canaux, des engins, des moulins, des ponts et chaussées.

51 Rapport du ministre de l'Instruction publique de la province de Québec 1872 et une partie de 1873, p. ix.

52 L'Opinion publique, 5 février 1870. 
La géologie et la métallurgie ouvriront avant longtemps une vaste carrière aux jeunes gens avides d'avenir. Depuis le lac Supérieur jusqu'au Golfe, notre territoire abonde en mines de toutes espèces [...]

Il faut plus de mathématiques, plus de géométrie pratique, plus de chimie appliquée à l'industrie et moins de chimie fantaisiste. Il faut plus de tenue de livres, plus d'opérations de banque et de commerce ; et par-dessus tout, il faut plus de langue anglaise 53 .

Le député H.-G. Joly, quant à lui, signale en Chambre qu'« il est absolument nécessaire de créer des écoles pratiques pour former des ingénieurs, des mécaniciens, des géomètres. Nous avons à construire plus de quinze lignes de chemins de fer et il nous est impossible de trouver parmi les Canadiens un ingénieur capable de rendre les moindres services [...] Des trésors métallurgiques incommensurables sont enfouis dans notre sol et nous n'avons personne pour les découvrir ou les exploiter avec succès 54 ».

D'autres porte-parole, à l'extérieur de l'arène politique, tels L.-O. David, U.-E. Archambault, Arthur Buies ou des éditorialistes de journaux comme L'Opinion publique, Le National, L'Instruction publique, La Minerve, etc., clament à l'unisson la nécessité de procurer à la jeunesse canadiennefrançaise, un enseignement pratique pour assurer le développement économique du Québec. Cet enseignement pratique s'oppose à l'enseignement « classique » par le type de formation qu'il préconise : au caractère humaniste du cours classique, il oppose une formation à caractère scientifique et technique. Or, sachant que les prêtres et frères-enseignants des collèges classiques sont issus d'une formation philosophique et humaniste, la question de la formation d'un personnel enseignant compétent en matière de sciences et de techniques est incontournable. Beaucoup plus qu'un simple problème pédagogique, la question de la capacité du clergé à prodiguer ou non un enseignement pratique apparaît dès lors comme un enjeu majeur de la lutte entre le clergé et les élites laïques dans le champ de l'éducation.

53 Le Pays, 20 août 1868.

54 DALQ, H.-G. Joly, 16 janvier 1874. 


\section{LA COMPÉTENCE DES PROFESSEURS}

Les indicateurs les plus révélateurs des visées politiques du discours sur l'importance des sciences appliquées et d'un enseignement technique sont sûrement les nombreux sous-entendus qu'on y retrouve, et qui mettent en doute les compétences pédagogiques des ecclésiastiques quand il s'agit de prodiguer ce type d'enseignement. C'est ainsi que l'on fait mention, dans ce discours, de la nécessité de former des professeurs compétents dans le domaine des sciences appliquées. Quand on sait que durant les années 1880, l'enjeu principal de la lutte entre le clergé ultramontain et une partie de la petite bourgeoisie canadiennefrançaise dans le secteur de l'instruction publique est la survie des écoles normales Jacques-Cartier et Laval, foyers de laïcisme pour les uns et berceaux de l'enseignement laïc pour les autres, on saisit mieux l'importance que revêt la question de la compétence des instituteurs, et de la valeur du lieu où ils enseignent.

Il faut rappeler ici que, sous la pression de nombreuses plaintes qui dénonçaient la multiplication des collèges et l'encombrement des professions libérales qui en résultait, le clergé avait transformé plusieurs collèges classiques en collèges dits «industriels » et «commerciaux » ou avait ajouté un enseignement «pratique» parallèle et complémentaire au cours classique 55 . Cette stratégie avait l'avantage de répondre aux critiques de la presse laïque, et de préserver le monopole du clergé sur l'enseignement supérieur. Cependant, elle ne donnait pas satisfaction à ceux qui réclamaient un enseignement plus pratique.

Chauveau, dans son livre sur l'histoire de l'instruction publique au Canada, nous donne un aperçu des critiques adressées aux collèges « industriels ».

On a donné ce nom à des institutions dont plusieurs ont été fondées avec la prétention d'être des collèges classiques, tandis que d'autres ont été établies dans l'intention expresse de remplir la lacune qui existait entre les institutions d'alors et les simples écoles. Depuis un assez long espace de temps, l'encombrement des professions libérales avait porté à modifier les études sous ce rapport et à préparer spécialement des jeunes gens pour le commerce et l'industrie; mais ce changement s'exécutant avec l'aide,

55 R. Heap, op. cit., p. 30-31. 
plutôt que sous le contrôle du gouvernement, il y a eu beaucoup d'irrégularités et de fluctuations dans le caractère de l'enseignement de plusieurs de ces maisons 56 .

Il est clair que Chauveau déplore ici l'impuissance de l'État quand il s'agit de « contrôler» le type d'études ou encore les changements académiques des collèges.

C'est dans le Rapport du surintendant de l'Instruction publique de 1866, déposé en 1867, soit quelques jours seulement avant qu'il ne devienne premier ministre de la province, que l'on perçoit le plus cette volonté d'instituer un système d'enseignement supérieur laïc parallèle à celui des collèges classiques. Chauveau revient alors de son voyage d'études en Europe et le rapport présente ses constatations. Truffé de remarques qui indiquent subtilement que les systèmes scolaires européens sont passés par les mêmes phases de développement que celui du Québec, le rapport met en relief les différentes stratégies par lesquelles les gouvernements européens ont remédié à des problèmes qui ressemblent étrangement à ceux qu'éprouve la province de Québec. Par exemple, il mentionne que :

En France et en Belgique on a tenté de remédier aux inconvénients d'une éducation classique trop généralement prodiguée, par l'introduction de cours scientifiques séparés dans les lycées ou athénées. On a cru depuis qu'il était nécessaire d'ajouter à cette réforme la création de nombreuses institutions spéciales destinées à préparer les jeunes gens au commerce et à l'industrie. L'École Normale Supérieure de Cluny [...] est destinée à fournir des instituteurs pour des établissements spéciaux ou professionnels de même que l'École Normale Supérieure de Paris en fournit à l'Université et aux lycées.

La Prusse a peut-être été le plus loin [...] dans cette voie Il y a chez elle trois différentes espèces d'institutions entre les universités et les écoles primaires : le : Les Realschule ou écoles des connaissances pratiques, qui préparent indifféremment pour le commerce ou l'industrie, ou même pour le service civil, sauf à se perfectionner plus tard dans le gymnasium (collège classique) ou dans l'une ou l'autre des deux espèces d'institutions ci-après mentionnées. 2e: Les Gewerbe Schule, ou écoles des arts et métiers, dont les élèves, s'ils veulent s'appliquer à la haute industrie,

56 P.-J.-O. Chauveau, L'Instruction publique au Canada, Montréal, 1876, p. 128. L'italique est de nous. 
passent ensuite aux instituts Polytechniques ou Écoles Supérieures des arts et métiers. 3e : Handelschule ou écoles de commerce [...]

Partout en Europe, comme ici en Amérique, l'établissement d'écoles normales, l'inspection régulière des écoles par des fonctionnaires salariés par l'État, l'examen des candidats à l'enseignement par des commissaires ou par les inspecteurs d'écoles, sont les principaux moyens auxquels on a eu recours pour élever le niveau de l'enseignement et le maintenir à la hauteur voulue 57 .

L'introduction de la science agricole dans le cursus des écoles normales sera certainement la première concrétisation de cette stratégie qui situe la lutte pour le monopole de l'autorité dans le domaine de l'éducation sur le terrain de la compétence des professeurs. Stratégie d'autant plus avisée que l'incapacité des éducateurs religieux à dispenser un enseignement pratique est facile à démontrer. En effet, les collèges classiques recrutent la grande majorité de leurs professeurs chez les séminaristes. Ce qui revient à dire que les professeurs des collèges n'ont pas fait d'études autres que leur cours classique et leur théologie ${ }^{58}$. On comprend dès lors les critiques qu'auront à subir les ecclésiastiques sur ce sujet. Maurice Laframboise, député de Shefford, répète en Chambre ce qui, là encore, semble refléter une opinion de plus en plus répandue :

[...] dans l'Ontario, on emploie des instituteurs laïcs au lieu que dans notre province nos instituteurs sont pour la plupart des ecclésiastiques. Ils donnent une excellente éducation littéraire, mais ne peuvent donner aussi bien une instruction pratique ${ }^{59}$.

Une personnalité politique très populaire à cette époque, L.-A. Chapleau, s'insurge contre les prétentions du clergé au contrôle des écoles techniques que l'on veut mettre sur pied. Il affirme alors sans détour que religion et technologie ne font pas bon ménage 60 .

Finalement, il va sans dire que cet argument spécifique qui souligne les faiblesses pédagogiques des ecclésiastiques, et à partir duquel on réclame les moyens de rehausser les compétences des instituteurs, rejoint les aspirations et les

57 Rapport du surintendant de l'Éducation du Bas-Canada pour l'année 1866, p. vi.

58 C. Galarneau, op. cit., p. 99-100.

$59 D A L Q$, M. Laframboise, 6 décembre 1876.

60 R. Heap, op. cit., p. 115. 
intérêts des défenseurs de l'enseignement laïc, à commencer par les instituteurs laïcs eux-mêmes. Ces derniers adhèrent d'autant plus facilement à ces arguments (dont l'un des enjeux est la création d'écoles de sciences appliquées et d'écoles techniques), que ce discours renforce leur position dans le champ de l'éducation. Les journaux des instituteurs, comme L'Instruction publique et L'Enseignement primaire, ne manquent pas de répéter ce discours qu'ils contribuent à renforcer. Les rubriques sur les sciences et leurs applications trouvent ainsi une place assez importante dans les pages de ces journaux 61 .

\section{L'ÉTAT DE LENSEIGNEMENT DES SCIENCES AU CANADA FRANÇAIS : DEUX POINTS DE VUE}

Signalons maintenant deux rapports préparés en 1880 pour la Commission sur les sciences, les lettres et les beaux-arts, de la Convention nationale de Québec de la Société Saint-Jean-Baptiste ${ }^{62}$. Le premier, celui de l'abbé J.-C.-K. Laflamme, s'intitule « Rapport sur l'état des sciences au Canada et sur les moyens de les faire progresser». Reprenant certains arguments typiques du discours libéral sur l'importance d'un enseignement pratique, sans toutefois tirer les mêmes conclusions, les propos du prêtre-éducateur révèlent les grandes lignes du discours spécifique qu'utiliseront dorénavant les défenseurs des collèges classiques. Le deuxième rapport, qui est l'oeuvre de C. Baillargé, ingénieur de la

61 Pour plus de détails, voir A. Labarrère-Paule, Les laïcs et la presse pédagogique au Canada français au XIXe siècle, Québec, P.U.L., 1963.

62 Il faut signaler ici que dans un court texte sur l'idéologie des Annales de la Société Saint-Jean-Baptiste, J.-P. Mathieu aborde timidement le problème de l'éducation comme facteur de développement. Nous croyons cependant que l'auteur, en limitant son analyse aux quatre volumes des Annales, a confondu les discours des rapporteurs et conférenciers (invités à présenter leurs idées, rapports ou expériences sur divers sujets) avec l'idéologie de la Société SaintJean-Baptiste. Du même coup, il passe à côté du sens réel des divergences et même des contradictions qui sont présentes dans les travaux de la Commission, n'y voyant qu'une « antinomie » de la part des idéologues de la Société au lieu d'indices révélant les luttes entre le clergé et la petite bourgeoisie professionnelle pour le contrôle de l'éducation. Voir J.-P. Mathieu, «L'idéologie des Annales de la Société Saint-Jean-Baptiste », dans F. Dumont, op. cit, note 2, p. 438-442. 
Ville de Québec ${ }^{63}$, évoque quant à lui la plupart des thèmes mentionnés plus haut, mais les présente de façon originale. Ce rapport fournit un exemple typique des discours de la deuxième moitié du XIXe siècle sur l'importance des sciences et des techniques.

En 1880, l'abbé Laflamme est professeur de physique et de géologie à l'Université Laval. Sa carrière est engagée, à la fois dans le champ religieux, le champ de l'éducation et, dans une moindre mesure, le champ scientifique. Détenteur d'une certaine autorité dans ces différents champs, il est le porte-parole tout désigné pour légitimer, en quelque sorte, le discours clérical sur l'enseignement des sciences et des techniques.

D'entrée de jeu, Laflamme se fait le défenseur des collèges : l'enseignement des sciences dans les collèges correspond à ce qu'il devrait être. Bien sûr, pour le professeur de l'Université Laval, l'enseignement des mathématiques est un peu trop court et «il est bien difficile que l'élève puisse se familiariser avec ces différentes sciences au point d'en tirer plus tard une grande utilité pratique 64 ». Après tout « ce qu'on doit attendre des collèges ce n'est pas la préparation, la création de spécialistes, qui, aussitôt leurs études finies, feraient leur marque dans une science en particulier ». La mission des collèges est tout autre. Ils « doivent donner à leurs élèves des connaissances scientifiques suffisantes pour qu'ils puissent embrasser avec honneur n'importe quelle carrière au sortir de leurs études, sacerdoce, droit, médecine, etc. 65 ». C'est ainsi que pour Laflamme, « l'enseignement des sciences, tel que donné dans les collèges, laisse peu à désirer 66 ».

Si les collèges répondent adéquatement au mandat qui leur a été donné, qu'en est-il des autres institutions? Pour Laflamme, c'est au-dehors des collèges classiques que les sciences n'occupent pas « avec honneur le rang auquel elles ont droit ». Ainsi, «les jeunes gens instruits ne peuvent pas être tous avocats ou

63 C. Baillargé fut l'un des architectes qui dessina les plans du Parlement d'Ottawa. Il fut aussi l'architecte de l'Université Laval et de la Terrasse Dufferin à Québec.

64 H.-J.-J.-B. Chouinard, Fête nationale des Canadiens français de 1880, Québec, 1881, p. 421.

65 Ibid., p. 424.

66 Ibid., p. 425. 
médecins. Bon nombre gagneraient plus facilement leur vie en étudiant ce que l'on désigne si vaguement sous le nom de génie civil ». Or, selon Laflamme, «nous n'avons pas d'écoles où les aptitudes de nos ingénieurs en herbe peuvent être cultivées 67 », et il faudrait créer une institution calquée sur l'École des Mines de Paris. Il est difficile d'expliquer le silence de Laflamme concernant l'École Polytechnique de Montréal, fondée en 1873. Il est, en effet, impossible qu'il ne soit pas au courant de l'École de génie de Montréal. Est-ce une façon de minimiser l'importance de cette école laïque ? S'agit-il tout simplement de signaler le peu d'importance qu'il lui accorde? Pressent-il que l'École Polytechnique, peu subventionnée par la Commission des écoles catholiques de Montréal, s'achemine vers une mort lente ? Toujours est-il que ce silence est pour le moins révélateur des tensions entre l'enseignement laïc et l'enseignement religieux au Québec. Bien que Laflamme admette l'importance d'une école de génie, il signale cependant que «l'établissement de ces écoles et leur fonctionnement présentent de très graves difficultés 68 ». Premièrement, les coûts seraient trop élevés. Deuxièmement, les élèves ne seraient pas nombreux. La solution, pour Laflamme, semble la suivante : «le gouvernement ne pourrait-il pas, pour commencer, choisir des jeunes gens de talents, recommandés par les supérieurs des collèges où ils auraient étudié, et les envoyer se former à l'école des spécialistes européens 69 ? »

Ces thèses, présentées par J.-C.-K. Laflamme, sont à notre avis, extrêmement instructives. En effet, ce sont celles que le clergé diffusera pendant plus de cinquante ans: l'une affirme que l'enseignement des sciences dans les collèges classiques ne laisse rien à désirer, compte tenu de la mission spécifique de ceuxci ; l'autre attribue la pauvreté de l'enseignement scientifique et technique à l'absence d'écoles spécialisées dans l'enseignement des sciences appliquées. Ces thèses détournent du clergé les critiques si longtemps et si souvent portées contre lui et les renvoient à ceux-là mêmes qui les avançaient. Mais surtout, pour Laflamme, la mise sur pied d'un enseignement des sciences appliquées au Québec n'est ni plus ni moins qu'un rêve utopique. Car, d'une part cela coûterait « des sommes considérables chaque année », pour quelques élèves qui pourraient de

67 Ibid.

68 Ibid., p. 426.

69 Ibid., p. 427. 
toute façon arriver « au même résultat (le génie civil) en étudiant tout simplement quelques années chez un patron », et d'autre part, seuls « les élèves riches [...] seraient à même de faire les déboursés nécessaires » pour ces longues études ${ }^{70}$. Laflamme mentionne alors une pléiade de problèmes qui l'amènent « naturellement » à proposer la solution la plus « pratique », c'est-à-dire, celle qui sert le mieux les intérêts du clergé : la préservation du système d'éducation tel qu'il est et, pour ceux qui ne désirent pas devenir prêtre, notaire ou médecin, un exil dans les pays européens.

Si les recommandations de l'abbé Laflamme ne remettent en cause ni le monopole, ni la mission des collèges classiques, il en va tout autrement de celles présentées par Baillargé. En effet, il déclare que «ce ne sont pas de simples écoles de dessin linéaire qu'il nous faut - celles-ci devraient être obligatoires dans toutes nos écoles ordinaires et maisons d'éducation -, ce sont des écoles de technologie, de polytechnie avec des professeurs capables d'enseigner ces sciences ». Il ajoute ensuite que « Nos Universités canadiennes, nos Collèges, nos Écoles Normales enseignent plus ou moins ces branches ; l'École Polytechnique de Montréal a fait des élèves dont la Province a droit de se féliciter et auxquels j'ai déjà plus d'une fois eu l'occasion de faire mon compliment 71 ». Comme Laflamme, Baillargé reconnaît qu'il faut des écoles de sciences appliquées aux côtés des collèges. Cependant, à la différence de Laflamme, il mentionne l'existence de l'École Polytechnique de Montréal, et surtout, il éclaire un aspect laissé complètement dans l'ombre par Laflamme et qu'il pose comme l'élément déterminant dans la mise sur pied d'un enseignement scientifique et technique : la nécessité d'un corps professoral compétent capable d'enseigner les sciences pures et appliquées. Ainsi la grande recommandation qu'il fait est la suivante :

Il faudrait dans chaque province une école gouvernementale, sorte d'école normale polytechnique où l'on formerait des professeurs auxquels l'on confierait ensuite les écoles des diverses villes et paroisses. Ces dernières, de simples institutions de dessin linéaire et paysagiste qu'elles sont aujourd'hui, mériteraient alors l'appellation d'écoles des arts et métiers, puisqu'on y enseignerait toutes les sciences se rapportant à l'art de bâtir, à la construction et au fonctionnement des usines et machines de toutes sortes, et où l'étude du dessin industriel aurait sa part légitime. Impossible à un gouvernement de doter un pays d'une institution plus utile et par le

70 Ibid., p. 426-427.

71 Ibid., p. 433. 
moyen de laquelle dans peu d'années, ce que le pays sauverait de milliers, de centaine de milliers de piastres que l'on dépense aujourd'hui à refaire constamment ce qui, faute de connaissances, est mal fait, ce que, dis-je, l'on sauverait de cette manière, payerait au centuple le coût de cette école mère et de toutes celles qui lui seraient affiliées 72 .

Finalement, l'ingénieur termine son rapport par cette tirade si souvent entendue et qui s'adresse aux collèges classiques : «Enfin, moins de grec et de latin, plus de physique, de mécanique, de chimie, de technologie et nous y arriverons 73 ».

En 1880, proposer la création d'une école normale polytechnique, au moment même où une campagne ultramontaine et antilaïciste se prépare à donner l'assaut aux deux écoles normales catholiques, constitue une prise de position contre une partie du clergé. De plus, c'est toute la formation humaniste des collèges qui est remise en cause avec cette phrase finale qui sert de conclusion à son rapport. Il serait naïf de croire que les propos de ces deux rapporteurs ne doivent rien à la lutte entre le clergé et une partie de la petite bourgeoisie professionnelle dans le domaine de l'éducation. Comment expliquer autrement que, malgré une évaluation assez similaire des besoins de l'enseignement des sciences appliquées, les solutions proposées par Laflamme s'opposent si radicalement à celles mises de l'avant par Baillargé ?

\section{L'ÉCHEC DES TENTATIVES POUR TRANSFORMER LE SYSTĖME D'ENSEIGNEMENT SECONDAIRE ET SUPÉRIEUR AU QUÉBEC}

Si le discours sur l'importance de la science appliquée et de l'enseignement technique s'inscrit dans une lutte entre le clergé et une partie de la petite bourgeoisie professionnelle, on peut dès lors se poser la question des effets réels de ce discours. À ce niveau, on ne peut que constater l'échec relatif des tentatives de création d'écoles de sciences, d'écoles techniques, d'écoles normales nouvelles, bref l'échec d'une restructuration importante de l'enseignement secondaire et

72 Ibid., p. 434-435.

73 Ibid., p. 436. 
supérieur. En effet, on voit bien apparaître, entre 1845 et 1855, quelques collèges industriels, mais plusieurs d'entre eux modifieront par la suite leurs programmes pour ne garder finalement que le cours classique ${ }^{74}$. L'Académie commerciale du Plateau, créée en 1855, représente le seul exemple du type d'institutions que l'on souhaitait ériger aux côtés des collèges classiques. Quant à l'École Polytechnique de Montréal, elle demeure, et ce jusqu'aux années 1920, une institution marginale par rapport aux collèges classiques qui constituent la filière dominante.

Cette situation s'explique en bonne partie par le fait que la réforme de l'enseignement remettait en question le pouvoir quasi absolu du clergé dans ce domaine. Toute volonté de changement était ainsi perçue par l'Église comme une atteinte directe à ses intérêts et privilèges et combattue avec force, finalement, avec succès.

L'Église, comme le montre la contribution de R.A. Jarrell à ce livre, ne condamne pas la science comme telle. Il est remarquable de constater que le discours du clergé, comme on le voit sous la plume de l'abbé Laflamme, n'est pas non plus hostile à l'idée d'un enseignement pratique. La position du clergé consiste moins à mettre en cause la nécessité d'un enseignement pratique qu'à défendre coûte que coûte ses intérêts contre les prétentions du pouvoir politique (et laïque) en matière d'éducation. C'est ainsi, par exemple, que lors du concile provincial des évêques, Mgr Larocque (représentant des évêques au Conseil de l'Instruction publique) fait part à ses collègues du fait qu'il craint que le développement de l'enseignement commercial et technique «ne fasse perdre des élèves aux collèges classiques et ne diminue les vocations ecclésiastiques 75 ». C'est cette même méfiance à l'égard de l'ingérence de l'État dans l'éducation qui incite l'Université Laval à refuser la subvention du gouvernement pour la création d'une école de sciences appliquées ${ }^{76}$. L'Église joue donc objectivement un rôle de frein face aux changements revendiqués par une certaine élite laïque parce qu'elle perçoit l'enseignement scientifique et technique comme un Cheval de

74 L.P. Audet, Le système scolaire au Québec, Montréal, Beauchemin, 1967, p. 25-26.

75 J. Grisé, Les conciles provinciaux de Québec et l'Église canadienne 18541886, thèse de doctorat, Université de Montréal, 1962, p. 110.

76 A. Maheux, «P.-J.-O. Chauveau, promoteur des sciences », dans Mémoires et comptes rendus de la Société royale du Canada, vol. 1, 1963, p. 91. 
Troie qui, après avoir franchi les portes du collège ou de l'université, grugera peu à peu ses pouvoirs dans les établissements qu'elle dirige.

Malgré son importance, le discours prônant l'instauration d'un enseignement scientifique et technique ne donne lieu à aucune réforme importante, les pouvoirs du clergé, tant au plan social, idéologique que politique, bloquant efficacement toute velléité de changement.

En 1875, le ministère de l'Instruction publique est aboli. On concède à un comité catholique, composé de sept évêques et de sept laïcs, la direction de l'éducation pour les Canadiens français. L'élimination de G. Ouimet avec le « Scandale des Tanneries », l'arrivée de Boucher de Boucherville à la tête du gouvernement, le mutisme des libéraux (commandé par la crainte de se voir taxés d'anti-catholiques), expliquent, en partie, que l'État ait abdiqué ses responsabilités dans le domaine de l'éducation face à l'Église. Évidemment, en concédant pratiquement la direction du système d'éducation aux évêques, l'espoir de voir s'ériger des académies commerciales, des écoles techniques, des écoles de sciences appliquées, qui concurrenceraient obligatoirement les collèges, se métamorphose subitement en utopie. Privés d'un moyen politique efficace d'intervention dans le secteur de l'éducation, les efforts pour modifier le système scolaire restent vains.

Ce discours sur la science, dont l'une des particularités est de mettre en cause un système d'éducation secondaire uniquement basé sur l'éducation classique, survit jusqu'à la fin du XIXe siècle et revient en force au cours des années 1920, au moment où sont mises en place les bases institutionnelles de l'enseignement scientifique au Québec. En effet, l'absence d'une filière scientifique pèsera lourd sur le développement des institutions d'enseignement scientifique supérieur créées à cette époque, et ravivera encore le débat sur la nécessité des réformes dans l'enseignement secondaire ${ }^{77}$.

77 F. Descarries-Bélanger, M. Fournier et L. Maheu, « Le frère Marie-Victorin et les 'petites sciences' », Recherches sociographiques, vol. XX, no 1, 1979, p. 739. 
Sciences et médecine au Québec.

Perspectives sociohistoriques

\title{
Chapitre II
}

\section{L'ultramontanisme et la science au Canada français *}

\author{
par Richard A. Jarrell \\ Professeur, Department of Natural Science, Atkinson College, \\ York University
}

\section{$\underline{\text { Retour à la table des matières }}$}

L'idéologie ultramontaine fut certainement l'un des aspects les plus caractéristiques de la société canadienne-française au 19e siècle. On ne peut toutefois en dire autant de l'activité scientifique et cet article se propose d'étudier la relation entre ces deux aspects. Puisque le terme " activité scientifique " a un sens très large, nous devons distinguer deux notions : celle de l'exercice de la science et celle de culture scientifique. Par la première, nous entendons la formation du savoir scientifique par la recherche et la publication d'ouvrages, l'enseignement de la science en vue de former des praticiens ainsi que l'utilisation des connaissances scientifiques par l'industrie, l'agriculture et les gouvernements. Ceux qui œuvraient dans le domaine scientifique au Canada du 19e siècle n'étaient pas forcément des professionnels au sens où l'on entend ce terme aujourd'hui. On ne retrouve pas dans un pays en transition entre l'état de colonie et

* Ce texte, dont l'original est en anglais, a été traduit par M. Richard Harrisson. 
celui de nation, le même degré de développement et la même diversité d'activités de recherche que l'on peut remarquer dans des pays comme la France et l'Angleterre. Par culture scientifique nous entendons les activités de nature généralement plus large débordant le cadre des seuls praticiens. Ces activités peuvent comprendre la diffusion et la lecture de travaux scientifiques, le fait d'assister à des conférences, la visite de musées, les travaux d'amateurs de moindre intérêt pour les praticiens, l'enseignement scientifique faisant partie d'une éducation libérale, de même que l'appui de la société envers la science.

Ces deux aspects de l'activité scientifique cœxistaient au 19e siècle, autant du côté anglophone que francophone. Comme nous le verrons en conclusion, la culture scientifique et l'exercice de la science sont liés entre eux. Chez les anglophones, la relation entre ces deux aspects semble avoir été plus étroite : à mesure que l'exercice de la science se développait, la culture scientifique déclinait ${ }^{78}$. Chez les francophones ce processus ne paraît pas avoir existé. D'après nos connaissances sur la science au siècle dernier et selon plusieurs critères, il s'avère que même au Québec les Canadiens français tiraient de l'arrière loin derrière les anglophones dans l'exercice de la science ${ }^{79}$.

78 Pour une esquisse de cette situation au Canada anglais, voir notre article, "Science as Culture in Victorian Toronto ", Atkinson Review of Canadian Studies, vol. 1, no 1, automne 1983, p. 5-12.

79 À ce jour, aucune compilation de données permettant d'établir des comparaisons n'a été publiée. Bien qu'elles soient incomplètes, les statistiques que nous avons recueillies font ressortir nettement le retard des francophones notamment dans le nombre des journaux et des articles publiés, des diplômés en sciences, des scientifiques membres de la Société royale du Canada (par exemple $10 \%$ en 1894), du personnel de la Commission géologique du Canada (6\% de 1842 à 1900), des organisations à vocation scientifique, etc. Pour ce qui est de la culture scientifique, le manque de données nous empêche de comparer des statistiques. Les récentes recherches sur l'aptitude à la lecture, la diffusion des livres et les bibliothèques par Galarneau, Lamonde, Hare, Wallot, Morin et d'autres laissent supposer que les francophones avaient un intérêt culturel durable pour la science mais là encore les données se font toujours rares. Veuillez consulter le récent recueil d'Yvan Lamonde, L'imprimé au Québec. Aspects historiques (18e-20e siècles), Québec, 1983, et Lamonde, Les bibliothèques de collectivités à Montréal (17e-19e siècle), Montréal, 1979. 
Ce phénomène peut être expliqué de différentes façons, mais jusqu'à récemment la science a si peu fait partie de la conscience des Canadiens français que peu d'hypothèses ont été soulevées. P.-J.-O. Chauveau, premier ministre du Québec, qui avait une attitude bienveillante envers la science, affirmait qu'une « affinité culturelle » était à la base de la préférence des Canadiens français pour les arts et la littérature alors que la science répondait mieux à la nature des AngloSaxons ${ }^{80}$. Nous pouvons écarter, à première vue, un si grossier déterminisme culturel. Certains auteurs contemporains tels que Ouellet, Lortie et Rousseau ${ }^{81}$, en apportant un souffle nouveau à l'histoire de la science canadienne-française, ont démontré que la science moderne au Québec s'appuie sur un véritable héritage scientifique. Duchesne 82 et d'autres historiens se sont appliqués à démêler les événements et leurs contextes. C'est une démarche nécessaire qui nous permettra d'éclaircir les causes du retard de la science au Québec.

Néanmoins, nous pouvons déjà accepter ou rejeter certaines hypothèses. Les intellectuels canadiens-français, surtout depuis les années 1960, s'entendent sur le rôle de l'Église catholique romaine et spécialement de son mouvement ultramontain dans la mise en veilleuse de la science au Québec. Depuis quelques décennies cela représentait un fait établi pour les Canadiens anglais. Nous examinerons cette hypothèse qui semble, tout d'abord, séduisante. Si nous pouvons l'étayer, nous serons alors en mesure d'évaluer d'autres explications.

L'historiographie sur cette question est plutôt mince. La science est à peine abordée dans les études historiques sur le rôle de l'Église dans la société

80 P.-J.-O. Chauveau, L'Instruction publique au Canada, Québec, 1876, p. 311.

81 Les travaux de Rousseau comportent un certain nombre de notices biographiques sur les naturalistes. Ceux de Lortie traitent des divers aspects de la science au 10e siècle. Un bon aperçu est l'article de Lortie, " La trame scientifique de l'histoire du Canada » dans G.F.G. Stanley, (éd.), Pioneers of Canadian Science, Toronto, 1966. Voir également Cyrias Ouellet, La vie des sciences au Canada français, Québec, 1964.

82 Voir tout spécialement La science et le pouvoir au Québec (1920-1965), Québec, 1978, et « Science et société coloniale : les naturalistes du Canada français et leurs correspondants scientifiques (1860-1900) », HSTC Bulletin, vol. 5, no 2, mai 1981, p. 99-139. Voir aussi Paul Carle, « Le cabinet de physique et l'enseignement des sciences : le cas du Séminaire de Québec et de l'Université Laval : 1663-1920 », thèse de doctorat, Université de Montréal, 1986 et l'article d'Yves Gingras dans le présent recueil. 
canadienne-française. On ne s'accorde pas, dans l'histoire et la sociologie des sciences sur le rôle de l'Église dans le développement scientifique. Les travaux de Draper et de White ${ }^{83}$, exemples typiques de l'ancienne littérature, surtout protestante, sur ce sujet, présument qu'une guerre entre la science et la religion était engagée. Dans la même veine, d'anciens écrits présentent Galilée comme un « martyr » de la science. Pendant près d'un demi-siècle, la sociologie des sciences, s'inspirant des travaux de Weber et plus particulièrement de la thèse classique de Robert Merton sur la science et la société dans l'Angleterre du 17e siècle, s'est penchée sur le rôle du protestantisme dans le développement de la science sans pour autant arriver à une conclusion ${ }^{84}$. D'autre part, peu d'arguments de valeur ont été apportés par les apologistes du catholicisme en réponse à l'école DraperWhite ${ }^{85}$. Au 19e siècle, la science était plus florissante dans les pays qui professaient le protestantisme (l'Angleterre, l'Allemagne, les États-Unis, etc.) que dans ceux qui professaient le catholicisme (l'Espagne, l'Italie, la Pologne, etc.), bien qu'avec le cas de la France la question est loin d'être tranchée.

Nous ne croyons pas que l'historiographie et la sociologie sur cette question peuvent nous apporter quelque lumière sur le problème qui nous occupe et nous n'en tiendrons pas compte. Nous nous limiterons à l'étude de la montée de l'ultramontanisme au Québec et de ses rapports avec la pensée libérale. Nous verrons ensuite comment les ultramontains percevaient la science et le progrès et quels furent les résultats concrets de cette vision durant la deuxième moitié du 19e siècle.

83 John W. Draper, History of the Conflict Between Religion and Science, Londres, 1875. Andrew Dickson White, A History of the Warfare of Science with Theology in Christendom, New York, 1896, 2 vol., réimpression 1960.

84 Voir par exemple, Robert K. Merton, Science, Technology and Society in Seventeenth Century England, New York, 1970 ; Charles Webster, The Great Instauration. Science, Medicine and Reform 1626-1660, Londres, 1975 ; Christopher Hill, "Puritanism, Capitalism and the Scientific Revolution », Past and present, vol. 29, 1964, p. 88-97 ; et, parmi d'autres, les ouvrages de A.-R. Hall, S.-F. Mason, R. Hooykaas.

85 À titre d'exemple, Sir Bertram Windle, The Catholic Church and its Reactions with Science, New York, 1927. 


\section{L'ULTRAMONTANISME DANS LA SOCIÉTÉ CANADIENNE-FRANÇAISE}

Bien que son influence ait toujours été prépondérante, l'Église catholique romaine établit son emprise sur le Québec vers 1840. Les répercussions des événements de 1837-1838, l'échec du radicalisme bourgeois, la nouvelle situation politique après la Confédération, la montée de la ferveur religieuse, de même que l'introduction par des membres importants du clergé de la philosophie ultramontaine, ont petit à petit assuré à l'Église une emprise sociale inégalée dans toute autre nation. L'évêque Ignace Bourget dirigeait le mouvement ultramontain dont le centre se trouvait à Montréal. L'ultramontanisme, tel qu'il s'est formé au 19e siècle, était une doctrine importée d'Europe et, comme le fait remarquer Monière ${ }^{86}$, elle était profondément enracinée dans la peur. Le radicalisme et l'anticléricalisme des révolutionnaires européens de 1848 (descendants des révolutionnaires français de 1789) ainsi que le rêve de l'unification de l'Italie (vite réalisé), même aux dépens du pouvoir temporel de la papauté, alarmèrent Pie IX et ses partisans. L'ultramontanisme fut adopté en France par ceux qui craignaient le pouvoir grandissant du Second Empire, surtout après la promulgation de la loi Falloux en 1850 qui enlevait à l'Église tout pouvoir en matière d'éducation. Par rapport au Canada français où l'Église restait intouchée et où, durant les années 1840, son emprise sur l'éducation grandissait, ces événements semblent à première vue bien éloignés. Si l'influence des idées révolutionnaires sur le Québec a toujours été faible, c'est qu'il y a peu en commun entre les radicaux canadiensfrançais et les socialistes ou autres groupes français. Pourtant, des hommes comme Mgr Bourget, irrésistiblement attirés par l'idéal romain de l'Église, se rallièrent avec ferveur à l'idéologie ultramontaine puisqu'elle s'avérait un moyen d'action politique efficace qui pouvait mener à un rare niveau de domination sociale.

86 Denis Monière, Le développement des idéologies au Québec des origines à nos jours, Montréal, 1977, p. 225. [Livre disponible dans Les Classiques des sciences sociales. JMT.] 
Selon Nadia Eid ${ }^{87}$, l'ultramontanisme au Canada se voulait : 1) une idéologie de la suprématie de l'Église sur l'État et sur toutes les classes sociales ; 2) une idéologie au service du clergé dans sa lutte contre la petite bourgeoisie alors en pleine ascension au Bas-Canada ; 3) le principe d'une alliance entre le clergé et les éléments conservateurs de la petite bourgeoisie ayant pour but le maintien du pouvoir et l'élimination des radicaux.

Cette conception conservatrice des relations entre l'Église et la société avait pour cible le libéralisme dans toutes ses manifestations. Les défenseurs de l'Église s'appuyaient sur l'encyclique Quanta Cura et sur le Syllabus (1864) de Pie IX qui condamnaient tout l'idéal libéral. En politique, les libéraux désiraient remplacer le pouvoir de Dieu à travers son Église par celui de l'État; plus rationnels, ils désiraient également remplacer la foi et la révélation par la seule raison. Ce que les ultramontains condamnaient avec le plus de vigueur c'était le libéralisme catholique: selon eux, les catholiques ne devaient pas s'enticher d'opinions libérales au sujet de la religion ou sur toutes autres questions. Cela semble avoir été l'avis de Pie IX et de ses partisans à Montréal et à Trois-Rivières. Malheureusement, plusieurs formes de libéralisme et même certaines idées à première vue inoffensives ont été condamnées de façon implacable par le clergé.

Est-ce que la science était pour les ultramontains une forme du libéralisme ? Il n'y a pas de réponse précise. Pie IX jetait l'anathème sur la civilisation moderne et le progrès alors que plusieurs de ses contemporains voyaient le lien évident qui unissait la science à ces deux notions. L'union du rationalisme et de la science pouvait engendrer des hérétiques de la trempe de Dormin. Le scientisme était une « mauvaise doctrine ». Bien que la science était perçue comme le principal agent du progrès par quelques catholiques d'Europe et plusieurs protestants, surtout en Angleterre et aux États-Unis, elle ne représentait pas pour Louis Veuillot, rédacteur de $L$ 'Univers et ardent défenseur de la papauté, une cible importante et ce, malgré son rejet inconditionnel de la modernité. En Angleterre, en France et aux États-Unis où la science était en plein essor, les idées libérales trouvaient facilement audience. Il y a de toute évidence un lien étroit, bien que difficile à établir d'après nos connaissances actuelles, entre l'intérêt accordé à la science et la portée du libéralisme dans certains pays. La Prusse cependant semble être une

87 Nadia F. Eid, Le clergé et le pouvoir politique au Québec, Montréal, 1978. 
exception à cette règle. Nous croyons qu'une certaine forme de libéralisme ou du moins une ouverture d'esprit est nécessaire au développement de la science dans la société.

Quand le clergé québécois attaquait le libéralisme, il entendait habituellement le « libéralisme catholique ». Pour Mgr Bourget, c'était l'ennemi à abattre surtout chez les politiciens libéraux de l'Institut canadien de Montréal et du Parti rouge ${ }^{88}$. Il fut le principal instigateur de l'alliance politique avec les conservateurs durant les années 1840. Le terme « libéralisme catholique " s'avéra alors une étiquette utile. Comme l'indique Jacques Monet ${ }^{89}$, l'alliance fut très efficace. En effet, la bourgeoisie conservatrice avec à sa tête Louis-Hippolyte Lafontaine voyait dans le système parlementaire britannique le levier capable de rendre aux Canadiens français sinon leur plein pouvoir économique, du moins la pleine possession de leur destin politique. La Confédération canadienne a été l'aboutissement logique de ce principe. L.-H. Lafontaine devait donc unifier son parti, créer une entente avec les conservateurs du Haut-Canada et former un gouvernement responsable. En échange de son appui, l'Église reçut une plus grande influence en éducation et dans le domaine des affaires sociales.

Le thème unificateur et prédominant de cette alliance était le nationalisme défenseur de la langue française, des traditions et de la religion catholique. Pour beaucoup d'ecclésiastiques et surtout pour Mgr Bourget, le catholicisme était la seule véritable base du nationalisme. Durant les années 1850, l'alliance fut respectée mais à partir des années 1860, certains ultramontains prirent leurs distances avec le Parti conservateur (contrairement aux déclarations du Nouveau monde) et se tournèrent vers ceux parmi les conservateurs qui supportaient les vues de l'Église. Le programme catholique de 1871 qui exprimait cette nouvelle position suggérait aux vrais catholiques de ne donner leur appui qu'aux candidats qui étaient conservateurs et dont la pensée était en accord avec les buts de l'Église. Comme on le voit, l'ultramontanisme au Québec fut un amalgame complexe de

88 Pour un aperçu de l'idéologie et du destin politique des Rouges, voir Jean-Paul Bernard, Les rouges. Libéralisme, nationalisme et anticléricalisme au milieu du XIXe siècle, Montréal, 1971.

89 Jacques Monet, «French Canadian Nationalism and the Challenge of Ultramontanism », Canadian Historical Association, Historical Papers, 1966, p. 41-55. 
conservatisme social et politique ainsi que de diverses formes d'anti-libéralisme. Toutefois, l'adhésion n'était pas toujours totale. La hiérarchie religieuse de Québec et ses associés de l'Université Laval, bien qu'ultramontains dans leur plus grande part, restaient à l'écart du débat mené par les monseigneurs Bourget et Laflèche. En 1876, un mandement de l'archevêque Taschereau attaquait le libéralisme catholique parce qu'il plaçait l'État au-dessus de l'Église, aussi parce qu'il voulait instituer la laïcité et qu'il prenait des « erreurs » pour des faits. Le rapport que fit au pape Mgr Laflèche sur les efforts de son Église dans la lutte contre le libéralisme, et la réponse de Pie IX, forcèrent Mgr Taschereau à réagir. Néanmoins, il ménagea subtilement les libéraux de Wilfrid Laurier (ce que n'aurait pas fait Mgr Bourget) en déclarant que : «L'Église respecte et même protège la liberté d'opinion et d'action de ses enfants dans les limites toutefois de la vérité, de la justice, de la charité, car la véritable liberté n'est pas une licence effrénée 90 ».

Les années 1880 virent la réalisation des visées ultramontaines au Québec. Les conservateurs régnaient sur la province et lorsque les libéraux prirent le pouvoir (pour une courte période) il n'y eut pas de véritable changement dans la politique du gouvernement. Le clergé régnait en maître sur l'éducation et s'assurait ainsi la continuité de sa domination. Si Denis Monière avait raison lorsqu'il déclarait que « les ultramontains réprouvaient aussi la science et ses applications. L'idée de progrès matériel [était] un épouvantail pour eux 91 », nous devrions voir dans la deuxième moitié du siècle l'alliance des conservateurs et du clergé retarder sinon annihiler le savoir scientifique autant dans l'éducation que dans le domaine culturel. Nous démontrerons dans les prochaines parties que rien de tel n'eut lieu. En fait, le clergé et ses alliés politiques étaient, à plusieurs points de vue, en faveur de la science. Nous avancerons l'idée que c'est leur façon d'envisager la science, différente de celle de leurs homologues anglophones, qui est à l'origine du nombre inférieur des carrières scientifiques chez les Canadiens français.

90 Mandement du 27 octobre 1876 dans Mandements, lettres pastorales et circulaires des Évêques de Québec, Québec, H. Têtu et C.-O. Gagnon, éds., 1889, vol. 6, p. 450.

91 Monière, op. cit., p. 217. 


\section{LA SCIENCE DANS LE DISCOURS ULTRAMONTAIN}

Un survol rapide de la littérature ultramontaine en particulier et des écrits sur les relations entre l'Église et la société, fait ressortir la diversité des opinions. Lorsqu'on aborde la science (ce qui est rare), les opinions divergent sur son rôle dans la société québécoise. Ce qui suit est un échantillonnage d'opinions, allant des réactionnaires à celles relativement libérales, qui ont eu cours dans la deuxième moitié du 19e siècle, époque où s'implanta l'idéologie ultramontaine.

L'abbé Alexis Pelletier et Jules-Paul Tardivel, deux extrémistes de la doctrine ultramontaine, ont sans doute exercé une influence négative sur le développement de la science. L'abbé Pelletier enseigna les mathématiques au Séminaire de Québec durant les années 1860, ce qui ne l'empêcha pas de vouer une grande admiration à Mgr Bourget et aux ultramontains de Montréal. Il fut l'auteur, sous différents pseudonymes, de plusieurs lettres et pamphlets virulents dans lesquels il attaquait les libéraux de tout poil, surtout ceux qui, croyait-il, étaient protégés par le Séminaire et l'archevêque de Québec. L'abbé Pelletier est reconnu comme le champion de la pensée de l'abbé Gaume qui prônait le remplacement dans les écoles des ouvrages "païens » de la littérature classique par ceux des anciens pères de l'Église. Plusieurs pamphlets de l'abbé Pelletier prétendaient qu'un changement dans l'éducation au Québec était souhaitable afin de chasser les doctrines antichrétiennes inculquées par les écrits des anciens Grecs et des auteurs latins (qui servaient, bien sûr, à l'enseignement du grec ancien et du latin). Les gaumistes, s'appuyant sur le Syllabus de Pie IX, pouvaient aisément démontrer que les idées païennes menaient à diverses erreurs telles le naturalisme, l'indifférentisme, la libre pensée, etc. Dans un ouvrage antérieur ${ }^{92}$, l'abbé Pelletier indiquait que dans l'esprit du vrai catholique les deux ordres du monde, le naturel et le surnaturel, sont liés. La science ferait alors partie de l'ordre naturel mais l'abbé reste obscur sur cette question. En fait, son ouvrage n'aborde pas la question de la science, bien qu'un lecteur attentif verrait dans son argumentation

92 Mgr Gaume, sa thèse et ses défenseurs. Les classiques chrétiens et les classiques païens dans l'enseignement, Saint-Hyacinthe, 1865. 
l'hypothèse d'une relation étroite entre la foi et la raison de même qu'entre la théologie et la science. Dans un autre pamphlet ${ }^{93}$, l'abbé Pelletier dénonce les ennemis d'une bonne éducation catholique : les libres penseurs, les libéraux et surtout l'odieux M. Dessaules. Il y indique aussi (brièvement) que la science peut être contaminée par les idées païennes.

Si le gaumisme avait été pris au sérieux au Québec, n'aurait-il pas menacé l'enseignement de la science dans les collèges ? Nous ne croyons pas : les écrits de l'abbé Pelletier s'attardent surtout sur l'aspect littéraire de la culture classique et considèrent que la science ne représente aucun danger dans une éducation catholique si elle reste intouchée par les idées subversives. Malgré le nombre important de ses partisans et le fait que les idées de l'abbé Gaume aient trouvé audience auprès de Pie IX, les vues de l'abbé Pelletier irritèrent la hiérarchie de Québec, particulièrement l'archevêque Baillargeon, et aucun geste ne fut posé pour implanter le programme gaumiste.

Polémiste entêté, l'abbé Pelletier avait d'autres cibles dont surtout le libéralisme sous toutes ses formes. Les enseignants et les administrateurs de l'Université Laval, les membres de l'Institut canadien, comme Dessaules, étaient ses ennemis. Dans son Syllabus, Pie IX avait bien stipulé qu'il n'avait aucunement l'intention de s'accommoder au libéralisme, au progrès ou à la civilisation moderne. Pour Pie IX, le libéralisme catholique était la pire des erreurs mais il semble avoir confondu ce qu'on peut appeler le catholicisme libéral avec le libéralisme catholique ${ }^{94}$. Catholicisme libéral signifie un relâchement de la foi pouvant mener à l'indifférentisme et à l'assujettissement au gallicanisme et aux pires excès intellectuels de la Révolution française et de l'Italie. Quant au libéralisme catholique, il pourrait désigner la philosophie de tout bon catholique possédant une conception libérale de la politique et de la société. Au Québec, ces deux notions cœxistaient dans le discours de la lutte contre le libéralisme. Pour Mgr Bourget et pour l'abbé Pelletier, le libéralisme était clairement défini et il devait être éliminé. Ils critiquaient la hiérarchie de Québec et les professeurs de l'Université Laval qui rejetaient le catholicisme libéral mais acceptaient le libéralisme catholique.

93 La réforme chrétienne des études classiques par un collaborateur du FrancParleur, Montréal, 1875.

94 Lovell C. Clark, The Guibord Affair, Toronto, 1971, p. 3. 
En 1872, l'abbé Benjamin Paquet, professeur de théologie à Laval, donna une série de conférences sur le libéralisme qui attira beaucoup d'attention. La riposte de l'abbé Pelletier ne se fit pas attendre bien que tous deux s'entendaient sur de nombreux points. L'abbé Paquet, se rangeant du côté du conservatisme canadien et prenant position contre le libéralisme politique, déclara que la loi, l'ordre et la soumission à l'autorité forment la véritable assise de la liberté. Il appuya l'Église dans sa dénonciation de cette sorte de libéralisme qui mène à la liberté de pensée, à l'indifférentisme et à l'indépendance de la science ${ }^{95}$. Il visait ainsi la science séparée de la foi et non pas la science que ses collègues de l'Université et du Séminaire enseignaient. En réponse à l'opposition farouche, de la part des ultramontains les plus radicaux, au progrès et à la civilisation moderne, l'abbé Paquet s'appliqua à démontrer l'appui de l'Église à de nombreuses innovations modernes: ne se réjouissait-elle pas de l'installation du câble sous-marin transatlantique ? Et, contrairement aux dires de certains libéraux, n'était-elle pas en faveur des chemins de fer ? Plus loin, un passage amusant relate la bénédiction d'un train italien par Pie IX. La science et la technologie étaient pour la plupart des libéraux intimement liées au progrès ${ }^{96}$. Un rejet total du libéralisme catholique pouvait naturellement mener à une condamnation du progrès scientifique et technologique, mais l'abbé Paquet ne tomba pas dans ce piège. Avec justesse, l'abbé Pelletier comprit l'intervention de son homologue: condamner le catholicisme libéral tout en ne se prononçant pas sur le libéralisme catholique, même si en réalité il ne l'approuvait pas.

Le libéralisme trouva un défenseur acharné en la personne de LouisAntoine Dessaules, radical et rougiste. Son plaidoyer en faveur de l'Institut canadien, de l'annexion aux États-Unis et de l'anticléricalisme manifestait les pires tendances du libéralisme. Devant l'intransigeance de Mgr Bourget et de ses partisans, Dessaules utilisa l'exemple de la science afin de démontrer la manière dont l'Église militante écrasait les droits des hommes libres. Le cas de Galilée, soulevé lors d'une conférence à l'Institut canadien en 1856, se révéla pour lui un moyen

95 Le libéralisme. Leçons données à l'Université Laval, Québec, 1872, p. 25. La réponse de Pelletier se trouve dans Le libéralisme catholique ou observations critiques sur l'opuscule de M. l'abbé Benjamin Paquet intitulé: Le libéralisme, par A de F, Montréal, 1872.

96 C'était certainement vrai chez les Canadiens anglais de l'époque. Voir Carl Berger, Science, God and Nature in Victorian Canada, Toronto, 1983. 
d'attaquer les ultramontains. Après avoir revu en détail l'Inquisition et ses atrocités, il fit remarquer : « [...] ce n'était pas tant Galilée que l'on persécutait que les principes de libre arbitre moral, d'indépendance philosophique qu'il introduisait dans l'enseignement, dans les études scientifiques 97 ». Tout en attaquant les éléments réactionnaires de l'Église, Dessaules souscrivait aux principes religieux catholiques: «Il y a deux cents ans que la vérité philosophique, la science moderne, la vraie science chrétienne, au fond, frappaient à la porte et n'étaient pas admises 98 !!! » Voulait-il suggérer que l'Église québécoise menaçait la science ? Non, la condamnation de Galilée n'était pour lui qu'une métaphore employée dans la lutte contre le conservatisme militant qui menaçait de détruire toute forme de pensée libérale au Canada français.

À la suite de la parution de La Grande Guerre Ecclésiastique de Dessaules, l'abbé Pelletier, dans un virulent pamphlet, se porta à la rescousse des ultramontains 99 . Il en profita pour discréditer à nouveau l'Université Laval. Dessaules croyait que le mépris des ultramontains envers Laval était dû à son manque de ferveur religieuse (un auteur de l'époque soupçonnait la présence de libres penseurs, de francs-maçons et de libéraux au sein de l'Université) mais l'abbé Pelletier rétorque que la faiblesse de Laval réside plutôt dans le manque de contenu religieux des cours scientifiques offerts aux étudiants en médecine et en droit ainsi que dans le laxisme présidant au choix des livres. Curieusement, l'abbé Pelletier, bien que conscient du danger que représentaient les ouvrages païens et le libéralisme, ne fait à peu près pas mention de la science : il ne se rendait pas compte qu'elle pouvait représenter une menace bien plus grande envers le programme ultramontain que Cicéron ou les membres du Parti libéral.

Notons cependant que l'abbé Pelletier n'était pas un élément des plus représentatifs de l'ultramontanisme au Québec. Les ultramontains ne formaient pas un groupe homogène. Il est faux d'affirmer comme le faisaient les extrémistes de l'époque que la hiérarchie de Québec était composée de libéraux catholiques par opposition aux bons ultramontains tels les partisans de Mgr Bourget. Les

97 Galilée, ses travaux scientifiques et sa condamnation. Lecture publique faite devant l'Institut canadien... le 14 mars 1856, Montréal, 1856, p. 47.

98 Ibid., p. 50.

99 Le Don Quichotte montréalais sur sa Rossinante, ou M. Dessaules et La Grande Guerre Ecclésiastique par Luigi, Montréal, 1873. 
archevêques Baillargeon et Taschereau étaient également, sous plusieurs aspects, ultramontains. Le vrai débat semble avoir été le désaccord entre les villes de Québec et de Montréal sur la façon de gouverner l'Église. Ce débat aboutit à l'importante controverse au sujet de la création d'une université distincte à Montréal 100.

Afin d'illustrer les divergences d'opinions entre les groupes ultramontains, nous allons étudier les réactions des journalistes à deux importants congrès scientifiques internationaux tenus à Montréal: le congrès de l'American Association for the Advancement of Science en 1857 et celui de la British Association en 1884. Alors que l'association américaine convergeait sur Montréal, Jean-Charles Taché, rédacteur du Courrier du Canada et l'un des plus importants défenseurs de l'ultramontanisme, fit reparaître un article du journal La Patrie de Montréal qui vantait les grands avancements scientifiques accomplis en Amérique du Nord britannique et soulignait l'importance d'un tel congrès à Montréal : « Et d'ailleurs, ce n'est pas la science qui est honorée de ce que l'on fait pour elle, c'est l'esprit humain qui s'honore lui-même dans cet hommage rendu à ce qui est sa plus noble et sa plus légitime conquête ${ }^{101}$. »

Les parutions subséquentes énuméraient les documents importants lus au cours du congrès et s'en prenaient à deux journaux d'Hamilton, le Daily Spectator et le Banner dont les correspondants devaient critiquer la faible participation des Canadiens français au congrès qu'ils expliquaient par la trop grande présence des prêtres dans l'éducation. Le National avait également calomnié les Canadiens français mais Taché répliqua en louant la valeur des abbés québécois Pilote, Casault, Ferland, Verreau et Horan :

Les hommes distingués dont les noms sont si indécemment jetés dans cette discussion se sont sans cesse occupés et cela depuis leur jeunesse, de l'éducation de nos jeunes gens: hommes de science, constamment employés dans le silence du cabinet, ils aiment peu le bruit, et s'accommodent mieux par état comme par goût du calme et des labeurs qui font les savants 102 .

100 Voir André Lavallée, Québec contre Montréal. La querelle universitaire 1876-1891, Montréal, 1974.

101 Courrier du Canada, 12 août 1857.

102 lbid., le 14 août 1857 ; voir aussi le 24 août 1857. 
La réaction d'un autre ultramontain, Jules-Paul Tardivel (le Veuillot canadien), à l'arrivée de la British Association en 1884, fut tout à fait différente. Tardivel, dans son journal La Vérité, alla même plus loin que l'abbé Pelletier: hystérique, il voyait partout des francs-maçons. Sous le titre flamboyant « La science moderne ", il consacre plusieurs colonnes à la critique de l'Association et de la science en général. Les protestants, les libres penseurs, les francs-maçons et les indifférentistes qui composaient la British Association devaient se rencontrer à McGill, un collège appuyé, selon Tardivel, par des journaux montréalais de même engeance. Aucun catholique ne pouvait décemment assister à cette rencontre. Pour bien montrer que les scientifiques ne méritaient aucune confiance, où qu'ils soient, Tardivel republia un article de 1875 du journal ultramontain londonien The Tablet sur les congrès scientifiques italiens (où l'on notait la présence de révolutionnaires) dont celui, plus récent, de Palerme. À cette occasion les bandits siciliens firent la trêve en l'honneur des savants et, fait également significatif, le seul étranger à assister au congrès fut Ernest Renan, le « notoire blasphémateur ». Cependant, Tardivel fit alors remarquer que les bons catholiques reconnaissent l'existence d'une science plus haute que la « science moderne 103 ».

Peu de temps après parut un article intitulé «La science moderne et ses dupes » qui condamnait la présence de Jésuites américains aux congrès scientifiques. Les journaux maçonniques de Montréal auraient aimé voir les Canadiens français joindre les rangs de l'association britannique dont l'indépendance d'esprit était reconnue mais ce souhait se révélait utopique vu l'antichristianisme notoire de l'organisation. N'avait-on pas remarqué la présence du père jésuite Costin de New York à la rencontre de l'« indépendante » American Association à Montréal en 1882, au cours de laquelle on décida d'ériger un monument à la mémoire de Charles Darwin, «le fameux impie 104 » ? De son côté, le Star appuya sans réserve la requête de la British Association pour une bibliothèque indépendante à Montréal. Une telle bibliothèque serait hors de la tutelle de l'Église et recélerait de «mauvais livres». Pire encore, le Star complimenta le professeur Youman pour son idée d'encourager la lecture des

103 La Vérité, le 9 août 1884.

104 Ibid., le 23 août 1884. 
œuvres d'auteurs laïques tels Darwin, Huxley, Tyndall, Spencer, Carpenter, etc., tous des libres penseurs 105 .

Finalement Tardivel prit la position suivante : la science n'est pas un « mal » mais la seule acceptable est «la vraie science »; c'est-à-dire, comme l'avait stipulé Léon XIII, la science qui ne mène pas à l'indépendance de la pensée et qui ne prend pas la place de la religion dans la vie de chaque homme. Par conséquent, les catholiques, n'étant pas assez instruits pour faire cette distinction, n'avaient aucune raison sérieuse d'assister à des congrès comme ceux de la British Association. Les catholiques se devaient donc de cultiver « la vraie science » :

[...] la vraie science, celle qui se constitue la « servante de la religion », est un grand bien, tandis que la fausse science, la science indépendante, celle qui veut s'émanciper du contrôle de l'Église, est un mal incalculable, mal d'autant plus à craindre que beaucoup ne le voient pas, mal si grand que toutes les richesses de la terre ne doivent pas nous engager à nous exposer 106 .

Pour ne pas recourir aux organisations non catholiques, les catholiques québécois intéressés par la science avaient la possibilité de fonder leurs propres sociétés :

Pour revenir aux objections dont il s'agit, il devrait suffire, pour les résoudre toutes du coup, de faire remarquer le zèle vraiment extraordinaire que, d'un commun accord, déploient, en faveur de la science moderne, les hérétiques, les partisans des sociétés secrètes et les libéraux de toute nuance, jusqu'aux radicaux. Il y a là un fait incontestable et incontesté. Or, ce fait seul n'est-il pas suffisant pour engager les catholiques prudents à se méfier de la science des savants modernes 107.

Vers la fin des années 1890, le prélat français Mgr Baunard préconisa une meilleure éducation scientifique pour les prêtres : pour Tardivel cet appel n'était pas pertinent. Les apôtres n'étaient pas des savants et « [...] c'est une des gloires de l'Église que, de tout temps, un nombre suffisant de ses ministres ont cultivé et fait avancer les sciences naturelles $108 »$.

105 Ibid., le 4 octobre 1884.

106 Ibid., le 13 septembre 1884.

107 Ibid.

108 Ibid., le 31 décembre 1898. 
Tardivel peut sembler un adversaire acharné de la science. Sans doute ses attaques contre certaines innovations, comme les tramways électriques dans la ville de Québec, le plaçaient au même rang que son maître Veuillot. Mais comme le constate Savard, «[...] la science et la technologie n'intéressent au fond que médiocrement Tardivel 109 ». En fait, après 1890 il tempéra quelque peu son propos. La Vérité fit paraître de courtes notices scientifiques et, après 1900, confia à J.-C.-K. Laflamme une rubrique de vulgarisation scientifique. Ainsi, pour le plus réactionnaire des ultramontains la science s'avéra une question négligeable. Selon lui, la science et le progrès n'avaient pas besoin d'un appui enthousiaste pas plus qu'il n'était nécessaire de la supprimer, comme c'était le cas avec la francmaçonnerie.

Une des singularités du Canada français au 19e siècle était que la majorité de ceux qui évoluaient dans le domaine scientifique, du moins en tant que professeurs, étaient des ecclésiastiques. Quelques-uns se trouvaient à l'extérieur de la capitale comme les frères Désaulniers, l'un à Nicolet et l'autre àSaintHyacinthe, et bien sûr l'abbé Provancher à Cap-Rouge, mais la plupart étaient concentrés au Séminaire et à l'Université Laval. Certains des diplômés du Séminaire de Québec comptaient parmi les plus importants professeurs de science du Québec: les abbés Demers, Holmes, Casault, Taschereau, Horan, Brunet, Laflamme, Hamel et le laïque Hubert Larue, professeur à Laval. On ne peut s'attendre d'un tel groupe (vu les fonctions de ses membres) à ce qu'il s'oppose à la science, mais la plupart d'entre eux étaient des ultramontains convaincus, jusqu'au cardinal Taschereau qui, malgré la méfiance que ressentaient à son égard des membres du clergé aux vues plus extrêmes, se faisait le protecteur du Cercle catholique de Québec, une organisation ultramontaine, active durant les années 1880, où discutaient d'importants politiciens conservateurs, des fonctionnaires, des professionnels et Tardivel lui-même.

Il est évident que les opinions professées par le groupe de Laval n'étaient pas aussi réactionnaires que celles de Tardivel ni si peu pertinentes que celles de leur ancien collègue l'abbé Pelletier. À plusieurs égards leurs vues différaient peu de

109 Pierre Savard, Aspects du catholicisme canadien-français au XIXe siècle, Montréal, 1980, p. 80. 
celles des intellectuels protestants de leur époque ${ }^{110}$. Thomas-Étienne Hamel, deux fois recteur de l'Université Laval et président de la Société royale du Canada, avait une bonne formation en physique mais ses vues étaient plutôt traditionnelles. En 1887, dans une allocution devant la Société royale, il prit position en faveur d'une "vraie science »: une science basée sur des faits démontrables, non sur des produits de l'imagination. Il s'en prit au darwinisme : bien qu'il ne pouvait démontrer que les idées de Darwin étaient fausses, elles n'étaient pour lui que pures hypothèses, ingénieuses certes, mais les faits confirmaient la théorie de la fixité des espèces. Dans la même allocution, il déplore le manque d'intérêt des jeunes Canadiens français pour la vraie science ; ceux-ci sont plus attirés par les carrières en journalisme, en politique et en administration publique ${ }^{111}$. Quatre ans plus tard, devant la Section III de la Société royale, il reprend le thème de la supériorité de l'observation scientifique sur les hypothèses. La théorie de Darwin n'est ni irrationnelle ni en désaccord avec la Bible (par là Hamel devance nettement ses collègues protestants), mais elle n'est pas scientifique puisqu'elle « ne s'appuie pas sur les faits ». Les hommes de science doivent se montrer prudents dans leurs théories et «[...] ne donner comme certaines que les notions parfaitement et rigoureusement démontrées 112 ». En se retranchant dans une pensée traditionnelle, que ses études à Paris quarante ans plus tôt auprès des grands théoriciens français du mécanisme avaient sans doute alimentée, Hamel se rendait incapable de rattraper l'avance prise par de nombreux hommes de science européens et américains.

Son collègue, J.-C.-K. Laflamme, probablement l'homme de science canadienfrançais le plus respecté de son siècle, partageait des opinions assez semblables du point de vue philosophique. En 1891, son discours devant les membres de la Société royale dont il était le vice-président avait une note de modernisme : il avança l'idée que la vulgarisation scientifique (pour laquelle il était doué) devait être favorisée au Canada.

110 A.B. McKillop, A Disciplined Intelligence : Critical Inquiry and Canadian Thought in the Victorian Era, Montréal, 1979.

111 T-E. Hamel, « Adresse du président », Mémoires de la Société royale du Canada, 1887, vol. 5, p. XIV-XXII.

112 T.-E. Hamel, « De la certitude dans les sciences d'observation », Mémoires de la Société royale du Canada, 1891, vol. 9, Section III, p. 7. 
On espère plutôt infuser, pour ainsi dire, dans tous les rangs de la société, sans distinction, les connaissances acquises par les chercheurs, et relever ainsi le niveau intellectuel des masses, les moraliser, et - qui sait même ? peut-être les rendre plus faciles à gouverner 113 .

On devait, à partir « de solides principes religieux » et d'un discernement appuyé sur « une philosophie saine et éclairée », s'adresser non seulement à l'intellect mais au cœur. C'était là justement l'objectif du programme d'enseignement des collèges classiques et de l'Université Laval. Laflamme était sans nul doute un élitiste : si les hommes sont égaux devant Dieu, devant la loi, ou en politique comme électeurs, ils ne le sont pas en intelligence. On ne pouvait faire mieux que de leur offrir une éducation plus poussée sous forme de cours de vulgarisation comme c'était le cas en Angleterre et aux États-Unis.

Pour Laflamme, les hommes de sciences dignes d'admiration étaient ceux qui s'en tenaient aux faits, comme l'abbé Provancher et Thomas Sterry Hunt. Peu après leur décès, en 1892, Laflamme, alors président de la Société royale, fit leur éloge devant les membres. Selon lui, l'abbé Provancher était un homme de sciences modèle jusqu'à ce qu'il s'écarte de son travail :

S'il se fût tenu dans les limites de sa spécialité, il n'aurait eu que des amis et des admirateurs. Mais ses excursions, surtout dans le domaine brûlant de la politique, excursions toujours faites d'ailleurs avec la meilleure foi du monde et le plus grand bien des études scientifiques, lui ont valu dans le temps, un certain nombre d'ennemis qui ne lui ont pas toujours pardonné assez facilement les rudes coups qu'ils en avaient reçus ${ }^{114}$.

Sterry Hunt, quant à lui, évitait un tel comportement. Il avait pour amis intimes Laflamme, Hamel et le cardinal Taschereau, tous des confrères de Laval de 1856 à 1862. Hunt ne s'embarrassait pas de la théorie atomique de la matière à laquelle adhéraient la plupart des physiciens et chimistes et s'en tenait plutôt à la théorie de la continuité de la matière. Si Laflamme doutait que Hunt ait raison, ce dernier, du moins, s'appuyait sur des bases solides et ne se laissait pas emporter

113 J.-C.-K. Laflamme, « Discours du vice-président », Mémoires de la Société royale du Canada, 1891, vol. 9, p. XLI.

114 J.-C.-K. Laflamme, " Discours du président », ibid., 1892, vol. 10, p. XLVI. 
par les spéculations ${ }^{115}$. Laflamme et Hamel, les doyens des sciences au Québec, partageaient la même vision conservatrice de la méthodologie scientifique: l'affrontement entre la spéculation scientifique et les principes religieux ne devrait pas tarder ; par contre, une observation attentive et une démonstration scrupuleuse assureraient l'harmonie.

Le scientifique le plus fécond de l'époque était sans contredit l'abbé Léon Provancher. Malgré la grande déférence dont il était l'objet, surtout admiré par son successeur, l'abbé Huard, il ressort que ses méthodes et ses preuves prêtaient quelquefois le flanc à la critique. Ses opinions sur la science différaient de celles de ses contemporains d'Europe et des États-Unis. S'adressant à l'Institut canadien à Québec, il attaqua la spécialisation scientifique parce que, disait-il : « [...] c'est là une route dangereuse à suivre, et qui peut aboutir aux plus funestes résultats », comme le montre l'exemple de Darwin. Ceux qui n'abordent pas la science avec une vue plus générale ne produisent, comme Darwin, que des «[...] idées absurdes, paradoxales ».

Tout comme ses collègues, l'abbé Provancher saisissait bien le concept d'une « vraie science » :

Dieu a parlé aux hommes de deux manières, par ses ouvrages et par sa parole. Si donc le naturaliste et l'exégète ne sont pas d'accord, c'est que le naturaliste a mal observé, qu'il y a erreur dans ses calculs et ses déductions, ou que l'exégète interprète mal la théologie 116.

La science doit aller de pair avec la théologie. Pauvre Arago qui à l'article de la mort ne comprenait pas pourquoi une bonne vie n'était pas suffisante pour assurer le salut ultime : « [...] ce n'est pas la science astronomique qu'Arago avait de trop, mais c'est la science du catéchisme qui lui manquait ${ }^{117}$. »

115 En réalité, Hunt jouissait d'une certaine notoriété à cause de ses opinions peu orthodoxes. Voir Morris Zaslow, Reading the Rocks, the Story of the Geological Survey of Canada, 1842-1972, Toronto, 1975, p. 75.

116 Léon Provancher, «Études exclusives et études spéciales en histoire naturelle », Annuaire de lInstitut canadien de Québec, 1875, p. 89-90. Pour l'accueil fait à la théorie de Darwin au Canada, surtout au sujet de Sir William Dawson, le critique le plus remarquable dont la réaction à Darwin, au point de vue philosophique, était assez semblable à celles de Hamel et de l'abbé Provancher, voir Carl Berger, op. cit., p. 56-72.

117 Ibid., p. 95. 
Un des professeurs de science du Québec faisant preuve de la plus grande largesse d'esprit fut peut-être l'abbé P. de Foville, un sulpicien français invité à devenir le doyen de la Faculté des arts à la section montréalaise de l'Université Laval. Diplômé de l'École Polytechnique de Paris et issu de la France des années 1880, il était plus moderne dans sa pensée que ses collègues québécois, surtout par sa conception du rôle de la science dans le progrès matériel. Il était d'avis que la science se doit d'être cultivée dans un nouveau pays, reprenant ainsi l'opinion de Taché, formulée trente ans plus tôt: «À moins d'une forte éducation scientifique, dans une certaine élite d'hommes spéciaux, qui formeront ensuite à tous les degrés l'esprit du pays, la prospérité matérielle de la nation est désormais en souffrance ${ }^{118}$. » Néanmoins, même si non-croyants et croyants peuvent d'égale manière enseigner la science aux Canadiens français, les meilleurs enseignants sont ceux qui incarnent « l'union pratique de la science et de la foi ».

Il y avait une grande variété de prises de positions au sein du clergé ultramontain et de leurs sympathisants laïques ; cependant, aucun d'entre eux n'était vraiment opposé à la science en général. Les plus critiques étaient ceux qui, comme Tardivel, connaissaient peu de choses sur la science. Ceux qui selon toute vraisemblance auraient pu s'y objecter, tel l'abbé Pelletier, se taisaient. Bien que certains parmi les plus éclairés, comme l'abbé de Foville et Laflamme, percevaient mieux la relation entre l'avancement scientifique et le progrès technologique, tous s'entendaient sur le besoin d'unir la science à la religion et de créer ce que Mgr Bartholemew Woodlock, successeur de Newman au rectorat de l'Université Catholique d'Irlande, appelait la science catholique : une science véritablement enclavée dans la philosophie. Les sciences basées sur la démonstration, comme la chimie et la physique ou les sciences naturelles, étaient sauves. La science spéculative et les sciences sociales, alors naissantes, étaient suspectes parce qu'elles engendraient des idées fausses. Par conséquent, la science se devait d'être conservatrice et de se conformer au modèle social imposé par les chefs de file ultramontains mus par la pensée de Pie IX.

118 P. de Foville, « Rôle de la Faculté des arts dans l'université catholique », Le Canada français, 1888, vol. 1, p. 82. 


\section{L'ACTIVITÉ SCIENTIFIQUE DANS UN CONTEXTE ULTRAMONTAIN}

Les premières grandes querelles entre les ultramontains et les éléments libéraux de la société québécoise se rapportaient à des questions d'ordre éducationnel. À partir de 1845, au cours de nombreux projets de lois sur l'éducation, Mgr Bourget et ses alliés conservateurs firent des pressions afin d'obtenir des changements au Bas-Canada. Cette alliance assurait le support de l'Église au parti de L.-H. Lafontaine et ce dernier devait en retour donner à l'Église un pouvoir accru en matière d'éducation. Avant la Confédération, l'Église insistait sur l'éducation religieuse dans les écoles, le droit de regard quant au choix des manuels scolaires et sur l'abandon des examens pour les professeurs cléricaux (dont le nombre augmentera considérablement de 1850 à 1870).

Après 1867, l'Église garda son influence sur les gouvernements conservateurs qui se succédèrent à la tête de la province. Il en résulta d'abord l'éclatement du conseil de l'Instruction publique en commissions distinctes catholiques et protestantes, puis en 1875 la suppression pure et simple du ministère de l'Instruction publique. Jean-Baptiste Meilleur, médecin et premier surintendant de l'Instruction publique au Bas-Canada, s'intéressait à la science et il était l'auteur d'un manuel de chimie. Il comprenait la nécessité de la science dans un pays en pleine croissance comme en font état les lignes qu'il écrivit en 1860 :

La science est nécessaire au succès, dans la culture et la pratique des arts, comme la chaleur et la lumière du soleil dans la végétation et dans le développement de l'organisme animal et végétal. Les amis des arts doivent donc ne pas négliger l'étude et l'application des sciences, s'ils ne veulent se borner à une pratique aveugle et hasardeuse des arts 119 .

Le programme d'études primaires dont il avait la charge ne comprenait pas de cours de sciences en tant que tels. Cependant, quelques notions scientifiques étaient incluses dans certains cours comme ceux de géographie par exemple. La situation était semblable au Haut-Canada. Toutefois, dans les écoles normales

119 J.-B. Meilleur, Mémorial de l'éducation du Bas-Canada, Montréal, 1860, p. 187. 
subventionnées par l'État les professeurs devaient posséder une certaine connaissance de base des principes scientifiques. En 1852, le premier concile provincial des évêques recommanda la création d'écoles normales confessionnelles: ces dernières furent instituées quatre ans plus tard. L'École normale Jacques-Cartier à Montréal et l'École normale Laval à Québec s'ajoutèrent à l'École normale de McGill pour les protestants. En pratique, les écoles étaient ainsi séparées sur une base linguistique. Des ecclésiastiques, des soeurs et des laïques choisis composaient le personnel des institutions catholiques. La plupart des étudiants logeaient dans des pensions choisies par l'école et tous se devaient d'être présents à l'éducation religieuse et aux activités. Mis à part le contenu religieux, le programme différait peu dans les écoles normales francophones et anglophones. Le directeur, Chauveau, succédant à Meilleur, favorisait l'enseignement de la science et veillait à ce qu'elle fasse partie du programme d'études.

Il y eut peu de changement au programme d'études jusqu'à la fin du siècle ${ }^{120}$. Les étudiants de première année pour le brevet d'enseignement primaire recevaient des cours d'arithmétique, de géographie et de physique. Ceux de deuxième année pour le brevet d'enseignement dans les écoles modèles suivaient des cours d'arithmétique, d'algèbre, de géométrie, d'astronomie, de chimie et de physique. Des cours de trigonométrie et d'histoire naturelle venaient s'ajouter au programme des quelques étudiants de troisième année qui désiraient obtenir un brevet d'enseignement secondaire. De 20 à $25 \%$ des heures de cours étaient consacrées aux mathématiques et aux sciences. Le programme de l'École normale McGill couvrait sensiblement les mêmes matières, mais le niveau était plus élevé, du moins en troisième année où l'on enseignait la géométrie, le calcul infinitésimal, la mécanique, la chimie organique et la géologie ${ }^{121}$. Ceci était sans doute dû à l'influence du principal John William Dawson. À McGill, un étudiant détenteur d'un baccalauréat ès arts pouvait se présenter à l'examen pour le brevet d'enseignement. De cette façon, entre 1861 et 1864, trois bacheliers ont obtenu

120 T.-G. Rouleau, Notice sur l'École normale Laval de Québec pour l'Exposition de Chicago, Québec, 1893, p. 9-12. Pour un aperçu historique voir Réal Bertrand, L'École normale Laval, un siècle d'histoire (1857-1957), Québec, 1957.

121 (Prospectus) McGill Normal School, Montréal, 1864-1865. 
leur brevet. Le programme pour les femmes, différent de celui des hommes dans les écoles normales catholiques, n'avait presque pas de contenu scientifique.

Les cours de sciences à l'École normale Laval étaient de faible niveau. Nous avons consulté les notes de cours de mathématiques et de sciences des étudiants, dont celles d'Antonio Courchesne en cosmographie et en géographie (1904), ainsi que les notes des cours d'astronomie et de chimie donnés par le principal, T.-G. Rouleau ${ }^{122}$. Ces cours étaient tous très élémentaires et sans contenu théorique. On peut noter aussi une nette différence dans le nombre des inscrits aux cours supérieurs de mathématiques et de sciences entre les écoles normales catholiques et protestantes. En 1858, tous les étudiants de McGill prenaient des cours de physique, pour 12\% à Jacques-Cartier et 36\% à Laval. La chimie était choisie par 22\% des étudiants de McGill, par 11\% des étudiants de Jacques-Cartier et par aucun à Laval. Les sciences naturelles étaient étudiées par tous les étudiants de McGill, 11\% des étudiants de Jacques-Cartier et 36\% des étudiants de Laval 123. Ces chiffres reflètent la place de ces cours dans le programme d'études et peutêtre aussi le fait que, dans les écoles catholiques, plusieurs femmes étaient tenues à l'écart des cours de sciences. Même si le niveau de l'enseignement des sciences à McGill était de meilleure qualité, les étudiants des écoles normales catholiques recevaient tout de même des notions de base suffisantes pour le faible contenu scientifique du programme des écoles primaires. Il ne faut pas oublier que les écoles normales catholiques formaient des professeurs laïques et qu'après 1850 le nombre des ecclésiastiques et des soeurs dans l'enseignement augmenta brusquement. Ces derniers avaient reçu leur formation dans les collèges classiques et les couvents.

Les collèges classiques, à l'instar des collèges français, faisaient le lien entre le niveau secondaire et l'enseignement supérieur. Après la création de l'Université Laval, les étudiants des collèges qui avaient terminé les deux dernières années du cours classique (Philosophie I et II) pouvaient se présenter àl'examen de l'université pour l'obtention du diplôme de baccalauréat. Le programme de la Faculté des arts se limitait au cours de philosophie pour les étudiants qui ne

122 Les notes de cours se trouvent aux Archives nationales du Québec (ANQ), Québec, fonds de l'École normale Laval, E0030/31/275-6 et E0030/3/16.

123 Rapport du Surintendant de l'Instruction publique, Journaux de IAssemblée législative, 1858, appendice 43. 
l'avaient pas complété ailleurs (la plupart des étudiants des collèges ne faisaient pas ces deux années de philosophie), ainsi qu'à des cours de rattrapage pour les étudiants en médecine et en droit. On peut supposer que le diplôme de Laval et le baccalauréat ès arts de Toronto ou de McGill étaient équivalents puisque de 1850 à 1870 les collèges anglophones avaient des programmes similaires au niveau du baccalauréat ès arts. Les étudiants de philosophie II, si l'on en juge d'après les notes de cours des archives du Séminaire de Québec, recevaient une base aussi solide en sciences élémentaires. Après 1875, le diplôme de Laval perdit son équivalence avec ceux de McGill et d'autres institutions canadiennes lorsque ces dernières offrirent un programme de baccalauréat ès sciences ainsi que d'autres cours plus avancés.

Au Séminaire de Québec, pionnier de ce qui allait devenir un vaste réseau de collèges à la fin du siècle, le programme d'études scientifiques avait été établi par les abbés Jérôme Demers et John Holmes. Il fut appliqué avec vigueur de 1830 à1850 par des ecclésiastiques renommés dont un certain nombre avaient étudié outre-Atlantique pour parfaire leur bagage scientifique. Plusieurs, tels les abbés Ovide Brunet et Laflamme, étaient de véritables hommes de sciences. Le Séminaire (et par conséquent l'Université) possédait la plus grande Faculté des sciences, le plus grand cabinet de physique, les plus importantes collections scientifiques (dans son musée), ainsi que la plus grande bibliothèque de toutes les écoles du Québec. Les autres collèges, moins bien pourvus, offraient quand même un enseignement de valeur comparable 124 .

Aucun indice ne nous permet de constater un changement dans la façon d'enseigner les sciences dans les collèges après la victoire du programme ultramontain. L'importance accordée aux sciences, les heures d'enseignement qui leur étaient imparties, ainsi que le niveau des cours n'ont été le lieu d'aucun changement notable jusqu'au début du 20e siècle. Il n'y eut aucune tentative pour mettre fin à l'enseignement scientifique ou pour réduire son contenu ${ }^{125}$. Le

124 Voir Claude Galarneau, Les collèges classiques au Canada français, Montréal, 1978, surtout le chapitre 7 et, du même auteur, "L'enseignement des sciences au Québec et Jérôme Demers 1765-1835 ", Mélanges Marcel Trudel, Ottawa, 1978, p. 84-94.

125 Au cours d'un congrès des collèges affiliés, tenu à Laval en 1880, un comité scientifique répondit à des questions concernant le programme d'études 
programme d'études scientifiques des collèges ne visait pas la formation de scientifiques professionnels comme c'était le cas dans les universités de Toronto, de Dalhousie et à McGill. Cependant, un programme de baccalauréat ès sciences fut institué à Laval mais il n'en sortit aucun diplôme avant 1900. Le gouvernement provincial de Chauveau et les gouvernements subséquents encourageaient fortement l'enseignement du génie mais, comme on le sait, Laval refusa de coopérer. L'École Polytechnique de Montréal, malgré les subventions gouvernementales, connut, àses débuts, un succès mitigé. L'enseignement des sciences, s'il avait peu évolué depuis 1850, continuait de faire partie de la formation classique nécessaire à l'éducation des membres des professions libérales, des prêtres et, en général, de l'élite de la société canadienne-française.

À part les collèges et les universités, les organisations culturelles et politiques possédaient des établissements où l'on étudiait les sciences. Les plus importants au Québec, avant 1850, étaient la Literary and Historical Society of Quebec (1824) et la Natural History Society of Montreal (1827), toutes les deux sous l'égide des anglophones dès leur création. Quelques francophones de la classe supérieure en faisaient partie. Durant les années 1860, des hommes comme le principal Dawson, le commandant Ashe ainsi que James Douglas jr contribuèrent à hausser la popularité des deux sociétés. Même alors, les Canadiens français se faisaient rares. Chacune de ces sociétés avait son journal et il est à noter que la seule publication scientifique de langue française à l'époque était Le Naturaliste canadien de l'abbé Léon Provancher et qu'elle n'était affiliée à aucune société. L'abbé Provancher et quelques membres de l'Université Laval avaient à plusieurs reprises tenté de fonder une société scientifique francophone, mais sans succès. Hors du système éducationnel, il n'existait aucun établissement francophone pour diffuser un certain savoir scientifique.

Le mouvement des Instituts canadiens, qui se constitua durant les années 1840, était le pendant francophone des organisations canadiennes-anglaises. Ces associations furent créées à l'exemple des Mechanics' Institutes britanniques et des groupes littéraires formés à travers le monde et qui faisaient partie d'un vaste mouvement de solidarité des classes moyennes. Les Instituts canadiens répondaient au besoin accru de savoir dans un monde en pleine mutation et

scientifiques. Il arriva à la conclusion qu'aucun ajout n'était nécessaire et que l'organisation était efficace, mis à part le flou de certaines questions d'examen. 
témoignaient de la rareté des moyens éducationnels et culturels capables de combler cette demande. La bourgeoisie canadienne-française dont l'importance grandissait ne différait pas de la bourgeoisie anglophone. Parce que des organisations comme la Literary and Historical Society of Quebec et les Mechanics' Institutes s'adressaient exclusivement aux anglophones et que l'entente entre les deux bourgeoisies s'était dissoute en 1837 et 1838, l'apparition d'organisations véritablement canadiennes-françaises était l'aboutissement logique de ces changements sociaux ${ }^{126}$. Les Instituts canadiens étaient assez semblables aux Mechanics' Institutes du Haut-Canada : ils possédaient des bibliothèques et des salles de lecture, ils organisaient des discussions de groupe, des conférences et des cours du soir. Malgré qu'ils aient prétendu le contraire, les Mechanics' Institutes n'offraient qu'en de rares occasions des cours techniques aux classes ouvrières. À l'instar des Instituts canadiens, ceux-ci avaient été fondés par la bourgeoisie et pour son usage propre. L'Institut canadien le plus renommé était celui de Montréal. Il servit de modèle à une douzaine d'autres dans la province et le Haut-Canada. La plupart, comme ceux du Haut-Canada, menaient des existences précaires et beaucoup ne survécurent que quelques années faute d'un milieu urbain capable de les soutenir. Par contre, ceux de Montréal et de Québec, les plus populaires, connurent une tout autre histoire. L'Institut de Montréal, haut lieu de la pensée libérale et du rougisme, vécut un long affrontement, comme on le sait, avec Mgr Bourget et ses partisans ultramontains. À la tête de l'Institut, on retrouvait des libéraux comme Dessaules, A.-A. Dorion, Éric Dorion et Joseph Doutre. Or, si l'on accepte que le libéralisme est favorable à la science ${ }^{127}$, on devrait observer un intérêt certain pour les activités scientifiques de la part des membres de l'Institut, ce qui n'est nullement le cas. En fait, l'arène politique drainait la presque totalité des énergies de l'Institut. En 1869, l'Institut fut condamné par Rome. De nombreuses défections suivirent et l'Institut se trouva isolé. Seul un petit noyau qui n'avait plus rien d'un centre culturel ou intellectuel survécut à l'affaire Guibord en 1875. Dessaules mourut en exil à Paris alors que plusieurs de ses anciens collègues s'étaient rétractés ou étaient entrés en politique.

126 R.A. Jarrell, « The Rise and Decline of Science at Quebec, 1824-1844 », Histoire sociale / Social History, vol. 9, no 19, mai 1977, p. 77-91.

127 Voir la conclusion. 
L'Institut de Québec, fondé en 1848, connut plus de succès que sa contrepartie montréalaise : depuis sa création il avait attiré dans ses rangs un nombre plus élevé de conservateurs et l'adhésion de l'Institut au conservatisme était totale. Il est peu étonnant d'ailleurs qu'il existe encore aujourd'hui ${ }^{128}$. Semblable à celui de Montréal, il se voulait le pendant nationaliste de la Literary and Historical Society of Quebec (L.H.S.Q.). Dès sa création, la science fut l'un des intérêts majeurs de l'Institut. Il était pourvu d'une bibliothèque et d'une salle de lecture. Il s'était donné pour tâche de "recueillir tous les documents qui ont rapport à l'histoire du pays, ainsi que tous les objets d'histoire naturelle qu'il sera possible de se procurer », et d'unir les jeunes Canadiens français pour « les porter à l'amour et à la culture de la science et de l'histoire et les préparer aux luttes plus sérieuses de l'âge mûr 129 ». Ce programme ressemblait beaucoup à celui de la L.H.S.Q. mais il avait la particularité de s'adresser aux enfants de « la Patrie ». Il y a peu de doute que l'équation nationalisme = langue française + catholicisme romain, régnait à l'Institut. Les Chauveau, R.-E. Caron, J.-C. Taché, Hector Langevin, Joseph Cauchon et Thomas Chapais, à la tête de l'Institut, étaient profondément conservateurs. Tous se montraient sympathiques envers le clergé ultramontain et quelques-uns comme Taché, rédacteur du Courrier du Canada (qui avait pour modèle L'Univers), Langevin, rédacteur de Mélanges religieux, ainsi que Cauchon, étaient des admirateurs de Louis Veuillot. Le libéralisme avait sans doute peu de chances de se faire entendre à l'Institut. Le conservatisme et la soumission à la hiérarchie étaient si profonds que le grand vicaire Légaré put obtenir du président J.-B. Chouinard, en 1882, le retrait immédiat de la bibliothèque d'un journal américain jugé « immoral ». Chouinard répondit « [...] nous sommes Canadiens français mais avant tout catholiques 130 ». Quatre ans plus tard, l'Institut retira son patronage au discours d'Arthur Buies lorsque le cardinal Taschereau fit remarquer que le journal La Lanterne avait été condamné.

Néanmoins, la science était appréciée et même enseignée à l'Institut canadien de Québec. Un certain nombre de conférences, qui furent plus tard publiées dans

128 Au sujet de l'Institut canadien de Québec, voir Jean Bruchési, « L'Institut canadien de Québec », Cahiers des dix, vol. 12, 1947, p. 93-114, et L'Institut canadien de Québec, 1848-1948. Annales du centenaire, Québec, 1948.

129 Annales du centenaire, s. 9.

130 J.-B. Chouinard à C.-E. Légaré, le 28 juin 1882, ANQ, fonds de l'Institut canadien de Québec. Souligné dans le texte. 
l'Annuaire, étaient de nature scientifique. Entre 1874 et 1889, environ 10\% des publications portèrent sur des sujets scientifiques et faisaient preuve d'un souci de vulgarisation. L'abbé Laflamme traita de géologie, J.M. Lemoine des oiseaux, l'abbé Provancher des insectes et d'histoire naturelle, Hubert Larue et Edward Barnard d'agriculture. La bibliothèque achetait des ouvrages scientifiques mais les lecteurs de Québec tout comme ceux de Toronto préféraient la littérature légère. Un petit musée où l'on pouvait trouver des spécimens d'histoire naturelle attirait peu l'attention et fut en fin de compte légué au Séminaire. L'Institut ne se prétendait pas une société scientifique. La culture scientifique faisait tout simplement partie de la culture générale et d'ailleurs son succès était limité. Il est remarquable que les membres qui démontraient une aptitude ou un penchant pour la science étaient des étudiants ou des diplômés du Séminaire. Voici donc un regroupement de conservateurs qui entretenaient des liens cordiaux avec les ultramontains mais qui ne rejetaient pas la science. Cependant, il serait plus juste d'affirmer, comme certains témoins de l'époque ont pu le remarquer, que le rôle de la science dans le monde moderne n'était pas apprécié à sa juste valeur. Un bénédictin français, C.-L. Guillement, posait cette question, en 1897, à l'abbé Laflamme : «Croyez-vous que si le Canadien élevé à l'école catholique continue à ignorer les sciences physiques et naturelles, il n'est pas exclu d'avance des grandes entreprises qui donnent la fortune et fournissent du travail aux ouvriers ? Faut-il que le Canadien soit l'employé et le serviteur de l'Anglais 131 »?

D'après lui, l'importance accordée à l'enseignement de la langue et de la littérature au détriment du savoir scientifique et technologique était l'un des problèmes des catholiques romains de France. L'abbé Laflamme, malgré son désir de rendre accessible aux masses le savoir scientifique, n'avait rien d'un réformateur. Il faudra compter une vingtaine d'années avant de voir les successeurs de l'abbé Laflamme à Laval apporter des améliorations réelles à l'enseignement scientifique.

La nature marginale de la science était encore plus prononcée dans les petits centres ${ }^{132}$. Le cas de l'Institut canadien-français d'Ottawa est typique. Cet institut

131 C.-L. Guillement à J.-C.-K. Laflamme, le 23 mars 1897, Archives du Séminaire de Québec, Univ. 64, no 22.

132 Plusieurs instituts et sociétés littéraires ont pris naissance au Québec mais la plupart ne vécurent pas longtemps. Les sources d'information pour l'étude 
fut fondé en 1852 par suite des difficultés que connurent les Canadiens français dans deux organisations où dominaient les anglophones. Contrairement à celui de Montréal, l'Institut d'Ottawa reçut dès sa création l'approbation de l'évêque. Il possédait une bibliothèque, une salle de lecture et un musée. De plus, des discussions hebdomadaires et des événements publics étaient organisés. On y avait une vision ultramontaine du nationalisme : par exemple, la constitution de 1882 stipulait que seuls seraient admis à l'Institut ceux qui, par au moins un de leurs parents étaient Canadiens français, et aussi catholiques romains. Le musée, dont Benjamin Sulte fut le conservateur pendant un certain temps, recelait peu de spécimens d'histoire naturelle et les amateurs sérieux devaient recourir au musée de la Commission géologique du Canada situé à deux coins de rue du musée de l'Institut. On donnait, à l'occasion, des conférences sur des sujets scientifiques ou techniques. On y offrait aussi divers cours comme par exemple, en 1897, des cours d'électricité, d'architecture et d'hygiène. Les commentaires de N.-M. Mathé sur les conférences de M. Triol, un jardinier français enseignant à Cyrville, nous indiquent le niveau de ces rencontres :

Ce vieux Monsieur Triol, homme très instruit, nous donnait des causeries des plus instructives sur la culture des melons, des concombres, des betteraves, voire de la vigne. Il nous donnait aussi des conférences sur la chimie pratique, qu'il illustrait d'expériences très intéressantes ${ }^{133}$.

Malgré la présence d'experts à Ottawa, la recherche scientifique appliquée à la fabrication des biens n'était pas un sujet prisé à l'Institut. La science en tant qu'élément culturel et la science appliquée aux activités quotidiennes étaient

de ces organisations ont été compilées dans Y. Lamonde, «Inventaire des études et des sources pour l'étude des sociétés littéraires », Recherches sociographiques, vol. 16, no 2, 1975, p. 261-275 (où l'on trouve une liste de ces organisations p. 277-280). Sur les aspects sociaux de la culture au Québec, voir Marcel Lajeunesse, Les Sulpiciens et la vie culturelle à Montréal au 19e siècle, Montréal, 1982. Nous ne savons presque rien sur les activités scientifiques de ces organisations. Étant donné la nature marginale de la science, même dans les grands centres de Montréal et de Québec, il y a peu de chances de trouver beaucoup d'activités en région. Cependant, seules de nouvelles recherches nous permettront de nous faire une idée plus exacte de l'étendue de la culture scientifique à cette époque.

133 N.-M. Mathé, «L'Institut de l'ancien temps », texte dactylographié, 1er mars 1928, Université d'Ottawa, Centre de recherches en civilisation canadienne-française, C36/111. 
comprises et acceptées, mais la science conçue comme faisant partie intégrante de la civilisation moderne ne revêtait aucune valeur particulière dans une société dont le seul souci était la sauvegarde de la langue et de la religion.

D'autres organisations culturelles, comme la Société Saint-Jean-Baptiste, qui affirmait s'intéresser à la science, ou les cabinets de lecture paroissiaux, avaient un intérêt moins marqué pour l'étude de la science que l'Institut canadien. Nous devons cependant souligner qu'aucune de ces organisations ne condamnait la science. Ces organisations, tout comme le clergé enseignant et les hommes qui contribuaient à la recherche comme les abbés Laflamme et Provancher, soutenaient que la science était une activité culturelle pouvant compléter l'éducation des personnes instruites mais qu'elle n'était d'aucune utilité pour les spécialistes. Cette vision dix-huitième siècle de la science était sans doute rassurante dans un contexte d'affirmation nationale et religieuse.

\section{CONCLUSION}

S'il est vrai qu'au 19e siècle la science au Canada français n'a pas dépassé le stade de la culture scientifique pour atteindre celui de la recherche scientifique et de ses applications dans l'industrie et l'agriculture, nous ne pouvons toutefois en imputer la faute à l'Église ultramontaine et à ses partisans laïques. Leur rôle dans le retard de la science était secondaire parce qu'il ne faisait que refléter l'image qu'avait d'elle-même et de ses objectifs la société québécoise. L'idéologie ultramontaine au Canada n'était pas en principe opposée à la science en général : les Canadiens français ont toujours favorisé la culture scientifique, suivant ainsi le courant culturel européen. Nous devons plutôt chercher pourquoi la pratique scientifique au Québec accusait un si grand retard par rapport au Canada anglais.

Dans des travaux antérieurs, nous avons déjà suggéré 134 que les énergies qui, idéalement, auraient pu être consacrées à la science avaient en fait été canalisées dans la lutte pour la survie linguistique, culturelle et politique de la nation. Le

134 R.A. Jarrell, « Rise and Decline », et « Colonialism and the Truncation of Science in Ireland and French Canada during the Nineteenth Century », HSTC Bulletin, vol. 5, no 2, mai 1981, p. 140-157. 
libéralisme (les rouges par exemple) et le conservatisme (les ultramontains) peuvent tous deux se montrer favorables à l'évolution de la science. Cependant, le libéralisme, champion de la liberté d'expression et méprisant face à toute autorité arbitraire, se montrait particulièrement favorable au progrès économique, à la science et à la technologie. Pour les libéraux, la science, dans laquelle ils voyaient le plus logique accomplissement de l'intellect humain, faisait figure de symbole. Comme l'a montré le sociologue Joseph Ben-David, le mouvement scientifique d'inspiration libérale a conduit, dans les pays occidentaux, à l'institutionnalisation de la science 135 . Une fois les structures institutionnelles mises en place, la science cesse d'être un outil idéologique privilégié pour devenir le champ de nouvelles carrières et pour venir en aide à la technologie et à l'industrie. Les intellectuels qui se servaient de la science comme outil idéologique n'étaient pas forcément des scientifiques ni même à l'aise avec les théories scientifiques, mais ils appréciaient la science dans le contexte de leurs idéaux libéraux :

Pour quelques privilégiés, la science était un refuge de la liberté de pensée, d'expression et de création au sein d'une société tiraillée par des principes religieux et politiques contradictoires et où la liberté était soit étouffée soit dénuée de sens. Pour un plus grand nombre, la science expérimentale était le symbole d'un idéal à atteindre : la création d'un nouvel ordre social ouvert au changement et à l'amélioration, établi sur des bases objectives et rationnelles et sans conflit excessif et permanent ${ }^{136}$.

Dans l'Angleterre du 18e siècle, la France du début du 19 siècle et dans les États-Unis et le Canada anglais de la fin du 19e siècle, où ces idées sur le rôle idéologique de la science circulaient, la bourgeoisie favorisa le passage du stade de mouvement scientifique à celui de la science institutionnalisée ${ }^{137}$. Cette transition, malgré les quelques traces de pensée scientifique chez des libéraux comme Dessaules, ne se fit pas au Canada français. La bourgeoisie canadiennefrançaise ne semblait pas avoir atteint la maturité nécessaire pour adhérer àla pensée libérale et utiliser la science comme outil idéologique. La bourgeoisie

135 Joseph Ben-David, The Scientist's Role in Society : A Comparative Study, Englewood Cliffs, 1971, spécialement les chapitres 5-6.

136 Ibid., $p$. 79. (Traduit de l'anglais)

137 Les États-Unis et le Canada anglais suivaient plus ou moins la trace de leurs précurseurs britanniques mais leur nature coloniale leur imposait un cheminement différent. Les facteurs du développement scientifique à l'intérieur d'un contexte colonial dépassent les cadres de cette étude. 
francophone québécoise s'inscrit mal dans l'analyse de Ben-David puisque contrairement à l'Angleterre, à la France et au Canada anglais, elle se développa sous deux régimes coloniaux distincts.

Un fait jouait en défaveur de la bourgeoisie canadienne-française: son pouvoir économique était trop faible (bien qu'il semble avoir été plus important qu'on le suppose généralement) pour soutenir efficacement sa liberté d'action politique. Cela dura jusqu'à la création du gouvernement responsable et de statuts distincts pour chaque province. Cependant, un trop grand nombre de membres de la classe supérieure s'engageaient dans les professions libérales, surtout en médecine et en droit, professions qui offraient un certain statut social mais aussi un trop faible revenu pour leur permettre de concurrencer les capitalistes anglophones. Un groupe libéral se tourna rapidement vers l'action radicale en 1837 et 1838. Leur défaite entraîna le rejet de leur vision par la grande majorité de la société. La société canadienne-française après deux siècles de soumission à l'État et à l'Église demeurait profondément conservatrice. À l'époque de la mission de Durham au Canada, la plus grande part de la bourgeoisie, déjà conservatrice dans l'âme, reconnaissait l'inefficacité de la solution radicale.

Quels étaient les objectifs de la bourgeoisie ? En plus des désirs de chacun d'acquérir un certain pouvoir et un statut social, la classe bourgeoise aspirait à gérer elle-même sa destinée et celle de ses compatriotes des classes inférieures par le levier du nationalisme. Le nationalisme qui prit forme dans les années 1840 et 1850, se posait en défenseur de la langue, de la tradition et de la religion. La majorité conservatrice de la bourgeoisie et l'Église trouvaient chacune satisfaction dans l'entente qui les unissait. La bourgeoisie avait une alliée puissante, unifiée en pensée et en action, dont les ramifications s'étendaient à toute la province et qui jouissait d'une influence considérable sur le peuple. L'Église était tout compte fait l'organisation sociale la plus puissante et la mieux intégrée du Canada. Comme l'écrit Nadia Eid : [...] le clergé [...] constituait un groupe social distinct, jouissant d'une identité propre, occupant une place spécifique au sein de l'échiquier social, et ayant, comme tel, des intérêts particuliers à défendre 138 ». L'entente entre la bourgeoisie conservatrice et l'Église signifiait que dorénavant la primauté de l'Église devait faire partie du nationalisme. 
Si l'existence, si minime soit-elle, d'une idéologie libérale est une condition préalable au développement de la science, nous pouvons alors affirmer que l'entente entre la bourgeoisie conservatrice et l'Église vouait ce développement à l'échec. Avant 1840, la science au Canada avait sensiblement la même importance chez les groupes sociaux anglais et français. Dans l'enseignement supérieur, le niveau de l'enseignement scientifique était à peu près semblable dans les deux communautés (il était même de meilleure qualité au Séminaire de Québec). C'était aussi le cas pour la culture scientifique si on compare par exemple la Literary and Historical Society of Quebec et la Société pour l'encouragement des arts et des sciences au Canada. Ce n'est qu'après 1850, en même temps que l'établissement de l'entente entre les conservateurs et le clergé, qu'apparut dans les deux sociétés canadiennes une divergence dans les façons de percevoir la science.

Les éléments libéraux de la bourgeoisie qui auraient pu appuyer massivement un mouvement en faveur de la science et se servir de cette prise de position dans leur idéologie n'ont pas réussi à influencer de manière significative et durable la société canadienne-française. Durant les années 1860, l'aile la plus radicale des libéraux était près de l'agonie. La science en tant que pratique ne fut pas, semblet-il, appréciée à sa juste valeur par la plus grande part de la bourgeoisie conservatrice. Préoccupée, avec l'Église ultramontaine, par la survie de la nation (une intervention qui fut efficace), elle négligea d'accueillir la nouvelle tendance de la science. Par contre, un intérêt culturel pour les sciences faisait partie des moeurs de la bourgeoisie et du clergé. L'acquisition d'un savoir et de principes scientifiques de base par la jeunesse, à condition que cet apprentissage reste intouché par les idées pernicieuses, faisait tout simplement partie d'une bonne éducation. Des professeurs de Laval et des laïques ultramontains qui publiaient dans les années 1880 Le Canada français ne voyaient rien de déplacé à aborder dans un même numéro des sujets aussi divers que la science, l'histoire et la religion. Le Naturaliste canadien, d'autre part, conserva, même après la mort de l'abbé Provancher, son style particulier et n'avait aucune des qualités des journaux scientifiques de l'époque. À partir de 1850, d'autres opinions se firent entendre. Ceux qui, comme Chauveau, possédaient quelques idéaux libéraux durent toutefois s'accommoder du climat conservateur afin d'obtenir une part de pouvoir et de prestige. Ceci ne favorisait guère l'émergence d'une conception plus utilitaire 
de la science dans la société québécoise ${ }^{139}$. En somme, l'appui mutuel que se donnaient la bourgeoisie conservatrice nationaliste et le clergé a figé l'épanouissement de la science parce qu'il n'avait pour eux aucun rôle évident dans le développement de la nation.

139 Les efforts du premier ministre Chauveau pour créer des écoles d'ingénierie, son Conseil des arts et des manufactures, le comité permanent de la législature sur l'industrie ainsi que son intérêt pour les écoles d'agriculture n'ont été que médiocrement fructueux. Toutes ses écoles et organismes existaient déjà au Canada anglais. Il faut se montrer prudent devant l'insistance de Brunet sur la force de l'«agriculturalisme » au Québec. Des hommes comme Barnard et Larue ont reconnu l'importance de la science dans le progrès de l'agriculture. De plus amples recherches sont toutefois nécessaires pour mieux comprendre le rôle de ces intellectuels libéraux à la fin du 19e siècle. Voir aussi l'article de R. Gagnon dans ce recueil. 
Sciences et médecine au Québec.

Perspectives sociohistoriques

\section{Chapitre III}

\section{La réception des rayons X au Québec: radiographie des pratiques scientifiques}

par Yves Gingras

Professeur, Département de sociologie, Université du Québec à Montréal

\section{$\underline{\text { Retour à la table des matières }}$}

Il est bien connu que du milieu du 19e siècle jusqu'à la Première Guerre mondiale, et même au-delà pour certaines disciplines, les Canadiens français étaient, à toutes fins utiles, absents des carrières scientifiques. Pour ne donner qu'un exemple, en 1901, moins de un et demi pour cent des effectifs étudiants inscrits à l'Université Laval ou à sa succursale de Montréal sont en sciences alors qu'à McGill la proportion est de près de $19 \% 140$. Ces chiffres reflètent évidemment la structure des collèges classiques de l'époque qui privilégie les carrières religieuses et les professions libérales au détriment des carrières de scientifiques ou d'ingénieurs ${ }^{141}$.

140 Yves Lamarche, « Position sociale des intellectuels et nationalisme : le cas de l'Action française », La Philosophie au Québec, Montréal, Bellarmin, 1976, p. 165, tableau 3.

141 Claude Galarneau, Les collèges classiques au Canada français, Montréal, Fides, 1978. 
Sans doute est-il possible de rendre compte de la différence d'attitude à l'égard des sciences entre les Canadiens français et les Canadiens anglais en invoquant la position économique dominante de la bourgeoisie canadienne-anglaise qui lui donne un accès privilégié aux quelques emplois existant dans les industries ou les institutions fédérales telles que le Geological Survey, le Biological Board ou les Dominion Experimental Farms ${ }^{142}$. L'existence de débouchés sur le marché du travail est sans doute un facteur important dans le choix de carrière des étudiants. Le fait, par exemple, que les postes d'enseignant étaient occupés par les membres des communautés religieuses limitait énormément les possibilités d'emplois des diplômés de la Faculté des sciences de l'Université de Montréal dont la formation préparait à l'enseignement.

Je tiens à remercier Raymond Duchesne pour ses commentaires sur une version préliminaire de ce texte et pour avoir mis à ma disposition ses notes prises dans les archives du Séminaire de Québec. Un bon nombre des premiers diplômés de la Faculté étaient d'ailleurs membres de communautés enseignantes. Cela étant dit, il ne faut pas oublier que les polémiques des années 1920 sur la position marginale des sciences dans l'ensemble du programme d'enseignement des collèges classiques montrent clairement que les structures sociales ont une inertie que les seules forces économiques ne peuvent vaincre facilement ${ }^{143}$.

Il faut donc délaisser la simple mécanique de l'offre et de la demande économique, qui court-circuite la spécificité de tout système d'éducation, et porter notre regard sur les aspects culturels de la pratique scientifique. On verra ainsi que le choix d'une carrière scientifique et la manière d'envisager les objets de la science sont fortement conditionnés par la structure du système d'enseignement qui favorise certaines dispositions au détriment de certaines autres. Comme l'écrit Pierre Bourdieu, « ceux qui ont pour 'culture' (au sens des ethnologues) la culture savante, véhiculée par l'école, disposent d'un système de catégories de perception, de langage, de pensée et d'appréciation qui les distingue de ceux qui n'ont pas

142 Raymond Duchesne, «Problèmes d'histoire des sciences au Canada français », R.A. Jarrell et N.R. Ball (éd.), Les sciences, la technologie et l'histoire canadienne, Waterloo, Wilfrid Laurier University Press, 1980, p. 2829.

C. Galarneau, op. cit., note 2, p. 221-223. 
connu d'autre apprentissage », ou, pourrions-nous ajouter, qui ont été formés dans un système scolaire différent ${ }^{144}$.

Partant de cette observation, nous nous proposons ici de jeter un regard quasi « ethnologique » sur les pratiques des scientifiques, de façon à voir comment l'attitude face à un objet scientifique donné diffère selon la trajectoire scolaire des agents. Dans cette optique, l'étude de la réception des rayons $\mathrm{X}$ constitue un choix privilégié, car il est peu fréquent que les scientifiques des deux principales universités québécoises du début du siècle, Laval et McGill, s'intéressent au même objet, quoique pour en faire un usage différent.

Notre approche du cas des rayons X au Québec part donc d'un certain nombre de faits déjà connus de façon à illustrer un problème plus large, à savoir les déterminants institutionnels et disciplinaires des différentes pratiques scientifiques ${ }^{145}$. Nous croyons que cette problématique permet d'éviter l'éternel (faux) problème du «retard du Québec », qu'il soit de nature économique ou scientifique. En effet, la problématique du «retard» est fondamentalement évolutionniste en ce qu'elle suppose toujours que ce qui est arrivé était nécessaire et que, conséquemment, ceux qui sont arrivés « deuxièmes » étaient « en retard ».

Avant de décrire les différents usages auxquels ont donné lieu les rayons $\mathrm{X}$ et de chercher ensuite à les relier à l'itinéraire scolaire des acteurs ainsi qu'au niveau de développement des institutions universitaires de l'époque, rappelons brièvement les événements qui entourent la découverte de ces rayons.

144 Pierre Bourdieu, «Système d'enseignement et système de pensée », Rev. Int. Sci. Soc., vol. 19, 1967, p. 381.

145 Plusieurs auteurs ont abordé l'histoire des rayons X au Québec: René Bureau, "La physique et l'électricité à l'Université Laval au temps de Monseigneur J.-C.-K. Laflamme », Le Naturaliste canadien, vol. 79, déc. 1952, p. 330-345 ; Chs.-M. Boissonnault, Histoire de la Faculté de médecine de Laval, Québec, 1953, p. 282-286 ; J.-Edmour Perron, «La merveilleuse découverte des rayons $\mathrm{X}$ et son écho au Canada français ", Annales de l'ACFAS, vol. 6, 1940, p. 145-170, et J.-L. Bonenfant, "Comment les chanoines au Québec sont devenus transparents au XIXe siècle », La Société canadienne d'histoire de la médecine, Nouvelles du printemps, 1983, p. 1-9. 


\section{LES RAYONS X : DÉCOUVERTE ET DIFFUSION}

Le 8 novembre 1895, un physicien allemand, Wilhem Conrad Roentgen, étudiant les propriétés des rayons cathodiques, découvre par hasard un nouveau type de rayonnement possédant des propriétés inconnues jusqu'alors. Le 28 décembre, après avoir étudié certaines propriétés de ces rayons, il communique ses résultats à la Société de physique et de médecine de Wurtzburg. C'est alors qu'on apprend que les rayons $\mathrm{X}$, ainsi nommés parce que Roentgen en ignorait la nature, traversent le bois et plusieurs métaux comme le cuivre, l'argent et l'or, mais sont arrêtés par le plomb. Chose plus intéressante encore, les rayons $\mathrm{X}$ traversent la chair et non les os et agissent sur une pellicule photographique. De cette façon, Roentgen a pu photographier - on dira plus tard radiographier -la main de sa femme et voir clairement sa structure osseuse. Pour le savant, la photographie était un moyen pour étudier les propriétés des nouveaux rayons et non une fin mais, écrit-il, «les journaux en ont fait la chose la plus importante 146 ».

C'est l'aspect spectaculaire des radiographies, et non les rayons $\mathrm{X}$ en euXmêmes, qui est à l'origine du battage publicitaire qui a rapidement suivi la découverte. Dès le 5 janvier 1896, La Presse de Vienne publie à la une un article sur la nouvelle découverte et prédit l'influence qu'elle aura sur l'étude des maladies. Le lendemain, la nouvelle se propage à travers le monde comme une traînée de poudre et des articles paraissent dans le Daily Chronicle de Londres et Le Matin de Paris. Dès le 7 janvier, par exemple, le Frankfurter Zeitung discute de l'intérêt pratique des nouveaux rayons et écrit :

Les biologistes et les médecins, spécialement les chirurgiens, seront très intéressés par l'utilité pratique de ces rayons... [Le chirurgien] pourrait trouver la position d'un corps étranger, comme une balle ou une pièce

146 Cité par Bruce R. Wheaton, The Tiger and the Shark, Cambridge, Cambridge University Press, 1983, p. 17. 
d'obus, beaucoup plus facilement qu'il n'était possible jusqu'à maintenant 147 .

Ce genre d'application ne tardera pas à venir et un mois plus tard les rayons $\mathrm{X}$ seront utilisés, à l'Université McGill, pour localiser une balle dans la jambe d'un patient.

\section{LES RAYONS X À L'UNIVERSITÉ MCGILL : LA PRODUCTION DU SAVOIR}

Depuis 1893, les professeurs de physique de McGill possèdent leur propre édifice, le Macdonald Physics Building, fruit des largesses du roi du tabac William C. Macdonald. À l'époque, c'est un des laboratoires les mieux équipés au monde 148 et dont l'une des fonctions, quoique la moins importante aux yeux des dirigeants de McGill ${ }^{149}$, est la production de nouvelles connaissances. John Cox, un savant britannique formé à l'Université de Cambridge, avait été engagé en 1890 pour superviser la construction du nouvel édifice et agir à titre de directeur. $\mathrm{Au}$ moment de l'ouverture du laboratoire en 1893, Cox engage un nouveau professeur en la personne de Hugh L. Callendar. À l'instar du directeur, Callendar est formé à Cambridge mais, comme nous le verrons plus loin, il fait partie d'une nouvelle cohorte d'étudiants, ce qui le distingue de Cox sur plusieurs points.

Quoique le New York Times ait annoncé la découverte de Roentgen dès le 9 janvier, ce n'est que le 5 février que le Montreal Daily Star nous informe que des expériences utilisant les nouveaux rayons ont lieu à l'Université McGill. On y mentionne que, la veille, le professeur Cox a fait un exposé des découvertes du savant allemand et qu'il a répété ses expériences, en prenant une « photographie »

147 Les informations sur les découvertes des rayons sont tirées de Otto Glasser, Dr. W.C. Röntgen, Illinois, Thomas Publisher, 1945, la citation est à la page 57.

148 P. Forman, J.L. Heilbron et S. Weart, « Physics circa 1900. Personnel, Funding and Productivity of the Academic Establishments », Historical Studies in the Physical Sciences, vol. 5, Princeton, 1975, p. 92.

149 L. Pyenson, « The Incomplete Transmission of a European Image : Physics at greater Buenos Aires and Montreal, 1890-1920 », Proc. Am. Phil. Soc., vol. 122, no 2, 1978, p. 104. 
de sa main gauche, laissant clairement apparaître les os du savant montréalais. Le journaliste décrit l'expérience avec minutie. On apprend que la main a été exposée vingt minutes aux rayons et on donne même le type de plaque photographique employée, ainsi que leurs dimensions. À la fin de la séance, Cox ajoute qu'il veut maintenant utiliser le procédé en chirurgie, car les hôpitaux environnants lui ont plusieurs fois demandé d'utiliser la photographie aux rayons $\mathrm{X}$ pour des fractures des os difficilement localisables à l'aide des outils dont disposent alors les médecins.

Le lendemain de cette séance publique, Cox tente déjà de radiographier une lésion à la hanche d'un patient qui avait donné beaucoup de mal aux médecins. Comme le rapporte le Star :

The best surgical skill in the city has so far been unable to completely reduce the fracture, although the injured one is able to get around with the assistance of a cane and a crutch.

One of the leading surgeons of this city, who has become deeply interested in the case, and who has been closely following the experiments in Dr. Roentgen's discovery thought that the latter, if applied to the present case, might be able to reveal what the surgeons had been unable to discover, namely, the causes which hindered the fracture from being properly reduced 150 .

Malheureusement, après une exposition d'une heure aux rayons, la plaque ne laisse rien apparaître. Cox pense que cet échec s'explique par une durée d'exposition trop courte, où par la présence de plomb dans la peinture noire recouvrant la plaque photographique, ce qui serait suffisant pour bloquer les rayons X. Il compte donc utiliser la prochaine fois une plaque différente composée d'aluminium qui, selon lui, laissera passer les rayons. Même si elle fut un échec, cette expérience marque le début d'une nouvelle collaboration entre physiciens et chirurgiens.

En collaboration avec le docteur Robert C. Kirkpatrick, chirurgien à l'Hôpital général de Montréal, Cox multiplie les expériences et, le matin du 7 février, il réussit à localiser une balle dans la jambe d'un patient. La jambe était placée entre un tube de Crookes - appareil de verre scellé contenant un gaz à basse pression 
dans lequel on fait passer un courant électrique alimenté par une bobine à induction de Ruhmkorff - et une boîte de carton contenant la plaque photographique. Après un temps d'exposition de 45 minutes, le négatif montre clairement la présence d'une balle, ce qui permet une localisation précise. Une légère incision est alors pratiquée par le docteur Kirkpatrick et la balle est extraite sans difficultés.

Cette application précoce des rayons $\mathrm{X}$ est présentée le soir du 7 février à la séance de la Montreal Medico-Chirurgical Society 151. Pour saisir toute l'importance de cette expérience, il faut noter qu'à l'époque il était souvent difficile de localiser une balle et on devait alors se contenter d'appliquer des antiseptiques. L'importance de l'événement est aussi marqué par l'éditorial du Montreal Médical Journal, de mars 1896, où il est dit :

Ce n'est pas sans plaisir que nous attirons l'attention sur l'article du professeur Cox décrivant et illustrant la première application, à des fins de diagnostic, sur ce continent, de la remarquable découverte de Roentgen ${ }^{152}$.

Le journal adopte une attitude favorable à ces nouveaux développements et termine en mentionnant que, même si le nombre d'applications est peut-être restreint, il faut saluer cordialement la venue de chaque découverte permettant un diagnostic plus précis. Par la suite, on retrouvera souvent des comptes rendus d'applications médicales des rayons $\mathrm{X}$ dans des journaux comme l'Union médicale du Canada 153 .

À la suite de ces expériences d'une grande utilité mais techniquement élémentaires, Cox s'associe avec Callendar pour approfondir les connaissances des propriétés physiques des rayons X. Quelques mois plus tard, ils présentent les résultats de leurs recherches à la Société royale du Canada lors de la séance du 31 mai 1896. Publiée dans les Mémoires de la Société, leur communication passe en

151 J. Cox and Robt. C. Kirkpatrick, « The New photography with Report of a Case in Which a Bullet was Photographed in the Leg », The Montreal Medical Journal, vol. XXIV, mars 1896, p. 661-665.

152 The Montreal Médical Journal, vol. XXIV, mars 1896, p. 738.

153 L'Union médicale du Canada, vol. 26, janvier 1897, p. 46 ; février 1897, p. 118. Voir aussi J.K. Lipinski, « Original Publications in Diagnostic Radiology by Canadian Physicians 1896-1929 », La Société canadienne d'histoire de la médecine, Nouvelles du printemps, 1893, p. 8-12. 
revue plusieurs propriétés des nouveaux rayons 154. Les auteurs y discutent des effets physiologiques qui commencent à être rapportés de tous les coins du monde et qui décrivent l'assèchement de la peau, semblable à un coup de soleil, qui résulterait d'une exposition prolongée aux rayons $\mathrm{X}$. Cox et Callendar mentionnent cependant que ces descriptions sont le fait d'observateurs peu réputés et que leurs propres expériences n'ont montré aucun effet physiologique, même après une exposition très prolongée. Ils présentent aussi les résultats de leurs expériences sur les propriétés germicides des rayons et concluent que les rayons $\mathrm{X}$ n'ont aucun effet sur la croissance de cultures de bacilles. Ce n'est que quelques mois plus tard que des expériences plus précises confirmeront l'existence d'effets physiologiques nocifs liés à l'exposition aux rayons X 155 .

Les deux physiciens s'attaquent aussi au problème de la nature des rayons $\mathrm{X}$ et tentent de mesurer leur vitesse. Reprenant la méthode qui avait permis au savant français Hippolyte Fizeau de mesurer la vitesse de la lumière ${ }^{156}$, ils concluent que les rayons $\mathrm{X}$ ne peuvent être des atomes électrifiés en mouvement, car la vitesse mesurée, plus de 200 kilomètres par seconde, est beaucoup trop grande. Il s'agit alors probablement d'un genre de mouvement dans l'éther et des méthodes plus raffinées montreront peut-être que la vitesse des rayons est la même que celle de la lumière. Cette conclusion est intéressante, car elle suggère que les rayons $\mathrm{X}$ sont des ondes transversales comme la lumière, contrairement à l'opinion de Roentgen qui, à la fin de sa première communication, émettait plutôt l'hypothèse qu'il s'agissait de vibrations longitudinales de l'éther, milieu qui devait servir de soutien à la propagation de la lumière, comme l'air est le soutien à la propagation du son.

Au moment même où les physiciens de McGill effectuent leurs recherches, John Cunningham McLennan, alors assistant démonstrateur de physique à l'Université de Toronto, s'affaire lui aussi à reproduire les expériences de Roentgen et à améliorer l'état des connaissances sur ce nouveau rayonnement.

154 John Cox and Hugli L. Callendar, « Some Experiments on the X-Rays », Mémoires de la Société royale du Canada, vol. 2, 1896, section III, p. 171187.

155 L'Union médicale du Canada, vol. 26, juin 1897, p. 377.

156 Pour plus de détails sur l'expérience de Fizeau, on consultera R. Taton (éd.), Histoire générale des sciences, Paris, Presses universitaires de France, 1961, tome III, vol. 1, p. 173. 
Dès le 8 février 1896, le Daily Mail and Empire de Toronto fait état de ses travaux et mentionne que dans l'après-midi du sept, il a réussi avec quelques étudiants à photographier l'ossature d'une main après une période d'exposition aux rayons de dix minutes.

Au mois de mars, le Century Magazine publie un article de McLennan intitulé «Photographing the Unseen », réimprimé par la suite sous le titre «Roentgen Radiation 157 ». La lecture de ce document montre que McLennan met en application un plan de travail similaire à celui de ses collègues de McGill. Assisté de deux étudiants, il prend une série de photographies à l'aide des rayons $\mathrm{X}$ et s'efforce systématiquement de diminuer le temps d'exposition qu'il réussit bientôt à rendre " presque instantané ». Rappelons que Cox et Callendar durent exposer la plaque quarante-cinq minutes aux rayons avant d'obtenir un négatif permettant de localiser la balle dans la jambe du patient. McLennan étudie aussi les propriétés de réflexion des rayons. Discutant ensuite de l'intérêt chirurgical de la découverte, il décrit comment il a réussi à localiser une aiguille dans le pied d'une patiente, ce qui permit au chirurgien de l'enlever dès la première incision.

En somme, on voit que le jeune physicien de Toronto, qui deux ans plus tard se rendra au laboratoire Cavendish pour parfaire sa formation de chercheur ${ }^{158}$, approche les rayons $\mathrm{X}$ d'un point de vue semblable à celui de ses collègues de McGill : ils travaillent tous en fonction d'un programme de recherche précis dont la logique est dictée par la structure du champ scientifique de l'époque. En effet, la découverte des rayons $\mathrm{X}$ pose le problème de leur nature corpusculaire ou ondulatoire et les scientifiques sont aussitôt amenés à concevoir des expériences par analogie avec celles effectuées auparavant pour connaître les propriétés de la lumière. D'où les multiples tentatives à travers le monde de mesurer la vitesse de propagation des rayons, leur réflexion et réfraction sur des surfaces diverses ou encore leur polarisation. D'où aussi les nombreuses « découvertes simultanées ». Ainsi, uniquement au cours du mois de février 1896, on compte une quarantaine

157 Archives de l'Université de Toronto, Papiers McLennan, Scrapbook, vol. 1, p. 185.

158 H.H. Langton, Sir John Cunningham McLennan, A Memoir, Toronto, University of Toronto Press, 1939. 
d'articles de journaux en Amérique du Nord rapportant à peu près le même type de résultat ${ }^{159}$.

Le fait que les appareils de base nécessaires pour produire des rayons $X$ étaient disponibles dans la plupart des cabinets de physique, facilitait de beaucoup la reproduction des expériences de Roentgen tant par des physiciens professionnels que par des amateurs. De ce point de vue, les rayons $\mathrm{X}$ constituent peut-être l'une des dernières grandes découvertes de la physique directement accessible à un large public et aussitôt utilisée à des fins culturelles. Produits par des appareils de plus en plus complexes et coûteux, les phénomènes physiques découverts après 1900 pourront difficilement être intégrés à des pratiques culturelles et, en un sens, n'existeront que pour les spécialistes.

Avant de préciser les conditions institutionnelles qui rendent possible le regard savant posé par Callendar et McLennan sur les rayons $\mathrm{X}$, voyons tout d'abord comment la découverte de Roentgen fut reçue à l'Université Laval.

\section{LES RAYONS X À L'UNIVERSITÉ LAVAL : LA REPRODUCTION DU SAVOIR}

Au moment de la découverte des rayons $\mathrm{X}$, l'enseignement de la physique à l'Université Laval est dispensé par l'abbé Joseph-Clovis-Kemner Laflamme. Il avait succédé à son maître l'abbé Thomas-Étienne Hamel qui avait enseigné cette discipline de 1858 à 1874. Formé au Séminaire de Québec, Hamel avait dû parfaire sa formation scientifique à la Sorbonne où il avait préparé une licence ès sciences mathématiques. À son retour, il est chargé de l'enseignement de la physique, de la minéralogie et de la géologie ${ }^{160}$. En 1870, ces deux dernières

159 Une liste est présentée dans Ruth and Edward Brecher, The Rays. A History of Radiology in the United States and Canada, Baltimore, Williams and Wilkins, 1969, p. 27-28. Sur la réception des rayons X en Australie, voir Hugh Hamersley, «Radiation Science and Australian Medicine 1896-1914 », Hist. Rec. Austr. Sci., vol. 5, no 3, 1982, p. 41-63. Sur la sociologie des découvertes simultanées, voir Robert K. Merton, The Sociology of Science, Chicago, University of Chicago Press, 1973, chap. 16 et 17.

160 «Monseigneur Thomas-Étienne Hamel », Mémoires de la Société royale du Canada, vol. 8, 3e série, 1914, p. IV. 
disciplines sont confiées à Laflamme qui s'occupe aussi de la physique à compter de $1875^{161 .}$

Sur le plan strictement scientifique, Hamel contribua peu à l'avancement des connaissances. Membre fondateur de la Société royale du Canada, les quelques communications qu'il présenta aux réunions de cette société relevaient davantage de l'exercice de rhétorique typique d'une formation classique que de la communication scientifique proprement dite ${ }^{162}$.

Bien qu'il ait reçu une formation plutôt axée sur la géologie, Laflamme suit de près les développements de la physique et profite de ses conférences publiques pour entretenir la bonne société de Québec sur «L'électricité à Québec » ou sur les propriétés des accumulateurs électriques ${ }^{163}$. Alors qu'à McGill les cours de physique s'adressent en premier lieu aux futurs ingénieurs, ceux dispensés à Laval par Laflamme (et avant lui par Hamel) s'adressent plutôt à une clientèle qui se dirige vers les professions libérales et le sacerdoce de sorte que le niveau d'enseignement de la physique, et des sciences en général, demeure élémentaire. Malgré cela le cabinet de physique est toujours bien équipé et l'annuaire de l'Université ne manque pas de le signaler :

Le cabinet de physique à l'usage de la Faculté des Arts est très complet. Il renferme sur toutes les branches de la physique plus de 1000 instruments, comprenant la plupart des appareils qui servent à démontrer les découvertes les plus récentes ${ }^{164}$.

161 «Monseigneur J.-C.-K. Laflamme », Mémoires de la Société royale du Canada, vol. 5, 3e série, 1911, p. IV ; Henri Simard, « Mgr J.-C.-K. Laflamme », Annuaire de l'Université Laval, 1911-1912, p. 209-223.

162 Le titre même des communications porte la marque des cours de rhétorique : " Essai sur la constitution atomique » (prononcé en 1884) et «De la certitude dans les sciences d'observation » (présenté en 1891). À cette époque en effet, les titres des communications scientifiques sont plutôt de la forme : « Notes sur ... », « Contribution à ... », etc. D'ailleurs la structure des textes de Hamel, où fourmillent les interrogations et les exclamations, s'oppose en tout point à l'exposé plutôt terne et linéaire des "faits » scientifiques. Son intérêt pour les discours se reflète d'ailleurs dans son Cours d'éloquence parlée d'après Delsarte publié à Québec en 1906.

163 René Bureau, op. cit., note 6, p. 331-334.

164 Annuaire de l'Université Laval pour l'année académique 1904-1905, Québec 1904, p. 121-122. On retrouve la même description jusqu'en 1915. 
Les cours ne comportant pas de séances de laboratoire, une telle collection est évidemment sous-utilisée et fonctionne surtout comme marque de prestige et de distinction. Elle semble d'ailleurs perçue davantage sur le mode de «l'œuvre d'art » que de < d'outillage » scientifique comme le suggère les adjectifs employés dans la description de la collection: " une très belle machine électrique de Ramsden ", « de splendides modèles de roues hydrauliques », " une jolie machine de Wimhurst », «de magnifiques échantillons de soudure électrique », etc. Ce discours « mondain » et émerveillé face aux objets de la science se retrouve aussi dans le Journal du Séminaire

Le spinthariscope, commandé aux États-Unis par Mgr Laflamme, est arrivé cet après-midi. C'est une merveille. Tout lilliputien qu'il est, il nous donne le spectacle d'une ébullition d'étoiles et d'étincelles. Les confrères qui l'ont examiné en sont émerveillés 165.

À la même époque, l'Université McGill possède elle aussi une riche collection d'instruments scientifiques qui est rapidement utilisée par Callendar pour faire avancer des projets de recherche qu'il avait amorcés lors de son séjour au laboratoire Cavendish. Anticipant déjà les contributions de Callendar à la recherche scientifique, Cox note dans son rapport annuel de 1893 que la collection exceptionnelle d'instruments électriques, de thermométrie et de pyrométrie permettra au laboratoire de faire des travaux utiles dans ces branches de la physique dans un avenir rapproché 166 .

C'est dans un contexte de culture générale que Mgr Laflamme effectue quelques expériences avec les rayons $\mathrm{X}$ et discute de leurs propriétés devant divers auditoires. Il commence ses expériences avec les rayons $\mathrm{X}$ vers le 12 février, soit une semaine après les premiers essais de Cox. Ses premières photos ne sont pas réussies mais son ami Jules Guay, trésorier de la Société française de physique, lui écrit le 17 février suivant pour lui donner quelques précisions, ce qui lui permet par la suite d'obtenir d'excellents clichés ${ }^{167}$. C'est ce qu'indique le journal du séminaire en date du 2 avril où il est noté que les clichés reçus de la pharmacie Livernois, située sur la rue de la Fabrique à Québec, "sont

165 Cité par Boissonnault, op. cit., note 6, p. 285.

166 Annual Report of the Principal. McGill University, 1892-1893, p. 28.

167 Archives du Séminaire de Québec, U. 60, 90. 
admirablement réussis 168 ». Trois semaines plus tard, le journal La Vérité nous apprend que Mgr Laflamme a obtenu de nouvelles photographies «qui sont exposées chez Livernois 169 ».

Le 29 avril 1896, Mgr Laflamme fait une démonstration des propriétés des rayons devant les élèves et professeurs de la Faculté de médecine, et le 20 mai, il présente une «grande séance d'expériences avec les rayons $\mathrm{X}$... devant un tout petit comité formé presque exclusivement d'archevêques et d'évêques [qui ont] regardé à travers un chanoine au grand amusement de tous 170 ». Notons que la notion « d'expérience » dont il est question ici est assez différente de celle de Cox, Callendar et McLennan. Elle s'apparente davantage aux « expériences de Gala » du 18e siècle, qui visent un public de curieux, qu'aux expériences scientifiques proprement dites, faites dans le privé du laboratoire et dont les résultats sont ensuite rendus Publics dans les revues scientifiques 171.

Un an plus tard, Laflamme s'adresse aux médecins devant la Société médicale de Québec. Discutant cette fois devant un auditoire plus savant, il aborde le problème de la nature des rayons $X$ et note que « malgré la valeur très grande qu'il convient de donner à l'opinion du professeur de Wurzburg, l'opinion la plus commune est que les rayons $\mathrm{X}$ sont absolument analogues aux rayons lumineux ordinaires... mais que leurs longueurs d'onde sont comparables aux dimensions moléculaires 172 ». Mgr Laflamme exprimait ainsi de façon très claire l'interprétation qui sera finalement retenue. Cependant, son rôle est ici encore celui du vulgarisateur qui diffuse des connaissances et non celui du chercheur qui produit des connaissances.

\section{L'HONNÊTE HOMME ET LE SPÉCIALISTE}

\footnotetext{
168 Journal du Séminaire, vol. IV, p. 625.

169 La Vérité, 25 avril 1896.

170 Journal du Séminaire, 20 mai 1896, vol. IV, p. 642.

171 Gaston Bachelard, La formation de l'esprit scientifique, Paris, Vrin, 1972, p. 29-34.

172 L'Union médicale du Canada, vol. 26, avril 1897, p. 271.
} 
Les sections précédentes ont montré dans quel contexte les rayons $\mathrm{X}$ ont été utilisés par les professeurs de physique à l'Université Laval et à McGill. Comparant ces deux attitudes face à la découverte des nouveaux rayons, on ne peut manquer de constater qu'à Québec, on se limite à diffuser les connaissances produites par d'autres. Par exemple, Laflamme fait essentiellement de la vulgarisation scientifique et ses opinions sur la nature des rayons $\mathrm{X}$ circulent parmi les étudiants, les médecins et la haute société de Québec, et non dans les milieux scientifiques concernés comme la Société royale du Canada. Ses conférences renseignent les médecins sur les possibilités d'application des rayons $\mathrm{X}$ à la médecine sans toutefois contribuer à concrétiser une collaboration efficace entre médecins et physiciens. À McGill, au contraire, l'étude des rayons $\mathrm{X}$ fait partie d'un programme pour « étudier les conditions de production des rayons de Roentgen et les meilleures méthodes pour obtenir des photographies claires et rapides ", comme l'indique Cox dans son rapport annuel de 1896 soumis au président de l'Université McGill 173. Cox et Callendar publient d'ailleurs les résultats de leurs travaux dans des revues savantes comme Nature ou les Mémoires de la Société royale du Canada, s'adressant ainsi spécifiquement à la communauté scientifique.

Les raisons de cette différence d'attitude face aux nouvelles découvertes scientifiques doivent être cherchées tout d'abord au niveau de l'organisation de la recherche scientifique dans les universités à cette époque et ensuite dans l'itinéraire des agents formés par ces institutions.

Pour comprendre les conditions d'émergence de la recherche scientifique à l'Université McGill, il faut tout d'abord rappeler brièvement certaines transformations survenues au sein des principales universités britanniques au début des années 1870.

L'enseignement de la physique à l'Université de Cambridge, dispensé sur une base régulière depuis 1851, année de la création du Natural Science Tripos, demeurait trop théorique (ou livresque) et devint la cible, vers la fin des années 1860, de critiques de la part d'un groupe de réformateurs réunis principalement autour d'anciens élèves tels Georges Gabriel Stokes, Georges Biddell Airy et James Clerk Maxwell. Les discussions avec les autorités conduisirent à la

173 Annual Report of the President of McGill University, 1896, p. 23. 
création, en 1871, d'une chaire de physique expérimentale confiée à Maxwell. Entre 1866 et 1874, une dizaine de laboratoires de physique furent créés à Glasgow, Edimbourg et Londres, ouvrant ainsi la voie à une nouvelle forme d'enseignement davantage centrée sur le laboratoire par opposition à la salle de classe 174 .

Grâce à ces nouvelles institutions, il devint possible d'inculquer systématiquement à un certain nombre d'étudiants des dispositions favorables à l'égard de la recherche expérimentale. Ainsi, le nombre de chercheurs formés à Cambridge seulement passa de quatre ou cinq en 1875 à plus d'une quinzaine par année au cours des années quatre-vingt ${ }^{175}$.

Hugli L. Callendar fait partie de la génération de physiciens formés à la recherche par J.J. Thomson, qui succéda à Maxwell à la direction du laboratoire Cavendish en 1879. Lorqu'il arrive à McGill en 1893, Callendar ne conçoit plus son rôle comme étant limité à l'enseignement et compte bien poursuivre ses travaux de recherche. Débutées en 1885, ses expériences sur la thermométrie sont déjà connues par la communauté scientifique et en 1894, il est élu membre de la Royal Society de Londres, ce qui indique la position importante de Callendar dans le champ scientifique de l'époque. Entre 1893 et 1898, année de son départ de McGill, il publie régulièrement, seul ou avec des collaborateurs, dans plusieurs journaux scientifiques dont les Mémoires de la Société royale du Canada.

La trajectoire scolaire de Callendar est intéressante car elle constitue un bel exemple de transition d'une formation classique à une formation scientifique. En effet, ses études ne le préparaient nullement à la recherche en physique et c'est sous l'habile direction de Thomson qu'il a pu minimiser les désavantages de sa formation initiale. Comme le note ce dernier dans son autobiographie :

H.L. Callendar's career at the Laboratory was in some respects the most interesting in all my experience. He was on the classical side when at school and did not any physics. [...] He had never done any practical work in physics, nor read any of the theory except in a very casual way. [...] The problem was to find a subject for his research which would give full play

174 David B. Wilson, « Experimentalists Among the Mathematicians : Physics in the Cambridge Natural Sciences Tripos, 1851-1900 », Hist. Stud. Phys. Sci., vol. 12, no 2, 1982, p. 338-339; R. Sviedrys, "The Rise of Physical Laboratories in Britain », Hist. Stud. Phys. Sci., vol. 7, 1976, p. 405-436.

175 Wilson, op. cit., p. 350. 
to his strong points and minimise as much as possible his lack of experience. [...] It seemed to me that the most suitable research would be one which centered on the accurate measurement of electrical résistance 176 .

Le départ de Callendar de McGill en 1898 n'est d'ailleurs pas sans liens avec sa carrière de chercheur ${ }^{177}$. Comme ce sera le cas dix ans plus tard pour son successeur Ernest Rutherford, il est certain que Callendar était affecté par son éloignement de l'Europe, véritable « centre de gravité » du champ de la physique, et qu'il ne pouvait que saisir toute occasion de rejoindre la métropole ${ }^{178}$.

À la différence de Callendar, John Cox, diplômé en 1874, ne reçoit aucune formation de chercheur et se destine plutôt à l'enseignement. Ses écrits se conforment d'ailleurs à ce rôle d'enseignant: il publie deux volumes dont un manuel de physique, Mechanics, et un petit ouvrage de vulgarisation, Beyond the Atom, présentant les travaux de J.J. Thomson et de Ernest Rutherford (ce dernier ayant été son collègue à McGill entre 1898 et 1907) ${ }^{179}$. Son seul article scientifique est celui sur les rayons $\mathrm{X}$ publié avec Callendar dont nous avons discuté plus haut. Bien adapté à son rôle, Cox n'hésite pas à donner plus de cours de façon à laisser du temps à Callendar pour faire de la recherche. Il agira de même avec Rutherford qui prend la relève de ce dernier en $1898{ }^{180}$. La carrière de Cox est donc celle d'un professeur dont le temps est essentiellement consacré à l'enseignement et à la préparation des cours, ce que remarque d'ailleurs la revue Nature au moment de sa mort en 1923 :

176 J.J. Thomson, Recollections and Reflections, New York, Macmillan, 1937, p. 435.

177 H.A.M. Snelders, «Hugh L. Callendar », Dictionnary of Scientific Biography, vol. IV, New York, 1973, p. 19-20.

178 Sur Rutherford, voir A.S. Eve, Rutherford, London, Cambridge University Press, 1939, p. 153.

179 John Cox, Mechanics, Cambridge, Cambridge University Press, 2nd ed., 1909, Beyond the Atom, Cambridge, Cambridge University Press, 1913.

180 J.L. Heilbron, "Physics ai McGill in Rutherford's time », M. Bunge et W.R. Shea (ed.), Rutherford and Physics at the Turn of the Century, New York, Science History Publications, 1979, p. 42. 
While keenly interested in all developments of physics, Cox had not the practical training requisite for research in experimental physics, but devoted himself to the teaching and administrative side ${ }^{181}$.

Dans une certaine mesure, les commentaires de la revue Nature s'appliquent aussi à Mgr Laflamme ainsi qu'à ceux qui, avant lui, ont suivi une trajectoire similaire. Avant de s'initier à la recherche scientifique au laboratoire Cavendish, Callendar était d'ailleurs dans une position similaire à celle de Laflamme et des finissants du Séminaire de Québec. L'absence d'institutions de recherche permettant une « retraduction » des intérêts est donc un facteur à ne pas négliger pour expliquer l'absence de Canadiens français dans des disciplines scientifiques.

\section{DISCIPLINE ET EXCLUSION}

La possibilité d'accès à une discipline scientifique dépend du degré de spécialisation de cette discipline. Par exemple, depuis le milieu du XIXe siècle, la physique s'est institutionnalisée et spécialisée de telle sorte qu'il faut un apprentissage précis et assez long pour devenir physicien. Hamel par exemple n'a jamais reçu une formation de physicien. Sa présence au sein de la section III (physique, chimie, astronomie et mathématique) de la Société royale du Canada à titre de membre fondateur, par exemple, s'explique davantage par des considérations politiques -présence de francophones au sein de la Société - que par des motifs strictement scientifiques. Au tournant du siècle cependant, la section III sera surtout composée de chercheurs qui n'éliront que leurs semblables ${ }^{182}$. Cette professionnalisation fera en sorte qu'après la disparition de Hamel et de Laflamme - qui, avec l'ingénieur Charles Baillargé, sont les seuls Canadiens français au sein de la Société - les sections scientifiques de la Société royale ne compteront plus aucun Canadien français jusqu'au milieu des années 1920. Ainsi, l'abbé Henri Simard, qui succède à Laflamme au poste de professeur de physique en 1893, ne sera jamais élu au sein de la section IIIet devra se

181 «John Cox » Nature, vol. III, 1923, p. 817.

182 Sur l'évolution du mode de fonctionnement de la Société royale du Canada, voir Yves Gingras, "Croissance de la recherche scientifique et transformation de la section III de la Société royale du Canada », Scientia Canadensis, vol. 10, no 1, 1986, p. 53-71. 
contenter de faire partie de la section I (littérature, histoire et sciences humaines) qui regroupe les francophones ${ }^{183}$.

D'autres disciplines comme la botanique et l'entomologie ont, au milieu des années 1870, une structure qui laisse encore place à des recherches basées sur l'observation directe ou la cueillette de données, travail accessible à des « amateurs ». À compter du milieu du siècle cependant, l'étude de la physiologie végétale prend de plus en plus d'importance, contribuant ainsi à marginaliser les amateurs ou les simples collectionneurs. Il n'est donc pas surprenant que les quelques individus, qui ont fait de la science au Québec au cours du XIXe siècle se sont retrouvés dans des disciplines où il était encore possible de faire des contributions sans avoir à passer par un long apprentissage spécialisé alors inexistant au Québec. Ainsi, l'abbé Louis-Ovide Brunet se consacre à la botanique alors que son confrère l'abbé Léon Provancher choisit plutôt l'entomologie, sans ignorer la botanique ${ }^{184}$.

Dans cette perspective d'accès à une discipline scientifique, Laflamme constitue un cas limite. Au moment où débute sérieusement ses travaux en géologie, en 1882 - soit l'année même où il est choisi membre fondateur de la Société royale du Canada - cette discipline est en pleine transformation et la possibilité de n'être qu'un fin observateur sur le terrain perd de la légitimité. Le développement des connaissances est tel que la formation devient de plus en plus spécialisée et nécessite l'utilisation accrue de techniques et d'instruments de précision 185.

Laflamme fait partie de ces observateurs de terrain, et ses travaux portent la marque de sa formation théorique incomplète qui l'empêche d'être au centre des

183 « Henri Simard », Mémoires de la SRC, 3e série, vol. 22, 1928, p. IV.

184 Sur les carrières de Provancher, Brunet et Laflamme, on pourra consulter Raymond Duchesne, « Science et société coloniale. les naturalistes du Canada français et leurs correspondants scientifiques (1860-1900) », HSTC Bulletin, vol. 5, no 2, mai 1981, p. 99-139, et, du même auteur, "La bibliothèque scientifique de l'abbé Provancher », RHAF, vol. 34, no 4, mars 1981, p. 535556.

185 Roy Porter, «Gentlemen and Geology : The Emergence of a Scientific Career, 1660-1920 », The Historical Journal, vol. 21, no 4, 1978, p. 809-836. 
problèmes de sa discipline ${ }^{186}$. Son intérêt pour les problèmes théoriques ne se manifeste que par la préparation de textes de vulgarisation comme celui qu'il publie dans le Canada français en 1891 sur un débat qui, dans le champ scientifique, se fait plutôt dans des revues savantes comme Science, American Journal of Science, etc. 187.

En somme, si la présence de scientifiques francophones se fait plus rare à partir du tournant du siècle, ce n'est pas parce que les trajectoires possibles se sont modifiées mais bien parce que les rares portes sur lesquelles elles débouchaient se sont fermées : la géologie s'est professionnalisée et la description « à l'œil nu » des plantes ou des insectes a cessé, au XXe siècle, d'être une pratique scientifique légitime : l'ère des amateurs doués, tels que les Laflamme, Brunet et Provancher, était terminée. Les difficultés qu'éprouvera le Frère Marie-Victorin, un autodidacte, à se faire élire au sein de la section de biologie de la Société royale du Canada pourraient aussi être interprétées comme un effet de la marginalisation de la taxonomie dans le champ de la biologie. De ce point de vue, cet épisode de l'histoire des sciences au Québec ne se résume plus à un simple cas de conflit ethnique ${ }^{188}$.

\section{BRISER LE CERCLE DE LA REPRODUCTION}

À l'Université Laval, le fait que les professeurs de sciences étaient toujours choisis parmi les membres du clergé, anciens étudiants du Séminaire de Québec,

186 À propos de son séjour à la Harvard Summer School of Geology à l'été 1877, il écrit à Mgr Hamel :

Je ne sais pas plus distinguer les terrains les uns des autres que je ne le savais avant mon départ : ceci exigerait une connaissance de la paléontologie que je ne possède pas. Il y a un point sur lequel je crois être très bien renseigné. C'est le grand nombre d'hypothèses plus ou moins hardies, plus ou moins solides sur lesquelles reposent les connaissances géologiques. Toutes ces théories sonnent presque toujours le creux.

Cité par R. Duchesne, « Science et Société coloniale ... », op. cit., note 45, p. 115.

187 Ibid., p. 116.

188 Robert Rumilly, Le Frère Marie-Victorin et son temps, Montréal, Les Frères des Écoles chrétiennes, 1949, p. 115 et 120. 
rendait difficile sinon impossible la production d'un nouveau rapport aux sciences permettant la formation de chercheurs et non plus seulement d'enseignants. Hamel, par exemple, avait formé son successeur, Laflamme; ce dernier a enseigné à l'abbé Henri Simard qui lui succéda en 1893 et qui enseigna la physique à Laval jusqu'au milieu des années 1920. Tous ont ainsi reçu la même formation générale, suffisante pour un membre du clergé, un futur avocat ou un notaire, mais n'ouvrant aucunement la voie a une carrière scientifique. Lorsque la Première Guerre mondiale rendra évidente l'urgence de former de véritables scientifiques, il faudra importer de Suisse les premiers professeurs laïques de l'École supérieure de chimie, seule possibilité de briser le cercle de la reproduction 189 .

À McGill, le passage de l'enseignement à la recherche fut plus simple et s'est même fait, en partie, à l'insu des dirigeants : les professeurs étant recrutés en Angleterre, la deuxième génération de ceux qui ont quitté la métropole pour enseigner au Canada, en Australie ou au Japon ${ }^{190}$, n'avait déjà plus la même vocation que la première et sut imposer sa nouvelle vision des choses et prendre le temps de faire de la recherche. Ce faisant, elle fut à l'origine de la première génération des chercheurs canadiens-anglais formés à McGill qui, au tournant du siècle, prirent la relève de leurs maîtres lorsque ceux-ci regagnèrent la métropole.

Pour comprendre la différence d'attitude face aux rayons X - ou à la recherche scientifique en général - que l'on observe au tournant du siècle en sciences physiques, entre les savants de McGill et les professeurs de Laval, il est donc nécessaire de tenir compte du rôle de l'institution scolaire comme agent formateur d'habitus, c'est-à-dire de schèmes générateurs de pratiques et de critères d'évaluation des pratiques ${ }^{191}$. Cette approche des pratiques scientifiques permet

189 R. Duchesne, La science et le pouvoir au Québec, 1920-1965, Québec, Éditeur officiel, 1978, p. 6 ; Cyrias Ouellet, La vie des sciences au Canada français, Québec, ministère des Affaires culturelles, 1964, p. 16-17.

190 R. W. Home, "Origins of the Australian Physics Community », Historical Studies, vol. 20, août 1983, p. 383-400 ; K. Koizumi, " The emergence of Japan's First Physicists : 1868-1900 », Hist. Stud. Phys. Sci., vol. 6, 1975, p. 3-107 ; Yves Gingras, « De l'enseignement à la recherche : l'émergence d'une nouvelle pratique de la physique au sein des universités canadiennes ", Histoire sociale/Social History, à paraître.

191 Pierre Bourdieu, Le sens pratique, Paris, Minuit, 1980, chapitre 3. 
de distinguer différents usages sociaux des sciences dont les pratiques de « recherche » et de "vulgarisation » ne sont que deux exemples. En reliant ces différents usages aux contextes social, institutionnel et disciplinaire qui les rendent possibles, on peut ainsi comprendre leur émergence et leur transformation sans préjuger de leur valeur respective comme le fait toujours implicitement la problématique du « retard». 
Sciences et médecine au Québec.

Perspectives sociohistoriques

Chapitre IV

\title{
La vaccination à Montréal dans la seconde moitié du 19e siècle: pratiques, obstacles et résistances *
}

\author{
par Michael Farley, Peter Keating et Othmar Keel
}

Respectivement Sciences, technologie et communications, ministère des Affaires extérieures, Canada; Chercheur, Department of the History of Science, Harvard University; Professeur, Département d'histoire, Université de Montréal.

\section{$\underline{\text { Retour à la table des matières }}$}

La vaccination contre la variole a commencé à être pratiquée dans la province de Québec au début du 19e siècle. Cette pratique est restée cependant assez limitée au cours de la première moitié du siècle. Elle n'a été mise en œuvre qu'irrégulièrement et que dans certaines localités, et n'a été imposée et pratiquée plus systématiquement que dans certains milieux comme les garnisons. Pour se prémunir contre la variole, la population avait encore largement recours à la pratique de l'inoculation de la matière variolique prélevée chez un variolé 192.

* Cette étude a été rendue possible par une subvention FCAR du ministère de l'Éducation du Québec. Les auteurs remercient les participants du séminaire sur l'histoire et la sociologie des sciences au Québec et, en particulier, Richard Jarrell pour leurs commentaires. Ils remercient également Gilles Janson, Bettina Bradbury, René Durocher et Paul-André Linteau pour leurs remarques.

192 Bien que pratiquée depuis longtemps dans les pays de l'Orient, l'inoculation fut introduite en Europe par une anglaise, Lady Montagu, au 
À partir de la seconde moitié du 19e siècle, la persistance et la gravité des épidémies de variole, et la promulgation d'une loi sur la vaccination obligatoire des enfants en 1861 193, conduisirent à l'implantation d'une pratique plus active de la vaccination ; encore plus ou moins utilisée, elle était loin d'être généralisée malgré la loi. La pratique de la vaccination rencontra de nombreux problèmes et de nombreux obstacles d'ordre scientifique, technique, administratif, idéologique et social. À cet égard, il est particulièrement intéressant d'étudier le cas de Montréal.

Montréal a connu à la fois un mouvement très actif pour promouvoir et imposer la vaccination et un mouvement d'opposition à cette pratique. Du point de vue de l'histoire de la santé publique et de l'histoire des mentalités, il est tout aussi intéressant d'étudier les initiatives pour mettre en place cette mesure préventive que d'étudier les obstacles et les oppositions qu'elle a rencontrés.

La vaccination fut la première mesure d'envergure de médecine préventive qui ait été mise en oeuvre dans la ville de Montréal, comme dans les centres urbains importants d'autres pays. Cette mise en pratique de la vaccination, son rapport avec les premières politiques de santé et de médicalisation de la société ainsi que

début du dix-huitième siècle. Cependant, selon Darmon (Darmon, infra., note 3 , p. 76), l'inoculation était une pratique courante dans les milieux populaires avant qu'elle ne fût répandue dans les milieux médicaux. L'inoculation fut introduite au Canada en 1768 par le chirurgien militaire Latham, qui utilisait le système « Suttonien » inventé par Robert Sutton en 1758 en Angleterre (E. Gaumond, «La petite vérole », Cahiers de l'Hôtel-Dieu de Québec, no 5, 1950, p. 441). Sur les débuts de l'inoculation dans la province de Québec, cf. aussi J.J. Heagerty, Four Centuries of Médical History in Canada, Toronto, 1928, vol. 1, p. 78 et suiv., et B. Tunis. "Inoculation for Smallpox in the Province of Quebec, a Re-appraisal » in Ch.G. Roland (ed.), Health, Disease and Medicine : Essays in Canadian History, Toronto, 1984, p. 171-193. À la fin du 18e siècle (1798), le médecin anglais Edward Jenner (1749-1823) découvrit et mit en usage la vaccination, à savoir l'inoculation pratiquée avec le fluide de la variole de la vache et non pas avec celui recueilli sur les pustules de la variole humaine.

193 « Acte pour rendre plus générale la pratique de la vaccination », Statuts du Canada, vol. 24, Victoria, 1861, chapitre 24, articles 4 et 10. 
les résistances et oppositions rencontrées dans différents pays a donné lieu à des travaux nombreux et importants 194.

En ce qui concerne le Québec, les historiens n'ont accordé jusqu'ici leur attention - et encore seulement de façon passagère - qu'à un phénomène qui frappe l'attention, à savoir le mouvement de résistance à la vaccination qui s'est développé à Montréal, et qui semble avoir culminé lors des émeutes qui ont accompagné la grande épidémie de 1885-1886 195.

194 Pour l'Ontario, voir B.L. Craig, « State medicine in transition : battling smallpox in Ontario 1882-1885 ». Ontario History, vol. 75, 1983, p. 319-347 ; P.A. Bator, "The health reformers versus the common Canadian: the controversy over compulsory vaccination against smallpox in Toronto and Ontario 1902-1920 », Ontario History, vol. 75, 1983, p. 348-373. Pour les États-Unis, voir M. Kaufman, «The American Anti-vaccinationists and their Arguments », Bulletin of the History of Medicine, vol. 41, 1967, p. 463-478 et J.W. Leavitt, « Politics and Public Health : Smallpox in Milwaukee, 18941895 », Bulletin of the History of Medicine, vol. 50, 1976, p. 55-3568. Pour l'Angleterre, voir A. Beck, "Issues in the Anti-Vaccination Movement in England », Médical History, vol. 4, 1960, p. 310-332. C.W. Dixon, Smallpox (Londres, 1962), p. 282-296 ; F. Fraser, «Leicester and smallpox », Medical History, vol. 24, 1980, p. 315-332 ; A. Hardy, « Smallpox in London : Factors in the Decline of the Disease in the Nineteenth Century ", Médical History, vol. 27, 1983, p. 111-138. Pour la France, voir Y.-M. Bercé, Le chaudron et la lancette: croyances populaires et médecine préventive (1798-1830) (Paris, 1984), p. 151-196 ; P. Darmon, La longue traque de la variole (Paris, 1986); O. Faure, « La vaccination dans la région lyonnaise au début du XIXe Siècle : résistances ou revendications populaires ». Cahiers d'Histoire, 1984, nos 2-3, p. 191-209. Pour l'Allemagne, voir C. Heurkamp, « The History of Smallpox Vaccination in Germany: A First Step in the Medicalization of the General Public », Journal of Contemporary History, vol. 20, 1985, p. 617-636. Pour le Brésil, voir G. de Silva Araujo, The Immortalized Cow : Smallpox Vaccine and Wright's Vaccine in Brazil (Rio de Janeiro, 1972), et, enfin, pour les pays orientaux et l'Afrique voir D.R. Hopkins, Princes and Peasants : Smallpox in History (Chicago, 1983).

195 L'histoire de l'épidémie de 1885-1886 est rapportée dans les sources suivantes: M. Guyot, A Brief history of the smallpox epidemic in Montreal from 1871 to 1880 and the late outbreak of 1885 (Montréal, 1886) ; Win. Osler, Principles and Practice of Medicine (New York, 1892), p. 64-65; W.H. Atherton, Montreal Under British Rule, 1760-1914 (Montréal, 1914), p. 236-237; J.J. Heagerty, Four Centuries of Medical History in Canada (Toronto, 1928), p. 89-93 ; R. Rumilly, Histoire de la province de Québec (Montréal, 1941) vol. 5, p. 84-85; C. Bertrand, Histoire de Montréal 
On n'a pas étudié jusqu'ici le contexte plus général des débuts d'une politique de santé et de médicalisation dans lequel s'inscrit la mise en pratique d'un programme de vaccination. Il nous a donc semblé nécessaire de combler cette lacune en faisant une étude de la mise en place progressive de ce programme de vaccination à Montréal dans la seconde moitié du 19e siècle. Une étude approfondie des conditions dans lesquelles ce programme a été organisé et mis progressivement en oeuvre permet de mieux comprendre les obstacles de divers ordres qu'il a rencontrés. Par exemple, à diverses reprises, une partie du corps médical composée d'anglophones et de francophones s'est opposée à l'établissement d'un programme public et obligatoire de vaccination contrôlé par la municipalité. Un tel programme empiétait en effet sur les prérogatives professionnelles des médecins qui voulaient garder un monopole privé sur les actes thérapeutiques et sur les revenus qu'ils procuraient. Les médecins s'opposaient également à la déclaration obligatoire de leurs patients atteints de variole et à leur transfert dans des institutions spécialisées, car ils voulaient garder un contrôle de type «libéral » sur leur clientèle et sur le traitement de leurs patients.

Le programme de vaccination a donc rencontré des obstacles, des oppositions et des résistances de types très divers. L'analyse de ces obstacles dans leur diversité nous permet, croyons-nous, de mieux comprendre le mouvement de résistance à la vaccination dans la population ainsi que le mouvement antivacciniste dans certaines couches des élites ou des classes dominantes.

Tout d'abord, certaines oppositions ou réticences ne portaient pas sur la vaccination en tant que telle. Ce que des esprits libéraux condamnaient, c'était son

(Montréal, 1942), vol. 2, p. 191 ; Ch.-M. Boissonnault, «Un périodique oublié. La lutte contre la vaccination au 19e siècle. " Laval Medical, no 32, 1961, p. 178-184 ; K. Jenkins, Montreal (Montréal, 1966), p. 416-417 ; E. Desjardins, "La grande épidémie de 'picotte noire' » Union médicale du Canada, vol. 99, 1970, p. 1470-1477. Sur l'histoire de l'administration sanitaire et de la vaccination à Montréal de 1865 à 1885, on trouvera certaines indications et données dans: M. Farley, Oth. Keel, et C. Limoges, « Les commencements de l'administration montréalaise de la santé publique (18651885 », HSTC Bulletin : Journal of the History of Science, Technology and Medicine in Canada, vol. 20 (1982), p. 24-46, vol. 21 (1982), p. 85-109. 
caractère obligatoire, qui était vu comme une intervention abusive de l'État dans la sphère des libertés et des droits privés.

Par ailleurs, la vaccination pouvait encore faire problème à l'époque. L'opposition des milieux populaires, comme de certains médecins ou d'autres membres des élites (y compris certains échevins), était fondée sur des raisons qui sont compréhensibles. En effet, un certain nombre d'accidents et de cas de transmission de maladies comme la syphilis, l'érysipèle, la gale, les dartres, la cécité, parfois la variole elle-même, semblaient imputables à une pratique de la vaccination qui n'était pas encore au point du côté technique (matière vaccinale prélevée sur un sujet malsain, vaccin impur, adultéré ou dénaturé, etc.).

Dans les milieux médicaux et scientifiques d'alors, un débat était en cours. Les arguments des anti-vaccinateurs, à Montréal comme ailleurs, loin de paraître antiscientifiques, pouvaient sembler sensés à une époque où les conditions pratiques de la vaccination laissaient souvent encore beaucoup à désirer. Par ailleurs, la revaccination (indispensable pour une immunité durable) ne faisait pas encore l'unanimité ; chez les vaccinateurs eux-mêmes, les opinions étaient partagées sur plusieurs autres points.

Les statistiques, souvent fragmentaires, étaient quelque peu manipulées de part et d'autre : on en tirait donc aussi bien des arguments en faveur que contre la vaccination. Les anti-vaccinateurs mettaient en évidence le fait que de nombreux patients, même vaccinés, contractaient la variole, et que la mortalité chez les sujets atteints de variole n'était pas plus élevée chez les sujets non vaccinés que chez les sujets vaccinés.

Par ailleurs, l'opposition des milieux populaires et francophones se comprend d'autant mieux que la vaccination avait été rendue obligatoire par les autorités coloniales. Il nous semble donc que l'on comprend mieux la résistance populaire àla vaccination si on la considère comme un aspect de la résistance à la médicalisation, phénomène que l'on observe dans tous les pays à l'époque - et résistance qui repose sur des motifs compréhensibles - au lieu d'y voir un aspect caractéristique de la mentalité soi-disant rétrograde ou superstitieuse de la masse canadienne-française, voire d'une partie de ses élites. Cela est d'autant plus vrai que, comme nous venons de l'indiquer, cette forme de résistance à la médicalisation était surdéterminée ici par le fait que cette médicalisation était 
imposée non seulement par l'État et les classes dominantes, mais encore par des autorités considérées comme « étrangères ».

Tout ceci, bien entendu, ne signifie pas pour autant que le programme de vaccination n'avait aucun intérêt pour la santé publique. Ce programme avait indéniablement des aspects très positifs à ce niveau. Mais, précisément, pour comprendre comment il a pu finalement être mis en place, il nous semble nécessaire d'étudier les véritables significations des obstacles et des oppositions qu'il a rencontrés tout en cherchant à comprendre ces oppositions dans leur nature propre. Nous éviterons donc d'analyser cette question dans un esprit de simplification, entaché de positivisme et de scientisme, comme un épisode caractéristique du combat entre la science et les ténèbres ou entre le progrès et la routine de la tradition.

Loin d'un faux débat entre science et anti-science, notre étude se propose plutôt d'enrichir l'histoire des sciences, de la santé et des mentalités au Québec en faisant connaître, dans leur complexité et leur spécificité respectives, aussi bien la politique de santé et de vaccination que les obstacles et les oppositions qu'elle a connus à Montréal.

\section{LES DÉBUTS DE LA VACCINATION OBLIGATOIRE : 1861-1875}

La vaccination a été rendue obligatoire pour les enfants au Québec pour la première fois en $18611^{196}$; ce n'était pas, cependant, la première fois que l'on cherchait à mettre sur pied un programme de vaccination publique dans la province au 19e siècle. Déjà, à la suite du « Vaccine Act » de 1815, un bureau de vaccination avait été ouvert en 1817 à Québec 197. On l'avait placé sous la

Op. cit., note 2.

197 Sur ce premier programme de vaccination, voir B. Tunis, «Public Vaccination in Lower Canada, 1815-1823 : Controversy and a Dilemma », Historical Reflections, vol. 9, 1982, p. 264-278. Dès cette période, on observe des résistances à la vaccination - dues aux maladies ou accidents causés par des vaccins dénaturés - dans la population et parmi les médecins, voir p. 268 et 274 . 
direction de J. Wright, inspecteur des hôpitaux de l'armée britannique. Pendant quelques années, on essaya de mettre en pratique ce programme de vaccination. Cependant, en raison de désaccords politiques, de rivalités entre les praticiens et le bureau de la vaccine, ainsi que de divergences au sein de la profession ellemême (par exemple sur les conditions appropriées pour procéder à la vaccination), ce programme fut abandonné en 1823, en dépit du fait qu'il avait reçu l'appui du clergé local.

À partir de l'année 1823, qui vit la révocation de la loi de 1815, la vaccination fut laissée à l'initiative de vaccinateurs non médecins, de praticiens prives et des hôpitaux. À l'hôpital Montreal General par exemple, dès 1823, on pratiquait la vaccination gratuitement au dispensaire ${ }^{198}$. Mais, à la campagne, on continuait de recourir à la pratique ancienne de l'inoculation et il semble qu'au cours des années 1830 et 1840, celle-ci se soit de plus en plus répandue.

Dans un texte publié dans le British American Journal en 1845 199, A. Von Iffland, futur président du Collège des médecins, exposait les raisons qui, selon lui, étaient à l'origine d'une poussée récente de la variole au Canada. Selon Von Iffland, en abandonnant le programme contrôlé de vaccination des années 18101820, le gouvernement avait encouragé indirectement la pratique de l'inoculation et/ou une pratique de la vaccination par des médecins peu qualifiés et des profanes. Cela avait conduit à une généralisation de pratiques néfastes comme l'inoculation ou la vaccination improvisée (et la circulation de vaccins contrefaits ou dégénérés), ce qui aurait donné lieu à des cas de plus en plus nombreux de non-efficacité de la vaccination. Selon Von Iffland, avant même de préconiser la vaccination, il fallait donc interdire la pratique de l'inoculation et trouver une source de renouvellement pour le vaccin.

Les rédacteurs du British American Journal (où Von Iffland publiait son texte), tous deux professeurs à l'École de médecine de McGill, étaient en partie d'accord avec Von Iffland: selon eux, il fallait interdire la pratique de

198 " Minutes of the Board of Governors of the Montreal General Hospital », vol. 1, 1822-1832, février, 1823, Archives Université McGill.

199 A. Von Iffland, "Smallpox in the Rural Districts of Canada ", British American Journal of Medical and Physical Science, vol. 1, 1845-1846, p. 257260. 
l'inoculation comme on venait de le faire tout récemment en Angleterre 200. Cependant, à la différence de Von Iffland, ils ne croyaient pas que la vaccination était une méthode préventive. Dans une note en bas de page de l'article de Von Iffland, ils s'expliquaient ainsi : «We think that it (vaccination) is commonly a modifier of the type of a subsequent attack of Small-Pox, by no means a préventive ${ }^{201}$. » Mais si, comme l'enseignaient les professeurs de l'Université McGill, la vaccination ne prémunissait pas contre la variole, on pouvait dire qu'elle ne se distinguait plus de l'inoculation que par le degré moindre de contamination ou la gravité moindre des effets sur le corps ${ }^{202}$. Nous avons donc affaire ici à des médecins montréalais, faisant partie de l'élite médicale anglophone en tant que professeurs à l'université McGill et qui ne croient pas à la vaccination jennérienne, n'y voyant qu'une variante de la méthode de l'inoculation.

La pratique de l'inoculation fut effectivement interdite au Canada en 1853203. Ce n'est que cinq ans plus tard que fut promulguée la première loi qui avait pour objet de promouvoir la vaccination 204.

200 Pour une histoire de la législation portant sur la vaccination en Angleterre et les mouvements constitués pour combattre ces mesures, voir R.M. MacLeod, «Law, medicine and public opinion ; the resistance to compulsory health legislation, 1870-1907 », Public Law, vol. 12, 1967, p. 107-128, 189211 ; voir aussi du même, « The Frustration of State Medicine, 1880-1900 », Médical History (1967), p. 15-40.

201 Op. cit., note 8, p. 258.

202 Ceci fait partie du long débat sur la durée de l'immunité conférée par la vaccination. En Angleterre, même à la fin du siècle, bon nombre d'autorités médicales et scientifiques soutenaient que la vaccination pratiquée une seule fois conférait une immunité à vie. Par contre, en France et en Allemagne, la revaccination était préconisée dès le milieu du siècle. Ces différentes conceptions de l'immunisation reposaient souvent sur les conceptions différentes que l'on se faisait de la nature du vaccin jennerien. Plusieurs tenants de la thèse selon laquelle la vaccination conférait une immunité définitive chez le vacciné soutenaient également que le vaccin n'était qu'une forme atténuée de la variole. Ainsi puisque celui qui avait été atteint de la variole était immunisé à vie d'une deuxième attaque - c'est du moins ce que l'on croyait alors - selon ces auteurs, le vaccin devait conférer le même degré d'immunité. Voir, à ce sujet, Dixon, op. cit., note 3, p. 284-289.

203 «An Act to restrain the injurious practice of inoculating with the Smallpox », Statuts du Canada, 16 Victoria, 1853, chapitre 170. 
Toutefois, il ne s'agissait pas encore d'une loi visant directement le public comme cela allait être le cas avec la loi de 1861. Dans un premier temps, c'était la promotion et le contrôle de la vaccination dans les institutions médicales qui faisaient l'objet d'une législation. L'acte de 1858 stipulait que dorénavant, tout hôpital ou dispensaire qui recevait l'aide du gouvernement était tenu de vacciner gratuitement les indigents qui se présenteraient pour l'opération. Les hôpitaux étaient tenus aussi de fournir du vaccin à tout médecin qui en aurait fait la demande et d'établir des statistiques sur la pratique de la vaccination pour les communiquer à l'Assemblée législative. Les hôpitaux qui auraient refusé de participer au programme n'auraient plus bénéficié de l'aide du gouvernement 205.

On ignore quel a été le succès de ce programme. Les statistiques furent déposées devant le Conseil législatif de l'Union en 1860, mais elles ne furent pas publiées 206. L'année suivante, le Conseil promulgua une nouvelle loi sur la vaccination. On peut supposer que l'Acte de 1858 n'avait pas été suivi des effets attendus 207 : l'une des clauses de la loi de 1861 visait en effet à déplacer le centre de gravité du programme de vaccination des hôpitaux vers les municipalités, comme si l'on avait fait le constat de l'échec d'un programme de vaccination centré sur les hôpitaux. De fait, en 1861, le gouvernement du Canada-Uni rendait la pratique de la vaccination obligatoire par une loi stipulant que, dans les trois mois, les conseils municipaux d'un certain nombre de villes, dont Montréal, devaient créer un service pour la vaccination et ouvrir des bureaux à cet effet en différents endroits de la ville. À Montréal, des vaccinateurs publics furent

204 « Acte pour encourager et répandre la pratique de la vaccination », Statuts du Canada, 21 Victoria, 1858, chapitre 89.

205 lbid., article 2.

206 C'est uniquement l'Hôtel-Dieu de Saint-Hyacinthe qui répondit à la demande de la législature. Les Sœurs ont rapporté : «Il y a dans l'hospice un dépôt de vaccin et dix-sept enfants ont été vaccinés. » (« Legislative Council, Third Session, Sixth Parliament, 1859, Reports and Returns », " Return to an Address from the Legislative Council» (RG $14 \mathrm{cl}$ vol. 125) Archives publiques du Canada).

207 Il est à noter, toutefois, que le premier bureau de vaccination fut établi à l'Hôtel-Dieu de Québec en 1858, à la suite, peut-on supposer, de la loi passée la même année (Gaumond, op. cit., note 1, p. 435). 
nommés pour chacun des quartiers de la ville avant la fin de l'année ${ }^{208}$. D'après la loi de 1861, tout enfant né dans les municipalités désignées par l'acte législatif en question devait être vacciné avant l'âge de quatre mois, soit par un vaccinateur public, soit par un autre médecin. Dans ce dernier cas, la vaccination devait être certifiée et le certificat transmis à la ville. Il fallait aussi un certificat dans le cas où, l'enfant étant malade, la vaccination n'était pas pratiquée pour éviter le risque de mettre en danger sa santé. Enfin, la loi stipulait que les hôpitaux ne recevraient plus de fonds publics s'ils ne s'organisaient pas pour offrir un service à part pour les variolés 209.

Malgré les efforts du gouvernement et de la municipalité, à Montréal, la mise en application de cette loi laissait beaucoup à désirer. De plus, au cours des premières années, la ville, qui considérait la vaccination des non-indigents comme une pratique lucrative pour les vaccinateurs, hésitait à payer le loyer des bureaux de vaccination ; de plus, elle refusait de prendre en charge les frais d'impression des certificats de vaccination 210 . En dépit de ces conditions, un an après la promulgation de la loi de 1861, le British American Journal proclamait : « This Act, as far as this city is concerned, has been put completely into force » (...) ${ }^{211}$. Cet optimisme des éditorialistes du British American Journal n'était pas, cependant, partagé par tous les médecins. À partir d'une analyse des registres des cimetières, Fenwick, médecin du dispensaire de l'hôpital du Montreal General avait conclu, dès le début du programme de vaccination en 1861, que :

Referring again to these returns, it will be found that the great proportion of these deaths are among the children of the poor, and from the locality of the Roman Catholics we may infer the largest proportion to have been French Canadians, as nearly three-fourths of the population of those wards are of French extraction. The necessity of early vaccination cannot be too urgently enforced, and for the poorer class there are two hospitals and the Montreal Dispensary, public institutions, with constant supplies of fresh

208 Voir « The Vaccination Act », British American Journal, vol. 2, 1861, p. 572.

209 Op. cit., note 2, article 1.

210 « The Operation of the Vaccination Act », British American Journal, vol. 3, 1862, p. 59-60.

211 «The Vaccination Act », British American Journal, vol. 3, 1862, p. 27-28. 
vaccine lymph, where their children will be vaccinated gratis, if they will take the trouble of taking them there 212 .

On peut noter ici que ce type de distribution de la variole existait déjà à Montréal dans les années 1850, soit avant même tout programme de vaccination obligatoire et tout mouvement systématique d'opposition à la vaccination, et qu'il allait à nouveau être mis en évidence à plusieurs reprises au cours des années qui suivirent la loi de 1861 213. Mais, ces chiffres posaient un problème : comment pouvait-on s'assurer, en effet, que ces statistiques étaient fiables ? Car, malgré les lois en vigueur, un nombre important d'enterrements étaient effectués sans certificat médical de décès. D'autre part, en l'absence d'un système civil d'enregistrement, la connaissance du nombre des naissances ainsi que des causes de mortalité chez les nouveau-nés échappait aux médecins et particulièrement à ceux qui étaient censés vacciner les enfants. De plus, à partir du programme de vaccination de 1861, qui organisait la vaccination au niveau du quartier, l'hôpital ne pouvait plus être considéré comme lieu propice à la compilation des statistiques concernant l'importance et les effets de cette pratique. C'est pourquoi l'exigence de la mise en place d'un système normalisé de compilation des statistiques de santé publique devint un thème récurrent dans les revues médicales et dans les rapports des vaccinateurs publics 214 . Il est à noter toutefois que, malgré l'absence de données fiables, les éditeurs du Canada Medical Journal pouvaient se permettre de parler, à partir de la fin des années 1860, d'une « apparent vaccination of the majority of people » dans la ville de Montréal 215.

L'extension de la pratique de la vaccination depuis la loi de 1861 et l'irruption d'une nouvelle épidémie variolique en 1871 mirent la question de la théorie médicale de la vaccination au premier rang des préoccupations des deux sociétés médicales qui existaient à Montréal à l'époque.

212 G.E. Fenwick, « The Medical Statistics of the City of Montreal », British American Journal, vol. 2, 1861, p. 394.

213 Voir, par exemple, « Mortality Statistics », Canada Medical Journal, vol. 1, 1864, p. 153-154, 205-206.

214 Voir, par exemple, "The Vaccination Act », Canada Medical Journal, vol. 1, 1864, p. 493-494 ; « Editorial », Canada Medical Journal, vol. 3, 1867, p. 335 ; vol. 4, 1868, p. 380-381.

215 Voir le compte rendu de l'ouvrage de E.C. Seaton, A Hand-Book of Vaccination (Montréal, 1868), Canada Medical Journal, vol. 5, 1869, p. 354. 
L'enjeu des discussions qui eurent lieu au sein de ces deux sociétés était de la plus grande importance. Pour mettre en œuvre un programme de vaccination obligatoire, il fallait, en effet, constituer des réserves de vaccin et donc, savoir où se le procurer et comment s'assurer de l'authenticité et de la qualité de ce vaccin. Le vaccin utilisé au Canada avait été à l'origine envoyé de Londres et transmis ensuite à travers la chaîne des vaccinés. Il s'agissait donc de savoir si ce vaccin avait conservé ses propriétés actives et comment faire pour se le procurer en quantité suffisante. La question était compliquée par le fait qu'il n'y avait pas unanimité sur la question de l'origine du vaccin, et donc sur celle de sa nature et de Ses propriétés 216 .

C'est ainsi que, en juin 1871, F. W. Campbell, professeur à McGill et vaccinateur public de la ville, présenta un texte intitulé «Vaccination and Revaccination » devant la Medico-Chirurgical Society of Montreal 217. Par ce texte, Campbell prétendait prouver que « the Vaccine disease is not a preventative

216 Il est à noter que le débat sur l'origine du vaccin jennerien n'est pas encore terminé. Selon Razzell (P. Razzell, The Conquest of Smallpox : The Impact of Inoculation on Smallpox Mortality in Eighteenth Century Britain (Firle, Sussex, 1977), Jenner avait faussement identifié son virus vaccinal au «cowpox » et, en fait, le vaccin de Jenner n'est pas autre chose qu'une forme atténuée du virus variolique lui-même. Cependant, d'après Baxby (D. Baxby, Jenner's smallpox vaccine: the riddle of vaccinia virus and its origin (Londres, 1981), les études sur la séquence de l'ADN du virus vaccinal de Jenner tendent àmontrer que le vaccin de Jenner est une espèce distincte de virus, n'étant ni une forme de la variole ni une forme du virus qui provoque le « cow-pox » chez les vaches. Bien que de telles études infirment la thèse de Razzell, l'origine du virus vaccinal reste obscure. Si Jenner n'a pris son vaccin ni chez les êtres humains, comme l'affirme Razzell, ni chez les vaches, comme Jenner lui-même l'a affirmé, alors où se l'est-il procuré ? Baxby suggère que Jenner avait bel et bien prélevé son virus sur la vache mais que la vache en question souffrait d'une maladie similaire mais distincte du " cow-pox », le " grease ». Cette dernière maladie, d'après Baxby, aurait été causée par un virus dont le vecteur était une espèce de rongeurs disparue aujourd'hui d'Angleterre. Ceci expliquerait pourquoi le virus de Jenner ne se trouve plus qu'en un seul lieu d'habitation, à savoir les laboratoires médicaux où on le cultive.

217 F. W. Campbell, «Vaccination and Revaccination », Canada Médical Journal, vol. 12, 1871, p. 545-562. 
of Small-Pox, but in reality is the Small-Pox itself 218 ». Pour étayer cette thèse, il faisait appel aux célèbres expériences de Ceeley en Angleterre. Celui-ci avait réussi à inoculer des vaches à partir du virus de la variole humaine et à produire de la sorte de la vaccine animale analogue dans ses effets au vaccin jennerien. Plusieurs enfants avaient, en effet, été vaccinés et immunises avec de la lymphe ainsi produite. Campbell constatait en premier lieu que, « From the early part of the century cases of Small-Pox, after vaccination, have been increasing and now amount to four-fifths of the cases 219 ... » et, en second lieu, que « no cases are reported after re-vaccination ».

Campbell s'écartait donc de la doctrine jennerienne de deux manières. Tout d'abord, si, comme il l'affirmait, la vaccine n'était qu'une forme de la variole humaine atténuée par le passage dans l'animal, la vaccination n'était alors qu'une forme bénigne d'inoculation. Deuxièmement, pour Jenner, une seule vaccination conférait une immunité définitive, ce que Campbell contestait en préconisant la revaccination. La position hétérodoxe de Campbell ne fut pas approuvée au cours de la discussion qui suivit son exposé et la société ajourna ses travaux sans avoir abouti à un consensus sur la question de la nature du vaccin.

En décembre 1871, la Société médicale de Montréal consacra toute une séance à la question de la vaccination. Plusieurs problèmes furent soulevés concernant le vaccin et son efficacité. Les expériences les plus contradictoires furent rapportées. Ainsi, le docteur Dugas fit le compte rendu suivant : " Je suis en faveur de la

218 lbid., p. 547. Campbell, vaccinateur public et professeur de l'école de médecine anglophone, ne croyait donc pas au cow-pox jennerien, qui était, selon lui, non pas un préservatif, mais la maladie même de la variole !

219 Ibid., p. 559 (L'italique est de nous). Même si, comme Dixon l'a remarqué (Dixon, op. cit., note 3, p. 1), il y eut des irruptions de variole en Europe et en Amérique du Nord après 1850 au cours desquelles $90 \%$ des cas rapportés affectaient des individus vaccinés, il est néanmoins certain que les affirmations de Campbell constituent, même pour l'époque, des exagérations. Selon les registres de l'Hôpital général de Montréal pour l'année 1874, sont morts de la variole 28 individus non vaccinés et 2 individus vaccinés. Deux individus revaccinés étaient aussi atteints de la variole, mais, chez eux, « la maladie fut des plus bénignes », ( «Vaccination », Union médicale du Canada, vol. 4, 1875, p. 383). À l'Hôpital de la marine de Québec, sur les 131 individus hospitalisés pour cause de variole, 54 étaient vaccinés, dont un seul décéda. Sur les 69 individus non vaccinés, 37 décédèrent. (« Hôpital de la marine », Union médicale du Canada, vol. 4, 1875, p. 384). 
vaccination, et j'ai fait une expérience dans ma famille. Une de mes petites filles, âgée de 6 mois et non vaccinée, prit la variole. Je fis coucher mon fils alors âgé de 3 ans et vacciné depuis 5 à 6 mois avec elle pendant toute sa maladie, lui faisant toucher les pustules et respirer l'air infecté sans pouvoir lui inoculer la maladie 220 ». Le docteur Plante était, lui, d'une opinion différente : « Pour moi, je ne suis pas vacciné et j'ai été continuellement dans la salle de l'Hôtel-Dieu où il y a 16 à 20 picotés dont la plupart étaient vaccinés. Je reviendrai peut-être quand on me donnera du véritable cowpox 221 ». Enfin, le docteur Brousseau prit une position intermédiaire ; d'une part, il affirma : « Nous avons eu plus d'épidémies de variole depuis que la Corporation a passé une loi pour enjoindre la vaccination. » Mais, d'autre part, il observait qu'« il ne faut pas cependant rejeter le vaccin, nous devons faire des efforts pour en avoir de bonne qualité et pour cela le prendre où Jenner l'a pris lui-même 222 ».

Grenier, futur rédacteur en chef de l'Union médicale du Canada, ne conservait aucun doute quant à l'efficacité de la vaccination surtout « lorsque la vaccine a suivi les périodes telles que décrites par Jenner lui-même 223 ». Or, identifier les caractéristiques d'un vaccin comme étant celles décrites par Jenner, cela signifiait, pour Grenier, non seulement reconnaître son efficacité, mais aussi, identifier le vaccin comme étant issu à l'origine de la pratique même de Jenner et ayant été distribué depuis par le National Vaccine Institute de Londres. Cette question de l'identification de l'origine et de l'efficacité de la lymphe vaccinale prit une importance capitale lors du débat sur l'utilisation du vaccin.

Tandis que l'épidémie se propageait, aucune des deux sociétés ne parvenait donc à dégager un consensus scientifique sur la question de l'identité du vaccin et sur ce qui constituait le principe actif de la vaccination. À la séance de la Société médicale de Montréal du mois suivant, deux vaccinateurs publics (Larocque et Ricard) furent nommés membres d'un comité pour faire enquête sur le système de santé publique à New York et, plus précisément, sur les mesures à prendre en cas d'épidémie variolique. L'enquête, basée sur des données publiées dans le Médical

220 «Société médicale de Montréal, réunion du 20 décembre 1871 », Union médicale du Canada, vol. 2, 1872, p. 133.

221 Ibid., p. 133.

222 Ibid., p. 132.

223 Ibid., p. 134. 
Record de New York, fut conduite rapidement : le 31 janvier 1872, Larocque et Ricard présentèrent leur rapport devant la Société et, le lendemain, devant le Bureau de santé municipal. Au début de la semaine suivante, le rapport et les recommandations furent publiés dans The Gazette 224.

Les rédacteurs du Canada Medical Journal qui avaient pris ainsi connaissance du rapport s'opposèrent tout de suite àce qui en constituait l'innovation majeure par rapport au système qui était alors en vigueur. Larocque et Ricard proposaient que chaque cas de maladie contagieuse, y compris la variole, soit rapporté par le médecin traitant aux officiers publics de santé. Ces derniers auraient alors à décider si le patient devait être transporté à l'hôpital, et quelles mesures sanitaires devaient être prises quant aux lieux et aux personnes supposés contaminés. Selon les éditeurs du Canada Medical Journal, les officiers de santé Larocque et Ricard voulaient imposer par là une forme prétentieuse d'ingérence dans la pratique médicale privée : «Is not every practitioner quite as capable of deciding this question as either of the Health Officers, or both of them together 225 ? »

On pourrait donc dire que certains membres influents de la communauté médicale anglophone de Montréal s'opposaient ainsi, en raison d'intérêts étroitement corporatistes, à la mise sur pied d'un programme public de vaccination et au progrès que cela représentait. Certains anglophones avaient donc une part de responsabilité dans le retard avec lequel on mettait en pratique la vaccination obligatoire prescrite par la loi de 1861.

Pendant ce temps, le débat sur l'origine du vaccin avait pris d'autres tournures à la Société médicale de Montréal. Un certain M. Depaul, directeur de la vaccine à Paris, avait, semble-t-il, tenté de promouvoir l'utilisation d'un vaccin tiré directement de génisses du pays et non de souches supposées d'origine jennerienne. Le docteur Ricard, vaccinateur public à Montréal, préconisa l'utilisation de ce moyen pour se procurer du vaccin lors de l'assemblée de la société médicale. Grenier s'opposa à une telle pratique en disant que : «La vaccine animale peut être utilisée dans certaines circonstances exceptionnelles,

224 The Gazette, 5 février 1872. Voir aussi Union médicale du Canada, janvier 1872, p. 181.

225 «Éditorial », Canada Medical Journal, vol. 8, 1872, p. 380. 
mais le vaccin jennerien sera toujours la source où l'on devra puiser 226 ». Deux autres séances furent consacrées à la discussion de l'efficacité du vaccin. Au cours de ces séances, certains mirent la vaccination en accusation. Ainsi, le docteur Coderre affirmait qu'il y avait identité entre le virus variolique et le virus vaccin et en inférait que non seulement « la vaccine n'est pas un préservatif de la variole » mais encore que la maladie qu'elle provoque est « d'un caractère virulent et gangréneux. » Ricard et Larocque s'opposèrent immédiatement à Coderre et proposèrent la résolution suivante : «D'après l'histoire et l'expérience depuis Jenner jusqu'à nos jours, on reconnaît que la vaccine est le préservatif de la variole 227 ». Mais les médecins ne parvinrent pas à voter sur ce sujet, et la question de la vaccination fut laissée en suspens pour une semaine encore.

La séance de la Société médicale de Montréal consacrée à la vaccination reprit le 28 février. Elle commença par la lecture de la troisième partie d'un texte du docteur Coderre qui, après avoir tenté de prouver l'identité du virus vaccin et du virus variolique, cherchait à montrer les mauvais effets de la vaccination au Canada. Rottot, premier intervenant dans la discussion, s'opposa à la thèse de l'identité entre le virus vaccin et le virus variolique. Selon Rottot, c'était par une erreur dans la lecture de l'expérience que l'on identifiait le vaccin et le virus variolique : selon lui, ceux qui croyaient à une telle identité s'appuyaient toujours sur l'expérience de l'inoculation des vaches avec la variole. « Bien sûr, admettaitil, ils ont obtenu une pustule dont la matière transmise à l'enfant a produit une seule pustule. Cependant, poursuivait-il, s'ils avaient continué jusqu'à une troisième ou quatrième transmission, ils auraient vu réapparaître une variole confluente 228 . » Ceci prouvait donc que l'inoculation de la vache avec la variole humaine (en vue de recueillir ensuite la lymphe pour la vaccination) n'aurait eu pour effet que d'atténuer temporairement les effets du virus variolique et non pas de produire le vaccin qui, lui, ne cause jamais une variole confluente. Ceci prouvait, enfin, que la réaction produite par le vaccin était une réaction différente de celle produite par le virus variolique. D'autres intervenants donnèrent leur

226 Op. cit., note 29, p. 135.

227 « Séance extraordinaire du 21 février 1872 », Union médicale du Canada, vol. 2, 1872, p. 212.

228 « Séance du 28 février 1872 », Union médicale du Canada, vol. 2, 1872, p. 216. 
appui à la vaccination, et, cette fois, la motion proposée la semaine précédente fut votée à l'unanimité ${ }^{229}$. Trouvant peu de partisans à l'intérieur de la Société médicale de Montréal, le docteur Coderre organisa un groupe d'anti-vaccinateurs en dehors des institutions reconnues et, en juillet 1872, une lettre signée par 21 médecins fut envoyée aux membres du Comité de santé de la ville, protestant contre le « système » de vaccination alors en vigueur 230 .

Au cours du printemps de l'année suivante, on assiste à la réactivation de la Montreal Sanitary Association, regroupant entre autres les médecins Hingston (médecin à Hôtel-Dieu et professeur à l'École de médecine et de chirurgie), Larocque (officier de santé de la ville), Howard (médecin au Montreal General Hospital et professeur à l'Université McGill), Kennedy (professeur à l'Université Bishop et médecin à l'hôpital St. Patrick) et Leprohon (professeur à l'École de médecine et de chirurgie) ${ }^{231}$. En novembre, au nom de l'Association, Larocque contacta Mgr Bourget et gagna son appui au sujet de l'enregistrement des décès. Le même mois, l'Association se lança dans l'affaire de "l'hôpital civique ». Jusque-là, les variolés étaient isolés dans des salles séparées des hôpitaux du Montreal General et de l'Hôtel-Dieu. Voulant mettre sur pied une politique d'isolement des maladies contagieuses, la ville de Montréal avait, l'année précédente, fait une demande au gouvernement provincial pour obtenir l'autorisation d'ajouter une clause à la charte de la ville qui lui eût permis d'émettre des obligations d'une valeur approximative de \$30 000 pour financer la construction d'un tel hôpital. L'Association demandait que l'argent disponible à cet effet fut partagé entre le Montreal General et l'Hôtel-Dieu 232 et qu'un nouvel « Hôpital des maladies contagieuses » ne fût pas construit ${ }^{233}$. Mais le consensus à l'intérieur de l'Association semble avoir été fragile car il fut rapporté, un mois

$229 \quad$ Ibid., p. 217.

230 « Lettre à Messieurs les membres du Comité de santé, 30 juillet 1872 », Dossier "Vaccination", Collection Chagnon, Bibliothèque de la santé, Université de Montréal.

231 « Minutes of the Montreal Sanitary Association, May 3, $1873 »$, McCord Museum, Université McGill. Cette association avait été fondée en 1967. Elle avait servi de tremplin au maire Workman et à ses politiques et permis la nomination de Larocque comme officier de santé. Cf. sur ce point, M. Farley, Oth. Keel, et C. Limoges, op. cit., note 4, vol. 20, p. 28, 39 et 44.

232 Ibid., 25 novembre 1873.

233 Ibid., 2 décembre 1873. 
plus tard, que «À la dernière réunion, on discuta la question de l'hôpital des varioleux sans en venir à aucune conclusion $234 »$.

L'École de médecine et de chirurgie tergiversa, elle aussi, sur la question du nouvel hôpital tout en maintenant une position ferme sur la vaccination. En avril 1874, le maire de Montréal demanda à l'École de prendre position à la fois sur la nécessité d'un hôpital des variolés et sur la nécessité de la vaccination. L'École, par un vote, affirma qu'il y avait un besoin urgent d'un hôpital pour les contagieux et que la vaccination était «indispensable 235 ». Mais, lors d'une assemblée organisée par le Bureau de santé pour discuter la question de l'hôpital, et à laquelle les délégués montréalais des Facultés de médecine avaient été invités, le représentant de l'École de médecine et de chirurgie revint sur la position qu'elle venait de prendre sur cette question. Les représentants des autres Facultés avaient proposé, en effet, que le nouvel hôpital fût placé sous le contrôle du conseil municipal de la ville. L'École de médecine et de chirurgie intervint alors pour affirmer que, comme hôpital pour les variolés, le site offert par les dames de l'Hôtel-Dieu, avec la prise en charge religieuse que cela impliquait, était adéquat, voire nécessaire, puisqu'« aucune institution ne saurait offrir de meilleurs titres de confiance au public que l'Hôtel-Dieu 236 ». L'Union médicale du Canada s'opposait aussi à l'idée d'un hôpital municipal et non confessionnel pour les maladies contagieuses en tirant des motifs invoqués pour justifier le projet, des implications paradoxales. Selon les rédacteurs de ce journal, si l'on prétendait devoir éloigner les varioleux des hôpitaux existants du fait qu'ils représentaient un danger pour les autres malades, il était alors contradictoire de vouloir les installer dans un hôpital pour les maladies contagieuses, puisque les variolés auraient constitué à leur tour un danger pour les malades atteints d'autres affections contagieuses et réciproquement. Certes, personne ne pouvait le nier : la variole étant une maladie contagieuse parmi d'autres, la nécessité d'un hôpital pour les variolés apparaissait comme un cas particulier du besoin impérieux qu'il y avait de séparer les maladies contagieuses des autres dans tous les hôpitaux

234 «Association sanitaire », Union médicale du Canada, vol. 3, 1874, p. 47.

235 " Procès-verbaux, École de médecine et de chirurgie », 4 avril 1874, Archives de l'Université de Montréal.

236 "Hôpital des varioleux », Union médicale du Canada, vol. 3, 1874, p. 232. 
indistinctement. Il fallait donc, selon les auteurs de ce texte, concevoir la nécessité d'un hôpital des variolés comme faisant partie d'une campagne concertée contre la variole et non pas comme résultant, dans ce cas précis, des carences des hôpitaux déjà en place ou de l'inefficacité des praticiens privés dans le traitement des maladies contagieuses 237. En attendant, tout cela retardait la mise sur pied d'un hôpital pour les variolés, qui était un élément essentiel d'une politique de vaccination.

Entre-temps, le Bureau de santé avait pu se procurer du « véritable cow-pox ». Fin avril, Larocque reçoit du docteur Martin, de Boston, de la lymphe fraîche dont l'origine est connue et réputée : c'est le «celebrated Beaugency Stock ». Une génisse est publiquement inoculée et, au début de mai, elle se met à produire à son tour de la lymphe. Pour mettre en oeuvre un système de vaccination de bras à bras, c'est-à-dire afin de mettre en circulation uniquement de la lymphe " humanisée », les officiers de santé demandent la coopération des collègues en leur proposant de recommander aux parents d'amener leurs enfants au Bureau de santé. Ainsi les enfants déjà vaccinés serviront de dépositaires de la lymphe 238 .

Les éditeurs de l'Union médicale du Canada font une analyse quelque peu différente de la situation. Selon eux, c'est l'échec des bureaux de vaccination (dans la mesure où les sujets vaccinés n'étaient pas assez nombreux pour constituer une réserve suffisante de vaccin), et non pas la présence d'une génisse productrice de cow-pox qui explique pourquoi il faut amener tous les enfants au Bureau central de santé. Certains bureaux de vaccination étaient si peu fréquentés qu'il était impossible de propager, à partir d'une réserve suffisante, la vaccine déjà en circulation. Ce problème ne touchait pas seulement les vaccinateurs publics, mais il causait aussi des ennuis aux praticiens privés à tel point « que plusieurs ont jugé à propos de renoncer complètement à pratiquer la vaccination [...] 239 ». D'où, selon les éditeurs, la nécessité de centraliser le système. Mais, selon eux, la tentative du Bureau de santé est vouée à l'échec « à cause de la crainte excessive que notre population manifeste pour tout ce qui est du ressort officiel 240 ». La seule solution serait alors de centraliser d'une manière non officielle: «d'en

Ibid., p. 231-233.

« Vaccination », Union médicale du Canada, vol. 3, 1874, p. 287. « Vaccination », Union médicale du Canada, vol. 3, 1874, p. 182. Ibid., p. 183. 
confier la direction à nos institutions publiques de charité 241 ». Ainsi, avec un nombre limité de bureaux non officiels, il serait possible d'établir un système de vaccination de bras à bras.

Nonobstant des débuts prometteurs, le programme de vaccination et les mesures corrélatives requises pour la mise en application effective d'un tel programme n'avaient donc fait jusqu'ici que peu de progrès. Conçu en dehors de tout programme de santé publique qui aurait mobilisé les autorités hospitalières et les facultés de médecine et qui aurait prévu la mise en place d'une institution pour l'isolement des cas de variole ainsi que la production et la certification d'un vaccin d'origine connue, le programme de vaccination avait été laissé, pour l'essentiel, entre les mains des praticiens privés dont les opinions et les pratiques étaient, comme nous l'avons vu, très diverses dans ce domaine.

\section{LA NOUVELLE POLITIQUE SANITAIRE MUNICIPALE EN MATIÈRE DE VACCINATION : 1875-1885}

En 1874, le gouvernement provincial, par un amendement à la charte de la ville, autorisa le Conseil de ville de Montréal à légiférer lui-même en matière de lois ayant pour but l'assainissement de la santé publique, comme la vaccination obligatoire, l'inspection des domiciles privés, la désinfection des lieux publics ou des endroits susceptibles de propager les épidémies ${ }^{242}$. Le docteur Hingston, l'un des farouches défenseurs de la vaccination, fut élu maire en 1875243.

Élu sur un programme quasi exclusivement sanitaire, dans un contexte de variole endémique, Hingston tenta de mener sa lutte à deux niveaux, celui de la poursuite des mesures générales de santé publique et celui plus spécial d'une vigoureuse campagne pour la vaccination anti-variolique.

241

Ibid., p. 183.

Statuts du Québec, 37 Victoria, 1874, chapitre 51.

243 Sur la carrière de Hingston et les politiques sanitaires de la ville de Montréal à l'époque, voir M. Farley, Oth. Keel et C. Limoges. "Les commencements de l'administration montréalaise de la santé publique (18651885) », HSTC Bulletin. Journal of History of Canadian Science, Technology and Medicine, vol. 20, 1982, p. 24-46 ; vol. 21, 1982, p. 85-109. 
À partir de mars 1875, les adversaires de la vaccination commencèrent à s'organiser pour faire face au nouveau maire et à sa politique sanitaire. Des assemblées publiques se tinrent, réunissant des médecins et un bon nombre d'autres citoyens pour dénoncer les pouvoirs consentis à la ville par la charte refondue de 1874. Une première réunion eut lieu dans la salle de l'Union SaintJoseph : l'assemblée adopta une résolution demandant que le Bureau de santé municipal soit dorénavant composé de médecins, représentant chaque quartier, nommés sur la recommandation des médecins de ces quartiers. Il est clair que l'on visait ainsi à assurer au Bureau la présence sinon d'une majorité, tout au moins d'une minorité influente de médecins opposés à la vaccination obligatoire. Une deuxième réunion déboucha sur la fondation de l'Association sanitaire de la cité. Parmi les fondateurs de cette association, on trouve certains notables de la ville, comme par exemple les échevins Brunet et David, les médecins Dagenais, Coderre et Gauthier et les avocats Saint-Pierre et Roy 244.

Cette opposition à la vaccination ne se situait pas uniquement au niveau des instances du pouvoir municipal, mais aussi à celui des instances du pouvoir provincial. Périodiquement, les députés partisans du mouvement présentèrent des projets de loi pour la révocation de l'Acte sur la vaccination obligatoire de 1861. Ce fut le cas par exemple du «bill » proposé en 1874 par le docteur Lafontaine, représentant du comté de Napierville. S'appuyant sur une pétition signée par vingt-trois médecins montréalais, le projet de loi visait a obtenir l'abrogation de la vaccination obligatoire. Mais devant faire face à une opposition déterminée, le docteur Lafontaine retira le projet avant la deuxième lecture 245 .

En dépit de ces résistances, en décembre 1876, Hingston fit passer une loicadre (la Loi 105) régissant une nouvelle politique sanitaire. L'innovation majeure de la Loi 105 fut la réorganisation du Bureau de santé municipal en un organisme permanent. La Loi 105 donnait aussi à la ville de nombreux droits nouveaux en matière sanitaire: celui de construire son propre hôpital pour les maladies

244 «La question sanitaire », Union médicale du Canada, vol. 4, 1875, p. 188. Peu de temps avant la fondation de l'Association sanitaire, une assemblée de médecins avait formé la Ligue contre la vaccination compulsoire. Le président en était un médecin anglophone, le Dr A.B. Craig ! Voir ibid., p. 47. La Ligue fusionna avec l'Association sanitaire.

245 La Loi de vaccination, Union médicale du Canada, vol. 3, 1874, p. 88-89. 
contagieuses ; celui d'entrer dans les maisons privées pour vacciner les citoyens, celui de déménager les contagieux ou les cadavres dans des lieux de quarantaine ou dans des quartiers de la ville déjà contaminés ; celui d'empêcher que les morts, victimes d'une maladie contagieuse, ne soient transportés dans une église pour y recevoir une oraison funèbre ; celui, enfin, de séparer les gens de leur médecin de famille ${ }^{246}$. La nouvelle loi mettait à la disposition du Bureau de santé un groupe de médecins et de policiers chargés des différentes fonctions d'inspecteurs, de vaccinateurs et de recenseurs. On réorganisa aussi la pratique de la vaccination : la ville voulait qu'il y ait des groupes de vaccinateurs itinérants, allant vacciner les gens de maison en maison.

En plus de relancer le programme de vaccination, cette fois-ci sur une base décentralisée, l'administration de Hingston ouvrit, dès 1875, un hôpital pour variolés destiné aux patients catholiques ${ }^{247}$. Le contrôle de cet hôpital catholique, établi dans le parc Mont-Royal, fut confié aux soeurs de la Providence. La ville gardait toutefois un droit d'inspection à travers un comité de santé composé des médecins Dugdale et Larocque ${ }^{248}$.

Ce type d'hôpital n'eut pas la faveur des médecins. D'après la nouvelle loi de 1861, tous les médecins étaient tenus de signaler au Bureau de santé chacun des cas contagieux dont ils prenaient connaissance et, lorsqu'ils les soignaient, de les faire transférer à l'hôpital municipal pour les contagieux (qui n'existait pas encore à Montréal, au moment où la loi fut promulguée). En ouvrant ce genre d'hôpital, la municipalité était désormais en mesure d'appliquer la loi.

Or, un bon nombre de médecins étaient opposés à cette déclaration obligatoire et au transfert de leurs clients à l'hôpital. L'hôpital fut aussi mis en cause (en tant que foyer potentiel de contamination des lieux) par les commissaires du parc Mont-Royal qui demandèrent tout de suite sa suppression ${ }^{249}$. En raison de ces

246 Voir, op. cit., note 52, p. 35-36. Voir aussi Statuts du Québec, 38 Victoria, chap. LXXIII, p. 23, février 1875, article 1.

247 «Hôpital des varioleux », Union médicale du Canada, vol. 4, 1875, p. 575.

248 «Vaccination in Montreal », Canada Médical Record, vol. 3, 1874-1875, p. 569.

249 « Procès-verbaux du Conseil municipal », vol. 97, p. 88, 6 juin 1876, Archives municipales de Montréal. 
oppositions, l'hôpital fut fermé en 1881 250. Un nouvel hôpital pour les variolés ne sera ouvert qu'en plein milieu de l'épidémie de 1885.

Pendant toute la période où Hingston occupa la mairie (1875-1877), les débats sur la vaccination se poursuivirent au sein de la profession médicale. Vers le début de son mandat à la mairie, Hingston prononça devant un groupe de vaccinateurs un long discours 251 dans lequel il réfutait les thèses des antivaccinateurs. Ce texte eut une large diffusion: il fut publié en fascicule et reproduit largement dans la presse médicale. La mobilisation de la profession médicale s'était nettement accentuée et 150 médecins contresignèrent le texte de Hingston. Une soixantaine de ces médecins étaient des francophones ${ }^{252}$.

En dépit de la prise de position de la majorité des médecins francophones en faveur de la vaccination, l'idée persistait chez certains que les opposants à la vaccination étaient en train de l'emporter dans le milieu francophone. Faisant rapport en 1876 sur les statistiques de mortalité de Montréal, qui chiffrent à 653 le nombre de Canadiens français morts de la variole sur un total de 784 (soit 83\%), les éditeurs du Canada Medical Record faisaient le commentaire suivant : « Is it not shameful that so many of our French Canadian fellow citizens should be slaughtered by the neglect of vaccination [...] Its opponents hold doggedly to their anti-vaccination views, and the injury they have done and are doing is incalculable 253 ».

C'est en réaction à de telles allégations que, en 1876, dans l'éditorial de l'Union médicale du mois de décembre ${ }^{254}$, l'auteur, le docteur Lachapelle, s'emploie à réfuter la thèse selon laquelle les Canadiens français seraient responsables, par leur refus de se faire vacciner, du très fort taux de mortalité dû à la variole à Montréal.

250 Ibid., vol. 103, p. 50, 19 janvier 1881.

251 Win. Hingston, « Vaccination », Public Health Magazine, vol. 2, 1876, p. 141-161.

252 « Pronunciamento of Physicians of Montreal in favor of Vaccination », Public Health Magazine, vol. 2, 1877, p. 43-46. Dès 1876, la presque totalité des médecins francophones sont partisans de la vaccination. Cf. Union médicale du Canada, 1876, vol. 6, p. 160, note 1.

253 «The Mortality of Montreal », Canada Medical Record, vol. 4, 18751876, p. 119.

254 «La variole », Union médicale du Canada, vol. 5, 1876, p. 572-575. 
Se basant sur les statistiques du Bureau de santé, Lachapelle montrait que la différence du taux de mortalité par variole dans la population francophone et anglophone était assez faible, toute proportion gardée. En outre, cette différence était facilement compensée d'abord par le taux de naissance relativement plus haut chez les francophones, et ensuite par le fait que les anglophones habitaient les quartiers les plus salubres de la ville ${ }^{255}$. Selon l'auteur, les conditions insalubres dans lesquelles vivait la population francophone constituaient un facteur de première importance dans la propagation plus grande d'une épidémie, et dans la mortalité plus élevée due non seulement à la variole mais aussi aux autres maladies épidémiques dans la population francophone (la fièvre typhoïde, par exemple). D'ailleurs, poursuivait l'auteur, l'absence d'un programme soutenu et systématique de santé publique avait eu un impact négatif très marqué sur l'efficacité de la pratique de la vaccination. La vaccination était souvent pratiquée avec des vaccins altérés ou inopérants et la revaccination était rarement pratiquée. L'isolement, mesure essentielle pour tout programme visant le contrôle du virus variolique, n'était presque jamais observé, non seulement en raison du manque d'équipements hospitaliers appropriés, mais aussi parce qu'une population qui avait vécu jusqu'alors en dehors de l'observance de mesures sanitaires était mal préparée à subir la soustraction d'un membre de la famille qu'entraînait l'isolement ou la restriction des activités sociales et commerciales qui résultait de l'imposition d'une quarantaine.

Les résistances à des mesures comme l'isolement ou la quarantaine avaient trouvé leur expression la plus claire lors de l'émeute du 4 août 1875, au cours de

255 Lachapelle écrit en effet :

Nous avons toujours entretenu des doutes sur l'exactitude de cette assertion, et nous sommes heureux de pouvoir dire que les observations que nous avons faites depuis le début de la présente épidémie détruisent entièrement cette prétention : voici d'ailleurs les statistiques du Bureau de santé pour les huit semaines qui se sont écoulées depuis le 23 septembre jusqu'au 21 novembre : Population française, 478 mortalités, dont 141 par la variole. Population anglaise, 262 mortalités, dont 59 par la variole. En comparant ces chiffres entre eux, on pourra se convaincre que la proportion des variolés dans le total des décès ne diffère pas sensiblement et que la légère différence qui existe en faveur de la population anglaise est plus que compensée par le fait que celle-ci habite le quartier le plus salubre de la ville. (Ibid., p. 572). 
laquelle la maison de l'officier de santé Larocque, principal artisan de la nouvelle politique sanitaire, avait été saccagée par une foule déchaînée ${ }^{256}$.

Au cours des années suivantes, cette résistance, issue jusqu'alors d'une partie de la population, allait devenir plus spécifique à l'intérieur même de la municipalité. En effet, dès son entrée en fonction au début de 1877, le nouveau maire Beaudry allait se lancer dans une vigoureuse critique de la gestion en matière de santé publique de son prédécesseur Hingston, et plus particulièrement de la politique de vaccination obligatoire de son Bureau de santé. On voit en effet se dessiner, à travers les procès-verbaux des assemblées du Conseil municipal, une véritable réaction contre le Bureau de santé et ses agents, et, tout particulièrement, dans le domaine de la vaccination. Outre l'attaque du maire, on trouve trace par exemple d'un procès entre la ville et l'ancien officier de santé Dugdale qui tente de se faire payer des arriérés de traitement ; on relève aussi des pétitions de citoyens pour obtenir le renvoi de membres du Département de santé. De plus, le nombre de vaccinateurs est réduit à quatre 257.

Nonobstant ces conditions défavorables, la variole se mit à régresser et, à la fin de 1879, Larocque pouvait déclarer devant la Société médico-chirurgicale que la variole n'était la cause que du quart de la mortalité totale de la ville de Montréal 258. Un an plus tard, le Canada Médical Record reproduisait un article du Montreal Witness qui se montrait encore plus optimiste. Comme la variole avait pratiquement disparu, le rapporteur relatait de la manière suivante l'histoire de la victoire de la vaccination sur la variole. Selon lui, c'était la découverte du cow-pox à Longue-Pointe en 1878 qui était à l'origine de la régression de l'épidémie. Approuvé rapidement par tout le monde, le vaccin aurait été pratiqué sur des milliers de personnes, entraînant ainsi la disparition de la variole. L'auteur

256 Boissonnault, op. cit., note 4, p. 178. Comme le rappelle Heagherty (op. cit., note 4, vol. 1, p. 91), en 1875, plus de trois mille personnes envahirent l'hôtel de ville et ses abords pour protester contre le programme de vaccination obligatoire.

257 Voir M. Farley, Oth. Keel et C. Limoges, op. cit., note 52, vol. 21, p. 8587. En 1874, il y avait une vingtaine de vaccinateurs affiliés au Bureau de santé, ibid., vol. 20, p. 36.

258 «Board of Health », Canada Médical Record, vol. 8, 1880, p. 108-109. 
notait aussi que : «By this means, the public sentiment among the masses of the city of Montreal has been entirely in favor of vaccination 259 ».

Mais si la variole avait disparu temporairement, les problèmes qu'elle avait mis en évidence continuaient à se poser. L'enregistrement des statistiques médicales dépendait encore de l'initiative privée de tel ou tel médecin et ce genre de statistiques fournissait autant d'armes à des anti-vaccinateurs comme Coderre 260 qu'aux vaccinateurs eux-mêmes. Le vaccin animal découvert à Longue-Pointe et dont le Canada Médical Record faisait un si grand cas semble s'être épuisé dès 1882 ; on n'était donc plus en mesure de s'approvisionner en vaccin 261 . Enfin, la ville ne parvint pas à trouver un site pour y édifier un hôpital

259 « Animal Vaccine, How it is Propagated », Canada Médical Record, vol. 9, 1880 , p. 67.

260 Au début de 1879, par exemple, Coderre entre en polémique publique avec les médecins Larocque et Mount. Comme ils disposaient de données différentes provenant de sources différentes, le débat ne pouvait être qu'un dialogue de sourds. Coderre écrivait, par exemple : «Le docteur Larocque a bien su aussi omettre quelque part et défigurer ailleurs mon rapport de la visite que je fis avec le docteur Craig à l'hôpital des variolés il y a 3 ans. Il y avait, cette fois-là, 16 vaccinés sur 17 variolés [...] » Et, plus loin, Coderre écrivait à partir de ses «notes prises au hasard » : «Extrait du registre de la Fabrique Notre-Dame. Total : 203 décès ; vaccinés : 90 ; non vaccinés : 78 ; [...] (Bureau de santé et vaccination, La Minerve, 15 février 1879). Le médecin Mount avait antérieurement proposé au Rédacteur de La Minerve " de vous passer sous peu quelques statistiques que je suis à recueillir sur ce qui s'est passé quant à la picotte et la vaccination, dans la paroisse de Saint-Vincentde-Paul, depuis près de dix ans que j'y demeure (J.W. Mount au Rédacteur La Minerve, 4 février 1879). Mount avait donc, lui, des statistiques en faveur de la vaccination.

261 Le docteur Bessey relate comment il a trouvé vers 1882, à la ferme des soeurs de la Providence, des vaches pouvant fournir du "véritable cow-pox ». Prenant en charge une de ces vaches atteintes de cow-pox, Bessey décide de fonder à partir de là un institut vaccinal. Pour ce faire, il lui faut une somme d'argent assez importante et la reconnaissance des pouvoirs publics (pour l'animal en sa qualité de producteur du vaccin). Ceci lui permettrait d'installer l'animal sur une ferme d'état où le vaccin serait reproduit à travers la contamination des autres animaux. Cependant, le docteur Bessey se présenta à Québec et à Ottawa sans pouvoir obtenir la reconnaissance et les fonds nécessaires à la mise en place d'un institut public de vaccination à Montréal. (« A National Vaccine Institution », Canada Médical Record, vol. II, 1882, p. 8-9). Il est à noter que malgré tous les obstacles rencontrés, il s'était quand 
des variolés. Les problèmes que posaient la production et la conservation du vaccin, la compilation des statistiques sur la vaccination et l'ouverture d'un hôpital pour les variolés allaient se manifester de manière encore beaucoup plus critique lors de l'épidémie de 1885-1886.

\section{L'ÉPIDÉMIE DE VARIOLE DE 1885-1886 ET LA VACCINATION À MONTRÉAL JUSQU'À LA FIN DU SIÈCLE}

En 1885 et 1886, l'épidémie de variole causa 3164 décès à Montréal sur une population de 168000 habitants. Sur ce nombre de victimes, 2717 étaient des enfants de moins de dix ans. C'est W. Osler qui a publié la description la plus connue de l'origine et des causes de l'épidémie de 1885. Dans son célèbre traité de médecine générale, il écrivait :

On February 28 a Pullman-car conductor, who had travelled from Chicago, was admitted into the Hotel Dieu, the civic smallpox hospital being closed at the time. Isolation was not carried out, and on the 1st of April a servant in the hospital died of smallpox. Following her decease, with a negligence absolutely criminal, the authorities of the hospital dismissed all patients presenting no symptoms of contagion who could go home. The disease spread like fire in dry grass (...) 262

Osler notait ensuite que le secteur de la population montréalaise le plus durement frappé était le secteur francophone. En effet, selon le rapport sur l'état sanitaire de la ville de Montréal pour l'année 1885, l'épidémie de variole s'était distribuée entre les ethnies montréalaises de la manière suivante : sur les 4771 cas de variole rapportés au Bureau de santé, 3978 cas (83\%) provenaient des «Canadiens français ». Sur ces 4771 cas, 2471 (52\%) se manifestaient chez des

même opéré à Montréal plus de 41376 vaccinations anti-varioliques entre 1871 et 1882. Voir Rapport sur l'état sanitaire de la cité de Montréal, 1882, p. 32 et M. Tétrault, L'état de santé des Montréalais de 1880 à1914, M.A., Université de Montréal, 1979, p. 83.

262 Osler, op. cit., note 4, p. 64. 
individus non vaccinés, 1187 (25\%) chez des individus vaccinés et 23\% chez des individus dont la vaccination paraissait douteuse 263 .

Sur les 4771 cas rapportés, 28\% avaient été transportés dans les hôpitaux civiques de Montréal. Ces 1332 cas se répartissaient en 852 «Canadiens français » et 480 "d'autres nationalités ». En d'autres termes, 21\% des cas de variole chez les Canadiens français étaient hospitalisés, tandis que 61\% des variolés d'autres nationalités subissaient le même sort ${ }^{264}$. Sur les 852 Canadiens français hospitalisés, 249 étaient vaccinés tandis que, chez les « autres », 278 (sur 480) étaient vaccinés. L'écart entre les vaccinés canadiens-français et les « autres » vaccinés était plus réduit lorsqu'il s'agissait des décédés. Sur les 296 Canadiens français morts dans les hôpitaux civiques, 67 étaient vaccinés ; sur les 122 « autres » morts dans ces institutions, 36 étaient vaccinés 265.

Cette épidémie de variole s'accompagna d'émeutes spectaculaires qui symbolisent aux yeux des historiens l'apogée du mouvement contre la vaccination qui s'est développé à Montréal dans la seconde moitié du 19e siècle. Cette période de protestation faisait suite à celle où l'on avait tenté d'appliquer la loi de 1861 rendant la vaccination obligatoire au Canada.

263 «État sanitaire de la ville de Montréal pour l'année 1885 », Archives municipales, vol. 4, 1886, p. 46-47. À noter, cependant, que ces statistiques sont si peu fiables qu'on ne peut en tirer que des conclusions très prudentes sur le nombre respectif de vaccinés et de décédés chez les francophones et les anglophones. Au début de ce rapport, l'officier de santé municipal, Louis Laberge, qui en est l'auteur, note, en effet, que : « Je dois ajouter que dans les données statistiques concernant la petite vérole et la vaccination fournies dans le présent rapport, se présenteront (sic) des lacunes regrettables au point de vue scientifique. Les informations ont été ou manquantes ou incomplètes, surtout au début de l'épidémie et on peut assigner deux causes à ce fait : 1) Insuffisance absolue des lois sanitaires à cette époque, insuffisance telle que le bureau ne pouvait exiger aucun rapport de maladies contagieuses, rapport qui n'a été donné, au début, que par des personnes de bonne volonté : 2) Négligence et mauvais vouloir de beaucoup de médecins qui, dans les avis ou dans les certificats de décès transmis au bureau ne disaient point si les malades et les victimes avaient été ou non vaccinés. » Ibid., p. 8. Les italiques sont de nous.

264 Ibid., p. 62.

265 Ibid., p. 63. 
Les émeutes les plus importantes se produisirent les 28 et 29 septembre 1885, à la fin d'une semaine au cours de laquelle 226 des 245 sujets morts de la variole, étaient de nationalité canadienne-française. Comme le rappelle Rumilly ${ }^{266}$, le 28 septembre, la foule lacéra des affiches ordonnant la vaccination et isolant des maisons ; elle assiégea le Bureau de santé du faubourg de l'Est, y mit le feu ; puis se dirigea sur l'Hôtel de ville, y brisa des vitres. La police dut charger à coups de bâton. Il y eut quelques assomades; des coups de feu éclatèrent. La foule, un moment dispersée, se reforma pour briser les vitres du Herald et menacer les maisons des médecins vaccinateurs. Un commencement d'incendie détériora l'une de ces maisons. La police procéda à des arrestations. Le chef de police Paradis fut blessé. Le maire Beaugrand était malade ; il quitta son lit, courut à son bureau, consigna six cents militaires sous les armes et publia une proclamation invitant les citoyens à ne pas sortir le soir et à ne pas gêner l'action de la police et des troupes. L'infanterie et la cavalerie patrouillèrent toute la nuit.

Des manifestations continuèrent à se produire les jours suivants, malgré la proclamation du maire. Les cavaliers chargés de disperser les rassemblements étaient accueillis à coups de pierre dans les quartiers pauvres de l'Est de Montréal. Dans la semaine du 26 septembre au 2 octobre la variole causa 401 décès dans Montréal et sa banlieue, surtout des enfants en bas âge 267.

Selon la plupart des historiens, la résistance à la vaccination antivariolique, qui a culminé au cours de ces émeutes, provenait du secteur francophone et catholique de la population montréalaise. La cause de cette opposition aurait été l'ignorance de la population à l'égard de la science médicale, ignorance imputée à une mentalité particulièrement arriérée qui était alimentée, voire suscitée, par des

266 Voir R. Rumilly, Histoire de Montréal, Montréal, 1972, vol. 3, p. 175-176. Voir aussi les références de la note 4 . Sur ces événements, voir également les comptes rendus de la presse de l'époque, notamment les numéros des 28, 29 et 30 septembre de journaux comme le Star, la Gazette, La Presse, etc. Le 4 septembre 1885, le lieutenant-gouverneur avait mis en vigueur, à l'instigation du Conseil d'Hygiène de Montréal, l'Acte concernant la conservation de la Santé Publique, chap. XXXVIII des Statuts refondus du Canada qui rendait obligatoires la vaccination et l'isolement pour toute personne en cas d'épidémie. Voir: Bibliothèque Osler, Université McGill. Acc. 544 38/65/N/314. Cf. aussi op. cit., note 72, p. 27.

267 Ibid. 
croyances anachroniques répandues dans une partie du corps médical francophone formée d'opposants à la vaccination 268.

268 Dans sa description de l'épidémie de 1885, l'historien A.D. White affirme en effet que :

« In that year the smallpox broke out with great virulence in Montreal. The Protestant population escaped almost entirely by vaccination : but multitudes of their Catholic fellow-citizens, under some vague survival of the old orthodox ideas, refused vaccination and suffered fearfully. (...) The clergy at first tolerated and even encouraged this conduct : the Abbé Filiatrault, priest of St. Jame's Church, declared in a sermon that « if we are afflicted with smallpox, it is because we had a carnival last winter feasting the flesh, which has offended the Lord : ... it is to punish our pride that God has sent us smallpox. " The clerical press went further; the Etendard exhorted the faithful to take up arms rather than submit to vaccination, and at least one of the secular papers was forced to pander to the same sentiment. The Board of Health struggled against this superstition, and addressed a circular to the Catholic clergy, imploring them to recommend vaccination; but, though two or three complied with this request, the great majority were either silent or openly hostile. The Oblate Fathers, whose church was situated in the very heart of the infected district, continued to denounce vaccination ; the faithful were exhorted to rely on devotional exercises of various sorts ; under the sanction of the hierarchy a great procession was ordered with a solemn appeal to the Virgin, and the use of the rosary was carefully specified. "

(A.D. White, A History of the Warfare of Science and Theology in Christendom (New York, 1896, vol. 2, p. 60-61).)

Il est à noter que cette interprétation de White a été contestée à l'époque déjà par W.S. Tebb qui écrivait en 1899 :

It has been alleged (il cite White) that this epidemic (de 1885) was occasioned by the neglect of vaccination by the French Catholic population. In this connection, it is sufficient to quote from the late Dr. W.B. Carpenter (Dans A letter to the Right Hon. Lyon Playfair, C.B., p. 13-14, 1883) who, in referring to the 1874-75 epidemics of smallpox, and the resistance exhibited towards the proposed vaccination law, says : " I made a point of enquiring during my stay there, in August last, as to what has been the subsequent course of affairs. I learned on the very best authority that the objections of the French Catholics had been completely overcome... Vaccination being now (1883) as well carried out in Montreal by its officers of health as in the other great cities of the Dominion, smallpox having become almost entirely extinct. "

W. S. Tebb, A Century of Vaccination and What it Teaches, 2e éd., Londres, 1899, p. 102-103. Notons que Tebb était un anti-vaccinateur britannique bien connu à l'époque. 
Un bon nombre de raisons conduisent à s'interroger sur le bien-fondé d'une telle explication de la résistance à la vaccination. Tout d'abord, l'existence d'un mouvement contre la vaccination au cours de la deuxième moitié du dixneuvième siècle n'est guère un phénomène spécifique à la ville de Montréal ou à

Une erreur partagée par la plupart des historiens est de croire que les opposants à la vaccination à Montréal sont uniquement des Canadiens francophones et catholiques. Il est à noter qu'un auteur comme Boissonnault était plus nuancé à cet égard. Dans son étude sur la Ligue des AntiVaccinateurs, fondée en 1885 après l'épidémie en question, il affirme que : « Contrairement àce que l'on peut avancer de nos jours, la Ligue n'avait pas cette couleur nationaliste à laquelle faisait allusion L'Ami du peuple, de Charleroi, Belgique. En effet, elle avait pour président le docteur A.M. Ross et pour secrétairetrésorier, M.W. Costigan [...]. Elle comptait parmi ses fondateurs les docteurs Joseph Emery Coderre, A.M. Ross, David MacBean, D.D. Archambault et J.A. Roy, MM. W.W. Robertson, L. McLachlan, Stephens, etc. On voit bien donc que les deux éléments ethniques de cette province collaboraient étroitement dans cette affaire » (op. cit., note 4, p. 182-183). (Les italiques sont de nous.) Le journal L'Anti-vaccinateur canadien-français (1885), dirigé par le Dr J.E. Coderre avait un ton nationaliste anti-anglais très fort. Il publiait cependant les articles et statistiques des anti-vaccinateurs anglais. Le nationalisme du journal n'empêchait pas les anti-vaccinateurs francophones et anglophones d'être unis au sein de la Ligue contre la vaccination. Il est à noter que les anglophones membres de la Ligue étaient des membres influents de la société de l'époque. Le docteur Ross par exemple, avait reçu des honneurs des rois d'Italie, de Grèce, du Portugal ainsi que du Shah de Perse et de l'empereur de Russie pour ses travaux de naturaliste. Membre des Associations scientifiques partout en Europe et aux États-Unis, il était aussi membre des Collèges de médecins et de chirurgiens du Québec, de l'Ontario et du Manitoba. («Alexander Milton Ross », A Cyclopedia of Canadian Biography, Toronto, 1886-1888, p. 760762) ; W. W. Robertson, membre influent du parti libéral et avocat en chef de la Banque de Montréal, était Bâtonnier général du Barreau. («William W. Robertson>>, Q.C., Canadian Men and Women of their Time, Toronto, 1898, p. 869-870); tandis que G.W. Stephens était député provincial de la circonscription de Montréal centre. («Hon. George Washington Stephens », Canadian Men and Women of their Tîme, Toronto, 1898, p. 966). Stephens avait été auparavant pendant quatorze ans conseiller municipal libéral du quartier du centre et il demeura très actif sur la scène politique montréalaise. Il sera par la suite ministre dans le gouvernement Marchand. Voir Rumilly, op. cit., note 35, p. 122, p. 125, p. 247-251, p. 284. Un exemple de résistance aux mesures sanitaires est rapporté par le Montreal Star du 6 juin 1885. Il s'agit du Révérend M. Casey de l'Église presbytérienne (donc le milieu anglophone), qui, ayant contracté la variole, refuse d'être isolé à l'hôpital civique. 
la société canadienne-française. La plupart des pays européens et la plupart des autres états et provinces d'Amérique du Nord ont connu des mouvements de résistance à la vaccination et aux programmes qui l'avaient rendue obligatoire 269 . En Angleterre, par exemple, la vaccination avait été déclarée obligatoire en 1853 par un acte du Parlement, mais cinquante ans de résistance venue à la fois de la population, des organisations ouvrières et d'artisans et de certaines couches des élites aboutirent à la révocation de cette loi ${ }^{270}$. Il ne nous paraît donc pas pertinent d'attribuer la résistance à la vaccination unilatéralement à la mentalité particulièrement rétrograde de la population francophone de Montréal, alors qu'il y eut une résistance analogue dans un bon nombre de pays «avancés » (Angleterre, France, Allemagne, Belgique, Suisse, États-Unis, etc.). Dans ces différents pays, on trouvait également des médecins dont la position était critique ou réservée sur la vaccination. De nombreux médecins européens de la Ligue internationale des anti-vaccinateurs militèrent même avec acharnement contre la

269 Voir par exemple, les références dans la note 3. Il faut souligner le fait que vers 1885 (et après), il y avait aussi, en Ontario, une méfiance et une résistance importantes par rapport à la vaccination et aux mesures comme l'isolement, la désinfection des habitations, etc.! Le mouvement antivaccinateur en Ontario était conduit et soutenu par des médecins! Voir B. Craig, « Smallpox in Ontario : Public and Professional Perceptions of Disease, 1884-1885 », in Charles Roland (ed.), op. cit., note 1, p. 225 et suiv. Voir aussi B. Craig, op. cit., note 3. À Toronto, en 1906, les anti-vaccinateurs parvinrent à faire suspendre le règlement municipal de 1894 qui imposait la vaccination aux enfants des écoles. Cf. P. Bator, "'Saving Lives on the Wholesale Plan' : Public Health Reform in the City of Toronto, 1900-1930 », Thèse Ph.D., Université de Toronto, 1974, p. 92. Ce mouvement a continué avec beaucoup d'ampleur un peu partout en Ontario jusque dans les années 1920 ! Des médecins "réguliers ", des échevins dans plusieurs villes, et même le maire de Toronto (de 1903 à 1905) y militèrent activement ! Voir P. Bator, op. cit., note 3. La ligue contre la vaccination de Toronto était calquée sur le précédent de l'Angleterre. S'il faut parler de mentalité anti-scientifique ou bigote à propos des opposants francophones à la vaccination à Montréal au 191 siècle, que dire alors des anti-vaccinateurs anglophones en Ontario au 201 siècle ? ! ! Notons encore que le mouvement contre la vaccination en Ontario a eu bien plus d'ampleur qu'il n'en avait eu au Québec.

270 Voir R.M. MacLeod, op. cit., note 9. Entre 1880 et 1900, les mouvements contre la vaccination obligatoire ont obtenu certains succès dans d'autres pays comme l'Allemagne, la Suisse et la France où la vaccination obligatoire n'a pu être imposée qu'en 1902 ! Voir Darmon, op. cit., note 3, p. 374. 
vaccination, et ce jusqu'au début du 20e siècle. Dans la plupart des pays, l'activisme de certains médecins dans les mouvements contre la vaccination a d'ailleurs été plus soutenu et plus durable qu'il ne l'a été à Montréal.

Ceux qui avaient des réserves sur la vaccination ou qui s'opposaient à ce qu'elle soit obligatoire, n'étaient pas forcément des «retardataires » ou des « charlatans » 271, mais souvent des hommes de science progressistes qui travaillaient au développement de la santé publique. Ces réformateurs de la santé considéraient que les problèmes sociaux et médicaux étaient causés par un environnement physique et social qui était malsain et qu'il fallait transformer. Ils s'opposaient donc à ceux qui, dans la mouvance de la bactériologie récente, affirmaient que seuls les germes étaient responsables des maladies et des problèmes sanitaires. Pour les réformateurs sanitaires, l'hygiène urbaine et sociale était un préalable au bien-être social et le principal rempart contre la maladie. Certains d'entre eux acceptaient la vaccination comme un instrument auxiliaire de prévention, mais ils étaient opposés à ce que cette technique de prévention fasse obstacle ou à ce qu'elle remplace les initiatives pour éliminer l'air vicié, le surpeuplement, la pauvreté et les espaces urbains insalubres 272.

Sur le plan politico-culturel, ceux qui s'opposaient à la vaccination obligatoire en Angleterre n'étaient pas toujours des conservateurs ou des passéistes naturistes ou religieux, mais souvent, au contraire, des libéraux et des nouveaux radicaux (des philanthropes socialisants) qui étaient opposés à l'autoritarisme de l'État et à son ingérence dans la sphère de la vie privée et des décisions qui relèvent du libre-arbitre de l'individu.

De même, en Allemagne, ce furent surtout des membres du parti socialdémocrate qui s'opposèrent à la loi sur la vaccination obligatoire présentée par Bismarck devant le Reichstag en 1874. Les opposants à la vaccination contestèrent le fait que le gouvernement ait le droit de contraindre un père à faire vacciner ses enfants, alors que les bienfaits de la vaccination - et son innocuité n'avaient pas encore été définitivement prouvés. Les représentants du parti social-

271 Les termes sont de R. Duchesne, voir « Problèmes d'histoire des sciences au Canada français », in R.A. Jarrell et N.R. Ball (eds.), Les sciences, la technologie et l'histoire canadienne, Waterloo, 1980, p. 23.

272 Voir, par exemple, C. Heurkamp, op. cit., note 3 et R.M. Macleod, op. cit., note 9. 
démocrate firent valoir que l'amélioration du logement, de la nutrition et de l'habillement étaient plus importants pour prévenir la variole que la vaccination et qu'ils permettraient également l'éradication d'autres maladies infectieuses.

Comme on le voit, les réserves sur la vaccination et l'opposition à son imposition obligatoire ne venaient pas nécessairement de milieux politiques et sociaux arriérés ou conservateurs religieux : elles venaient souvent des milieux les plus progressistes. Il est donc erroné d'imputer automatiquement à une mentalité traditionaliste et obscurantiste toute attitude critique ou réservée à l'égard de la vaccination, comme on l'a fait jusqu'ici pour le cas de Montréal.

Une telle perspective sur l'opposition à la vaccination à Montréal repose d'ailleurs sur le fait que l'on «dramatise » à l'excès l'épidémie de 1885-1886, en la présentant comme un événement tout à fait anachronique qui n'aurait jamais dû se produire dans un pays « civilisé » à l'époque.

Or, si à nos yeux, le chiffre de trois mille morts paraît accablant, cette réalité prend un autre visage si l'on fait une mise en perspective historique et si l'on établit une comparaison avec le nombre de décès dus à la variole dans d'autres villes ou pays au cours des trois ou quatre dernières décennies du 19e siècle.

C'est ainsi que la grande épidémie de variole de 1870-1871 a fait de 60000 à 90000 victimes en France. Rien qu'à Paris, il y eut 10539 décès par variole en 1870 et 2771 décès en $1871^{273}$. En 1871, il y eut 3647 décès par variole à Hambourg et, la même année, Berlin perdit plus de 5000 de ses habitants à cause de cette épidémie. Pour toute l'Allemagne, il y eut en 1871-1872, au moins 162000 morts par variole. Toujours en rapport avec la variole, en Belgique, il y eut 21315 décès en 1871 et 8704 en 1872 ; en Angleterre même, 19904 décès en 1872 ; en Hollande, 12476 morts en 1872. En Autriche il y eut plus de 141000 décès dus à la variole pour les années 1872-1874, et Vienne et Prague furent particulièrement affectées. En 1895-1896, la ville de Gloucester perdit 434 sujets sur une population de 40000 habitants lors d'une épidémie de variole ${ }^{274}$. Aux

273 Hopkins, op. cit., note 3, p. 89-96.

274 Ibid., p. 94. En 1895, le mouvement contre la vaccination était encore très fort en Angleterre ! Gloucester, au coeur même de la patrie de Jenner, en était le sanctuaire. La campagne de désobéissance à la loi d'obligation y avait connu un succès complet ! C'est ainsi que 2000 personnes furent atteintes par la variole. Voir Darmon, op. cit., note 3, p. 377. 
États-Unis, la variole causa 2000 morts à Philadelphie en 1871 et 1500 à Baltimore en 1872-1873. Il y eut, à Cincinnati, 800 morts par variole en 18691870, et 1400 , l'année suivante. On signale plus de 1700 morts par variole à New York en 1874-1875 et plus de 1000 à Boston en 1872-1873 275.

Sans aucun doute, l'épidémie de 1885 fut d'une gravité exceptionnelle, mais de telles épidémies ont fait rage dans la plupart des pays dans la seconde moitié du 19e siècle et même dans ceux où la vaccination était pratiquée. La très forte mortalité par variole à Montréal lors de l'épidémie de 1885 s'explique aussi par la forme particulièrement virulente de la maladie.

Pour ce qui est des émeutes de 1885 à Montréal, il faut tenir compte du fait qu'elles se situent dans un contexte où les tensions politiques et sociales entre francophones et anglophones étaient déjà exaspérées par l'affaire Riel 276. Dans ces émeutes, il est difficile de faire la part de ce qui était provoqué par cette affaire et de ce qui l'était par la politique sanitaire contraignante de la municipalité.

Il faut noter d'ailleurs que les manifestations populaires les plus importantes ont été provoquées davantage par des initiatives pour imposer une quarantaine à certaines habitations, ou pour isoler certains individus que par des pratiques de vaccination à proprement parler 277 .

Par ailleurs, comme on l'a déjà indiqué, les résistances à la vaccination dans la population s'expliquaient par des raisons qui peuvent se comprendre d'un point de vue rationnel. En effet, la population constatait que la vaccination pratiquée dans des conditions improvisées, s'avérait inopérante ou même dangereuse, provoquant la cécité ou des maladies graves comme l'érysipèle, la tuberculose, la syphilis, ou

275 Ibid., p. 283 et suiv. La terrible épidémie de 1871 en Europe a traumatisé de nombreux médecins, déçus par l'inefficacité apparente de la vaccination. Beaucoup ont préféré revenir alors à des méthodes comme l'isolement ou la séquestration. La variole continua à sévir en Europe dans les années suivantes. À Paris, par exemple, il y a eu 5000 morts entre 1879 et 1881 ; à Marseille, 13546 décès entre 1872 et 1907, dont 2052 en 1886, 1141 en 1903, 1894 en 1907 ! Voir Darmon, op. cit., note 3, p. 366 et suiv.

276 Voir R. Rumilly, Histoire de Montréal, Montréal, 1972, vol. 4, chap. 12, « L'Affaire Riel et la « picotte » », p. 163-185.

277 Voir plus loin dans le texte. 
même des cas graves ou mortels de variole ${ }^{278}$. En effet, quand le vaccin avait été prélevé sur un sujet vacciné, mais qui était atteint auparavant d'une de ces maladies, la vaccination contaminait alors ceux sur qui elle était pratiquée. Comme dans d'autres pays, on préférait alors recourir pour se prémunir contre la variole à des pratiques traditionnelles comme celle consistant à faire contracter aux enfants une forme bénigne de la maladie, afin qu'ils soient immunisés par la suite.

Les milieux populaires anglophones semblent s'être pliés plus aisément à la politique sanitaire contraignante de la municipalité parce qu'ils étaient plus directement soumis aux élites anglophones qui militaient pour la vaccination. En effet, la campagne pour imposer la vaccination obligatoire a été menée à partir de 1885 par un lobby anglophone militant comprenant des industriels et des grands négociants dont les intérêts étaient menacés par la propagation de cette épidémie. (L'Ontario, d'autres provinces et les états américains voisins ne voulaient plus laisser pénétrer des marchandises en provenance de Montréal qui pouvaient être contaminées par des ouvriers non vaccinés). Ces derniers, en liaison avec le comité de vaccination de la ville, s'étaient constitués en ligues qui forçaient leurs ouvriers et leurs employés à se faire vacciner. En 1885, ces ligues auraient obligé ainsi 21000 personnes à se faire vacciner ${ }^{279}$.

Cette campagne pour imposer les mesures anti-contagion et la vaccination par la force s'est faite avec des accents anti-francophones qui ne pouvaient que

278 Sur les accidents qui survenaient lors de la vaccination au 19e siècle, voir Dixon, op. cit., note 3, p. 141-159 et Darmon, op. cit., note 3, p. 226 et suiv. Sur les accidents survenus après la vaccination à Montréal lors de l'épidémie de 1885 et la frayeur que cela provoqua, cf. note 72, p. 26.

279 Cf. «État sanitaire de la ville de Montréal pour l'année 1885 », vol. 4, 1886, p. 37, Archives municipales. Voir aussi Rumilly, op. cit., note 85, p. 175. La campagne pour la vaccination obligatoire était orchestrée par la presse anglophone, notamment par Richard White, éditeur-propriétaire de la Gazette et par Hugh Graham, éditeur-propriétaire du Star, dans un esprit anticanadien-français. Les deux journalistes conduisirent des délégations à l'Hôtel de ville. Le Conseil de ville mit Hugh Graham à la tête d'un comité d'isolement et R. White à la tête d'un comité de vaccination. Voir Rumilly, ibid. La vaccination obligatoire imposée par les employeurs a provoqué la résistance des employés. Certains allèrent jusqu'à se mettre en grève ou à quitter leur emploi plutôt que d'obtempérer. Voir là-dessus Witness, 5 septembre 1885 et Star, 30 septembre. 
provoquer des réactions hostiles chez de nombreux Canadiens français. Par ailleurs, les agents de la police sanitaire qui étaient chargés de faire appliquer des mesures de quarantaine ou d'isolement dans les quartiers francophones, étaient souvent étrangers à la population et agissaient avec brutalité et hostilité à l'égard des réfractaires 280 .

Dans différents pays, on a vu, au moment des grandes épidémies, une exacerbation des tensions entre les classes sociales. À l'époque du choléra de 1832, par exemple, cette haine de classe s'est manifestée dans différents pays d'Europe par des soupçons et des accusations de part et d'autre: les classes dominantes rendant les classes laborieuses responsables du fléau en raison de leurs conditions de vie insalubres et immorales et les classes populaires soupçonnant les classes privilégiées d'un complot pour les empoisonner et les décimer 281.

Il est donc d'autant plus compréhensible que, à Montréal, les milieux populaires aient réagi par des attitudes de méfiance ou de résistance à des mesures sanitaires contraignantes imposées par des milieux perçus comme hostiles non seulement en tant que classes dominantes, mais encore en tant qu'étrangers oppresseurs.

Il faut souligner néanmoins le fait que si la vaccination n'était pas encore généralisée à Montréal, cela était moins en raison de l'opposition rencontrée dans

280 Voir plus loin dans le texte «I'Affaire Gagnon ». Voir aussi Rumilly, op. cit., p. 179. Le Herald attribua l'épidémie à la malpropreté de la population canadienne-française. La presse anglaise, exaspérée par l'affaire Riel, faisait feu de tout bois. Cet article suscita une vive réaction; des manifestants brisèrent les vitres du Heraid. Voir Rumilly, op. cit., p. 174.

281 Voir René Baehrel. « La haine de classe en temps d'épidémie », Annales, Économies, Sociétés, Civilisations, no 3 (juillet-septembre 1952), p. 351-360. Voir aussi J. Piquemal, «Le choléra de 1832 en France et la pensée médicale », Thalès, vol. 10 (1959), p. 28 : « on empoisonne les gens exprès ; c'est un complot des puissants. La chasse aux " empoisonneurs » commence à certains carrefours et manque de soulever, contre le gouvernement, une foule toujours convulsive, déçue par la Révolution de Juillet». Voir aussi L. Chevalier (éd.). Le choléra, la première épidémie du XIXe siècle. La Rochesur-Yon, 1958. Sur les résistances populaires à la vaccination à Paris au début du 19e siècle et sur le caractère non religieux de ces oppositions, voir L. Chevalier, Classes laborieuses et classes dangereuses, Paris, 1958. (Réédition : Librairie générale française, 1978, p. 533.) 
certains milieux, qu'en raison d'une organisation très insuffisante des services de santé municipaux. Y était pour quelque chose aussi la négligence des médecins à vacciner et la négligence des gens à se faire vacciner ou revacciner. On peut le constater une fois de plus dès le début de l'épidémie de 1885. Comme on le sait, l'origine de l'épidémie à l'Hôtel-Dieu et la décision ultérieure des autorités hospitalières ont eu pour effet de répandre la variole dans les quartiers francophones de la ville. Or, peu de temps après les premières manifestations de l'épidémie, les vaccinateurs publics ont vacciné, en quelques semaines, près de 3000 enfants dans «des institutions publiques et des quartiers pauvres de la cité 282 ». Cependant, en raison « de la qualité inférieure de la lymphe vaccinale, un nombre très considérable de vaccinés eurent aux bras des enflures d'un caractère érysipélateux [...] 283 ». Ainsi, « sur l'avis de quelques professeurs de médecine » et en raison "des grandes chaleurs » du commencement de l'été, le Comité d'hygiène de la ville suspendit la vaccination publique jusqu'au mois d'août ${ }^{284}$. On ne peut donc pas imputer à la population francophone une opposition à la vaccination lorsque la possibilité de se faire vacciner n'existe même pas. D'autant plus que lorsque, en raison des progrès de l'épidémie, quatre bureaux de vaccination furent finalement ouverts, ils «furent littéralement envahis par une foule de personnes » de sorte " qu'on fut obligé de créer treize autres bureaux dans les différentes parties de la ville [...] » et que ces bureaux « étaient soumis à un véritable siège pendant les heures réglementaires et la police fut même parfois requise d'y maintenir le bon ordre 285 ». L'empressement pour la vaccination était tel que l'on estime à peu près à 80000 les individus qu'on est parvenu à vacciner entre septembre et décembre 1885286.

282 Op. cit., note 88, p. 26. Plus tard, lors de la rentrée scolaire de septembre, les Commissions des écoles catholiques et protestantes exigèrent des élèves des certificats de vaccination avant de les admettre. N'en étaient exemptés que les enfants pauvres. Cf. Star, 14 septembre 1885.

283 Ibid., p. 26.

284 Ibid., p. 31.

285 Ibid., p. 31.

286 Ibid., p. 32. Le rapport note, cependant, que seulement 20000 de ces vaccinations étaient des premières vaccinations, "chiffre qui couvrirait à peine le total des naissances depuis trois ans ». Ibid., p. 30 et p. 92. Voir aussi Star, 14 septembre 1885. 
Toutefois, même la réouverture des bureaux de vaccination en août ne mit pas fin aux problèmes d'organisation logistique de la vaccination. Pour vacciner, il faut du vaccin, et, dès septembre, il était complètement épuisé ${ }^{287}$. Il fallut alors en importer de Boston. Mais cela ne fut pas sans entraîner d'autres complications. Un médecin écrit au Canada Médical Record que « vaccinating in hot weather with vaccine brought from a distance is a delusion and a snare. I will never do it again, for it has done the cause (it is a " cause » in this city) a great deal of harm $288 »$.

En effet, le vaccin importé était d'une qualité tellement inégale qu'il fallait en moyenne quatre inoculations avant d'être tout à fait sûr que la vaccination était vraiment efficace. Voici une autre difficulté : lorsqu'elle est pratiquée - et elle l'est tout de même sur une assez grande échelle -, les conditions techniques d'une vaccination efficace sont rarement réunies: on manque de vaccin ou bien le vaccin est mal conservé et donc inefficace ; des gens qui se croient immunisés, ne craignant pas de s'exposer à la maladie, la contractent et en contaminent d'autres. De même, on néglige de procéder à la revaccination.

Il faut noter aussi que si l'épidémie s'est répandue, ce n'est pas seulement en raison du fait que la vaccination était insuffisante et inadéquate, mais aussi en raison du fait que la population s'opposait, non pas tant à la vaccination en ellemême, qu'à ses modalités contraignantes ainsi qu'aux autres mesures prophylactiques qui allaient à l'encontre des moeurs, des habitudes et des traditions.

Plusieurs personnes étaient opposées, par exemple, au caractère obligatoire du programme de vaccination sans pour autant s'opposer à la vaccination en tant que telle. C'était le cas, par exemple, du professeur de jurisprudence médicale à l'Université McGill, G. Doutre, qui dénonçait comme abusive l'autorité accordée aux vaccinateurs publics et qui prescrivait l'autovaccination des citoyens ${ }^{289}$.

287 «Smallpox », Canada Médical and Surgical Journal, vol. 14, 1885, p. 125.

288 «Local and Regional », Canada Medical Record, vol. 13, 1885, p. 284285.

289 La Minerve, 1er octobre 1885. Des journaux comme La Minerve et Le Monde menaient une campagne contre la vaccination obligatoire et l'isolement des malades par contrainte. Voir Rumilly, op. cit., note 85, p. 178. 
D'autres doutaient de la capacité des vaccinateurs publics à contrôler la qualité du vaccin. Après la campagne désastreuse de vaccination menée dans différentes institutions (orphelinats, écoles, couvents, asiles) par les vaccinateurs publics en avril 1885, on peut comprendre que le docteur Poitevin se soit opposé à l'entrée des vaccinateurs à l'asile de Bethléem pour les orphelines puisqu'il y avait de bonnes raisons de soupçonner que le vaccin distribué par le Bureau de santé était de qualité douteuse 290 .

D'autres encore s'opposaient au caractère arbitraire des règlements d'hygiène et doutaient de la compétence des personnes autorisées à mettre en oeuvre des mesures prophylactiques autres que la vaccination, comme l'isolement, le déplacement des personnes contaminées, la déclaration de cas épidémiques, le déplacement des cadavres et les mesures sanitaires telles que la désinfection des maisons, le fait de brûler ou de détruire les objets, les vêtements, et les meubles ayant pu être contaminés ou pouvant servir de vecteur de contamination.

Ce dernier point nous fait comprendre que les émeutes des mois de septembre et octobre 1885 ne visaient pas uniquement la vaccination. Par exemple, l'opposition au transport à l'hôpital en vue de l'isolement était très répandue. Le cas le plus célèbre fut « l'affaire Gagnon ». En novembre 1885, la police de la santé voulut emmener à l'hôpital les enfants d'un ouvrier nommé Gagnon, soupçonnés d'avoir contracté la variole. Gagnon s'y opposa catégoriquement. Avec sa famille, il résista ensuite par les armes à deux tentatives d'arrestation. Le maire Beaugrand prit alors lui-même la direction des opérations. Des agents parvinrent à s'emparer de Gagnon et d'autres donnèrent l'assaut à la maison. Dans la bousculade qui s'ensuivit il y eut un échange de coups de feu et l'affaire provoqua une crise au niveau de la politique municipale. Un des enfants de Gagnon vint à mourir. La Minerve et Le Monde accusèrent le maire d'avoir provoqué ce décès par des brutalités inutiles et par une violation de domicile 291. D'ailleurs, ce n'était pas uniquement certains citoyens qui s'opposaient au transfert obligatoire des cas de variole à l'Hôpital civique. En effet, les éditeurs du Canada

290 Sur les accidents survenus lors de cette campagne de vaccination, voir la lettre du Dr E.A. Poitevin, dans La Patrie, 11 mai 1885.

291 La Patrie, 7 novembre 1885. Voir Rumilly, op. cit., note 85, p. 179. Sur les résistances au déplacement des varioleux à l'hôpital, voir op. cit., note 88, p. 41. 
Médical Record avaient fait rapport sur cet hôpital au mois de juin. Ayant constaté que l'institution était suroccupée, ils en venaient déjà à la conclusion suivante : "Seriously, we cannot conscientiously advise any one to go to the present Hospital $292 »$.

L'autre mesure qui suscitait les manifestations populaires les plus hostiles (et qui fut une des causes des émeutes de 1885) était le placardage des maisons, où s'était déclaré un (ou des) cas de variole, en vue de les isoler. Les autorités se heurtaient aussi à une vive résistance quand elles voulaient faire désinfecter ces habitations 293.

Il faut noter enfin que ces mesures pouvaient mettre dans le dénuement complet des personnes dont les conditions d'existence étaient déjà des plus précaires. Déplacer les gens de leur domicile, c'était les laisser sans rien ; les isoler, c'était souvent priver la famille d'un support essentiel.

Si l'épidémie a fait autant de ravages, c'est sans doute, en plus de sa virulence particulière, qu'elle a atteint une des populations les moins bien protégées sur le plan sanitaire en Amérique du Nord: les habitants vivaient dans des conditions socio-économiques très précaires et l'infrastructure sanitaire était tout à fait insuffisante dans les quartiers populaires (notamment francophones).

On a souvent affirmé qu'il a fallu la «leçon » de 1885 pour convaincre la population francophone des vertus de la vaccination et que la différence du taux de mortalité entre les anglophones - lesquels, cela est pris pour acquis, étaient vaccinés - et les francophones avait administré une preuve irréfutable de l'efficacité de la vaccination. Cependant, les contemporains ont tiré d'autres leçons de l'épidémie de 1885.

Pour les anti-vaccinateurs francophones et anglophones, l'épidémie a démontré la nocivité effective de la vaccination et, ceci, à une très grande échelle. Dans son feuillet imprimé et adressé à l'Assemblée provinciale en 1886, le docteur Ross utilisa l'épidémie comme experimentum crucis en s'appuyant sur les statistiques « officielles » : «I refer to the official report from the Civic Hospital :

292 «Smallpox », Canada Médical Record, 13, 1885, p. 235. Selon l'auteur, l'hôpital, bien trop petit, est un foyer de contagion!

293 Voir « État sanitaire de la ville de Montréal pour l'année 1885 », op. cit., note 88 , p. 36. 
of these seventy-three were vaccinated, 56 had one mark, 13 two marks and 4 three marks 294 ». Autrement dit, la vaccination, même répétée jusqu'à trois fois, n'avait pas pu protéger ces individus contre la variole. C'est à la suite de l'épidémie encore, que l'on vit se reformer la Ligue contre la vaccination obligatoire - qui avait fusionné en 1875 avec l'Association sanitaire de Montréal et que commença la publication de l'Anti-vaccinateur canadien-français.

La position de la municipalité sur cette épidémie fut exprimée par le «Comité du Conseil d'hygiène de la ville de Montréal qui avait été nommé pour s'enquérir sur l'origine de l'épidémie, le 9 novembre 1885 ». Dans leur rapport publié dans La Patrie le 20 janvier 1886 295, Lévesque et Graham tiraient la leçon suivante de l'épidémie : la vaccination, à elle seule, ne parviendra jamais à prévenir une épidémie de variole. Cette conclusion reposait avant tout sur lidentification des conditions dans lesquelles s'était déclarée l'épidémie. Notant qu'entre janvier et avril, il n'y avait eu aucun cas de variole signalé à Montréal ni dans ses faubourgs, ils affirmaient que "Quoi qu'il en soit de l'apathie ou même de la répugnance qu'une certaine partie de notre population pût ressentir à l'endroit de la vaccination [...] il n'en est pas moins vrai que la faute capitale a été de laisser pénétrer dans notre ville et dans une de nos grandes institutions de charité un cas étranger de variole 296 ». Ils recommandèrent donc qu'un hôpital de varioleux soit toujours ouvert et que les modalités de quarantaine et d'isolement soient strictement observées, surtout à l'égard des compagnies de transport et des municipalités environnantes, car « il ne servirait pas à grand-chose de soumettre notre population à une police sanitaire rigoureuse si on laisse subsister autour de nous plusieurs foyers de contagion sans restreinte aucune 297 ».

294 A.M. Ross, "Address to Members of the Provincial Assembly ", Bibliothèque Osier, Acc. 544 38/65/N/3/1. Ces statistiques et d'autres sont reprises dans A.M. Ross, Smallpox and Vaccination (Toronto, 1888), p. 2122.

295 « Rapport du Comité du Conseil d'Hygiène de la ville de Montréal nommé pour s'enquérir sur l'origine de l'épidémie, le 9 novembre 1885 », La Patrie, 20 janvier 1886.

296 Ibid. L'italique est de nous.

297 Ibid. La variole sévissait en effet dans plusieurs municipalités autour de Montréal. 
C'est seulement plus tard que l'on découvrit qu'un système de quarantaine et d'isolement n'était qu'un moyen partiellement efficace pour contrôler une épidémie. Restait à régler la question de la vaccination et les trois problèmes qu'elle posait. Il fallait d'abord être en mesure de se procurer du vaccin de qualité contrôlée. Les auteurs du rapport sur l'épidémie avaient déjà proposé qu'« aucun vaccin ne devrait être livré au commerce sans avoir reçu l'approbation d'une autorité régulièrement constituée [...] 298 ». À Québec, l'Institut vaccinogène de Ste-Foy ouvrit ses portes en 1887. Le docteur Gauvreau, qui en était le premier directeur, écrivit aux médecins de la Gazette médicale de Montréal que «Cet établissement a été fondé par le Gouvernement provincial dans le but de fournir à notre population un vaccin pur, et par le fait même, faire cesser cette antipathie qui existe, non contre la vaccination, mais contre l'emploi de vaccin provenant de l'étranger 299 ». Ce qui ne veut pas dire que le vaccin produit localement demeurait au-dessus de tout soupçon. En 1894, deux journaux rapportèrent deux décès survenus à la suite de la vaccination : on en rendit responsable à nouveau du « mauvais vaccin ». Mais, à la différence des années précédentes, on put trancher clairement la question : « The verdict of the jury of physicians at the inquest upon the body of the child [...] stated that the vaccine produced at the Quebec vaccine «farm » was perfect 300 ».

Deuxièmement, pour vacciner il fallait savoir qui l'on vaccinait. D'où la nécessité reconnue depuis longtemps pour le département d'hygiène de tenir un registre des naissances afin de pouvoir contrôler la vaccination des enfants. Et, de fait, un comité fut formé en avril 1886 pour formuler un projet de loi sur les statistiques vitales ${ }^{301}$. En 1891, on parvint enfin à instituer un registre central des naissances ${ }^{302}$, mais la compilation des statistiques vitales au niveau de la province ne débuta que deux années plus tard avec la «Loi concernant la

298 Ibid.

299 «Institut vaccinogène », Gazette médicale de Montréal, vol. 1, 1887, p. 164. L'italique est de nous.

300 «Vaccination and the Vaccine Supply », Montreal Medical Journal, vol. 23, 1894, p. 92.

301 The Gazette, 26 avril 1886.

302 « Report of the Sanitary State of the City of Montreal for the Year 1891 », Montreal Medical Journal, vol. 21, 1893, p. 720. 
compilation des statistiques relatives au mouvement de la population 303 ». Décrit comme un « complément indispensable » aux règlements d'hygiène par le Conseil d'hygiène de la province, il a fallu quatre projets de loi différents avant de satisfaire ceux qui voyaient dans ces projets « un acheminement vers l'enregistrement civil 304 ».

Mais établir et tenir un registre des naissances n'était qu'un début. Par le registre, on apprit justement que, en 1891, par exemple, le nombre total d'enfants non vaccinés à Montréal se chiffrait à près de 15000 305. Ces 15000 enfants non vaccinés nous permettent de comprendre les difficultés de mettre sur pied un programme de vaccination obligatoire et de régler tous les problèmes engendrés par un tel programme. Il faut savoir donc, enfin - et c'est le troisième problème -, qui va vacciner tous les enfants ; et c'est à ce propos que même le Comité du Conseil d'Hygiène s'en prenait aux vaccinateurs publics. Il écrivait à ce sujet : «Entre ceux qui regardent la vaccination comme une panacée et les antivaccinateurs à tous crins, il devrait y avoir place pour l'opinion de ceux qui ont foi dans les traditions que le temps a sanctionnées 306 ». Cette tradition veut que ce soit le médecin de famille, et non pas l'officier de santé, qui ait le contrôle de la vaccination. De toute évidence, les médecins de famille n'ont vacciné qu'à leur gré, à partir de 1891. A Montréal, dans les dernières années du 19e siècle, on était donc encore loin d'une vaccination antivariolique généralisée. C'est seulement après une nouvelle épidémie survenue au Québec en 1903 que le Conseil provincial d'hygiène rendit la vaccination obligatoire dans les municipalités, et donc aussi à Montréal ${ }^{307}$. Il est à noter cependant que la mortalité par variole

304 «Rapport du Conseil de la Province de Québec», Documents de la Session, 1894-1895, 59 Victoria, no 6, p. 16-17. Voir aussi P. Parrot, " History of Civil Registration in Quebec », Canadian Public Health Journal, vol. 21, 1930, p. 529-540 ainsi que P. Parrot, «La division de la démographie », Bulletin sanitaire, no 48, 1948, p. 43-68.

Op. cit., note 111, p. 719.

306 Op. cit., note 104.

307 Voir T. Copp, Classe ouvrière et pauvreté, Montréal, 1978 (1974), p. 100 ; P.A. Linteau et al., Histoire du Québec contemporain, Montréal, 1979, vol. 1, p. 36 ; M. Farley, O. Keel et C. Limoges, op. cit., note 4, vol. 21, p. 96 . Il y a eu, cependant, encore des irruptions de variole et certaines résistances à la vaccination à Montréal dans les premières décennies du siècle. Voir A.D. 
était déjà devenue minime à Montréal dès 1887, soit bien avant la vaccination obligatoire et que cela était probablement dû aux initiatives du Conseil d'hygiène de la ville dans les domaines de la quarantaine et de l'isolement, (en plus de la vaccination d'une partie de la population) ${ }^{308}$.

\section{CONCLUSION}

Dans cette étude, nous avons voulu reconstituer le contexte scientifique, administratif et socio-politique dans lequel la vaccination a été progressivement implantée à Montréal dans la seconde moitié du 19e siècle. Cette reconstitution permet, croyons-nous, de mieux comprendre les différents types d'obstacles et de résistances que la mise en place de cette pratique a rencontrés.

Nous avons décrit tout d'abord les étapes successives de l'implantation de la vaccination et montré comment elles s'inscrivaient dans le cadre de différents programmes de santé publique mis en place par les autorités politiques municipales, provinciales, coloniales et fédérales. La vaccination nous est ainsi apparue comme étant un des fers de lance des débuts d'une politique étatique de médicalisation de la société.

Nous avons établi, par ailleurs, qu'il ne suffisait pas que la vaccination soit reconnue et acceptée par les médecins et la population comme un moyen certain et inoffensif de protection contre la variole pour qu'un programme de vaccination publique fût en mesure de fonctionner effectivement.

Nous avons vu en effet que la mise en œuvre d'un programme de vaccination supposait la réalisation simultanée d'un ensemble de conditions : la production et la distribution d'un vaccin dont la qualité fut garantie, la constitution et la reconnaissance d'un corps de vaccinateurs publics, la normalisation de la théorie et de la pratique de la vaccination (l'adhésion à la pratique de la revaccination) et

Groulx, «Elimination of Smallpox in Montreal by vaccination », Canadian Public Health Journal, vol. XXI, no 1 (janvier 1940), p. 6 et suiv.

308 Voir Farley et al., ibid. et M. Tétreault, L'état de santé des Montréalais de 1880 à 1914, (M.A.) Université de Montréal, 1979. 
la mise sur pied par les autorités d'un système de compilation des statistiques médicales (en particulier, pour ce qui était de la variole).

De plus, pour pouvoir contrôler et, si possible, enrayer les épidémies de variole par la vaccination, il fallait coordonner cette pratique avec d'autres mesures et institutions de santé publique comme les hôpitaux pour les maladies contagieuses, les politiques d'isolement et de décontamination des lieux et le contrôle, sur le plan sanitaire, de la circulation des biens et des personnes.

Pour ce qui est des résistances à la vaccination, nous avons montré qu'elles se manifestaient plutôt à l'égard des modalités autoritaires, intempestives et répressives de la mise en pratique de la vaccination (et dans certaines circonstances socio-politiques particulières) qu'à l'égard de la vaccination en tant que telle. Ainsi, nous avons montré que les médecins, même favorables à la vaccination, voyaient souvent l'existence des vaccinateurs publics ainsi que les politiques d'isolement et de déclaration obligatoire des cas de variole ou d'autres maladies contagieuses comme autant d'atteintes à la liberté de l'exercice de leur profession libérale et au contrôle de leur clientèle. Une partie du corps médical offrait donc une résistance à ces mesures et, notamment, au fait d'empiéter sur les droits de leurs clients en leur imposant des vaccinateurs publics ${ }^{309}$. À ce niveau, un certain nombre de médecins de Montréal avaient une attitude semblable à celle de certains confrères étrangers qui, favorables à la vaccination, refusaient par contre d'en faire une obligation sur le plan juridique ${ }^{310}$.

De la même manière, nous avons vu que les résistances populaires à la vaccination portaient le plus fréquemment sur ce qui apparaissait comme contrainte arbitraire et comme risque ou danger (vu l'expérience des maladies ou décès survenus après la vaccination) dans le système de vaccination publique. Par ailleurs, ces résistances s'expliquent par le refus global d'un ensemble de mesures sanitaires contraignantes qui étaient vécues comme des ingérences abusives des autorités dans la vie des citoyens.

Comme nous l'avons indiqué, les grandes épidémies ont généralement pour effet de faire apparaître, en les accentuant, les tensions sociales et ethniques qui existent dans un milieu donné. À Montréal, les oppositions de classe se doublaient

310 Voir sur ce point Darmon, op. cit., note 3, p. 382 et suiv. 
de tensions ethniques et politico-culturelles entre francophones et anglophones. Les mesures sanitaires contraignantes étaient perçues par les milieux populaires comme un instrument de domination et de répression de la classe dominante anglophone. Puisque les industriels ou patrons anglophones obligeaient leurs ouvriers francophones à se faire vacciner, on ne pouvait considérer dans ces milieux que comme répressives des initiatives analogues venant des autorités sanitaires.

La population qui avait déjà une certaine prévention contre la vaccination à cause des accidents survenus ne pouvait donc qu'être méfiante quand on voulait lui imposer par la force une telle opération, dans des conditions souvent hasardeuses (vaccin dont la qualité ne semblait pas éprouvée ou qui avait déjà donné lieu à des accidents ; décision de vacciner des enfants déjà malades qui l'auraient mal supporté ou de vacciner par les grandes chaleurs, ce qui provoquait souvent des réactions assez graves, etc.).

Comme il n'y avait pas encore unanimité sur la nécessité de la revaccination et que l'on utilisait souvent du vaccin dégénéré, la population était témoin de cas de variole, parfois mortels, après vaccination. On pouvait donc croire que la maladie était imputable à la vaccination elle-même, ce qui non seulement enlevait toute crédibilité à l'opération, mais qui la faisait même apparaître dangereuse. D'autant plus que du vaccin prélevé chez des sujets atteints d'une maladie grave (comme la syphilis) transmettait celle-ci aux nouveaux vaccinés. Tout ceci ne pouvait que renforcer la méfiance de la population et conduire certains à penser que leurs ennemis, en propageant le poison vaccina] «anglais », menaient « une guerre contre les Canadiens Français 311 » et que cette guerre venait « des Anglais qui veulent nous tyranniser 312 ».

311 Voir L'Anti-vaccinateur canadien-français (1885), vol. 1, no 1, p. 2.

312 Ibid. L'Anti-vaccinateur canadien-français publie un extrait d'une lettre ouverte que lui a adressée dans ses colonnes le journal L'Ami du peuple de Charleroi, Belgique, où il est écrit : «L'opposition contre l'abominable loi de la vaccine obligatoire a pris chez vous des proportions héroïques. Si vos tyrans anglais persistent à inoculer la syphilis vaccinale aux sujets de tous âges, chassez-les du Canada; il ne faut pas tolérer que vos maîtres vous empoisonnent et vous tuent pour satisfaire les exigences d'une poignée de charlatans à leur solde ». Ibid., p. 17. 
De tels sentiments de méfiance et d'hostilité par rapport à la vaccination ne pouvaient qu'être exaspérés par les accents anti-francophones de la campagne en faveur de la vaccination des milieux patronaux et de la presse anglophones. À ce moment, les tensions entre francophones et anglophones étaient déjà portées au plus haut degré par l'affaire Riel. Les interventions de la police sanitaire ne pouvaient donc qu'attiser encore la tension existante et faire rejeter par la population des mesures contraignantes dont l'exécution était souvent confiée à des agents étrangers agissant avec brutalité.

D'une façon générale, nous pensons avoir montré que l'existence à Montréal d'un mouvement de résistance à la vaccination (et plus globalement à certains aspects contraignants de la médicalisation de la société) ne saurait être considérée comme expression typique de la mentalité soi-disant particulièrement arriérée et/ou empreinte de cléricalisme 313 de la population canadienne-française. En

313 Pour ce qui est de la position du clergé, il se trouve que les autorités ecclésiastiques, contrairement à ce que l'on pourrait croire en lisant des auteurs comme White, sont intervenues pour appuyer les politiques de vaccination et de contrôle sanitaire. Les dignitaires de l'Église se sont même engagés directement dans la campagne pour la vaccination lors des épidémies en faisant lire au prône des circulaires du bureau de santé recommandant cette mesure. Lors de l'épidémie de 1885, Mgr Fabre engagea ainsi les fidèles à se faire vacciner et il se fit même vacciner deux fois pour donner l'exemple. D'autres membres du clergé agirent de même. Voir Rumilly, op. cit., note 85, p. 176. Certains curés communiquèrent, après l'épidémie de 1885, au bureau de santé des statistiques prouvant l'efficacité indiscutable de la vaccination dans leurs paroisses. Voir op. cit., note 88, p. 34. Le maire Hingston avait reçu l'appui constant de Mgr Bourget pour sa politique sanitaire et de vaccination. L'intervention du clergé en faveur de la vaccination et des mesures sanitaires lors de l'épidémie de 1885 avait été notée par J.J. Heagherty, op. cit., note 1, vol. 1, p. 91 : « The clergy did everything in their power to induce their flocks to obey the orders of the authorities ». Ceci a été souligné aussi par K. Jenkins, op. cit., note 4, p. 419 : « Once it became obligatory, the measure (la vaccination) took on tyrannical attributes in their eyes (...) And since not all the wisdom of the curés could convince them otherwise, they resisted with violence, an attempt to placard an infected home ». Les italiques sont de nous. Dès la première législation (1815) pour encourager et diffuser la pratique de la vaccination, l'évêque catholique romain, appuyant les autorités civiles et militaires, s'était adressé au clergé rural pour l'exhorter à soutenir ces mesures et à dissiper « ... les préjugés que le vulgaire pourrait y opposer ». Cité par B. Tunis, op. cit., note 6, p. 267. La position officielle du clergé a donc été favorable à la vaccination, même si certains de ses membres, au niveau local, 
effet, comme on l'a vu, des mouvements contre la vaccination et contre la médicalisation ont existé dans la plupart des pays occidentaux au 19e siècle. Or, ces différents pays se distinguaient par des traits socioculturels et socio-religieux très différents de ceux de la société canadienne-française. Il est à noter d'ailleurs que ces mouvements contre la vaccination et la médicalisation ont pris en général dans ces pays une ampleur beaucoup plus grande qu'à Montréal (notamment en Angleterre !) et qu'ils ont duré plus longtemps 314.

De même, le fait que certains médecins se soient engagés dans une campagne contre la vaccination n'est guère un phénomène propre au Québec et à la constellation socio-culturelle qui le caractérise à l'époque. En effet, là encore, il a existé dans plusieurs pays très différents des groupes de médecins qui étaient très réservés sur la vaccination ou qui lui étaient même carrément hostiles ${ }^{315}$. Leur activisme et leur influence a le plus souvent surpassé de loin ceux des médecins anti-vaccinateurs montréalais qui, vers 1876, étaient déjà assez marginaux dans la communauté médicale et qui, dix ans plus tard, n'étaient plus qu'une poignée d'individus ostracisés par leurs confrères. En tous les cas, il ne paraît pas pertinent dans ces conditions d'expliquer l'existence d'un mouvement d'anti-vaccination chez les médecins de Montréal par un prétendu retard scientifique de la communauté médicale francophone ou par son obédience à des valeurs passéistes.

Ceci vaut aussi bien pour d'autres membres des élites montréalaises (où l'on trouve d'ailleurs aussi des anglophones) qui, à côté de certains médecins, militaient contre la vaccination obligatoire. Le Québec n'est pas non plus un cas particulier à cet égard. En effet, de nombreux représentants des élites, et non des moindres, se sont engagés dans plusieurs pays dans la lutte contre la vaccination. Tout comme le Dr Ross, une des figures de proue du mouvement contre la

avaient à cet égard une attitude différente. En Europe, le clergé catholique a été le plus souvent en faveur de la vaccination. En Angleterre, un certain nombre de «clergymen » étaient actifs dans le mouvement contre la vaccination. Voir sur ce point les références des notes 3 et 9 . Sur l'attitude de l'Église en Europe et la vaccination dans les États pontificaux, voir Y.M. Bercé, op. cit., note 3, p. 91 et suiv.

314 Voir les références des notes 3 et 9, et Darmon, op. cit., p. 169 et suiv. et p. 340-381.

315 Voir les références des notes 3 et 9, et Darmon, ibid. Voir aussi sur les médecins ami-vaccinateurs étrangers, L'Anti-vaccinateur canadien-français, vol. 1, no 1 (1885). 
vaccination à Montréal, ces anti-vaccinateurs étrangers, loin d'appartenir à des milieux cléricaux ou conservateurs, étaient au contraire des esprits éclairés et libéraux, voire des socialistes, et des partisans du progrès scientifique et social ${ }^{316}$.

En conclusion, il nous semble qu'en considérant la vaccination comme un élément parmi d'autres d'un programme de médicalisation de la société québécoise de la deuxième moitié du 19e siècle, il devient possible d'interpréter

316 Sur les membres des élites scientifiques ou professionnelles qui étaient engagés dans les mouvements contre la vaccination dans différents pays, voir les références des notes 3 et 9. Le docteur Ross, natif de Belleville, en Ontario, était un philanthrope socialisant et un réformiste militant. Il était l'ami personnel du général Garibaldi, dont il soutint indéfectiblement la cause. Lors de son séjour aux États-Unis, il s'engagea très activement dans la lutte contre l'esclavage, aux côtés des abolitionnistes radicaux. Il s'engagea par la suite comme chirurgien dans l'armée de la République mexicaine du président Juarez qui luttait contre l'empereur Maximilien. L'article de la Cyclopedia of Canadian Biography (voir note 77) le décrit ainsi : " For several years past, Dr. Ross has laboured with his characteristic zeal and energy in behalf of moral and physical reform. He is always on the side of the poor and the oppressed, no matter how unpopular the cause may be (...). During the smallpox epidemic in Montreal (1885), Dr. Ross was a prominent opponent of vaccination, (...). In place of vaccination he strongly advocates the strict enforcement of sanitation and isolation. He maintains that personal and municipal cleanliness is the only scientific safeguard against zymotic diseases ». Comme d'autres anti-vaccinateurs, Ross considérait qu'il menait un combat scientifique contre une forme de "despotisme » obscurantiste de l'« establishment » de la profession médicale. À ses yeux, cet « establishment» défendait la vaccination parce que c'était une pratique lucrative pour les médecins, qui conférait, par ailleurs, une autorité politique à la profession et qui semblait permettre de faire l'économie de réformes sociosanitaires auxquelles l'oligarchie médicale n'était pas favorable. Voir A.M. Ross, Smallpox and Vaccination, Toronto, 1888. Ross écrit : « What avails it that we have rid ourselves of ecclesiastical despotism if we are to be handed over, bound hand and foot, to the tender mercies of a place-hunting, dollar worshipping, medical priesthood », p. 19. Ross s'attaque dans ce pamphlet à l'Acte de la vaccination obligatoire en Ontario. Il est ànoter que vers la même époque, des médecins influents admirent publiquement en Angleterre, que la position des anti-vaccinateurs avait une base scientifique sérieuse. Ils montrèrent qu'il y avait des dangers à vacciner de très jeunes enfants, même dans des conditions parfaites et que le vaccin pouvait produire des érysipèles post-vaccinatoires. Voir R.M. MacLeod, op. cit., note 9, p. 198. 
les événements qui ont entouré l'épidémie de 1885 comme un révélateur des obstacles à la fois scientifiques, techniques, socioculturels et politiques à la mise sur pied d'un système de santé publique, au lieu d'y voir, comme le fait une certaine historiographie, l'expression de l'ignorance des «masses» face à la science et à l'innovation 317.

317 Rumilly, par exemple, écrit : «La masse, en tous temps et en tous pays, est routinière et s'oppose à la nouveauté, qu'elle soit d'ordre mécanique, artistique ou médical. Les Montréalais se sont soulevés contre la vaccination comme les Français ont coulé les premiers bateaux sur le Rhône, détruit les premiers appareils de télégraphie ». R. Rumilly, Histoire de la Province de Québec, Montréal, 1941, vol. 5, p. 83. Voir aussi K. Jenkins, op. cit., note 4, p. 419 : « Many of the ignorant among the French Canadians seemed indifferent to the danger. They opposed isolation and refused vaccination, out of a superstitious dread of the operation ». 
Sciences et médecine au Québec.

Perspectives sociohistoriques

\title{
Chapitre V
}

\section{Origines géographiques et lieux de pratique des diplômés en médecine au Québec de 1834 à 1939 *}

\author{
par George Weisz \\ Professeur, Humanities and Social Studies of Medicine, \\ McGill University
}

$\underline{\text { Retour à la table des matières }}$

Afin d'assurer sa pérennité, toute institution doit se tailler un bassin de clientèle (ou un marché de diplômés) stable, c'est-à-dire un cadre social et géographique d'où proviendront les étudiants voulant obtenir un diplôme et où ils pourront éventuellement retourner. Le nombre d'étudiants, leurs origines sociales et géographiques, leur formation scolaire et l'évolution possible de leurs carrières auront une influence prépondérante sur le type d'enseignement dispensé par l'institution, sur ses ressources ainsi que sur sa réputation et son rôle dans la société.

* La version anglaise de cet article est parue dans Histoire Sociale /Social History, vol. 19, mai 1986. Le texte a été traduit par M. Jean Beauchesne. Cette recherche a été subventionnée par le Fonds FCAR. Je tiens à remercier Fiona Colgan, Phil Teigen et Peter Keating pour leur aide. Je remercie également Brian Young, Robert Sweeny, Sherry Olson et Yvan Lamonde, qui ont lu et commenté une version préliminaire de ce texte. 
Tout au long de cet essai, nous procéderons à l'analyse des bassins de clientèle établis aux XIXe et XXe siècles par les Facultés et les écoles de médecine québécoises. Cette analyse portera surtout sur les aspects quantitatif et géographique des données disponibles. Le lecteur ne doit toutefois pas interpréter cette insistance sur l'aspect géographique comme s'il s'agissait du seul facteur explicatif, tant du point de vue historique qu'épistémologique. Il ne s'agit là manifestement que d'un fil conducteur dans l'histoire complexe de l'enseignement de la médecine qui déborde largement le cadre de la présente analyse ${ }^{318}$. Et s'il n'est nullement question de couvrir l'ensemble du sujet, il n'en demeure pas moins que cet aspect géographique ouvre toute une série de nouvelles perspectives qui ne sont généralement pas abordées par les historiens des institutions d'enseignement.

Bien que la majeure partie de cet essai consiste en une compilation des résultats d'une vaste enquête à caractère empirique ${ }^{319}$, certains des résultats obtenus et des anomalies constatées permettent d'avancer des interprétations et des hypothèses plus spéculatives qui, à ce stade, visent essentiellement à stimuler les recherches futures. La notion même de «bassin de clientèle » est

318 Les origines sociales des étudiants constituent sans aucun doute un fil conducteur beaucoup plus révélateur. Malheureusement, les écoles de médecine semblent ne s'être aucunement intéressées aux origines familiales de leurs étudiants. Par conséquent, j'ai préféré me consacrer à la tâche consistant à retracer les origines sociales d'une population à la fois plus restreinte et mieux documentée, les professeurs de médecine. Un bref exposé des résultats préliminaires de cette étude a été fait par Jacques Ferland, en octobre 1984, lors du congrès annuel de la Société d'histoire de l'Amérique française, son exposé s'intitulait «Biographie collective des professeurs des Facultés de médecine au Québec, de 1840 à 1930 ».

319 Pour cette étude, on a surtout consulté les annuaires publiés annuellement par les établissements examinés qui tous dressaient la liste de leurs étudiants et des origines géographiques de ces derniers. La comparaison de ces annuaires avec les registres manuscrits de McGill révèle qu'ils sont relativement exacts ; les petits écarts constatés pour n'importe quelle année disparaissent lorsqu'on calcule la moyenne mobile de trois ans. Les lieux de pratique des diplômés ont été déterminés à partir des listes d'anciens élèves publiées par McGill et Bishop, ainsi que des registres du Collège des médecins et chirurgiens pour les établissements francophones. Les limites de cette dernière source de renseignements sont exposées plus loin dans la section « Mobilité des diplômés ». 
probablement la plus importante à cet égard. En ayant recours à cette notion, nous voulons d'abord suggérer que le recrutement scolaire comporte un ensemble de constantes qui ne peuvent pas s'expliquer uniquement par des décisions individuelles; ensuite que l'enseignement de la médecine constitue en quelque sorte un produit offert par les établissements d'enseignement aux consommateurs. Le marché des diplômés est partiellement influencé par un deuxième marché plus éloigné de la sphère d'activité des établissements d'enseignement, à savoir celui des services médicaux ou, plus précisément, le recours aux services médicaux par la population d'une région précise, ce qui détermine la valeur du diplôme de médecine.

Bien qu'il ait existé des différences importantes entre les secteurs francophone et anglophone considérés dans leur ensemble, il nous est possible d'avancer que l'essentiel des différences existant entre les diverses écoles de médecine résulte, au moins partiellement, des variables démographiques auxquelles tous ces établissements ont dû continuellement s'adapter. À certains égards et surtout en fonction du nombre considérable d'étudiants ne provenant pas du Québec, l'Université McGill a toujours constitué un cas unique parmi les écoles de médecine du Québec et du Canada. Cette singularité nous a incité à approfondir notre examen du cas de McGill. À d'autres égards, l'Université Laval offre cependant à l'analyse une singularité tout aussi intéressante dans la mesure où elle avait conservé une clientèle essentiellement rurale. Bien que les diverses caractéristiques scolaires et scientifiques de chacun de ces établissements ne puissent être expliquées uniquement par la nature de leur clientèle, cette variable a néanmoins joué un rôle déterminant quant à certaines facettes de l'organisation de ces universités, comme nous tenterons de le démontrer. 


\section{HISTORIQUE DES ÉTABLISSEMENTS D'ENSEIGNEMENT}

Avant 1850, la majorité des médecins pratiquant au Québec avaient reçu leur formation à titre d'apprentis. De 1842 à 1847, des 187 médecins auxquels on accorda le droit de pratique dans l'Est du Canada, cinquante-deux avaient obtenu un diplôme officiel de médecine alors que trente-sept autres avaient étudié au moins un certain temps dans une école de médecine. De ces cinquante-deux diplômés, vingt-quatre seulement avaient reçu leur diplôme d'un établissement québécois (McGill), alors que les autres l'obtinrent aux États-Unis ou en Europe ${ }^{320}$. Avec la mise sur pied d'un réseau dynamique d'écoles de médecine dans les années 1840, ce profil commença à se modifier. Dès les années 1880, près de 90\% des médecins autorisés à pratiquer au Québec avaient reçu leur formation dans une école de médecine québécoise 321.

Six écoles de médecine ont existé à une époque ou une autre dans cette province ${ }^{322}$. L'une d'entre elles, la St. Lawrence Médical School de Montréal, a connu une existence éphémère, disparaissant peu après sa formation en 1857.

320 Ces chiffres proviennent d'un exposé préparé et présenté par Barbara Tunis en 1983 lors du Séminaire inter-universitaire sur l'histoire de la médecine au Québec.

321 Voir le graphique 5. Voir aussi J. Bernier, «Les praticiens de la santé au Québec, 1871-1921; quelques données statistiques », Recherches sociographiques, vol. 20, 1979, p. 41-58.

322 Sur l'histoire générale de chacun de ces établissements, voir C.-H. Boissonnault, Histoire de la Faculté de Médecine de Laval, Québec, 1953 ; L.-D. Mignault, "Histoire de l'École de Médecine et de Chirurgie de Montréal », L'Union médicale du Canada, vol. 55, 1926 ; M. Abbott, "The Faculty of Medicine of McGill University », dans Surgery, Gynecology and Obstetrics, vol. 660, 1935, p. 242-253 ; S. B. Frost, McGill University : For the Advancement of Learning, vol. 1, 1801-1895, Montreal, McGill-Queen's University Press, 1980 ; vol. 2, 1895-1971, 1984 ; E.H. Bensley, « Bishop's Medical College », The Canadian Medical Association Journal, vol. 72, 1955, p. 463-465 ; A. Lavallée, Québec contre Montréal : la querelle universitaire 1876-1891, Montréal, Presses de l'Université de Montréal, 1974, ainsi que les chapitres pertinents de l'ouvrage de J.J. Heagerty, Four Centuries of Médical History in Canada, Toronto, McMillan, 1928. 
Nous l'exclurons donc de notre étude. La Montreal Medical Institution, créée en 1823 en tant que constituante de l'Hôpital général de Montréal (fondé en 1819), est la plus ancienne de ces écoles. Elle devint en 1829 la Faculté de médecine de l'Université McGill décernant son premier diplôme en 1833. À Québec, une école de médecine fut établie à partir de cours dispensés par l'Hôpital de la marine et fut constituée en corporation en 1847. En vertu des dispositions de la Loi de 1847 sur les soins médicaux, cette corporation ne pouvait délivrer de diplômes, puisqu'elle n'était affiliée à aucune université reconnue. Cette situation fut régularisée en 1852, lorsqu'elle devint la Faculté de médecine de l'Université Laval.

Des médecins francophones et anglophones fondèrent en 1843 l'École de médecine et de chirurgie (EMC), la deuxième école de médecine de Montréal. Quelques années plus tard, les médecins anglophones quittèrent cette école pour se joindre au corps professoral de McGill transformant ainsi l'EMC en établissement essentiellement francophone. Sans affiliation à une université reconnue, les diplômés de cette école, contrairement à ceux des Universités McGill et Laval, n'avaient pas le droit de pratiquer au Québec et devaient se présenter à l'examen provincial pour obtenir le droit d'exercer leur profession. Ce n'est qu'en 1867, à la suite de l'affiliation de l'EMC à l'Université Victoria de Cobourg (Ontario), que le diplôme de l'EMC fut reconnu au même titre que ceux des écoles de médecine universitaires.

Au cours des années 1870, deux autres écoles de médecine virent le jour à Montréal. En 1871, un groupe de médecins anglophones fondèrent une école de médecine affiliée au Collège Bishop de Lennoxville. Le nombre d'inscriptions n'ayant jamais été élevé, cette école disparut en 1905 lorsqu'elle fut absorbée par l'Université McGill. En 1877, à la suite d'une tentative infructueuse visant l'intégration de l'EMC àl'Université Laval, la hiérarchie de l'Église catholique opta pour l'établissement à Montréal d'une succursale de la Faculté de médecine de l'Université Laval, dont le corps enseignant se composait majoritairement de professeurs ayant quitté l'EMC. La succursale de l'Université Laval à Montréal et l'EMC se firent donc concurrence pendant treize ans avant de fusionner sous le nom d'EMC en 1890 pour devenir, en 1919, la Faculté de médecine de l'Université de Montréal. Pour les besoins de l'analyse en cours, nous continuerons d'utiliser l'abréviation EMC, même pour la période postérieure à 1919, pour désigner cette Faculté. 
Il est important de souligner que les écoles de médecine ne jouissaient pas d'une autonomie complète quant à l'admission des étudiants. La Loi sur les soins médicaux de 1876 accordait au Collège des médecins et chirurgiens (fondé en 1847) des pouvoirs considérables en matière d'enseignement de la médecine, $\mathrm{y}$ compris le droit de soumettre à un examen les futurs étudiants en médecine. Bien que la Loi Hall de 1890 ait exempté les bacheliers ès arts, en médecine et ès sciences de cet examen, il fut néanmoins requis de tous les autres candidats souhaitant étudier la médecine. Jacques Bernier 323 a récemment soutenu que le Collège des médecins et chirurgiens a pu, de fait, imposer au cours des dernières décennies du XIXe siècle certaines normes relatives à l'enseignement de la médecine et à l'admission des étudiants en médecine. Si l'on peut partager presque sans réserve cette opinion, il faut reconnaître néanmoins que ces normes scolaires laissaient tout de même place à des différences appréciables entre les diverses écoles et Facultés, le recrutement de leur clientèle ne constituant pas la moindre de ces différences.

\section{LES DIPLÔMÉS EN MÉDECINE DES SECTEURS ANGLOPHONE ET FRANCOPHONE}

Le graphique 1 montre le nombre de diplômés en médecine au Québec de 1830 à 1940. On peut y constater une augmentation constante en chiffres absolus durant tout le XIXe siècle. À l'instar d'autres pays, le nombre de diplômés en médecine, tout comme celui de l'ensemble des étudiants inscrits aux études supérieures, augmenta considérablement à la fin des années 1890. Le nombre commença à diminuer avant 1914 en raison de la réforme de l'enseignement de la médecine amorcée en 1909 par le Collège des médecins et chirurgiens ; cette réforme prolongeait le programme d'études en médecine d'une année, le faisant passer de quatre à cinq ans ${ }^{324}$. Puis la Première Guerre mondiale entraîna une

323 J. Bernier, « La standardisation des études médicales et la consolidation de la profession dans la deuxième moitié du XIXe siècle », Revue d'histoire de l'Amérique française, vol. 37, 1983, p. 51-65.

324 En France une réforme similaire apportée à la même époque à l'enseignement de la médecine a également réduit le nombre de diplômés en médecine. 
diminution encore plus marquée. Après 1918, le nombre de diplômés a peu à peu retrouvé, puis dépassé son rythme de croissance d'avant-guerre. Il y eut une nouvelle baisse au milieu des années 1920 causée par des conditions d'admission plus strictes, avant que ne se stabilise le nombre d'inscriptions. Malgré ces fluctuations annuelles importantes du nombre de diplômés, la tendance générale à la croissance est plutôt étonnante. Cette situation contraste avec la tendance observée en Europe où toute période de croissance rapide alterne avec une période de stagnation et même de diminution, résultant de mesures adoptées par l'administration scolaire ou du désintéressement provisoire des étudiants à l'égard d'une profession en apparence saturée ${ }^{325}$. (Il n'y a qu'en 1909, puis d'une façon beaucoup moins marquée au milieu des années 1920, que de telles mesures restrictives et efficaces semblent avoir été adoptées au Québec.) La situation québécoise au XIXe siècle contraste également avec celle des États-Unis où le nombre de diplômés en médecine a baissé dramatiquement après la fermeture de près de la moitié des écoles de médecine américaines entre 1900 et $1920{ }^{326}$. Puisque le climat social et politique du Québec d'alors interdisait la création et la prolifération d'établissements d'enseignement supérieur, comme ce fut le cas au XIXe siècle aux États-Unis, une pareille restructuration systématique n'était pas nécessaire au Québec.

325 En ce qui concerne la France, voir G. Weisz, « Reform and Conflict in French Medical Education 1870-1914 », dans R. Fox et G. Weisz (eds.), The Organization of Science and Technology in France, 1808-1914, Cambridge, Cambridge University Press, 1980, p. 62-64.

326 W. G. Rothstein, American Physicians in the Nineteenth Century : From Sects to Science, Baltimore, Johns Hopkins University Press, 1972, p. 287. Ce phénomène sera examiné plus en détails ultérieurement dans cet essai. 


\section{Graphique 1}

Nombre de diplômés en médecine au Québec (Moyenne mobile de 3 ans)

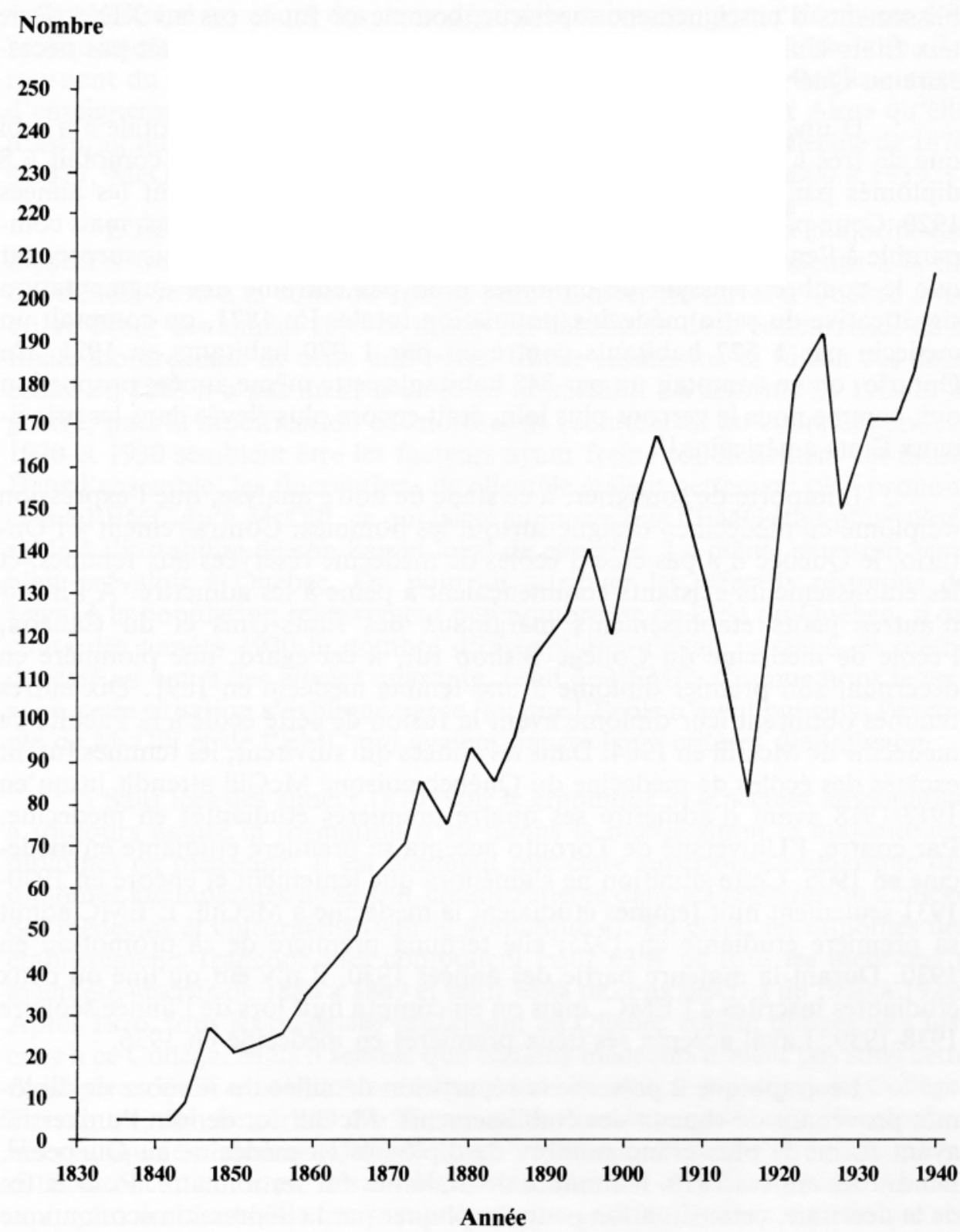


D'une manière générale, le ratio diplômés/population totale n'a subi que de très légères variations. Au cours des années 1870, on comptait 6,8 diplômés par 100000 habitants au Québec, contre 7,3 durant les années 1920. Cette proportion est élevée par rapport aux pays européens, mais comparable à l'ensemble de l'Amérique du Nord ${ }^{327}$. Il est encore plus surprenant que le nombre croissant de diplômés n'ait pas entraîné une augmentation significative du ratio médecins/population totale. En 1871, on comptait un médecin par 1527 habitants contre un par 1070 habitants en 1921. En Ontario, on en comptait un par 848 habitants cette même année ; proportion qui, comme nous le verrons plus loin, était encore plus élevée dans les principaux États américains ${ }^{328}$.

Il importe de souligner, à ce stade de notre analyse, que l'expression « diplômé en médecine » désigne surtout les hommes. Contrairement à l'Ontario, le Québec n'a pas créé d'écoles de médecine réservées aux femmes, et les établissements existants commençaient à peine à les admettre. À l'instar d'autres petits établissements marginaux des États-Unis et du Canada, l'école de médecine du Collège Bishop fut, à cet égard, une pionnière en décernant son premier diplôme à une femme médecin en 1891. Dix autres femmes obtinrent leur diplôme avant la fusion de cette école à la Faculté de médecine de McGill en 1904. Dans les années qui suivirent, les femmes furent exclues des écoles de médecine du Québec puisque McGill attendit jusqu'en 1917-1918 avant d'admettre ses quatre premières étudiantes en médecine. Par contre, l'Université de Toronto accepta sa première étudiante en médecine en 1906. Cette situation ne s'améliora que lentement et encore en 1930-1931 seulement huit femmes étudiaient la médecine à McGill. L'EMC admit sa première étudiante en 1925 ; elle termina première de sa promotion en 1930. Durant la majeure partie des années 1930, il n'y eut qu'une ou

327 En France, on comptait 2,3 diplômés par 100000 habitants vers 1910. En Ontario, en Pennsylvanie et au Massachusetts, on en dénombrait de 6 à 8 par 100000 habitants.

328 Par exemple, en 1910, la rapport médecin/habitants était de 1 médecin par 636 habitants en Pennsylvanie, 1 par 617 dans l'État de New York, 1 par 567 au Massachusetts, 1 par 658 au Maryland et 1 par 740 au Connecticut. Voir le rapport d'Abraham Flexner sur la situation dans ces États, Médical Education in the United States and Canada: A Report to the Carnegie Foundation for the Advancement of Teaching, New York, Carnegie Foundation, 1910. 
deux étudiantes inscrites à l'EMC, mais on en compta huit lors de l'année scolaire 1938-1939. Laval accepta ses deux premières en médecine en 1936.

\section{Graphique 2}

Nombre de diplômés en médecine par école (Moyenne mobile de 3 ans)

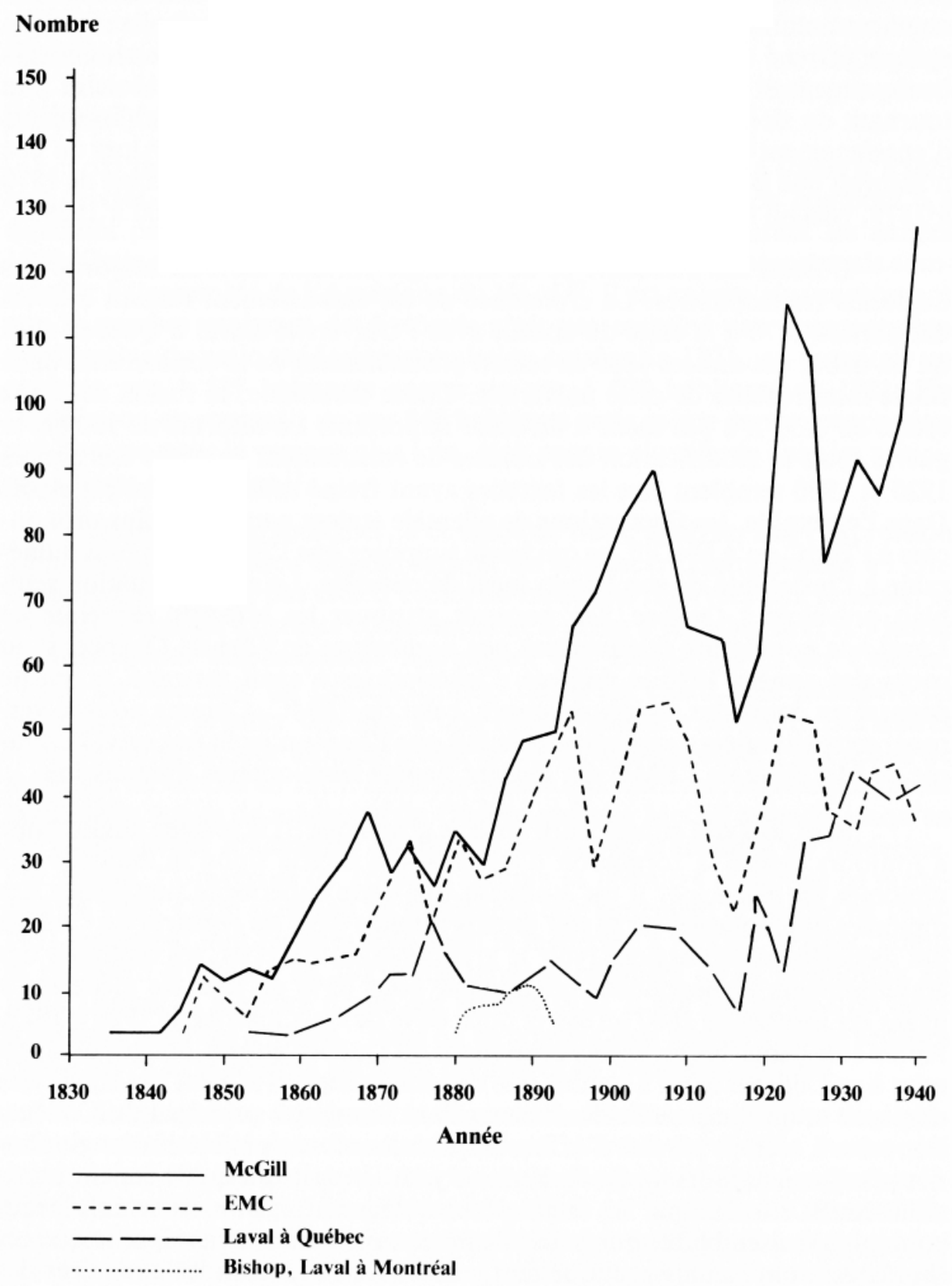


Le graphique 2 présente la répartition détaillée du nombre de diplômés provenant de chacun des établissements. McGill fut de loin l'université ayant formé le plus grand nombre de diplômés en médecine au Québec ${ }^{329}$. Durant les années 1870, le nombre de diplômés fut stationnaire. Pour la fin de la décennie, cette situation peut s'expliquer par la dépression économique qui sévit de 1873 à 1879. Mais les causes immédiates semblent plutôt avoir été la nouvelle concurrence que représentait l'ouverture de l'École de médecine de Bishop en 1871 et, de façon significative, l'affiliation de l'École de médecine et de chirurgie à l'Université Victoria en 1867, ce qui avait entraîné une diminution du nombre de francophones à McGill. Le nombre d'inscriptions augmenta durant la majeure partie des années 1880, s'accroissant à un rythme effréné au cours des deux décennies suivantes, avant de chuter très brusquement en raison de la Grande Guerre et de la réforme scolaire. Au tournant du siècle, McGill a commencé à distancer les autres établissements d'enseignement quant au nombre de diplômés qu'elle formait. Alors qu'elle n'assurait que la formation de $41 \%$ de tous les diplômés en médecine de 1870 à 1879, McGill augmenta ce pourcentage à environ 55\% de 1900 à 1939.

L'École de médecine et de chirurgie formait alors la majorité des médecins francophones. La croissance de cet établissement ralentit à la fin des années 1870 à la suite du conflit avec l'Université Laval à Québec ainsi qu'au début des années 1880 en raison probablement de la concurrence de la filiale montréalaise de cette université. Chose étonnante, la fusion des deux écoles en 1893 n'a pas mené à un essor important. La réforme de 1909 et la guerre, puis la modification des normes de recrutement au cours des années 1920 et 1930 semblent être les facteurs ayant

329 Même McGill ne possédait pas des effectifs étudiants particulièrement importants selon les normes nord-américaines, comme le démontrent les chiffres suivants concernant le nombre annuel moyen de diplômés formés dans les principales écoles de médecine (ces chiffres proviennent des volumes annuels pertinents du Journal of the American Medical Association) :

\begin{tabular}{lcccccccc}
\hline & $\begin{array}{l}\text { Johns } \\
\text { Hopkins }\end{array}$ & Harvard & Columbia & Penn. & Toronto & McGill & EMC & Laval \\
\hline $1881-1883$ & - & 70 & 120 & 114 & - & 32 & 26 & 10 \\
$1901-1903$ & 75 & 132 & 154 & 141 & 62 & 92 & 40 & 22 \\
$1930-1932$ & 71 & 134 & 102 & 132 & 127 & 95 & 36 & 44 \\
\hline
\end{tabular}


freiné soudainement cet essor. Dans l'ensemble, les fluctuations de clientèle étaient nettement plus prononcées à l'EMC qu'à McGill, ce qui laisse supposer que l'EMC était plus vulnérable à l'instabilité de son bassin local de clientèle. La même situation semblait prévaloir à Québec. On pourrait attribuer les effectifs restreints de Laval à la population relativement peu nombreuse de l'Est du Québec, si au cours des années 1930 le nombre d'inscriptions n'avait rattrapé, et même dépassé au cours des années quarante, celui de l'EMC. Comme nous le verrons, cette situation s'explique par le fait que l'École n'avait pas suivi l'exemple de McGill et de l'EMC qui avaient haussé leurs critères d'admission.

Sauf lors des années 1870 (voir le graphique 3) le secteur anglophone a toujours assuré la formation d'au moins la moitié sinon la majorité des diplômés en médecine. Il est étonnant que cette supériorité numérique des diplômés anglophones ne se soit jamais reflétée dans les registres du Collège des médecins et chirurgiens (voir le graphique 4). En effet, les diplômés des établissements francophones comptaient pour 63\% de tous les médecins y ayant été inscrits de 1880 à 1889 et pour 68\% de ceux inscrits de 1920 à 1929. Après 1876, tous les médecins pratiquant au Québec étaient obligés de s'inscrire à ce Collège. Mais il semble que certains médecins n'aient pas suivi cette consigne et qu'il existerait des lacunes dans le registre principal du Collège. Par contre, rien ne permet d'affirmer qu'un nombre significatif d'anglophones pratiquaient alors au Québec sans s'y être inscrits ou qu'ils étaient particulièrement touchés par les lacunes constatées au registre. Il semble beaucoup plus vraisemblable que le fait de ne pas avoir été inscrits signifie que ces diplômés n'ont jamais pratiqué au Québec. En fait, selon les annuaires des diplômés de l'Université McGill, seulement quelque 25\% de ces diplômés auraient vécu à Montréal une décennie après avoir terminé leurs études ${ }^{330}$. Une étude semblable des annuaires beaucoup plus restreints de l'Université Bishop, de 1872 à1905, révèle que moins des deux tiers des diplômés en médecine restèrent au Québec. Ces chiffres expliquent certainement le nombre inférieur de diplômés anglophones inscrits au Collège des médecins et chirurgiens.

330 Les lieux de pratique des diplômés de McGill sont abordés plus en détail dans la section « Mobilité des diplômés ». 


\section{Graphique 3}

Pourcentage de diplômés selon les secteurs anglophone et francophone (par décennie)

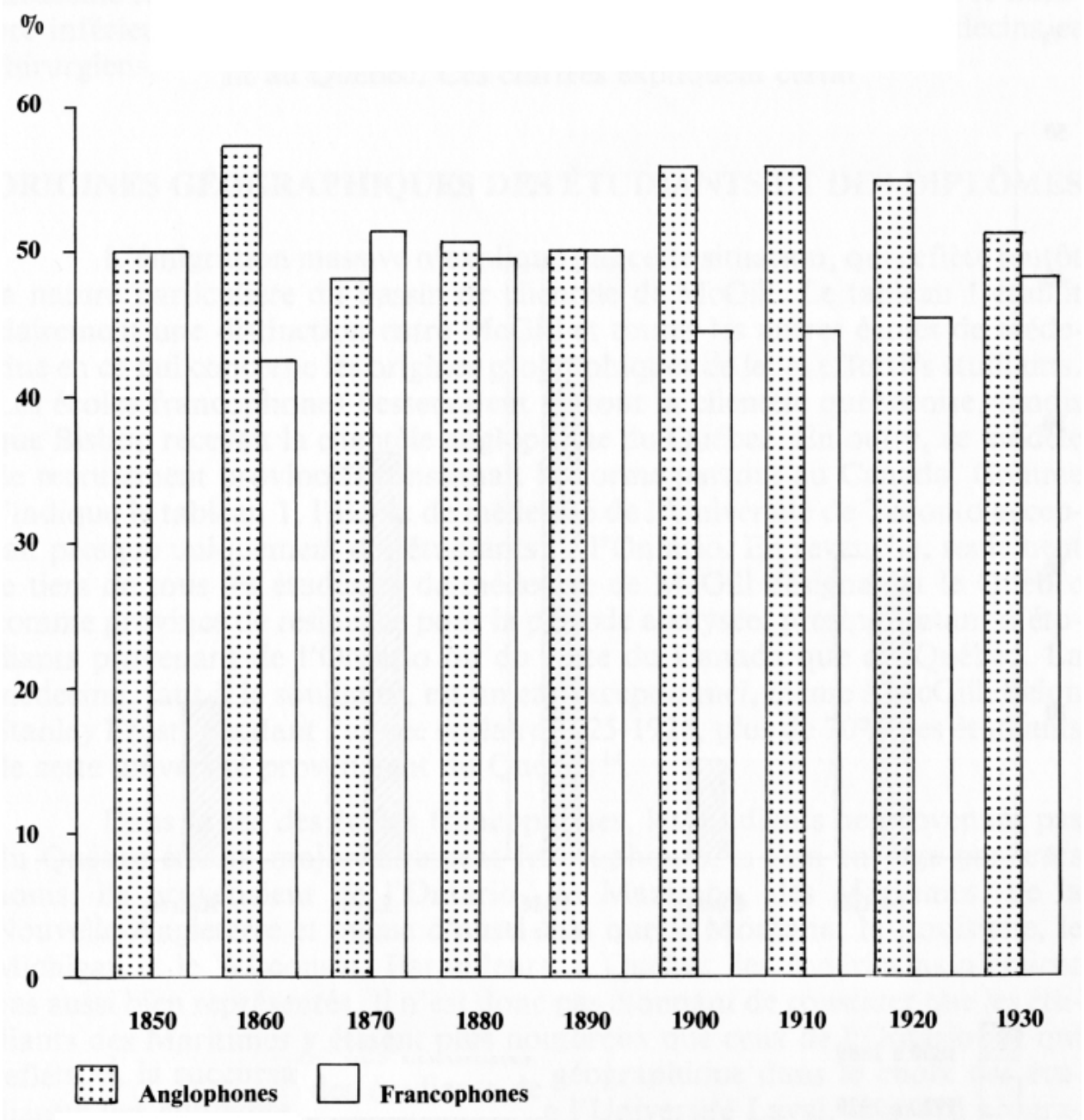




\section{Graphique 4}

Pourcentage des diplômés inscrits au Collège des médecins et chirurgiens selon le lieu de formation de 1880 à 1889 et de 1920 à 1929

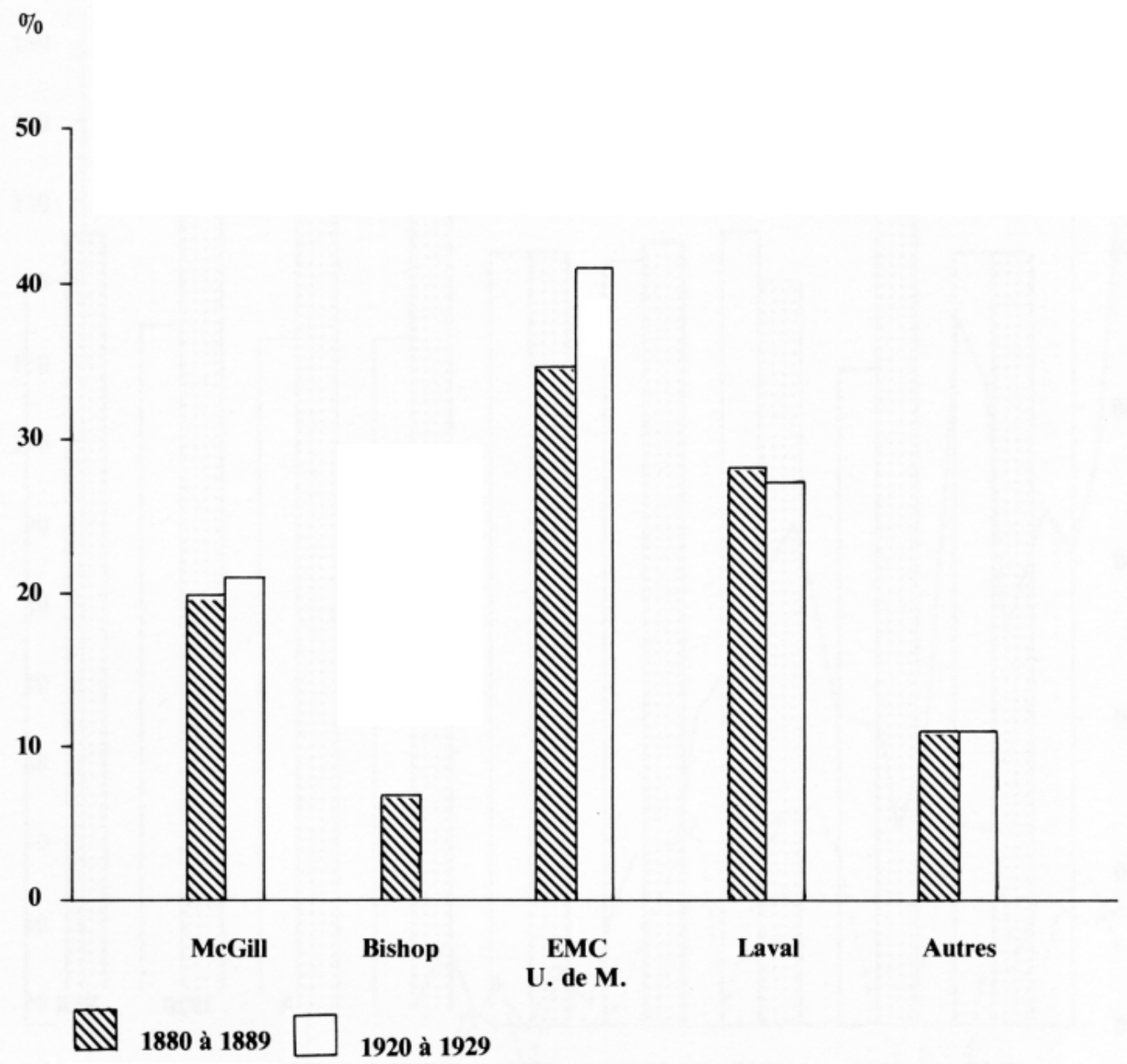




\section{ORIGINES GÉOGRAPHIQUES DES ÉTUDIANTS ET DES DIPLÔMÉS}

L'émigration massive n'explique pas cette situation, qui reflète plutôt la nature particulière du bassin de clientèle de McGill. Le tableau 1 établit clairement une distinction entre McGill et toutes les autres écoles de médecine en ce qui concerne les origines géographiques de leurs effectifs étudiants. Les écoles francophones desservaient surtout la clientèle québécoise, tandis que Bishop recevait la clientèle anglophone du Québec. En outre, ce modèle de recrutement provincial constituait la norme partout au Canada. Comme l'indique le tableau 1, l'École de médecine de l'Université de Toronto acceptait presque uniquement des étudiants de l'Ontario. En revanche, seulement le tiers de tous les étudiants de médecine de McGill désignaient le Québec comme province de résidence pour la période analysée, presque autant d'étudiants provenant de l'Ontario ou du reste du Canada que du Québec. La médecine, faut-il le souligner, est un cas exceptionnel, même à McGill. Selon Stanley Frost, pendant l'année scolaire 1925-1926, plus de 70\% des étudiants de cette université provenaient du Québec ${ }^{331}$.

Dans le cas des écoles francophones, les étudiants ne provenant pas du Québec étaient majoritairement francophones, si l'on en juge par leurs noms ; ils provenaient de l'Ontario, du Manitoba, des Maritimes, de la Nouvelle-Angleterre et même d'aussi loin que le Montana, la Louisiane, le Michigan et le Wisconsin. Par ailleurs, à Québec, les Américains n'étaient pas aussi bien représentés. Il n'est donc pas étonnant de constater que les étudiants des Maritimes y étaient plus nombreux que ceux de l'Ontario, ce qui reflétait l'importance de la proximité géographique dans le choix des étudiants. À la succursale montréalaise de l'Université Laval, le profil géographique des étudiants de l'extérieur du Québec était par contre semblable à celui des étudiants de l'École de médecine et de chirurgie.

L'École de médecine de l'Université Bishop recrutait une partie plutôt importante de sa clientèle en dehors du Québec (18,4\% du nombre total des

331 Stanley Frost et Sheila Rosenberg, The McGill Student Body : Past and Future Enrolment, Montréal, sans date, p. 41. 
inscriptions). Fait encore plus étonnant, cette clientèle se composait d'un pourcentage relativement élevé d'étudiants originaires ni du Canada, ni des ÉtatsUnis (8,5\%) et dont l'immense majorité provenait des Antilles britanniques.

\section{Tableau 1}

Provenance géographique des étudiants en médecine selon l'université fréquentée (\%)

\begin{tabular}{lccccc}
\hline & Qué. (a) & $\begin{array}{c}\text { Ont. } \\
\text { (a) }\end{array}$ & $\begin{array}{c}\text { E. et O. du } \\
\text { Canada }\end{array}$ & É.U. & Autres \\
\hline McGill (1849-1939) & 30 & 27 & 24 & 16 & 3 \\
Bishop (1872-1905) & 82 & 5 & 1 & 4 & 9 \\
EMC (1846-1930) & 91 & 3 & 2 & 4 & 1 \\
Laval-Q. (1865-1930) & 93 & 1 & 3 & 3 & - \\
$\begin{array}{l}\text { Laval-M. (1880-1889) } \\
\text { Université de Toronto }\end{array}$ & 93 & 3 & 1 & 3 & 1 \\
$\begin{array}{l}\text { 1904-1905, 1921-1922, } \\
\text { 1926-1927, 1931-1932, } \\
\text { 1936-1937) }\end{array}$ & - & 91 & 7 & 1 & 1 \\
\hline $\begin{array}{l}\text { Note : a) Pour la période précédant la Confédération, on peut considérer l'Est } \\
\text { et l'Ouest du Canada comme étant le Québec et l'Ontario respectivement. }\end{array}$ \\
\hline
\end{tabular}

McGill est en soi un cas unique qui nécessite une analyse plus poussée. Le graphique 5 indique les origines géographiques des étudiants selon les décennies. Le pourcentage de Québécois étudiant la médecine à McGill a atteint son sommet durant les années 1860: presque 50\% de la clientèle totale. Dès lors, ce pourcentage a varié entre $25 \%$ et $35 \%$. Par ailleurs, le pourcentage d'étudiants ontariens y oscilla autour de 50\% jusqu'en 1889, chuta rapidement jusqu'en 1900, 
puis plus lentement jusqu'en 1929, pour finalement tomber abruptement à $6 \%$ au cours des années 1930. La perte de l'Ontario comme principal bassin de clientèle ne semble pas avoir affecté McGill outre mesure, puisqu'en revanche sa Faculté de médecine attirait alors bon nombre d'étudiants d'abord des Maritimes, puis de l'Ouest du Canada. En fait, le pourcentage d'étudiants de l'Ontario additionné à celui des autres provinces anglophones demeura relativement stable, oscillant entre 50\% et $60 \%$ de 1869 à 1919 . L'afflux d'étudiants en médecine issus de l'Est et de l'Ouest du Canada s'amorça de façon importante au cours des années 1880, culminant entre 1900 et 1910, pour demeurer pratiquement stable jusqu'au milieu des années 1920, avant de diminuer de façon marquée par la suite.

\section{Graphique 5}

Provenance géographique des étudiants de McGill

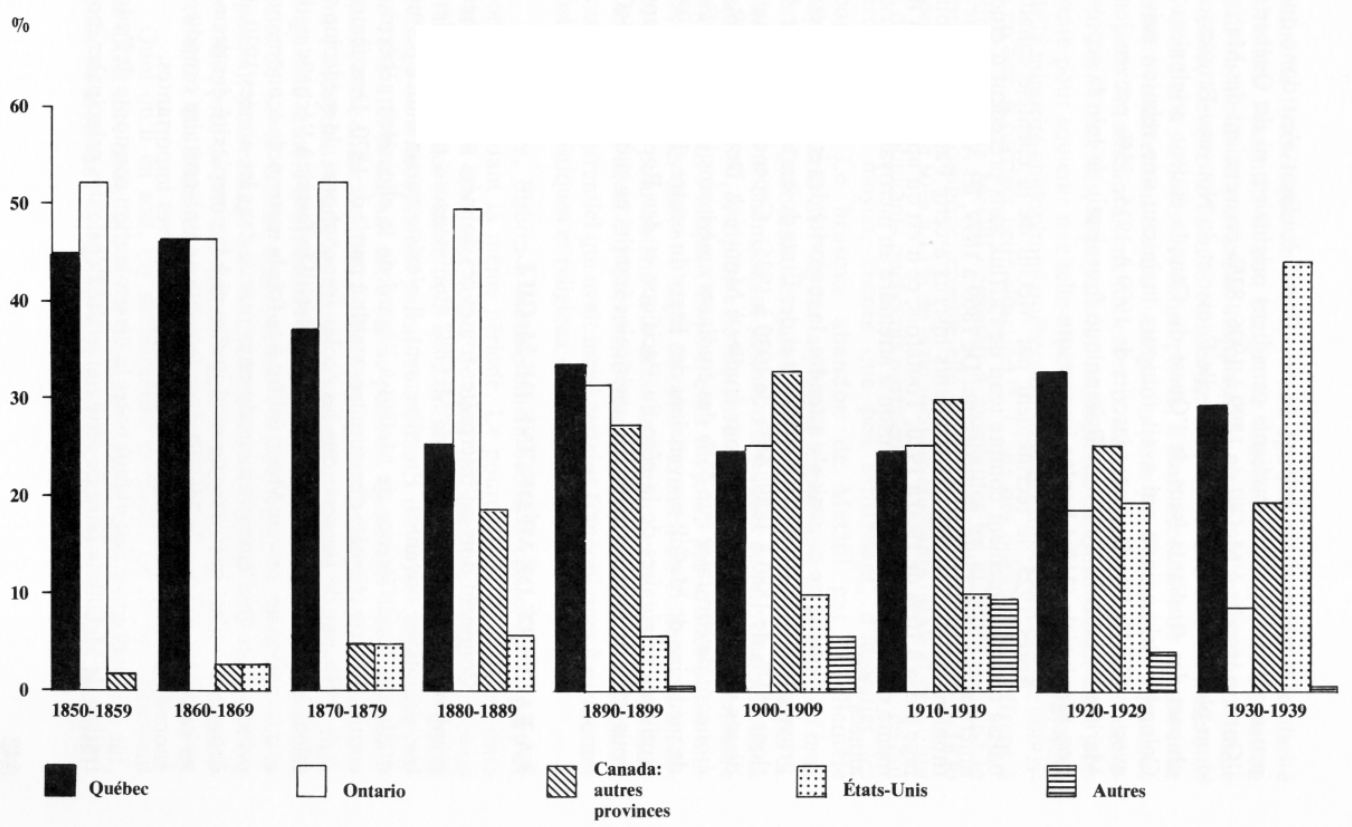

La composition interne de cet effectif étudiant s'est donc quelque peu modifiée. Des 229 étudiants canadiens originaires ni du Québec ni de l'Ontario inscrits à McGill de 1899 à 1906, 82\% provenaient des Maritimes, dont plus des deux tiers de la Nouvelle-Écosse et du Nouveau-Brunswick. La plupart des étudiants issus de l'Ouest du Canada étaient originaires de la Colombie- 
Britannique qui avait toujours maintenu une relation privilégiée avec McGill 332. Des étudiants inscrits de 1909 à1915, 55\% provenaient des Maritimes, mais la Colombie-Britannique fournissait de loin la représentation provinciale (31\%) la plus importante.

Après 1925, le recrutement par McGill de la clientèle canadienne baissa considérablement compte tenu de l'afflux sans précédent d'étudiants américains à sa Faculté de médecine. De 1869 à 1899, les Américains ne constituaient qu'environ 5\% des étudiants inscrits à cette Faculté. Ce pourcentage passa à10\% de 1900 à 1920. Toutefois, ce n'est qu'après 1920 qu'il augmenta de façon spectaculaire jusqu'à atteindre un incroyable 44\% durant les années 1930.

Comme on pouvait s'y attendre, la majorité des étudiants américains provenaient de la Nouvelle-Angleterre et des États du centre de la côte Atlantique (51\% de 1880 à 1889 ; 64\% de 1930 à 1935). Cependant, quelques étudiants venaient de très loin pour étudier à Montréal. De 1880 à 1889, il est étonnant de constater que 46\% des étudiants américains inscrits à la Faculté de médecine de McGill provenaient des États du centre. De 1930 à 1935, les étudiants originaires de la côte du Pacifique et des Rocheuses comptaient pour 25\% de tous les étudiants américains inscrits en médecine à McGill.

\section{LA FACULTÉ DE MÉDECINE DE MCGILL}

Comment doit-on interpréter toutes ces données sur les origines géographiques du corps étudiant de McGill ? Commençons par réfuter les deux interprétations suivantes. Premièrement, il n'existe aucun indice permettant d'alléguer l'indifférence de McGill à l'égard de la clientèle québécoise. Au contraire, cette clientèle demeura très stable à partir de 1870. Deuxièmement, il ne suffit pas de suggérer que les écoles francophones de médecine recrutaient à l'échelle provinciale, alors que McGill le faisait à l'échelle nationale et

332 De 1906 à 1915, McGill avait dans cette province une école affiliée, McGill University College of British Columbia ; les étudiants pouvaient y poursuivre leurs deux premières années d'études en arts et en sciences. D'ailleurs, le recteur de l'Université de Colombie-Britannique durant les années 1920 était un diplômé en médecine de McGill. 
internationale, ou que Montréal fut à la fois la métropole économique et le principal centre d'enseignement du pays jusque dans les années 1930. Pareil énoncé, s'il n'est pas faux, ne rend justice ni à la complexité des données ni au caractère unique de McGill dans le contexte universitaire canadien. Cet énoncé nécessite donc, à tout le moins, des réserves importantes.

En premier lieu, il faut noter la détermination constante de l'administration de McGill de faire de cette université l'égale des principales écoles de médecine de l'Amérique du Nord. À une époque où les frais de scolarité constituaient l'essentiel de son budget de fonctionnement, cette aspiration reposait au moins en partie sur l'ampleur du nombre d'inscriptions. Même après 1880, lorsque la Faculté commença à recevoir une aide financière de l'Université et à solliciter des fonds privés, il était nécessaire de compter sur un nombre relativement élevé d'inscriptions pour justifier les investissements requis pour les améliorations majeures et stimuler aussi l'intérêt des donateurs privés. Toutefois, la population anglophone du Québec était alors trop restreinte pour soutenir une telle aspiration. Ainsi la tendance démographique de la minorité anglophone québécoise au cours du XIXe siècle ne contribuait en rien à corriger cette situation ${ }^{333}$. L'une des possibilités s'offrant à l'administration de McGill consistait à augmenter les effectifs issus de la communauté francophone, comme elle semble l'avoir fait de 1855 à 1870 environ, lorsque de 10\% à 13\% de la population étudiante totale et près d'un quart de tous les étudiants québécois portaient un nom francophone, ce qui se révèle le seul moyen, encore que peu satisfaisant, d'identifier les francophones ${ }^{334}$. Le brusque abandon de McGill par la clientèle francophone 335

333 Voir en annexe. Tout porte à croire que cette faculté n'a jamais songé sérieusement à desservir davantage la clientèle francophone. Cela étonne à peine puisqu'il existait déjà des établissements francophones parfaitement adéquats et que, fait encore plus important, il y avait un clivage manifeste entre l'élite anglophone et la majorité francophone. En considérant ce clivage comme un fait acquis aux fins de la présente étude, je ne cherche pas à suggérer qu'on doit le tenir pour allant de soi. Il est certain qu'en lui-même, ce fait pose un problème historique majeur que nous ne pouvons aborder ici.

334 Seuls les étudiants portant à la fois un nom de famille et un prénom français ont été considérés comme francophones dans le cadre de cette étude. Le même critère a été utilisé pour identifier les étudiants anglophones fréquentant des universités francophones, aspect qui sera examiné plus loin. 
à partir de 1870 fut largement responsable de la chute du taux d'inscriptions des Québécois, tel qu'observé précédemment au graphique 5. La chronologie de ce changement permet d'expliquer ce renversement de la situation. Avant 1870, le diplôme de McGill était le seul diplôme universitaire décerné à Montréal. Puisque l'EMC n'était toujours pas affiliée à une université, ses diplômés étaient obligés de subir l'examen du Collège des médecins et chirurgiens pour obtenir leur droit de pratique et ce, jusqu'à l'affiliation, en 1867, de l'EMC à l'Université Victoria. Par la suite, McGill perdit cet avantage concurrentiel qui avait incité certains francophones à surmonter les obstacles linguistiques et religieux existants ${ }^{336}$.

Par ailleurs, Bishop a étonnamment réussi à conserver sa part de francophones pendant la même période. Le pourcentage de francophones dans la population étudiante totale de cette institution s'élevait à environ 16\% tant à la fin des années 1870 qu'à la fin des années 1880, tandis que le pourcentage de francophones parmi les étudiants d'origine québécoise passait de 18\% à 29\% durant cette même période. Quels que soient les motifs expliquant cette situation (les chiffres impliqués n'étant pas très élevés), Bishop fut l'exception. Dans les écoles francophones, tout comme à McGill, l'unilinguisme semble avoir été de rigueur. De 1860 à 1865, 19\% de tous les étudiants de Laval étaient anglophones (ou, du moins, portaient un nom anglophone) ; pourcentage qui tomba à environ $4 \%$ après 1880. À la fin des années 1850, près de $9 \%$ des effectifs étudiants de l'EMC étaient anglophones. Au cours des décennies suivantes, ce pourcentage varia entre 2 et $5 \%$.

Quoi qu'il en soit, cet unilinguisme croissant ne fit probablement qu'une différence marginale sur le nombre d'inscriptions à McGill. Bien sûr, la Faculté de médecine de McGill a su faire face énergiquement à la concurrence de Bishop, de

335 Le nombre de francophones inscrits à McGill s'élevait annuellement à 17 de 1861 à 1865 et chuta à 4 de 1871 à 1876. De 1910 à 1914, on en comptait 7 annuellement (soit $2 \%$ du total des effectifs étudiants et $11 \%$ des étudiants québécois). On y remarquait aussi un nombre croissant de francophones provenant des autres provinces et des États-Unis. Au cours des années 1880, ces derniers y étaient plus nombreux que les francophones du Québec.

336 En ce qui concerne l'opposition de l'Église catholique à l'inscription des étudiants catholiques à McGill, voir Lavallée, op. cit., p. 13 et Boissonnault, op. cit., p. 212. 
l'École St. Lawrence et de l'EMC ${ }^{337}$. Mais elle a aussi prospecté à l'extérieur du Québec. Dès le début, l'Ontario a constitué pour McGill un bassin de clientèle privilégié. De 1840 à 1867, l'Est et l'Ouest du Canada ne représentaient évidemment pas deux unités politiques distinctes. Même après la Confédération, il semble probable que les Canadiens anglais ont continué à considérer ces deux régions comme une seule et unique entité géographique. Plus fondamentalement, aucun programme d'enseignement de la médecine comparable à celui de McGill n'existait alors en Ontario. Certes, il y avait des écoles de médecine, mais il s'agissait d'écoles indépendantes n'étant que vaguement ou pas du tout affiliées à des universités et disposant souvent d'installations insuffisantes d'enseignement hospitalier ${ }^{338}$. Par conséquent, et en dépit de la concurrence, McGill pouvait prétendre être le seul établissement anglophone canadien à offrir une formation universitaire en médecine comparable à celle dispensée à Boston, New York ou Philadelphie. McGill exerçait une influence si considérable sur la médecine pratiquée en Ontario que la Loi de 1869, imposant un examen de qualification à tous les médecins voulant y pratiquer, visait en partie à endiguer l'afflux de diplômés de McGill dans cette province ${ }^{339}$. Toutefois, cette situation changea dès 1887 grâce à la formation de l'École de médecine de l'Université de Toronto, ce qui mit fin au monopole de McGill en matière d'enseignement universitaire de la médecine. Dès lors, le pourcentage d'étudiants provenant de l'Ontario baissa considérablement, laissant entendre une fois de plus que le pouvoir d'attraction de McGill dépendait de son aptitude à monopoliser un bassin de clientèle régional particulier. Petit à petit, McGill et Toronto se partagèrent la clientèle anglophone du centre du Canada (à l'instar des écoles francophones qui se partageaient la

337 Pour une opinion partisane sur les efforts déployés par McGill pour empêcher l'EMC d'obtenir une charte lui permettant de décerner des doctorats en médecine, voir Mignault, op. cit., p. 69. Quant aux tactiques employées par McGill pour empêcher les professeurs de Bishop d'occuper des postes supérieurs à l'Hôpital général de Montréal, voir les éditoriaux dans le Montreal Médical Record parus régulièrement au cours des années 1880.

338 Par exemple, voir G.W. Sprague, "Trinity Medical College », Ontario History, vol. 58, 1966, p. 63-98 ; R.D. Gidney et W.P.J. Millar, « The Origins of Organized Medicine in Ontario 1850-1869 » dans C.G. Roland, (ed.), Health, Desease \& Medicine : Essays in Canadian History, Toronto, 1982, p. 65-95.

339 Gidney et Millar, op. cit., p. 82-84. 
population francophone du Québec). L'Ontario a continué à fournir d'importants effectifs étudiants à McGill jusqu'à la fin des années 1920, mais ils représentaient un pourcentage décroissant de la population étudiante de McGill et du nombre d'étudiants ontariens poursuivant des études en médecine 340 .

Cette baisse d'inscriptions fut néanmoins compensée par l'arrivée d'étudiants des Maritimes et plus tard de l'Ouest du Canada. McGill courtisa cette clientèle en offrant des examens d'admission dans tout le Canada ${ }^{341}$. L'augmentation croissante des effectifs étudiants de l'Ouest du pays s'explique par son énorme explosion démographique. Dans le cas des Maritimes, par contre, la croissance démographique fut plus modeste ${ }^{342}$. L'inauguration d'un lien ferroviaire entre Montréal et Saint-Jean en 1890 et l'intégration progressive ${ }^{343}$ des Maritimes à la zone d'influence économique de Montréal, furent encore plus déterminants. Dès 1898, McGill comptait deux fois plus d'étudiants des Maritimes qu'en 1890. L'établissement d'un lien ferroviaire semble avoir intégré les Maritimes non seulement aux marchés économiques du centre du Canada, mais aussi à son marché de diplômés. Des informations fragmentaires et anecdotiques sur les médecins du Nouveau-Brunswick permettent de croire qu'avant 1890, ces médecins avaient tendance à obtenir leurs diplômes dans les établissements du nord-est des États-Unis ${ }^{344}$. Les voies d'accès favorisaient plutôt les déplacements vers le sud que vers l'ouest. Par contre, l'inauguration d'un lien ferroviaire et la

340 En 1887-1888, le nombre d'étudiants originaires de l'Ontario dans les six écoles de médecine ontariennes était trois fois et demie plus élevé que le nombre total d'étudiants ontariens inscrits à McGill. En 1931-1932, le nombre de ces étudiants à la seule Université de Toronto était vingt fois plus élevé qu'à McGill.

341 Frost, op. cit., p. 73.

342 Voir R. Beaujot et K. McQuillan, Growth and Dualism : The Demographic Development of Canadian Society, Toronto, Gage, 1982.

343 L. D. McCann, «Metropolitanism, Branch Firms and Canadian Urban Development, 1867-1929 : The Case of the Maritimes », Acadiensis, vol. 13, 1983, p. 112-115, montre de façon convaincante comment Montréal, durant les années 1890 et au début des années 1900, supplanta Halifax et Saint-Jean comme région métropolitaine dominante dans les Maritimes pour, à son tour, céder sa place à Toronto dans les décennies qui ont suivi la Grande Guerre. Je tiens à remercier Brian Young d'avoir porté cet article à mon attention.

344 W. B. Stewart, Medicine in New Brunswick, Moncton, New Brunswick Society, 1974. 
nouvelle influence économique de Montréal dans cette région ont fait de McGill un choix naturel pour les étudiants en médecine provenant de l'Est du Canada. La brusque diminution du nombre d'étudiants de l'Est et de l'Ouest du Canada à la fin des années 1920 se compare à bien des égards à la baisse, quarante ans plus tôt, du nombre d'étudiants provenant de l'Ontario.

Dans les deux cas, il semble que cette situation ait été attribuable à l'existence d'un enseignement adéquat de la médecine dans les régions où elle faisait auparavant défaut. Des réformes majeures de l'enseignement furent entreprises partout au Canada juste avant et après la Première Guerre mondiale. Les écoles de médecine de Dalhousie et de Western, intégrées complètement à leur université locale dès 1911 et 1912, s'améliorèrent de façon significative. Des écoles de médecine furent également ouvertes en Alberta en 1913 et en Saskatchewan en $1926^{345}$. Seule la Colombie-Britannique ne comptait aucune école de médecine en 1930.

Ces changements peuvent expliquer pourquoi McGill perdit de son pouvoir d'attraction auprès des étudiants canadiens, mais ils n'expliquent pas l'invasion d'étudiants américains après 1925. Pour bien comprendre ce dernier phénomène, nous devons reconnaître qu'avant 1920, le recrutement de la clientèle correspondait somme toute aux normes d'une économie de marché. Ce qui revient à dire que, même si McGill cherchait alors à prendre de l'expansion et avait même probablement recruté activement, la répartition régionale de la clientèle étudiante résultait essentiellement du choix des étudiants. Ce choix dépendait d'ailleurs de l'existence d'écoles de médecine dans les diverses régions du Canada. Les seuls obstacles artificiels restreignant l'admission en médecine n'étaient pas imposés par McGill, mais plutôt par le Collège des médecins et chirurgiens qui exigeait soit un certificat d'études secondaires, soit la réussite d'un examen de connaissances générales préparé et administré par le Collège. Cet examen n'était d'ailleurs pas particulièrement difficile.

Après 1920, la situation de McGill se modifia. Dans la foulée d'une tendance générale en Amérique du Nord, cette institution adopta des normes plus élevées en matière d'enseignement de la médecine. En résumé, vers 1880, un important mouvement de réforme s'amorça afin de transformer graduellement 
l'enseignement de la médecine aux États-Unis. Les objectifs étaient puissamment articulés autour du contenu du rapport Flexner publié en $1910^{346}$ et dont l'essentiel des recommandations était en application vers 1930. Ce rapport cherchait à imposer à peu près l'équivalent d'un programme universitaire de premier cycle pour tous les futurs étudiants en médecine, à éliminer les écoles indépendantes de médecine, à contingenter le nombre de diplômés en médecine, à utiliser les techniques de laboratoire dans le cadre du programme de médecine et, enfin, à affilier les écoles de médecine aux grands hôpitaux en vue d'améliorer la qualité de la formation clinique. Tous ces changements nécessitèrent l'intégration des écoles de médecine aux universités et l'accroissement des sources de financement, afin d'augmenter les ressources et ne plus compter uniquement sur les frais de scolarité.

Si les motifs et les résultats de ces changements ont fait l'objet d'âpres débats parmi les historiens de la médecine américaine, ce sont surtout leurs conséquences pour l'Université McGill qui nous préoccupent ici. Bien que les normes d'admission de cette université au tout début du siècle étaient relativement élevées dans le contexte nord-américain, elle dut se battre pour se maintenir au niveau des nouvelles normes instaurées après la Grande Guerre. Cette situation résultait du fait qu'un grand nombre de ses diplômés s'établissaient ensuite aux États-Unis, où ils devaient se conformer aux exigences de chacun des États 347 pour pratiquer la médecine. Durant les années 1920, des exigences d'admission encore plus strictes furent imposées. D'abord une, puis deux et finalement trois années d'université, comportant une solide formation en sciences, furent exigées ; le B.A. ou le B.Sc., étaient considérés comme la formation optimale pour être admis en médecine 348 . Simultanément, la Faculté de médecine de McGill contingenta le nombre de ses

346 Pour la référence complète, voir note 11. L'étude de ces réformes a donné naissance à une véritable «industrie ». Deux études récentes à ce sujet ont suscité une grande controverse : celle de E.R. Brown, Rockefeller Medicine Men : Médical Care and Capitalism in America, Berkeley, University of California Press, 1979 et un chapitre pertinent de celle de P. Starr, The Social Transformation of American Medicine, New York, Basic Books, 1982.

347 Dans l'annuaire de McGill de 1919-1920, les exigences des commissions médicales des États américains ont été expressément citées comme le motif de l'adoption d'un nouveau programme d'une durée de six ans.

348 L'évolution de ces exigences est clairement exposée dans les annuaires de la Faculté de médecine de McGill. 
admissions à 100 et mit sur pied un comité d'admission pour évaluer les candidats. Elle pouvait se permettre de contingenter puisque, dès 1880, elle obtenait des dons privés importants et certains fonds de l'Université de sorte que les frais de scolarité représentaient une partie décroissante du budget de cet établissement 349 .

Selon le doyen de cette Faculté, celle-ci recevait en moyenne 600 demandes d'admission par année de 1925 à $1930{ }^{350}$ et au-delà de 1000 au cours des années suivantes. Pour la première fois de son histoire, elle pouvait activement sélectionner ses effectifs étudiants. Le dossier scolaire devint le principal critère d'évaluation. Vers 1938, 77\% de ses 103 finissants avaient obtenu au préalable un diplôme de premier cycle comparativement à seulement 27\% à l'Université de Toronto ${ }^{351}$. Une homogénéité confessionnelle accrue semble avoir été un autre objectif. L'étude des archives de McGill permet d'établir que la Faculté de médecine, tout comme l'ensemble de cette université, accordait la préférence aux protestants anglo-saxons. Le nombre d'étudiants catholiques admis diminua un peu, alors que celui des étudiants juifs fut réduit considérablement. En 1925-1926, 24\% de tous les étudiants en médecine étaient juifs ; en 1936-1937, seulement $10 \%$ l'étaient. Parmi tous les étudiants universitaires, la proportion de juifs chuta de $26 \%$ à $12 \%$. À cet égard comme à bien d'autres, McGill suivait l'exemple des plus éminentes universités américaines ${ }^{352}$.

349 Les dépenses en capital étaient presque exclusivement financées grâce à des dons privés et des subventions de l'université. La proportion des budgets annuels courants défrayée grâce aux frais de scolarité chuta de 57\% en 1910 à seulement 32\% en 1932. Voir les rapports annuels de l'Université McGill de ces années-là. Dès 1905, McGill a assuré totalement le financement de sa Faculté de médecine. Frost, op. cit., p. 50.

350 « Survey of the Medical Faculty, 1920-1930 », rédigé par C. Martin, au nom d'un comité d'étude et provenant des archives de McGill : 38/30/2. Les chiffres des années 1930 ont été extraits des statistiques du Bureau du registraire de McGill.

351 Journal of the American Médical Association (JAMA), vol. 97, 1939, p. 611-645.

352 Ces chiffres ont été tirés de rapports préparés par le Bureau du registraire de McGill et y étant conservés. Frost, op. cit., p. 128, donne des chiffres différents à partir des registres étudiants, mais ceux du Bureau du registraire semblent plus exacts. Quant aux mesures discriminatoires adoptées par les universités américaines à cette époque, voir Jerome Karabel, « Status-Group 
Néanmoins, le critère confessionnel ne favorisait pas les Américains. Au contraire, les juifs américains furent la cible des politiques discriminatoires de McGill 353. En outre, des archives administratives démontrent clairement que l'augmentation de la clientèle américaine mit l'Université dans un certain embarras. Dans un important rapport adressé au Conseil de la Faculté en 1930, le doyen d'alors, Charles Martin, exprima son inquiétude quant à l'effritement de l'influence traditionnelle de McGill au Canada. Il y déclarait que les Canadiens ne s'y inscrivaient plus en aussi grand nombre que par le passé de sorte que l'élite des médecins canadiens était plutôt formée dans d'autres universités. Il proposait donc que McGill s'efforce d'atteindre un niveau d'excellence de réputation internationale non pas pour y attirer les étudiants étrangers, mais plutôt pour inciter les étudiants canadiens les plus ambitieux à poursuivre leurs études dans un contexte scolaire infiniment supérieur à tout ce qui existait ailleurs au pays ${ }^{354}$. Martin semblait indiquer que les difficultés éprouvées par McGill dans le recrutement d'étudiants canadiens découlaient de la qualité supérieure de l'enseignement de la médecine dispensé dans presque toutes les provinces. Il s'agit d'une explication très plausible, comme nous l'avons déjà suggéré. Par contre, Martin semble avoir ignoré que ce relèvement des normes de recrutement restreignait encore davantage la clientèle potentielle, surtout en raison du fait que l'Université de Toronto, plus proche des provinces de l'Ouest, fut nettement plus lente à exiger un diplôme de premier cycle comme condition préalable à l'admission. On peut imaginer les conséquences de la politique de McGill si l'on se rappelle qu'en 1920, il n'y eut que 1109 diplômés des universités canadiennes ayant obtenu un B.A. ou l'équivalent. Si on se limite à l'enseignement

Struggle, Organizational Interests, and the Limits of Institutional Autonomy », Theory and Society, vol. 13, 1984, p. 1-39.

353 Cette politique est clairement énoncée dans une lettre datée du 14 janvier 1938 et extraite des archives de McGill, RG2, c : 48, que le vice-doyen de la Faculté de médecine envoya au recteur de l'Université ; il y expliquait que pour les huit à dix places réservées annuellement aux juifs, la préférence était d'abord accordée aux juifs canadiens, ce qui rendait très difficile l'admission de juifs américains. En outre, il y ajoutait que la seule autre discrimination de la Faculté envers les Américains était dirigée contre les noirs.

354 «Survey of the Medical Faculty 1920-1930 ». Une déclaration encore plus percutante à cet égard est consignée dans le "Memorandum on Proposed Four-Year Medical Course » du 2 janvier 1935 tiré des archives de McGill, RG 12, c : 71. 
universitaire dispensé dans les principales régions canadiennes de recrutement de McGill (le Québec anglophone, les Maritimes et la Colombie-Britannique), ce nombre n'est que de 253 355. Compte tenu que tous ces diplômés ne se dirigeaient pas vers la médecine et que le nombre d'étudiants admis en médecine à McGill fluctuait autour de 100, on comprend que le nombre potentiel de candidats canadiens admissibles était relativement faible.

Par ailleurs, les universités américaines étaient bondées d'étudiants. Le nombre d'étudiants dans l'ensemble des institutions d'enseignement supérieur passa de 355000 en 1910 à 1174000 en 1928. Les collèges et les universités étaient en grande partie responsables de cette augmentation puisqu'ils accueillaient près de $75 \%$ de la population étudiante totale de sexe masculin 356 . Par conséquent, malgré des normes d'admission plus élevées, le nombre de candidats admissibles augmentait rapidement. On peut aussi supposer que le prestige grandissant de la profession médicale et la disparition des possibilités traditionnelles de carrière durant la Dépression ont incité une plus forte proportion de candidats à présenter une demande d'admission en médecine.

Néanmoins, à la même époque, alors que le bassin potentiel de clientèle ne cessait de s'accroître aux États-Unis, l'accessibilité aux écoles de médecine y diminuait. La hausse des critères de formation fit baisser de 162 en 1906 à 85 en 1920 le nombre de ces écoles ; le nombre d'étudiants en médecine chuta alors de 25000 à seulement $1400{ }^{357}$. On peut donc facilement imaginer la nature des pressions ayant poussé un grand nombre d'Américains à s'inscrire dans des écoles de médecines étrangères. D'ailleurs, dès 1930, le rapport annuel portant sur l'enseignement de la médecine publié par l'American Médical Association s'inquiétait du nombre toujours croissant d'Américains étudiant la médecine à l'étranger (et revenant présumément aux États-Unis pour y pratiquer) ${ }^{358}$. Cette année-là, la grande majorité étudiait en Grande-Bretagne (321), tout

355 Ces chiffres sont calculés à partir du livre de R.S. Harris, A History of Higher Education in Canada 1663-1980, Toronto, University of Toronto Press, 1976, p. 612.

356 C.B. Burke, "The Expansion of American Higher Education », dans K. Jarausch, (ed.), The Transformation of Higher Learning, Chicago, University of Chicago Press, 1983, p. 12.

$357 \quad$ Voir note 9.

358 JAMA, vol. 97, 1931, p. 625-626. 
particulièrement dans les universités écossaises. Le contingent suivant le plus important (277) était inscrit dans les universités canadiennes, dont 75\% à McGill. En 1937, le nombre d'étudiants américains au Canada atteignait 487, beaucoup plus que la moitié d'entre eux étant inscrits à McGill ${ }^{359}$. Cette université a dû sembler particulièrement attirante pour les nombreux étudiants américains admissibles, mais incapables de se faire admettre à Harvard, Johns Hopkins, etc. McGill était proche, sa réputation était aussi bonne que celle des meilleures universités américaines (à l'exception, peut-être, de Johns Hopkins), les frais de scolarité y étaient nettement inférieurs à ceux des grandes écoles américaines 360 ; enfin, McGill éprouvait certaines difficultés à recruter un nombre suffisant d'étudiants canadiens. Cet afflux d'Américains semble donc résulter autant d'une faiblesse démographique que du prestige international de McGill. L'Université de Toronto, dont la réputation était assurément égale à celle de McGill, n'admit qu'une poignée d'Américains durant cette même période (10 en 1930, 12 en 1937). Un bassin régional plutôt immense ainsi que le refus de relever brusquement ses critères d'admission garantirent à Toronto un nombre suffisant d'étudiants canadiens 361.

Enfin, signalons un dernier point. Les deux écoles francophones de médecine connurent d'importants changements durant les années 1920 et 1930, puisqu'elles étaient désormais financées par le gouvernement provincial ainsi que par des organismes privés comme la Fondation Rockefeller. Ces changements se

JAMA, vol. 113, 1939, p. 772.

360 En 1930, les frais de scolarité étaient de 310\$ à McGill, de 610\$ à Johns Hopkins, de 400\$ à Harvard, de 525\$ à Columbia et de 510\$ à l'Université de Pennsylvanie. JAMA, vol. 97, 1931, p. 638-645.

361 On remarque des différences similaires dans le recrutement des écoles de médecine américaines en ce qui concerne les étudiants provenant de l'extérieur de l'État. Des établissements comme Columbia et l'Université de la Pennsylvanie, qui se trouvent dans de très grandes villes, recrutaient essentiellement dans leur État respectif. Johns Hopkins et Yale, situées dans des États moins peuplés, recrutaient de 75 à 85\% de leur clientèle à l'extérieur de leur État respectif. Harvard représentait un cas unique, puisqu'en dépit de sa situation géographique dans un État fort peuplé, elle recrutait surtout à l'extérieur de l'État du Massachusetts. Mais, nous savons que Harvard cherchait activement à former une élite nationale plutôt que locale. (Ces conclusions se fondent sur les rapports annuels concernant l'enseignement de la médecine parus dans le JAMA au cours des années 1920 et 1930.) 
traduisirent notamment par l'ajout de laboratoires, de nouveaux locaux, des programmes améliorés, des professeurs recrutés a l'étranger. Mais ni Laval, ni l'EMC n'essayèrent d'imposer des critères d'admission identiques à ceux exigés par McGill. En 1920, l'EMC, alléchée par la promesse d'une subvention annuelle de 25000 dollars de la Fondation Rockefeller et s'inspirant d'un modèle introduit dans les écoles de médecine en France en 1893, exigea pour tous les candidats une année d'études en sciences préparatoire au cours de médecine. Seuls ceux qui pouvaient réussir l'examen sanctionnant cette année préparatoire étaient admis immédiatement en première année et ce, quelle que fût leur formation scolaire. Mais l'EMC n'exigeait pas pour autant un diplôme de premier cycle comportant une solide base en sciences. Laval n'a même pas établi d'année préparatoire en sciences à cette époque, en dépit d'un vote en ce sens de sa Faculté de médecine en 1931. Laval continua plutôt à admettre tous les diplômés des collèges classiques ${ }^{362}$. Tout diplômé d'un tel collège avait certainement reçu une meilleure formation que le diplômé d'un « high school » américain ou canadien, bien que Laval ait sans doute exagéré la valeur du baccalauréat classique en le comparant systématiquement au B.A. ou au B.Sc. dans ses annuaires et les statistiques pertinentes qu'elle envoyait au Journal of the American Médical Association ${ }^{363}$. De plus, les politiques d'enseignement de Laval et de l'EMC étaient résolument tournées vers la France plutôt que les États-Unis et c'était la France qui la première avait imposé cette exigence d'une année préparatoire en sciences. Néanmoins, il est également vrai que leurs stratégies de recrutement reflétaient les limites de leurs bassins de clientèle. Si McGill n'avait pas puisé dans la clientèle américaine presque illimitée, ses effectifs étudiants auraient

362 Les critères d'admission sont exposés dans les annuaires de ces écoles. Mais il faut voir tout particulièrement le dossier D35/672 12.11.1 («Conditions d'admissions-inscriptions, 1889-1948») dans les archives de l'Université de Montréal ; voir aussi Boissonnault, op. cit., p. 372-373.

363 En fait, la réputation de Laval était plutôt mauvaise au cours des décennies qui ont précédé et suivi le tournant du siècle. À cet égard, pour connaître les opinions d'un médecin belge qui a fait une étude sur les écoles de médecine d'Amérique du Nord, voir O. Laurent, Les universités des États-Unis et du Canada et spécialement leurs institutions médicales, Bruxelles, H. Lamertin, 1894, p. 297-299. Voir aussi Flexner, op. cit., p. 325 et Boissonnault, op. cit., p. 394. 
considérablement diminué en raison de ses nouveaux critères d'admission. Et c'est précisément le sort qu'auraient certainement connu les écoles francophones.

Grâce à la croissance démographique de Montréal, l'EMC put introduire cette année de formation préparatoire à la médecine. Il est probable que cette décision ne fut pas sans rapport avec la diminution du nombre de diplômés vers la fin des années 1920. Située dans une région beaucoup moins urbanisée, Laval n'était pas dans une position lui permettant de lancer cette réforme. Il est également probable que le maintien de ses critères d'admission a joué un certain rôle dans l'augmentation majeure de ses effectifs au cours des années 1920 et 1930.

\section{LE RECRUTEMENT AU QUÉBEC}

Pour analyser les tendances en matière de recrutement des écoles francophones, on doit examiner de près les origines régionales de la clientèle provenant du Québec. Aux fins de cette analyse, le Québec a été divisé en onze régions, décrites à l'annexe 1 . Le recrutement dans chaque région pour chacune des trois plus importantes écoles de médecine est résumé au tableau 2. Deux tendances sont faciles à dégager : le recrutement des étudiants québécois de ces trois établissements est devenu de plus en plus local ; il est aussi devenu de plus en plus urbain, partout, sauf à Laval.

La caractéristique la plus frappante du recrutement à Laval ainsi qu'à l'EMC consiste en sa nature locale. Ces deux établissements semblent s'être divisé la province aux fins de leur recrutement. Cette situation devait exister même avant l'affiliation systématique des collèges classiques à l'Université Laval ou à l'Université de Montréal 364. Durant les années 1870, l'EMC recruta 24\% de ses étudiants dans la ville de Montréal et 26\% sur l'île de Montréal et dans la banlieue environnante. Le reste de sa clientèle provenait principalement des Cantons du Nord, de la rive nord du Saint-Laurent et de l'Est du Québec. Par contre, cette dernière région était sous-représentée de façon significative comparativement à

364 Les collèges étaient affiliés à Laval au XIXe siècle. Mais aucun d'entre eux n'était affilié à Montréal avant la fondation de l'Université de Montréal en 1919. 
son pourcentage de la population francophone de la province (indice de représentativité : 0,38). Dès 1920, la clientèle issue du Montréal métropolitain comptait pour $67 \%$ des effectifs de cette école, les régions ayant perdu de l'importance à cet égard. De même, la nature de ce recrutement changea. Au cours des années 1870, l'EMC attirait une nombreuse clientèle rurale (58\%). Cette tendance reflétait bien la forte population rurale francophone et était présumément attribuable au réseau des collèges classiques qui permettait aux fils de familles moins fortunées de se joindre à ceux de la bourgeoisie rurale et de recevoir une formation de niveau secondaire. Bien qu'un grand nombre de ces étudiants aient opté pour la prêtrise, certains d'entre eux choisirent la médecine ${ }^{365}$.

Il est important de souligner que, déjà à cette époque, l'indice de représentativité de Montréal était en fait significativement plus élevé à l'EMC qu'à McGill (3,39 contre 2,27 au cours des années 1870). En d'autres termes, les francophones de Montréal étaient davantage sur-représentés à l'EMC par rapport à la population francophone totale, que les anglophones de Montréal fréquentant McGill l'étaient par rapport à la population anglophone. Dans une société alors essentiellement rurale, ce sont surtout les fils des familles urbaines (présumément de classe moyenne) qui s'intéressaient et avaient accès à la médecine. Au cours des années suivantes, le nombre de Montréalais inscrits à l'EMC a augmenté considérablement. Durant les années 1920, 50\% des étudiants de cette école étaient originaires de Montréal, alors que 27\% provenaient d'autres centres urbains. L'EMC était ainsi devenue un établissement dont la clientèle, à forte prédominance urbaine, reflétait le déplacement de la population francophone rurale vers Montréal, ainsi que l'essor des autres centres urbains du Québec. Par ailleurs, la proportion de la clientèle montréalaise à l'EMC était inférieure à celle de McGill (50\% au lieu de 71\% au cours des années 1920); mais la surreprésentation de Montréal, comparativement à l'ensemble de la population provinciale, était considérablement plus élevée (2,20 à l'EMC contre 1,42 à McGill). L'indice de représentativité de Montréal, qui avait chuté pendant un demi-siècle (en raison de l'augmentation de sa population), atteignit son plus bas niveau (1,77) dans les années 1910. Durant la décennie suivante, il s'éleva à 2,2 en dépit de la croissance démographique. En outre, cette tendance toujours

365 C. Galarneau, Les collèges classiques au Canada français, Montréal, Fides, 1978, p. 141-144. 
grandissante à la sur-représentation des Montréalais se retrouvait également à McGill. Il semblerait qu'à l'EMC du moins, les normes de plus en plus strictes d'enseignement de la médecine au cours de cette décennie auraient favorisé les Montréalais qui jouissaient d'un meilleur accès aux établissements d'enseignement, ainsi que, peut-être, de plus grandes ressources financières 366 .

Tout à fait à l'opposé de l'EMC, l'École de médecine de Laval recrutait ses étudiants essentiellement dans la ville de Québec et dans l'Est du Québec. Prises conjointement, ces deux régions fournissaient $72 \%$ des étudiants en 1870 et $75 \%$ en 1920. Les Cantons du Nord, la rive nord du Saint-Laurent et la région métropolitaine de Montréal constituaient les seuls autres bassins importants de clientèle. Il n'y a que dans les deux premiers cas où la proportion d'étudiants reflétait presque le pourcentage régional de la population francophone. La ville de Québec était largement sur-représentée par rapport à sa proportion de la population francophone, faisant ressortir une fois de plus les nombreux avantages de résider dans un centre urbain où se trouve une école de médecine. Il est également important de souligner que l'indice de représentativité de la ville de Québec a chuté considérablement au début de ce siècle pour augmenter à partir des années 1920, comme ce fut le cas pour Montréal (tant à McGill qu'à l'EMC). Mais puisque la croissance de la ville de Québec fut beaucoup moins rapide que celle de Montréal et que son influence sur sa région périphérique était moindre, le pourcentage des étudiants provenant de Québec inscrits à Laval diminua durant les années 1920 (25\%) comparativement aux années 1870 (32\%). La majorité des étudiants de cette université étaient originaires des régions rurales de l'Est du Québec. Par conséquent, le cas de Laval est singulier parmi les écoles médicales québécoises en ce sens que cette institution fut la seule à continuer à desservir une clientèle rurale fort nombreuse et à s'adapter aux tendances démographiques de ses principales régions de recrutement. En fait, la proportion d'étudiants provenant des zones rurales resta pratiquement stable de 1871 (50\%) à 1921 (51\%). Encore une fois, le réseau des collèges classiques a rendu possible ce modèle de

366 Durant sa brève existence, la constituante montréalaise de l'Université Laval a eu recours à des modèles de recrutement similaires à ceux de l'EMC. Cependant, Montréal et ses régions environnantes y étaient encore mieux représentées (71\% de tous les étudiants au cours des années 1880). 
recrutement rural à l'image des réalités démographiques constituant le bassin de clientèle de Laval.

L'information disponible sur les modèles de recrutement à l'échelle provinciale des deux écoles francophones de médecine montre sous un angle fort intéressant l'évolution des conditions d'admission au cours des années 1920. Il n'est probablement pas fortuit d'associer l'évolution des conditions d'admission à l'EMC à un contexte d'urbanisation croissante et de concentration de la clientèle à Montréal. À Laval, le maintien des vieux critères d'admission se fit dans le contexte d'un recrutement plutôt rural. Il faut prendre garde d'associer de façon simpliste origines rurales et critères d'admission moins stricts aux étudiants issus des classes moins privilégiées de la société. Néanmoins, il est fort probable que, dès le début du XXe siècle, la clientèle de Laval ait été d'origine relativement plus populaire que celle de l'EMC.

Ainsi, l'étude de Claude Galarneau semble indiquer que la clientèle des collèges classiques de Montréal et de Québec était beaucoup plus bourgeoise qu'ailleurs en province ${ }^{367}$. Si ses conclusions sont fondées, la prédominance croissante de la clientèle montréalaise à l'EMC doit avoir été suivie d'un embourgeoisement relatif de la population étudiante de l'EMC comparativement à celle de Laval.

Un certain nombre d'autres indices tendent à confirmer cette hypothèse. Par exemple, les frais de scolarité étaient beaucoup moins élevés à Laval qu'à l'EMC. En 1921, ces frais étaient de 90\$ par année pour un programme de cinq ans à Laval comparativement à $175 \$$ pour un programme de six ans à l'EMC ${ }^{368}$. De plus, Laval offrait un grand nombre de bourses à ses étudiants en médecine 369 . Néanmoins, ces faits ne sont qu'indicatifs et seules des recherches empiriques plus approfondies permettraient de mettre clairement en évidence une différence significative des origines sociales des clientèles respectives de ces deux écoles. Si une telle différence existe réellement, alors on peut comprendre plus facilement la

367 Galarneau, op. cit., p. 156.

368 Les frais annuels de scolarité à McGill s'élevaient à 240\$. En 1931, ils étaient de 310\$ à McGill, 235\$ à l'EMC et 165\$ à Laval. Voir les annuaires de ces diverses universités ainsi que les rapports annuels sur l'enseignement de la médecine parus dans le JAMA.

369 O. Laurent, op. cit., p. 298. 
nature des difficultés qu'aurait rencontrées Laval si elle avait adopté de nouvelles normes d'admission qui auraient exigé des sacrifices financiers considérables de la part des étudiants des couches sociales moins fortunées.

Comme l'indique le tableau 2, Montréal fournissait à McGill l'essentiel de sa clientèle québécoise. De 1870 à 1879, près de la moitié des étudiants de McGill étaient originaires de Montréal. À part Montréal, seulement deux autres régions, l'Outaouais et les Cantons du Sud contribuaient de façon significative aux effectifs étudiants de McGill ; ces deux régions représentaient alors 37\% de la population anglophone du Québec. Dès 1920, 84\% de la clientèle québécoise de McGill provenait de l'île de Montréal et 8\% d'autres centres urbains de la province. Dès lors, l'Outaouais et les Cantons du Sud cessèrent de lui fournir un grand nombre d'étudiants en médecine.

Cette diminution n'était pas seulement le reflet des tendances démographiques générales de cette époque. Au cours des années 1870, le taux d'inscription de la clientèle provenant de l'Outaouais reflétait fidèlement sa proportion de la population anglophone (indice de représentativité : 1,01) alors que les Cantons du Sud étaient plutôt peu représentés (indice de représentativité : 0,64). À partir de 1920, ces deux régions devinrent fort peu représentées. Hormis les avantages pour tous les étudiants en médecine de résider dans une grande ville, ce phénomène illustre peut-être aussi la marginalisation croissante des communautés anglophones à l'extérieur de Montréal.

Comme ce fut le cas dans les écoles francophones, la surreprésentation de Montréal parmi les étudiants de McGill diminua, à mesure que la proportion des anglophones à Montréal se rapprochait de celle des Montréalais (anglophones) fréquentant McGill. Dans cette institution, l'indice de représentativité était de 1,17 au cours des années 1910 et monta à 1,42 au cours de la décennie suivante. En plus de la modification des conditions d'admission favorisant les étudiants d'origine urbaine, il est vraisemblable que l'immigration joua aussi un rôle indirect dans cette sur-représentation accrue de Montréal. La baisse de l'indice de représentativité de cette ville au cours des années 1910 résulte de la croissance rapide de la population non francophone à Montréal en raison de l'afflux d'immigrants au début de ce siècle. Il faut néanmoins préciser que la majorité de ces immigrants ne constituait pas, de fait, une clientèle potentielle pour McGill. Ce n'est qu'au cours des années 1920, grâce à l'émergence d'une deuxième 
génération plus scolarisée, que quelques-uns de ces groupes d'immigrants (tout particulièrement les juifs) purent fournir des effectifs étudiants considérables à McGill (bien qu'ils étaient plutôt mal accueillis), augmentant ainsi l'indice de représentativité de Montréal. 
Tableau 2

Provenance régionale au Québec des étudiants en médecine Recrutement au Québec

\begin{tabular}{|c|c|c|c|c|}
\hline & \multicolumn{2}{|c|}{ Pourcentage } & \multicolumn{2}{|c|}{$\begin{array}{l}\text { Indice } \\
\text { de représentativité (a) }\end{array}$} \\
\hline & $1870-1879$ & 1919-1929 & $1870-1879$ & $1919-1929$ \\
\hline & \multicolumn{4}{|c|}{ École de médecine et de chirurgie } \\
\hline 1. Montréal & 21 & 50 & 3,39 & 2,20 \\
\hline 2. Île de Montréal & 3 & 3 & 0,91 & 2,20 \\
\hline 3. Banlieue de Montréal & 23 & 14 & 1,50 & 1,49 \\
\hline 7. Cantons du Nord & 14 & 7 & 0,92 & 0,93 \\
\hline 9. Rive Nord & 15 & 9 & 1,55 & 1,05 \\
\hline 11. Est du Québec & 13 & 3 & 0,38 & 0,10 \\
\hline Autres & 6 & 13 & 0,38 & 0,68 \\
\hline Royaume-Uni & 5 & 1 & - & - \\
\hline \multirow{2}{*}{ Total } & 100 & 100 & & \\
\hline & \multicolumn{4}{|c|}{ Laval } \\
\hline 3. Banlieue de Montréal & 6 & 5 & 0,39 & 0,53 \\
\hline 7. Cantons du Nord & 10 & 7 & 0,66 & 0,98 \\
\hline 9. Rive Nord & 6 & 6 & 0,62 & 0,70 \\
\hline 10. Québec & 32 & 25 & $-b$ & $-b$ \\
\hline 11. Est du Québec & 40 & 50 & 1,17 & 1,59 \\
\hline 11a. Région de Québec & 6 & 8 & - & - \\
\hline $\begin{array}{l}\text { 11b. Est du Québec(régions } \\
\text { rurales) }\end{array}$ & 35 & 42 & - & - \\
\hline \multirow[t]{2}{*}{ Total } & 100 & 100 & & \\
\hline & \multicolumn{4}{|c|}{ McGill } \\
\hline 1. Montréal & 49 & 71 & 2,27 & 1,42 \\
\hline 2. Île de Montréal & 3 & 13 & 1,25 & 1,42 \\
\hline 3. Banlieue de Montréal & 6 & 2 & 1,07 & 0,42 \\
\hline 5. Outaouais & 14 & 5 & 1,01 & 0,63 \\
\hline 6. Cantons du Sud & 15 & 6 & 0,64 & 0,48 \\
\hline Autres & 13 & 3 & 0,39 & 0,19 \\
\hline Total & 100 & 100 & & \\
\hline
\end{tabular}


Note: a) Proportion d'étudiants d'une région donnée inscrits dans un établissement, divisée par la population de cette région exprimée, selon la langue, en pourcentage de la population de l'ensemble du Québec.

b) Le nombre d'étudiants de cette région était trop peu élevé pour en déterminer des ratios utilisables.

\section{MOBILITÉ DES DIPLÔMÉS}

Les différentes régions où pratiquent les médecins diplômés représentent, pour une institution, un aspect tout aussi important que celui du lieu de recrutement de ses étudiants. Le tableau 3 fournit certaines données quant à deux groupes de ces diplômés, l'un ayant commencé à pratiquer au cours des années 1890 et l'autre durant les années 1920. Dans le cas des anciens de McGill, leur lieu de résidence a été consigné irrégulièrement dans des annuaires. Nous avons consulté l'annuaire de 1924 pour connaître le lieu de résidence des diplômés du premier groupe et celui de 1947 pour ceux du deuxième groupe. Les établissements francophones ne semblent pas avoir suivi la carrière de leurs diplômés, fort probablement parce qu'ils ne les considéraient pas comme une source éventuelle de financement. Nous nous sommes donc fiés à une autre source, à savoir les registres du Collège des médecins et chirurgiens de 1908 à 1943. Ces registres indiquent le lieu de pratique au Québec des diplômés. Par ailleurs, la non-inscription à ces registres peut porter à croire, à première vue, que ces diplômés n'ont jamais pratiqué au Québec. Cette méthode n'est évidemment pas infaillible puisqu'il est possible que certains médecins ne s'y soient pas inscrits tout en pratiquant leur profession au Québec. Encore plus important, l'inscription même n'écartait nullement la possibilité pour le médecin d'émigrer par la suite. Le nombre de diplômés non inscrits au Collège pourrait, par conséquent, constituer un indicateur minimum de l'émigration des médecins.

Dans l'ensemble, le tableau 3 suggère une explication simple de la faible densité de médecins qui, comme nous l'avons vu, était particulière au Québec. Parmi les diplômés des années 1890, seulement 44\% demeurèrent dans cette province pour y pratiquer; proportion qui, pour ceux des années 1920, s'accrut à 
53\%. McGill était principalement responsable de cet état de choses, mais Laval et l'EMC avaient également formé un nombre considérable de médecins qui avaient émigré pour pratiquer leur art. Cependant, nous avons utilisé un indicateur plus utile que ces pourcentages absolus: l'indice de rétention, soit le nombre de diplômés qui ont pratiqué au Québec divisé par le nombre de diplômés provenant de cette province. Cet indice fournit des résultats presque similaires (environ 80\%) pour les trois établissements, si nous combinons les deux décennies étudiées. En outre, le nombre de nouveaux médecins par tranche de population anglophone ou francophone, est aussi remarquablement semblable. McGill formait quatre médecins québécois par 10000 habitants non francophones au cours des années 1890 et 1920. Ensemble, Laval et l'EMC ont assuré la formation d'un peu plus de trois médecins par 10000 habitants francophones. Cette différence insignifiante est aussi frappante que la constance des statistiques d'une décennie à l'autre, ce qui confirme la stabilité historique du Québec à absorber ses diplômés en médecine.

Tableau 3

Diplômés en médecine pratiquant au Québec selon le lieu de formation

\begin{tabular}{|c|c|c|c|c|c|c|c|}
\hline & & & & & $\begin{array}{r}\text { Dip } \\
\text { qu } \\
\text { prat }\end{array}$ & $\begin{array}{l}\text { non } \\
\text { is } \\
\text { t au } \\
\text { c }\end{array}$ & $\begin{array}{l}\text { Indice } \\
\text { de } \\
\text { rétention } \\
\text { (a) }\end{array}$ \\
\hline & & $\begin{array}{c}\text { Nombre } \\
\text { de } \\
\text { diplômés } \\
\text { pratiquant } \\
\text { au } \\
\text { Québec }\end{array}$ & $\begin{array}{c}\text { \% du } \\
\text { total des } \\
\text { diplômés }\end{array}$ & $\begin{array}{c}\text { \% des } \\
\text { diplômés } \\
\text { québécois }\end{array}$ & $\mathrm{N}$ & $\%$ & \\
\hline McGill & 1890-1899 & 142 & 25 & 62 & 29 & 8 & 0,77 \\
\hline & 1920-1929 & 186 & 26 & 60 & 54 & 11 & 0,80 \\
\hline Laval & 1890-1899 & 96 & 84 & 86 & 1 & 33 & 0,86 \\
\hline & 1920-1929 & 76 & 76 & 82 & 4 & 13 & 0,84 \\
\hline EMC & 1890-1899 & 241 & 61 & 64 & 9 & 30 & 0,66 \\
\hline U. de M. & $1920-1929$ & 380 & 78 & 85 & 18 & 30 & 0,89 \\
\hline
\end{tabular}

Note : a) Nombre de diplômés pratiquant au Québec divisé par le nombre de diplômés provenant du Québec. 
Seulement un quart des diplômés en médecine de McGill exercèrent au Québec, ce qui n'est pas étonnant, si l'on tient compte du fait que cette université recrutait surtout sa clientèle à l'extérieur de la province. Toutefois, en chiffres réels, ce nombre est plutôt élevé et comparable aux effectifs formés à Laval. Quelque 60\% des diplômés formés au cours de ces deux décennies et originaires du Québec y sont restés pour pratiquer. À ce nombre s'ajouta un certain nombre de diplômés non québécois qui se sont installés au Québec après leurs études. Au total, une perte nette d'environ $20 \%$ des diplômés fut enregistrée pendant ces deux décennies. Les médecins qui émigrèrent durant les années 1890 se partageaient en deux groupes sensiblement égaux, s'installant soit aux États-Unis, soit au Canada anglais, tandis que durant les années 1920, la majorité de ceux qui le firent se sont établis dans le pays voisin. Par l'intermédiaire de McGill, l'Ontario perdit proportionnellement davantage de diplômés qui étaient originaires de cette province que le Québec. Au cours des années 1920, la perte nette de diplômés originaires de l'Ontario s'éleva à 38\%. Il semble évident que le fait de quitter le milieu familial pour étudier à Montréal représentait déjà pour eux un début de déracinement.

À Laval, environ 80\% de tous les diplômés s'installèrent au Québec. Compte tenu du très petit nombre d'inscriptions de l'extérieur du Québec, ce pourcentage démontre le comportement particulier des diplômés québécois dont le taux d'émigration était d'environ 15\%. La rétention nette de ces diplômés était d'environ 85\% au cours de ces deux décennies, soit un taux légèrement plus élevé qu'à McGill, surtout durant les années 1920. Cette comparaison étonne pour deux raisons. D'abord, ces taux sont très semblables en dépit de bassins de clientèle on ne peut plus différents, l'un étant anglophone et dominé par Montréal, l'autre francophone à moitié rural. Enfin, fait aussi surprenant, il y a la constance remarquable de ces taux lors de deux décennies fort différentes, tant au point de vue du développement économique que des tendances démographiques.

Comparativement à ces deux derniers établissements, l'EMC se révèle certainement le cas le plus intéressant. Au cours des années 1890, environ 60\% des diplômés décidèrent de rester au Québec. Seulement 64\% de tous les diplômés originaires de cette province y exercèrent, soit un pourcentage presque identique à celui des Québécois inscrits à McGill qui demeurèrent dans leur 
province. Pourtant, contrairement à McGill, l'EMC ne pouvait compter sur l'apport d'une clientèle provenant de l'extérieur du Québec pour contrebalancer en partie ce mouvement d'émigration. Par conséquent, la rétention nette de diplômés au cours des années 1890 fut seulement de 66\%, soit le taux le plus faible de toutes les principales écoles de médecine. Par contre, cette situation changea complètement au cours des années 1920. Pas moins de 85\% des diplômés originaires de Québec s'y installèrent et furent rejoints par un petit nombre de diplômés provenant d'autre régions. L'indice de rétention s'éleva alors à 89\%, le taux le plus élevé parmi les trois établissements existants.

Ce changement marqué correspondait au taux global d'émigration au Québec qui a été très élevé au cours des années 1890 et beaucoup moins élevé lors des années $1920{ }^{370}$. Mais ce recours aux seules tendances démographiques n'explique pas cette énorme différence entre le choix des diplômés de Laval d'une part, et celui des diplômés de l'EMC et de McGill d'autre part. De plus, le caractère restrictif croissant des politiques américaines ne semble pas avoir été un facteur majeur, puisque les taux d'émigration des diplômés de Laval et de McGill restèrent pratiquement inchangés des années 1890 aux années 1920. Sans prétendre à une explication définitive, nos données nous permettent néanmoins de clarifier certains aspects du problème. Elles indiquent un certain nombre de faits connexes qui peuvent être résumés de la façon suivante. Premièrement, Montréal et Québec ne représentaient pas des lieux de pratique particulièrement intéressants pour les diplômés en médecine des années 1890. Deuxièmement, les diplômés originaires de Montréal quittaient souvent non seulement cette ville mais aussi la province, alors que ceux provenant de Québec s'installaient dans d'autres régions du Québec. Troisièmement, ces deux villes devinrent des lieux de pratique nettement plus intéressants pour les diplômés des années 1920, mais cet intérêt accru pour Montréal a entraîné des changements particulièrement brusques de comportement chez les diplômés de l'EMC.

Ces tendances sont illustrées au tableau 4 qui indique le taux net de rétention des diplômés pour les régions du Québec ayant fourni un nombre suffisamment important d'étudiants. Montréal n'était pas un lieu de pratique particulièrement

370 P.-A. Linteau, R. Durocher, J.-C. Robert, Histoire du Québec contemporain, Montréal, Boréal Express, 1979, p. 42. 
affectionné par les diplômés de McGill des années 1890. Seulement 41\% des diplômés originaires de Montréal décidèrent alors de s'y installer. Le nombre additionnel de diplômés de l'extérieur de Montréal porta l'indice net de rétention à 76\%. Par contre, la région périphérique de Montréal qui fournissait un nombre modeste de diplômés ainsi que les Cantons du Sud, dont l'apport fut plus considérable, attiraient relativement plus de diplômés. Dès 1920, la proportion de natifs de Montréal qui choisirent d'y pratiquer leur profession s'éleva à 50\%. L'afflux de nouveaux Montréalais contribua à augmenter l'indice de rétention à 94\%, soit presque le seuil d'équilibre. Cependant, d'autres régions perdaient leur pouvoir d'attraction auprès des diplômés de McGill. Par conséquent, l'indice de rétention au Québec des diplômés de cette université est demeuré stable, comme nous l'avons vu antérieurement.

Parmi les diplômés de l'EMC des années 1890, 60\% de ceux qui étaient originaires de Montréal quittèrent cette ville à la fin de leurs études. Les deux tiers d'entre eux quittèrent le Québec définitivement. Toutefois, l'exode vers Montréal en provenance d'autres régions, particulièrement de sa banlieue, a fait augmenter le taux de rétention net de Montréal à 92\%. Au cours des années 1920, 72\% des diplômés originaires de cette ville choisirent d'y exercer, alors que l'exode rural vers Montréal s'accentuait. Le nombre de nouveaux médecins y surpassa donc considérablement celui des diplômés (indice de rétention : 1,40). Même Laval, où l'on ne compta pourtant qu'un seul diplômé montréalais au cours de cette décennie, vit alors 16 de ses diplômés s'installer à Montréal.

Québec suscitait encore moins d'intérêt que Montréal chez les diplômés francophones des années 1890. Moins de la moitié des diplômés en étant originaires y pratiquèrent. La plupart des autres diplômés ne quittèrent pas la province, et s'établirent plutôt dans la région périphérique de Québec ou dans l'Est de la province. D'autre part, peu de médecins de l'extérieur venaient exercer à Québec. Il en résulta que l'indice net de rétention à Québec des diplômés de Laval n'atteignit que 70\%, un taux moins élevé que celui des diplômés de McGill à Montréal. Paradoxalement, les régions avoisinantes, y compris les régions surtout rurales de l'Est du Québec, d'où provenait la grande majorité des diplômés, réussissaient plutôt bien à attirer ces derniers, entraînant par le fait même un indice de rétention au Québec plutôt élevé. 


\section{Tableau 4}

Indice de rétention des principales régions de recrutement au Québec (a)

\begin{tabular}{lcc}
\hline & $1890-1899$ & $1920-1929$ \\
\hline & 0,76 & McGill \\
1. Montréal & 3,00 & 0,94 \\
2. et 3. Île et banlieue de Montréal & 0,23 & 1,10 \\
5. Outaouais & 0,94 & 0,25 \\
6. Cantons du Sud & École de médecine et de chirurgie \\
& 0,92 & 1,40 \\
1. Montréal & 0,57 & 0,42 \\
2. et 3. Île et banlieue de Montréal & 0,35 & 0,45 \\
7. Cantons du Nord & 0,39 & 0,27 \\
9. Rive Nord & 0,76 & 0,33 \\
11. Est du Québec & & Laval \\
\hline & 0,70 & 1,10 \\
10. Québec & 1,25 & 0,35 \\
11a. Région de Québec & 0,80 & 0,66 \\
11b. Est du Québec & & \\
\hline
\end{tabular}

Note : a) Nombre de diplômés pratiquant en région divisé par le nombre de diplômés originaires de chacune de ces régions.

Au cours des années 1920, Québec affichait un léger surplus de nouveaux médecins par rapport au nombre de ses diplômés. Elle ne parvenait encore à conserver que $57 \%$ de ses diplômés mais réussissait à en attirer des régions avoisinantes. L'Est du Québec, qui constituait toujours le principal bassin de clientèle étudiante de l'Université Laval, perdit ainsi au moins le tiers de ses diplômés. Tout de même, en tenant compte de l'urbanisation croissante de toute la province, les diplômés de Laval continuèrent à être attirés en nombre étonnant par les régions rurales. Le groupe le plus nombreux de diplômés de Laval (soit plus de 26\% du total) pratiqua dans les comtés ruraux de l'Est du Québec, 24\% 
exercèrent à Québec et $24 \%$ quittèrent définitivement la province. Selon les critères contemporains, on doit reconnaître que Laval jouait un rôle essentiel en formant ainsi des médecins pour les régions rurales.

D'une manière générale, les variations du taux d'émigration des diplômés de l'VEMC (ainsi que ceux de Laval) semblent donc avoir été liées au développement économique et à la croissance démographique des grandes villes. La croissance économique et l'urbanisation exercent une influence sur la médicalisation des populations - de même que sur les lieux de pratique des médecins -, de façons diverses et complexes qui n'ont jamais été analysées en profondeur. Ces facteurs entraînent une meilleure scolarisation, une augmentation des revenus disponibles (deux facteurs facilitant le recours aux médecins), une densité de clientèle accrue et un réseau plus vaste d'hôpitaux pour s'y affilier. Tous ces facteurs (et il en existe bien d'autres) contribuent à orienter les choix de carrière des jeunes médecins.

Mais, pour les jeunes médecins, peut-être la démographie pure et simple constitue-t-elle à la fois l'aspect le plus simple et le plus frappant de l'essor d'une grande ville. À partir de ce point de vue, il devient plutôt facile d'expliquer l'attrait croissant de Montréal pour les médecins francophones et anglophones. De 1891 à 1931, la population de cette ville passa de 256723 à 818577 habitants offrant ainsi des perspectives énormes aux médecins. De fait, malgré la concentration toujours croissante des diplômés à Montréal, le nombre de médecins par habitant y passa, en raison de la croissance démographique, d'un médecin par 636 habitants en 1911 à un médecin par 711 habitants en 1931.

La croissance de Québec fut beaucoup moins spectaculaire que celle de Montréal. De toute façon, cette ville n'a jamais monopolisé le recrutement, ni le placement des diplômés de Laval. Son évolution démographique a quand même joué un rôle à cet égard. Son impopularité auprès des diplômés des années 1890 pourrait bien avoir reflété sa stagnation démographique car, en 1891, sa population ne s'était que très légèrement accrue par rapport à ce qu'elle était vingt ans plus tôt. La clientèle disponible dans l'Est du Québec était beaucoup plus grande. Cependant, de 1911 à 1931, la population de Québec s'accrût de 66\%. Parallèlement, dès 1921, son impopularité auprès des diplômés avait entraîné une densité de médecins plutôt faible (1 médecin par 744 habitants comparativement à 1 médecin par 644 habitants à Montréal). Il est donc possible que ces faits aient 
transformé Québec en lieu de pratique plutôt intéressant pour les diplômés de Laval des années 1920. De fait, dès 1931, le nombre de médecins par habitant avait augmenté à 1 médecin par 677 habitants, soit un rapport plus élevé qu'à Montréal même (1 médecin par 711 habitants). Néanmoins, Laval représentait toujours au Québec un établissement d'enseignement particulier, dans la mesure où elle continuait à former un très grand nombre de médecins qui iraient pratiquer en région rurale.

\section{CONCLUSION}

Cette étude des origines régionales et du lieu de pratique des diplômés en médecine ne met en évidence aucune distinction importante entre les secteurs francophone et anglophone des établissements d'enseignement médicaux. Par contre, on retrouve des différences importantes entre les différentes écoles de médecine. Ces différences résultent dans une large mesure des réalités démographiques auxquelles ces écoles ont dû s'adapter et des stratégies de recrutement que chacune d'entre elles a dû élaborer.

McGill fut un cas d'espèce parmi les écoles de médecine au Québec et même au Canada, puisque la majeure partie de sa clientèle provenait de l'extérieur de la province. Cette situation s'explique en partie, par son influence et sa réputation internationale. Elle reflète également la faible population anglophone locale ainsi que l'incapacité de McGill à attirer un nombre suffisant d'étudiants du Canada anglais, après que ces derniers eurent la possibilité de poursuivre leurs études dans des établissements locaux comparables à McGill. Après 1920, cette université se retrouva dans une position inconfortable, car elle dut puiser une partie importante de sa clientèle au nord-est des États-Unis. Le recrutement dans cette région était assuré grâce à un accroissement considérable de la demande pour une formation médicale et à un contingentement strict des places disponibles dans les universités américaines.

Étant toutes deux situées à Montréal, McGill et l'EMC possédaient beaucoup de traits communs, et ce nonobstant leurs nombreuses différences. Dès le début du XXe siècle, elles recrutèrent essentiellement leur clientèle dans les régions urbaines, tout particulièrement Montréal, alors que Laval continuait à recruter 
dans les régions rurales, surtout dans l'Est de la province. Bien que les diplômés de Laval avaient alors de plus en plus tendance à s'établir dans les grandes villes, cette institution formait encore, dans une large mesure, des médecins de campagne. En outre, au XIXe siècle, de nombreux diplômés québécois de l'EMC quittaient la province. Cette émigration diminua considérablement au cours du XXe siècle. À Laval, tout comme à McGill, la situation fut plus stable durant les deux décennies étudiées, mais l'indice général de rétention des diplômés originaires de Montréal et de Québec était comparable. Alors que la majorité des diplômés de Laval demeurèrent au Québec, ceux de McGill d'origine québécoise qui émigrèrent furent partiellement remplacés par des diplômés non originaires du Québec qui s'y établirent.

La croissance démographique rapide de Montréal rendit cette ville particulièrement attirante pour les diplômés francophones et anglophones des années 1920. Cette situation prévalait aussi à Québec, quoiqu'à une moindre échelle, pour les diplômés de Laval.

Nous avons vu que la nature même de ces bassins de clientèle a également eu une influence sur quelques-unes des caractéristiques scolaires de chacun de ces établissements. De plus, le fait que McGill assurait la formation de nombreux étudiants désirant pratiquer aux États-Unis l'obligea à adopter dans les années 1920 des critères d'admission de plus en plus stricts exigés par l'American Medical Association et les commissions médicales des divers États. Les écoles francophones, et aussi dans une moindre mesure l'Université de Toronto, recrutaient localement et eurent moins besoin de procéder aussi rapidement à de tels changements. De fait, les effectifs réduits de l'EMC et de Laval ne justifiaient pas l'adoption totale des nouvelles normes américaines. Contrairement à Laval, l'EMC bénéficiait d'une certaine marge de manœuvre pour hausser ses critères d'admission, parce qu'elle se trouvait dans une ville peuplée.

Des recherches plus approfondies permettraient sans doute de découvrir d'autres liens entre le recrutement, les caractéristiques pédagogiques et l'orientation vers la recherche de chacun de ces établissements. L'importance des effectifs étudiants de McGill a généré des ressources financières considérables à même les frais de scolarité et, plus tard, grâce aux contributions des anciens élèves. Bien que le modèle de recrutement de McGill puisse avoir résulté de la nécessité démographique, il a bel et bien contribué à la réputation, soigneusement 
entretenue d'ailleurs, d'excellence internationale de cette université, excellence qui lui a permis d'obtenir de nombreux dons privés. Il ne serait pas étonnant si d'autres recherches démontraient que l'intégration de McGill au réseau des écoles d'élite d'Amérique du Nord a accéléré l'adoption d'un certain nombre de nouvelles politiques administratives, à savoir l'ouverture de postes d'enseignement à temps plein à l'université et dans les hôpitaux, l'embauche de professeurs de réputation internationale, rôle essentiel de la recherche et de la publication au cours d'une carrière dans l'enseignement, politiques qui donnaient à McGill une longueur d'avance sur les établissements francophones. Par ailleurs, il ne faudrait pas s'étonner d'apprendre que Laval, qui formait un grand nombre d'étudiants provenant des régions rurales pour qu'ils deviennent médecins généralistes, possédait elle aussi des caractéristiques institutionnelles particulières. En plus d'avoir des ressources financières plus limitées, cette institution jouait un rôle social tout à fait unique. On peut au moins soutenir que les changements instaurés à McGill et dans les établissements d'élite américains auraient été totalement inopportuns eu égard au rôle particulier joué par Laval et qu'ils auraient même été improductifs. À cet égard comme à bien d'autres, il est moins utile de comparer ces établissements à l'établissement idéal que de déterminer dans quelle mesure chacun de ces établissements a joué le rôle particulier qu'on exigeait de lui, tout en s'adaptant à un cadre social particulier. 


\section{Annexe}

\section{Population de certaines régions du Québec}

\begin{tabular}{|c|c|c|c|c|c|c|c|c|c|}
\hline \multirow[b]{2}{*}{ Région } & \multicolumn{3}{|c|}{1871} & \multicolumn{3}{|c|}{1901} & \multicolumn{3}{|c|}{1921} \\
\hline & Nombre & $\begin{array}{c}\text { \% sur } \\
\text { l'ensemble du } \\
\text { Québec }\end{array}$ & $\begin{array}{c}\% \\
\text { d'anglophon } \\
\text { es dans la } \\
\text { région }\end{array}$ & Nombre & $\begin{array}{c}\text { \% sur } \\
\text { l'ensemble du } \\
\text { Québec }\end{array}$ & $\begin{array}{c}\% \\
\text { d'anglophones } \\
\text { dans la région }\end{array}$ & Nombre & $\begin{array}{c}\text { \% sur } \\
\text { l'ensemble du } \\
\text { Québec }\end{array}$ & $\begin{array}{c}\% \\
\text { d'anglophones } \\
\text { dans la région }\end{array}$ \\
\hline 1. Montréal & 107621 & 9,1 & 46,8 & 203068 & 12,4 & 43,7 & 728210 & 31,1 & 37,8 \\
\hline 2. Le de Montréal & 36589 & 3,1 & 18,0 & 147845 & 9,0 & 26,7 & - & - & - \\
\hline 3. Banlieue de Montréal & 154812 & 13,1 & 10,1 & 204292 & 12,5 & 9,9 & 199027 & 8,5 & 11,1 \\
\hline 4. Valleyfield/Beauharnois & 26394 & 2,3 & 64,2 & 51404 & 3,1 & 33,8 & 47537 & 2,0 & 27,7 \\
\hline 5. Outaouais & 67215 & 5,7 & 57,0 & 83241 & 5,1 & 43,9 & 117692 & 5,0 & 31,3 \\
\hline 6. Cantons du Sud & 123459 & 10,4 & 52,2 & 153516 & 9,4 & 39,9 & 196805 & 8,4 & 29,4 \\
\hline 7. Cantons du Nord & 146854 & 12,4 & 5,8 & 159629 & 9,8 & 3,6 & 143813 & 6,1 & 2,5 \\
\hline 8. Trois-Rivières & 8414 & 0,7 & 8,6 & 9984 & 0,6 & 5,1 & 22367 & 1,0 & 6,0 \\
\hline 9. Rive Nord & 92434 & 7,8 & 4,2 & 107862 & 6,6 & 1,8 & 167695 & 7,2 & 3,8 \\
\hline 10. Ville de Québec & 59699 & 5,0 & 31,5 & 68842 & 4,2 & 17,2 & 93093 & 4,0 & 10,6 \\
\hline 11. Est du Québec (a) & 353040 & 30,0 & 11,9 & 446475 & 27,3 & 8,7 & 628083 & 26,8 & 6,2 \\
\hline Total & 1185166 & & & 1636168 & & & 2344322 & & \\
\hline
\end{tabular}

Note a) Compte tenu des objectifs poursuivis, nous avons divisé cette région en deux parties ne coïncidant pas avec celles délimitées par le recensement. Québec métropolitain : rayon de 25 milles. Est du Québec : à l'extérieur du rayon de 25 milles. 


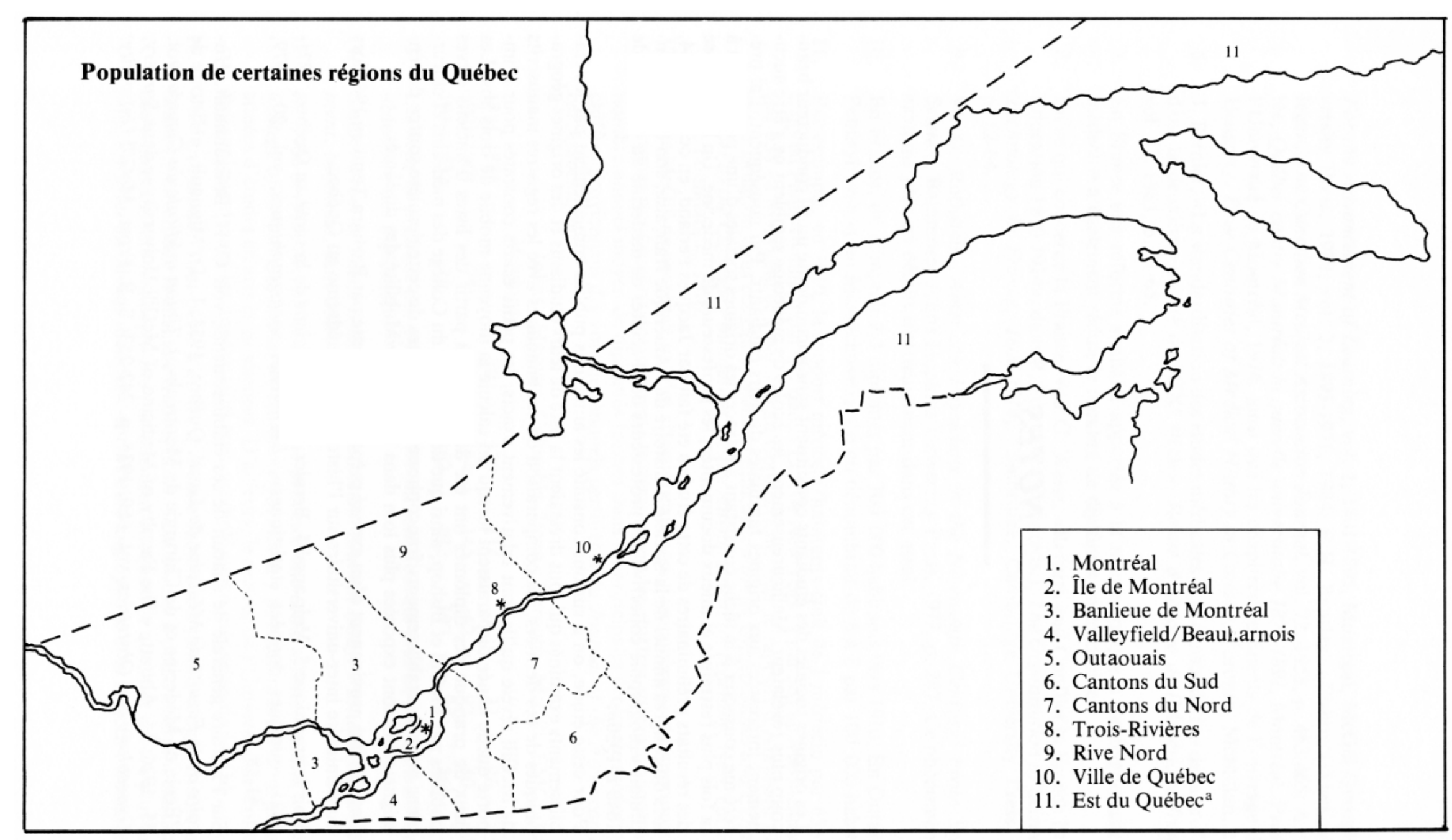

Note a) Compte tenu des objectifs poursuivis, nous avons divisé cette région en deux parties ne coïncidant pas avec celles délimitées par le recencement. Québec métropolitain: rayon de 25 milles. Est du Québec: à l'extérieur du rayon de 25 milles. 
Sciences et médecine au Québec.

Perspectives sociohistoriques

\title{
Chapitre VI
}

\section{Entre l'hôpital et l'université: l'Institut du cancer de Montréal*}

\author{
par Marcel Fournier \\ Professeur, Département de sociologie, Université de Montréal
}

$\underline{\text { Retour à la table des matières }}$

L'activité scientifique est évidemment, comme le suggèrent certaines études récentes, de l'ordre de la conversation entre des chercheurs emmurés dans leur laboratoire, mais plus encore, car elle exige, pour être effective, des agents dotés d'une formation scientifique et bien au fait de ce qui s'écrit dans ce domaine, des instruments et des équipements scientifiques, et enfin des contextes institutionnels convenables. Les sciences (et leur histoire) ne doivent pas être réduites, en poussant à l'extrême, ni au seul développement des disciplines, tels les paradigmes, etc., ni à la seule manipulation de textes et d'instruments en laboratoire : elles sont le résultat de deux vecteurs, celui de l'action sociale, soit les interactions et les négociations, par laquelle les groupes de scientifiques donnent une signification à leurs diverses activités intellectuelles et manuelles, et celui de la régulation sociale qu'exercent à la

* Financé par le CRSH (Conseil de recherche en sciences humaines) et le fonds FCAR (Formation des chercheurs et aide à la recherche), ce projet de recherche a été réalisé en collaboration avec Louis Maheu, Francine Descarries-Bélanger et C. Richard du Département de sociologie de l'Université de Montréal. 
fois les milieux ou communautés scientifiques et les diverses institutions qui les composent. Et s'il est possible de parler de "périodes » dans le développement des sciences, c'est qu'à un moment donné, dans une conjoncture précise, la rencontre de l'une et l'autre - l'action des scientifiques et la régulation des institutions - avec leurs caractéristiques propres (lieux de formation et itinéraires socioprofessionnels des chercheurs, mode d'organisation des laboratoires, mode de subvention, etc.) donne à l'activité scientifique une configuration particulière : chaque période se définit par un type de connaissance, par exemple l'ensemble de concepts et de procédures, mais en autant que ce type apparaît lié à des conditions sociales particulières, comme les identités et les idéaux scientifiques, la délimitation des domaines et des procédures en secteurs distincts, le mode d'organisation de la production et de l'évaluation des connaissances, les supports et les systèmes d'emploi, etc. ${ }^{371} \mathrm{Ni}$ une discipline scientifique dans son ensemble, ni une activité scientifique particulière menée par un ou plusieurs chercheurs ne sont susceptibles de bien exprimer la tension qui, propre à la science, unit et oppose le dedans et le dehors, l'interne et l'externe, le cognitif et le social. Mieux que la discipline ou le laboratoire, le centre de recherche est un lieu d'observation privilégié, du fait que son histoire particulière révèle non seulement l'influence des initiatives individuelles et collectives, mais aussi la valeur des institutions administratives ou politiques en ce qui a trait à la formation, à l'évaluation, à la subvention, etc., et, plus largement, la situation du contexte sociohistorique.

Notre analyse porte sur l'Institut du cancer de Montréal (I.C.M.), officiellement incorporé en 1947. Le dépouillement d'une abondante documentation, notamment les rapports annuels, les budgets, les procès-verbaux du Conseil d'administration, les articles dans les journaux, les publications scientifiques, etc., et aussi l'interview de chercheurs qui sont associés ou ont été associés à l'Institut, permettent de dégager les principaux enjeux, à la fois scientifiques, institutionnels et sociaux, auxquels cet Institut de recherche a été confronté et qui, à chacune des périodes de son développement, ont déterminé l'orientation des activités de recherche : se préoccuper de thérapie ou développer la recherche clinique et la recherche fondamentale; demeurer en milieu hospitalier ou chercher une affiliation avec une université ;

371 Voir R.D. Whitley, « From, the Sociology of Scientific Communities to the Study of Scientists' Negotiations and Beyond ", Informations sur les sciences sociales, vol. 22, no 4 et 5, 1983, pp. 681-720. 
dépendre d'un organisme subventionnaire principal ou diversifier les sources de subvention, etc. Parce que la science n'existe en réalité qu'en autant qu'elle est matérialisée dans des espaces (ou édifices) et dans des équipements (ou instruments) et qu'elle est incorporée, sous la forme de compétences et d'habitus, dans des agents, ces enjeux se manifestent souvent sous la forme soit de relocalisation ou d'agrandissement de l'espace, soit dans le renouvellement des équipements scientifiques, soit dans un changement du personnel de recherche ou de direction.

\section{De la thérapie à la recherche : les causes du cancer}

L'I.C.M. est à l'origine le produit de la rencontre des trajectoires de deux médecins, l'un, le docteur Louis-Charles Simard (1900-1970), médecin à l'Hôpital Notre-Dame et l'autre, le docteur Antonio Cantero (1902-1977), spécialiste en gastroentérologie et professeur à la Faculté de médecine de l'Université de Montréal. Médecins, tous les deux ont le souci de soulager la douleur et de guérir la maladie ; chercheurs, ils sont préoccupés de découvrir les causes et le fonctionnement de la maladie. Complémentaires, la formation, l'orientation et la position des deux fondateurs sont à la source d'une tension qui caractérisera l'Institut tout au long de son développement : situé dans une institution hospitalière tout en étant affilié, à partir de 1951, à une université, il est en effet tiraillé entre la réalisation d'activités thérapeutiques et la réalisation de recherches à caractère fondamental. Mais cette localisation institutionnelle et cette double orientation permettent à l'I.C.M. d'acquérir, assez rapidement, une visibilité sociale sur le plan local et une autorité scientifique sur le plan international.

Tout au cours des années 1930 et 1940, la recherche sur le cancer réalisée aux États-Unis suivait aussi ces deux voies : d'un côté, des recherches expérimentales, habituellement sur des animaux telles les souris, orientées vers la connaissance des causes et de la nature biochimique du cancer; de l'autre, des recherches chimiques étroitement reliées à la thérapie et aux traitements des malades, à savoir la pathologie de diverses tumeurs, la mise au point de tests et de techniques chirurgicales, le recours aux rayons $\mathrm{X}$, le développement de la chimiothérapie, etc. Durant ces décennies, principalement à la suite de la création en 1937 du National Cancer 
Institute, la recherche américaine sur le cancer connaît une croissance considérable et mobilise des ressources financières de plus en plus élevées : plus de 14 millions en 1951372 .

Au Canada, on peut observer le même mouvement : mise sur pied en 1931 par la Canadian Medical Association d'un Comité sur le cancer, constitution en 1935 sous l'initiative du Gouverneur général d'un fonds, The King George V Silver Jubilee Cancer for Canada, jouissant de près d'un demi-million de dollars, et en 1937, création de la Canadian Society for the Control of Cancer, qui deviendra plus tard, en 1945, la Canadian Cancer Society ${ }^{373}$. Au Québec, la fondation en 1926 de l'Institut du radium de l'Université de Montréal traduit cette nouvelle sensibilité des milieux médicaux et gouvernementaux à l'égard du cancer. D'abord dirigé par le docteur Ernest Gendreau, ce centre, qui bénéficie de subventions gouvernementales pour l'acquisition de radium, demeure jusqu'au début des années 1940 le principal lieu de traitement par radiation et d'hospitalisation. Il comprend alors un personnel médical composé d'une quinzaine de médecins, soit les chefs de laboratoire, les consultants, etc., et un personnel hospitalier composé de cinq religieuses, d'une vingtaine d'infirmières diplômées et de six techniciens ${ }^{374}$.

372 Voir R. F. Bud, « Strategy in American Cancer Research After World War II. A Case Study », Social Studies of Science, vol. 8, 1978, pp. 425-459. Pour l'Allemagne: R. Hohfeld, "Two Scientific Establishments which shape the Patern of Cancer Research in Germany : Basic Science and Medicine », dans N. Elias, H. Martins et R. Whitley, Eds., Scientific Establishments and Hierarchics, Sociology of the Sciences, vol. VI, 1982, pp. 145-168.

373 Voir docteur A. D. Kelly, The Cancer Movement in Canada, 1930-1950, National Institute of Canada, non daté, 23 pages.

374 Dans son étude La science et le pouvoir au Québec, 1920-1965, Éditeur officiel du Québec, Québec, 1978, Raymond Duchesne fait une brève allusion à l'Institut du radium: "Ernest Gendreau, après avoir organisé la Faculté de médecine et la Faculté des sciences de l'Université de Montréal, obtint du gouvernement provincial en 1924, la somme fabuleuse pour l'époque, de 100000 \$ pour la création de l'institut du radium » (p. 13). Et en note, Duchesne précise, sur la base d'une entrevue avec Léon Lortie qui fut secrétaire de cet organisme, que « l'Institut devait s'occuper de recherches médicales et physiques, mais que le docteur Gendreau s'en tint au traitement médical ». Sur la base de sa pratique, celui-ci publiera un ouvrage en 1936.

En raison de la controverse, particulièrement sur sa mauvaise administration, dont son premier directeur sera l'objet, il y aurait lieu d'effectuer une analyse plus détaillée de cet institut qui, au moment de son incorporation en 1926, réunissait en 
Parmi les médecins qui, au Québec, s'impliquent alors dans la « lutte contre le cancer », le docteur Louis-Charles Simard est, avec les docteurs Edward Percival, Jean Bouchard et Carleton Price, sans aucun doute l'un des plus actifs. La première initiative de ce médecin, chef de service d'anatomie pathologique à l'Hôpital NotreDame et professeur agrégé à l'Université de Montréal, est la mise sur pied en 1941 d'un centre anticancéreux. Il s'agit d'une clinique externe, semblable à celle dont l'American College of Surgeon préconise alors l'organisation dans les grands hôpitaux. Dotée d'un secrétariat avec registres et puis d'un laboratoire de cytologie exfoliatrice, cette «clinique des tumeurs » a pour objectif « d'établir un diagnostic précis, d'établir un programme de traitement approprié et de surveiller les cancéreux déjà traités 375 ». Dès ses études qu'il poursuit à Strasbourg sous la direction des professeurs Roussy, Leroux, Cornie et principalement de Pierre Masson, le docteur Simard s'intéresse à l'étude des tumeurs et publie des articles dans le Bulletin de IAssociation française pour l'étude du cancer ${ }^{376}$. Aussi publiée dans ce Bulletin en 1930, sa thèse d'agrégation à la Faculté de médecine de l'Université de Montréal porte sur « la maladie de Paget du mamelon : cancer épidermétrope ». Tout en poursuivant des travaux en anatomie-pathologie, le docteur Simard demeure au cours des années 1930 préoccupé par la question du cancer -article de « Tumour of the Palm Having the Structure of a Mix Tumour of the Salivary Glands », en 1938 dans l'American Journal of Cancer - et il fait siennes les vues de l'Association médicale canadienne qui, afin d'enrayer les ravages faits par le cancer, veut créer une Société contre le cancer ${ }^{377}$. Il multiplie alors ses interventions publiques et ses conférences devant des

plus du docteur Gendreau, Mgr V.-J. Piette, protonotaire apostolique, les docteurs Louis de Lotbinière-Harwood, Télesphore Parizeau, Albert Lesage et Georges Baril, le professeur Arthur Léveillé et le financier Louis de Gaspé Beaubien. À la fin des années 1940, le président du Conseil d'administration de l'Institut du radium était $\mathrm{M}$. T. Taggart Smith de la Banque d'épargne et son directeur médical et scientifique, le docteur Origène Dufresne. Voir O. Dufresne, «L'Institut du "Radium” », L'Action universitaire, décembre 1935, pp. 4-8.

375 Docteur Louis-Charles Simard, «Un Institut qui fait honneur à la médecine canadiennefrançaise », Le Devoir, 1956. Voir aussi Roger Daoust, Historique et revue des activités scientifiques, Montréal, Institut du cancer de Montréal, document interne, novembre 1975, 18 pages.

376 Voir L.-C. Simard, président de VA CFA S 1946-1947, « Note biographique et bibliographique » dans Annales de l'ACFAS, 1947.

377 L.-C. Simard, « La lutte anticancéreuse dans la province de Québec », Union médicale du Canada, tome 36, septembre 1937, pp. 967-968. 
clubs sociaux, à la radio, etc., conscient qu'il est de la nécessité de démystifier les croyances populaires sur le cancer et d'inciter la population à se prêter au dépistage et au traitement précoce. Ses initiatives personnelles sont en parfait accord avec celles d'organismes nationaux de lutte contre le cancer auxquels lui-même participe : le Centre anticancéreux est ouvert quelques années après la création en 1938 de la Canadian Society for the Control of Cancer et l'Institut du cancer de Montréal, quelques années après la fondation en 1947 de l'Institut national du cancer. En 19481949, L.-C. Simard devient président de cet organisme qui, affilié à la Société canadienne du cancer, subventionne des travaux de recherche fondamentale et la formation des spécialistes, tout en coordonnant les programmes provinciaux de lutte contre le cancer. Le docteur Simard participe à ces organismes, avec une double préoccupation : à la fois contrer le taux alors élevé de mortalité due à la prolifération de cellules cancéreuses, par exemple le cancer du sein chez les femmes ${ }^{378}$, et accroître le nombre de chercheurs canadiens- français en médecine, nombre qui lui semble «pas assez grand ${ }^{379}$ ». La transformation du Centre anticancéreux en un Institut du cancer indique que ses tâches ne se limitent plus seulement au dépistage, au diagnostic et au traitement, mais aussi, d'une manière plus conséquente, il est tourné vers la recherche : l'objectif de l'Institut est de "déterminer les causes et de découvrir le traitement du cancer 380 ». Dans le contexte sociopolitique des années 1930 et 1940, cette double préoccupation prend une légère teinte nationaliste: « Nationaliste dans l'action, il [le docteur Simard] s'est toujours, écrira-t-on, affairé à améliorer la qualité de la pratique médicale et ce n'est pas par hasard qu'aujourd'hui dans la province nous connaissons des réalisations spectaculaires 381 ».

Lorsqu'il crée l'Institut du cancer de Montréal, incorporé en 1947 et affilié à l'Hôpital Notre-Dame en 1949, L.-C. Simard a déjà acquis une renommée dans les milieux de la médecine et de la recherche scientifique. En effet, en 1946-1947 il est

378 L.-C. Simard, «Sur la fréquence du cancer du sein chez les femmes dans la province de Québec », Union médicale du Canada, vol. 37, 1938.

379 L.-C. Simard, «La recherche scientifique en médecine et la guerre », Union médicale du Canada, vol. 71, juillet 1942, p. 696.

380 Simon Lauzé, « Dr L.-C. Simard », L'Équipe, infra, note 12, p. 15.

381 L.-C. Simard et A. Cantero, Les laboratoires de recherche de l'Institut du cancer de Montréal, document interne, janvier 1966, 29 p. (p. 2). 
président de l'ACFAS (Association canadienne-française pour l'avancement des sciences) ${ }^{382}$.

Si L.-C. Simard détient tout le capital social, tel que la légitimité et les relations sociales, nécessaire à la mise sur pied d'un Institut du cancer, il n'a ni le temps ni le leadership scientifique pour assurer la direction des laboratoires de recherche; il s'associe avec le docteur Antonio Cantero qui, spécialiste en gastro-entérologie, a déjà parallèlement à sa pratique médicale, orienté son intérêt vers la cancérologie ${ }^{383}$. Des conditions dans lesquelles ce dernier effectue ses premières recherches, dès 1937, ses collaborateurs en donnent une description qui contribue à construire la «légende »: une caisse d'oranges et quelques planches lui servent de table dans une cage d'ascenseur désaffectée de l'ancienne École de médecine vétérinaire, ruelle Providence ; de faibles appuis financiers de l'ordre de 150\$ qui, provenant de l'Institut du radium et de la maison Hoffman-La Roche, lui permettent d'acheter quelques

382 En plus de la présidence de l'ACFAS (1946-1947), les postes qu'a occupés le docteur L.-C. Simard sont: membre de la Société royale du Canada; de l'Association française pour l'étude du cancer; de l'Association médicale canadienne (membre de l'Editorial Board) ; de la Société de biologie de Montréal (président en 1942-1943); de la Société canadienne d'histoire naturelle (président en 1943-1944); de Society of the Sigma XI (McGill Chapter); de la Société médicale de Montréal; de la Montreal Medical-Chirurgical Society; de la Canadian Physiological Society; de l'American Associationfor the Advancement of Science ; de l'Institut national du cancer du Canada ; de l'Union médicale du Canada (président du Bureau de direction en 1945); du Comité médical du Conseil national des recherches (membre de l'exécutif en 1943). Il est aussi secrétaire général de la Revue canadienne de biologie depuis 1943. Notes biographiques et bibliographiques, op. cit., $p$. 126. Le docteur Simard accédera aussi en 1950 à la présidence de la Section V (Sciences biologiques) de la Société royale du Canada et se verra attribuer de nombreuses distinctions honorifiques : prix scientifique de la province de Québec, médaille Léo Parizeau de l'ACFAS, etc. Voir : S. Lauzé, « Dr L.-C. Simard » dans L'Équipe, hôpital Notre-Dame, vol. 10, no 2, juin 1970, pp. 14-15; G. Préfontaine, « Éditorial », Revue canadienne de biologie, vol. 30, n' 2, juin 1971, pp. 89-96.

383 Fils d'ingénieur et né à Ofena en Italie, A. Cantero a quatre ans lorsque ses parents s'établissent à Sudbury. Après ses études secondaires au Collège des Jésuites de cette localité, celui-ci poursuit ses études en médecine à l'Université McGill et effectue des stages à la Clinique Mayo de Rochester (1928-1930) et à l'Hôpital Michœl Reage de Chicago (1930-1932) pour ensuite se spécialiser en gastro-entérologie (R. Daoust, « Antonio Cantero, 1902-1977 », Délibérations de la Société royale du Canada, série IV, tome XVII, 1979, pp. 69-73 ; Curriculum vitoe d'A. Cantero, Archives de la Faculté de médecine, Université de Montréal). 
animaux et d'amorcer des études ${ }^{384}$. Les difficultés éprouvées par le docteur Cantero dans la poursuite de ses activités de recherche illustrent bien les problèmes que doit affronter à l'époque tout pionnier en sciences : argent, locaux, cobayes, équipement, personnel, tout est parcimonieusement compté. Il racontera lui-même son histoire :

J'avais le principal : ma tête. Et aussi mon indépendance de chercheur libre. Je me suis alors isolé du reste du monde et j'ai travaillé sans relâche. J'avais en tête des hypothèses que je voulais vérifier. J'ai acheté quelques cobayes : des rats et des souris. Mes premières recherches pratiques ont porté sur le rôle des glandes endocrines dans le développement des tumeurs mammaires chez la souris. Je me suis mis en communication avec des endocrinologues américains, préoccupés par le même type de recherche. Ce qui m'a plu, c'était cette liberté, cette solitude qui m'entouraient, indispensable au chercheur, à mon avis. J'étais confiant. Je savais que ce n'est pas nécessairement dans les grands laboratoires qu'on fait les plus grandes découvertes 385.

Lorsque Antonio Cantero se joint à L.-C. Simard, il dispose déjà d'un local de recherche dans le nouvel édifice de l'Université de Montréal et bénéficie de subventions de recherche un peu plus élevées. Il a réussi à intéresser à ses recherches de jeunes diplômés universitaires, dont ses premiers collaborateurs; de plus, ses travaux ont attiré l'attention de spécialistes américains qui l'ont invité à participer au Congrès international de recherche sur le cancer d'Atlantic City et à publier en 1949 et 1950 ses résultats de recherche dans l'Acta Union Inter Cont. Cancrum. À la légitimité et au capital de relations sociales du docteur Simard, le docteur Cantero apporte donc une crédibilité scientifique ${ }^{386}$, assurant à l'I.C.M. son insertion dans des milieux scientifiques non seulement canadiens mais aussi internationaux. Alors que L.-C. Simard occupe (jusqu'en 1970) les postes de président et de directeur général de l'Institut, A. Cantero prend la responsabilité (de 1950 à 1967) de la direction de ses laboratoires de recherche et exerce la fonction du «directeur

lbid., p. 71.

385 Monique de Gramont, «Quand on cherche, on trouve. Antonio Cantero », Châtelaine, décembre 1976, p. 91.

386 Le docteur Cantero participe aussi en 1979 à une mission scientifique au Brésil et est professeur invité en oncologie à l'Institut Oswald Cruz de Rio de Janeiro. Il maintiendra par la suite des relations étroites avec l'Institut du Cancer de Rio de Janeiro. Enfin, dans les années 1950, le docteur Cantero accédera à diverses sociétés savantes tant sudaméricaines qu'américaines (New York Academy of Sciences en 1954, American Chemical Society en 1952) ou canadiennes (Société royale du Canada en 1953). 
scientifique ». L'« oeuvre maîtresse » de ce médecin-chercheur sera «sa contribution à l'organisation et au développement des recherches à l'Institut du cancer 387 », et il la réalisera en s'associant des chercheurs de formation universitaire scientifique et qui se consacreront uniquement à la recherche : ce seront, parmi les premiers collaborateurs, Roger Daoust et Gaston de Lamirande, tous deux diplômés en sciences, l'un en biologie et l'autre en chimie de l'Université de Montréal. Pour la grande majorité, les articles que publie le docteur Cantero à partir du début des années 1950 jusqu'en 1973 sont rédigés en collaboration avec des chercheurs de l'Institut : parmi les chercheurs les plus fréquemment co-auteurs avec le docteur Cantero, l'on retrouve Gaston de Lamirande (25 articles), Claude Allard (23 articles), G. Weber (19 articles) et Roger Daoust ( 9 articles). Tout en laissant à ses chercheurs une «très large liberté dans le choix et la conduite de projets de recherche », le docteur Cantero exerce le rôle du " patron », «à la main de fer et au cœur d'or », dira-t-on, qui voit à ce que «tout le travail entrepris soit mené rondement et complété 388 » et surtout, il inculque à ses proches collaborateurs un esprit et une éthique. Non seulement il leur enseigne à mettre en pratique sa propre devise «Bien faire et laisser braire », mais aussi il les incite très tôt à présenter les résultats de recherche dans des congrès scientifiques et à publier des articles dans les meilleures revues internationales. L'Institut est donc, à l'origine, une véritable école de formation ${ }^{389}$ et d'autoformation : préparation de communication et répétitions publiques, apprentissage et maîtrise de la langue anglaise, discussion "houleuse » des textes et rédaction de multiples versions des articles, etc. Pour leur part, les premiers collaborateurs du docteur Cantero s'initient à la recherche sur le cancer et poursuivent, parallèlement à leurs activités de recherche, leur formation universitaire et scientifique.

Détenteur en 1947 d'un B.Sc. biologie de l'Université de Montréal, Roger Daoust (1924-) poursuit immédiatement à la même université ses études de maîtrise en

389 On peut aussi parler d'une «socialisation» en ce sens que l'influence qu'exerce le docteur Cantero ne touche pas uniquement à la recherche scientifique mais aussi à la vie sociale elle-même: celui-ci est en effet un guide en gastronomie, en relations sociales et aussi en matières culturelles (littérature, peinture, etc.). Le médecin-chercheur qui dans ses loisirs est aussi un peintre, avouera lui-même : « Je suis un homme de la Renaissance. J'aime la littérature, la peinture, la musique. L'art agit sur moi comme une nourriture » (Châtelaine, décembre 1976, p. 94). 
biologie sous la direction de $\mathrm{H}$. Prat et du docteur Cantero. Sa thèse de maîtrise présentée en 1950 porte sur les « enzymes du métabolisme des acides nucléiques dans les tissus normaux et cancéreux ». Et tout en travaillant à l'Institut du cancer de Montréal, Daoust réalise ses études de doctorat au Department of Anatomy de l'Université McGill sous la direction du professeur C.-P. Leblond et obtient en 1953 son Ph.D. avec une thèse dont le sujet porte sur «les acides nucléiques dans les cellules au repos et en division ». Même s'il a déjà publié quelques articles avec le docteur Cantero, cette année 1953 marque le véritable début de sa carrière scientifique: publication de deux articles avec Leblond, l'un dans le Journal of Biological Chemistry et l'autre dans le Canadian Journal of Medical Sciences, affiliation à l'American Association for the Advancement of Science, à la New York Academy of Science et à la Société de biologie, nomination au poste de secrétaire du Cancer Club de Montréal, etc. Deux ans plus tard, Daoust obtient des bourses pour effectuer des études postdoctorales en histologie et histochimie d'abord à Londres en 1955-1956 au Chester Beaty Research Institute, sous la direction du professeur A. Haddow et à Copenhague en 1956-1957 au Fibiger-Laboratiet, sous la direction du professeur J. Eugelbreth-Holm.

Pour sa part, ancien élève du Collège Sainte-Marie (1935-1943), Gaston de Lamirande (1923-) a une formation universitaire en chimie à l'Université de Montréal où il exerce pendant ses études la tâche de démonstrateur (1946-1948) : L.Sc. en 1946, M.Sc. chimie organique en 1949 avec une thèse dont le titre est « Mise au point au sujet de la distillation fractionnée des esters méthylliques des acides gras », et enfin D.Sc. chimie organique en 1949 avec une thèse sur la « Pyrolise d'acides gras en phase pseudo-gazeuse ». D'abord orientée vers la recherche appliquée dans le secteur de la pétrochimie, Gaston de Lamirande qui conserve un lien avec la chimie président de la Société de chimie de Montréal en 1956, membre de l'Institut de chimie du Canada depuis 1949, registraire en 1961-1963 de l'Association des chimistes professionnels du Québec -, bifurque un peu par hasard vers la cancérologie: rencontre de R. Daoust, ouverture d'un poste à l'I.C.M., etc. Tout comme Daoust, il accède au début des années 1950 à diverses associations scientifiques tant canadiennes (Société de biologie de Montréal, Montreal Physiological Society, Canadian Physiological Society) qu'américaines (A.A.A.S., New York Academy of Sciences). Et celui-ci effectuera, mais pour un bref séjour en 1958, un stage au Chester Beaty Research Institute de Londres; il publiera alors en collaboration avec 
Haddow un article dans la revue Nature (1958, vol. 182, p. 1 144-1 146). Ses domaines de recherche étant le métabolisme des acides nucléiques et des protéines, les enzymes de l'anabolisme et du catabolisme, les tumeurs primaires et transplantées du foie du rat (cancérogénèse), de Lamirande est amené à collaborer avec Roger Daoust (7 articles entre 1950 et 1980) et surtout avec C. Allard (plus de vingt-cinq articles et de nombreuses communications entre 1950 et 1960).

Sur le plan administratif, R. Daoust et G. de Lamirande font aussi équipe : alors qu'entre 1966 et 1974 le premier assume la responsabilité de la direction des laboratoires de recherche, l'autre l'assiste à titre de directeur adjoint. Et en 1974, au moment où Daoust est nommé directeur général de l'Institut, de Lamirande accepte, pour une année, la tâche de directeur intérimaire des laboratoires de recherche. L'année suivante, celui-ci est nommé vice-doyen à la recherche et aux études supérieures à la Faculté de médecine de l'Université de Montréal.

À plus d'un égard, la situation dans laquelle se retrouvent ces chercheurs illustre bien les conditions de la recherche scientifique au lendemain de la Seconde Guerre mondiale : formation scientifique incomplète, faiblesse des budgets de recherche et exiguïté des locaux, absence de sécurité d'emploi pour les chercheurs, faible organisation des milieux scientifiques québécois et canadiens, etc. En dépit de cette situation, l'Institut du cancer de Montréal réussit à s'organiser rapidement, d'une part en obtenant un solide appui financier de l'I.N.C. - une subvention consolidée (Black Grant) de 40 000\$ en 1950 - et d'autre part, en effectuant une percée dans les milieux scientifiques internationaux : un article paru dans Science en 1950, deux articles dans Cancer Research en 1952, un article dans Nature en 1953, etc. La stratégie de recherche consiste, pour cette petite équipe, à « ne pas s'éparpiller en surface sur une multitude de projets » mais « au contraire à se concentrer sur quelques points précis ». «Par l'ingéniosité de nouvelles méthodes, par la patience », on cherche, dans un effort coordonné, à « fournir une ou deux pièces, si petites soient-elles, à l'édifice de la connaissance complète du cancer 390 ». Spécialisés principalement en cancérogénèse chimique, les chercheurs de l'Institut, qui entre autres réussissent à mettre au point une méthode de comptage utilisée dans les autres laboratoires, acquièrent une notoriété et sont identifiés par des chercheurs américains au

390 L.-C. Simard, «Un Institut qui fait honneur à la médecine canadiennefrançaise », op. cit. 
«Montreal Group ». Enfin, sur le plan local, l'Institut obtient aussi du crédit auprès du public par l'organisation, pour les médecins, de démonstrations et de leçons relatives au diagnostic du cancer, par la présentation de conférences publiques - près de soixante entre 1942 et 1956 - et par la publication d'articles dans les revues médicales et dans divers journaux.

\section{Entre l'hôpital et l'université}

Même si le développement des sciences biologiques exige à l'origine que la médecine se sépare du malade et que le médecin prenne ses distances de l'hôpital pour se doter d'un lieu de travail où il peut mener une pratique expérimentale, qui ne se confond ni avec la démonstration anatomique ni avec la pratique médicale, il n'en demeure pas moins que le laboratoire de biologie participe, en tant qu'« endroit commode » ou «topos », à la fois au laboratoire scientifique, par exemple en chimie, et à l'hôpital comme lieu de recherche et qu'il peut être localisé dans différentes institutions ${ }^{391}$. Au Québec, l'histoire des Facultés de médecine est souvent étroitement associée à celle d'un ou de plusieurs hôpitaux : par exemple, ce sont des médecins de l'hôpital Notre-Dame qui, jusqu'au milieu des années 1940, sont les doyens de la Faculté de médecine de l'Université de Montréal ; à partir des années 1930 et 1940, le personnel médical de cette institution accorde une importance de plus en plus grande à l'enseignement et à la recherche : rappelons les travaux des docteurs Simard et Masson sur les tumeurs, ceux du docteur A. Bertrand sur les méthodes nouvelles de séro-diagnostic de la syphilis, ceux, plus récents, du docteur C.-R. Grignon sur l'effet de la cortisone sur la cirrhose, etc. Mais si l'hôpital peut constituer un lieu de recherche et offrir divers avantages institutionnels - locaux et équipements, reconnaissance sociale, critère d'utilitarisme, etc. -, la recherche n'apparaît possible, lorsqu'elle devient expérimentale, qu'en autant qu'elle se dissocie de la clinique d'une manière plus ou moins complète selon le cas, et aussi qu'elle accueille des non-médecins.

391 Claire Salomon-Bayet, L'institution de la science et l'expérience du vivant, Paris, Flammarion, 1978, p. 398 et suiv. 
Au moment où, en 1947, le Centre anticancéreux se transforme en Institut du cancer de Montréal ${ }^{392}$, celui-ci se voit attribuer une «certaine autonomie» institutionnelle, mais celle-ci est toute relative : ce « service autonome », qui conserve un nom bien distinctif et peut intéresser des «personnes étrangères à l'Hôpital », demeure en effet une «filiale de l'Hôpital» et doit permettre à son Conseil d'administration l'accès à tous ses livres de comptabilité. Par ailleurs, même si les statuts de l'Institut limitent ses activités aux «enquêtes et recherches scientifiques pour découvrir les causes et les remèdes pour la maladie du cancer », ses responsables maintiennent une préoccupation pour le traitement lui-même; ils effectueront en 1963 une démarche officielle pour modifier leur charte de façon à y inclure cette dimension de leurs activités et obtenir l'autorisation d'« établir des services cliniques pour le traitement du cancer 393 ». L'Institut du cancer de Montréal entend ainsi être un « tout », non seulement en participant à la recherche et à l'enseignement, mais aussi, de par son intégration à un grand hôpital, en collaborant au «dépistage, au diagnostic et à la surveillance ». Cependant, l'orientation de l'Institut national du cancer dans ses politiques de subvention, l'attraction de l'université et surtout la restructuration du système de santé lui-même contribueront à cantonner l'I.C.M. dans le secteur de la recherche.

S'il est un problème que rencontre l'I.C.M. tout au cours des années 1950, c'est celui de sa «stabilisation » et de sa «permanence » : non seulement les chercheurs qui y travaillent n'ont pas de statut officiel mais aussi ils se retrouvent, comme l'Institut lui-même, dans une situation de totale insécurité, dépendants qu'ils sont de l'obtention, année par année, de subventions de recherche. L'entente qui, conclue en 1959, lie l'Institut du cancer de Montréal, l'Institut national du cancer et l'Université de Montréal, constitue une première réponse pour assurer à l'I.C.M., selon les termes de l'entente, « un maximum de permanence et de continuité dans ses travaux de

392 Les personnes qui ont en 1942 demandé par requête la Charte pour l'I.C.M. sont toutes étroitement reliées à l'Hôpital Notre-Dame : en plus du docteur L.-C. Simard, ce sont Armand Chaput, industriel et président du Conseil d'administration de l'Hôpital et Paul-Émile Bonnier, comptable agréé et trésorier de la même institution (Lettres patentes constituant en corporation l'Institut du cancer de Montréal, 11 novembre 1942, libro 206, folio 145).

393 Lettres patentes supplémentaires, Institut du cancer de Montréal, 9 septembre 1963, libro 1181, folio 7. La valeur des propriétés mobilières que peut posséder la corporation passe de 25000 \$ à 3000000 \$. 
recherche en cancérologie » et « offrir aux hommes de science qui se consacrent aux recherches... une sécurité et des appointements convenables, en même temps qu'une large mesure d'indépendance professionnelle ». Par cette entente, l'I.N.C. consent à " défrayer par des octrois [...] le coût de tous les travaux de recherches fondamentales proposés par le personnel scientifique du Laboratoire de recherche de l'I.C.M. et acceptés par l'I.N.C. »; il accepte aussi de «fournir à l'Université de Montréal les fonds suffisants pour permettre à ladite université d'adjoindre à son personnel, sur la recommandation du Comité de relations conjointes, certains hommes de science poursuivant des recherches sur le cancer dans le Laboratoire de recherches de l'I.C.M. et de payer pour les appointements desdits hommes de science». En retour, l'Université de Montréal confère des «titres universitaires appropriés et les privilèges s'y rattachant aux chercheurs admis dans son personnel » et les autorisent à participer à l'enseignement de la Faculté de médecine, « si cette faculté le désire, pourvu que le temps consacré à cet enseignement n'excède pas quatre heures par semaine pour chaque chercheur ».

Au lendemain de l'entente, on pense que < d'avenir de l'Institut du cancer de Montréal et de ses laboratoires est assuré 394 ». La même année, le docteur Cantero, directeur du laboratoire de recherche, reçoit une subvention de 78 000\$, c'est-à-dire la plus haute subvention octroyée par l'Institut national du cancer à un groupe de chercheurs québécois ${ }^{395}$. Et si pour les chercheurs eux-mêmes, ces «obscurs laborantins », cette entente n'apporte pas une sécurité complète, elle leur en attribue pas moins un statut social équivalent à celui du professeur d'université, statut auquel accéderont au cours des années 1960 les chercheurs seniors de l'I.C.M.: Roger Daoust, Gaston de Lamirande, Bernard Messier, Vijai N. Nigam et d'autres. Et aux tâches d'enseignement que ces chercheurs acceptent, s'ajoute celle de la direction des travaux de recherche de candidats aux diplômes supérieurs.

Mais dans un contexte où le statut social du professeur d'université est plus élevé que celui de chercheur et où l'université cherche à monopoliser des activités d'enseignement et de recherche en sciences, l'affiliation de l'I.C.M. à l'Université de

394 Alfred Ayotte, « Nouveau pas en recherche scientifique », La Presse, lundi 25 mai 1959.

395 La Presse, 20 août 1959. Quant à l'Université McGill, elle reçoit alors un montant total d'environ 70000 \$, dont 44250 \$ attribués au docteur J.-H. Quastel et $24000 \$$ au docteur C.-P. Leblond. 
Montréal est elle-même une source de tensions: celle-ci suscite en effet des insatisfactions chez les chercheurs ; de plus, elle fait naître une inquiétude au sein de l'ensemble de l'organisme, celle d'être absorbé par l'université. Le docteur L.-C. Simard manifestera publiquement cette inquiétude lors d'une assemblée spéciale au bureau d'administration de l'I.C.M. et rappellera l'idéal que doit poursuivre cet organisme. Voici la version de cette intervention que donne le bureau d'administration dans le procès-verbal de son assemblée : l'inquiétude du docteur Simard s'expliquerait par le fait qu'il ne veut pas que l'on déménage à l'Université de Montréal les laboratoires de recherches de l'Institut du cancer de Montréal. C'est pourquoi il voudrait profiter de la circonstance pour entreprendre les démarches nécessaires à la réalisation de son rêve dont les grandes lignes sont les suivantes : un local qui regrouperait le secrétariat, la surveillance, le dépistage, la radiothérapie, ainsi que les laboratoires de recherches et un département composé d'une quinzaine de lits pour y loger les malades pendant quelques jours, à la manière des grands centres en dehors du pays. Cet ensemble serait l'orgueil de l'Hôpital Notre-Dame et de l'Université de Montréal ${ }^{396}$.

Déjà équipé d'appareils modernes en radiothérapie et en radiodiagnostic, l'Institut du cancer de Montréal intensifie, à la fin des années 1960, son action dans les domaines du dépistage et du traitement. Coup sur coup, en 1967 et en 1969, on organise, avec la participation d'un médecin résidant, un service de soins à domicile à l'intention des malades cancéreux à l'Hôpital, et l'on met sur pied, avec l'engagement d'un spécialiste, un centre de reconstruction maxillo-faciale. Cependant, à un moment où le gouvernement provincial entreprend, par le biais de la Commission CastonguayNepveu, une réorganisation de l'ensemble des services de santé, la possibilité pour l'I.C.M. de poursuivre et de développer ses activités proprement thérapeutiques apparaît d'autant plus compromise que seul le laboratoire de recherche «a su se développer selon les ambitions de son fondateur et a su soutenir la réputation de son personnel 397 ». Ce laboratoire regroupe, sous la direction de Roger Daoust, plus de quarante personnes, dont huit chercheurs, et dispose en 1970 d'un budget supérieur à 550 000\$, comparativement à $95000 \$$ dix ans plus tôt.

396 Procès-verbal de l'assemblée du bureau d'administration de l'Institut du cancer de Montréal, mardi 29 mars 1966, p. 124.

397 L'Institut du cancer de Montréal, 1970, document interne, 12 p. (p. 8). 
L'Institut du cancer de Montréal, dont le nom n'apparaît pas, contrairement aux autres Instituts de cardiologie, de réhabilitation, de recherches cliniques et de neurologie, sur la liste des institutions hospitalières susceptibles de recevoir des subventions statutaires de la part du ministère des Affaires sociales, entreprendra une lutte acharnée: rédaction de textes, conférences et articles dans les journaux, démarches multiples, etc. Tout en rappelant son histoire et ses nombreuses contributions, l'I.C.M. réaffirmera sa vocation originale qui est d'être un "véritable centre de lutte anti-cancéreux » - avec centre de dépistage, de traitement et de surveillance, programme de recherches cliniques et fondamentales sur le cancer, secrétariat et département d'archives. Il proposera un plan de développement comportant deux aspects principaux : d'abord une réorganisation administrative, c'està-dire la définition claire des juridictions entre l'Hôpital et l'Institut, la composition différente du Conseil d'administration, le mode de financement basé non sur des octrois annuels, mais sur des subventions statutaires, etc., et ensuite la construction d'un pavillon qui, tout en assurant le regroupement des diverses activités de l'Institut, offrirait la possibilité d'accroître l'espace disponible à la recherche et aussi d'organiser une véritable hôtellerie avec deux étages de lits ${ }^{398}$. Face à la menace d'être totalement intégré au milieu hospitalier et de devenir un "hôpital d'incurables", l'I.C.M. veut défendre son autonomie et «demeurer un centre anti-cancéreux actif 399 ».

À la suite de l'adoption en 1973 de la Loi de l'organisation des services de santé et des services sociaux (Bill 65), l'I.C.M. est cependant contraint de redéfinir ses orientations afin de se conformer à la nouvelle loi et à ses règlements. Il doit en effet abandonner à l'Hôpital les services cliniques pour le traitement du cancer et limiter ses activités à la recherche. Après de nombreuses réunions auxquelles participent des représentants du ministère, de l'Hôpital, de l'Université et de l'Institut, il est convenu -

398 Ibid.

399 L'Institut du cancer de Montréal et ses laboratoires de recherche, mars 1971, 19 pages (p. 7). Dans ce document, l'I.C.M. formule d'une manière très explicite ses revendications, à savoir la reconnaissance de l'I.C.M. comme «centre anticancéreux subventionné par le gouvernement provincial comme une institution hospitalière avec un budget global ». Quant au projet de construction d'un édifice, il est toujours présent, mais " pour un avenir immédiat », on suggère diverses mesures, par exemple occuper la Résidence Notre-Dame comme hôtellerie, accorder des lits d'hospitalisation pour la radiothérapie et la chimiothérapie, reloger la clinique des tumeurs et l'équipe de surveillance, etc. 
« Nous n'avons pas le choix si nous voulons survivre 400 » - que l'Hôpital assumerait dorénavant toute responsabilité relevant directement des soins aux patients et créerait les structures nécessaires pour coordonner les activités cliniques en cancérologie d'où la création d'un Centre d'oncologie ; que l'Institut poursuivrait des recherches fondamentales et cliniques en cancérologie de même que des études épidémiologiques et opérationnelles permettant d'évaluer l'amélioration des soins accordés aux patients cancéreux et continuerait de participer à l'enseignement universitaire ; enfin, que l'Université conserverait son autorité en matière de recherche et d'enseignement ${ }^{401}$. L'I.C.M. n'abandonne donc pas totalement ses préoccupations pour le traitement et pour la recherche clinique, mais il devra redéfinir son mode d'intervention dans ces secteurs d'activités: poursuite des recherches en immunothérapie et développement des recherches épidémiologiques et opérationnelles quant à l'évaluation des méthodes de dépistage, aux protocoles de traitement, etc. L'Institut vise à devenir un «centre majeur de recherches et d'enseignement en cancérologie », c'est-à-dire un «centre où des équipes multidisciplinaires poursuivront des recherches fondamentales et appliquées en cancérologie, engageront des études en collaboration avec les cliniciens et contribueront au développement de l'enseignement universitaire en cancérologie 402 ». Si la réorganisation des services de santé oblige ainsi l'I.C.M. à réduire et à réorienter ses activités, elle lui offre néanmoins un nouveau support financier : en effet, le ministère des Affaires sociales s'engage à fournir un budget de soutien - 180000 en 1973-1974 -, assurant la stabilité, la continuité et le bon fonctionnement de l'Institut.

Dans sa relation avec le grand public, l'Institut du cancer de Montréal n'en conserve pas moins sa «mission sociale ». Par sa localisation dans un hôpital, par la nomination d'un médecin-chercheur au poste de directeur scientifique et par la mise sur pied d'un centre de dépistage du cancer du sein, ce centre de recherche demeure

400 Propos du docteur Jean-Louis Léger, directeur général de I'I.C.M., lors de l'assemblée spéciale du 27 juin 1973.

401 Roger Daoust, L'Institut du cancer de Montréal, Historique et revue des activités scientifiques, novembre 1975, p. 4. Ces changements nécessitent une révision des lettres patentes, la formation d'une fondation et la renégociation des contrats d'affiliation avec l'Hôpital Notre-Dame et l'Université de Montréal.

402 Daoust, LInstitut du cancer de Montréal, orientations et développements, novembre 1975, 12 p. (p. 1). 
toujours engagé dans la « lutte contre le cancer ». L'un des objectifs de l'Institut n'estil pas, à la toute fin des années 1970, d'« identifier les facteurs cancérigènes » et par là, «contribuer à réduire encore davantage l'incidence du cancer 403 », cette «maladie » qui, depuis la Seconde Guerre mondiale, est devenue la « seconde cause de mortalité au Canada 404 ? » Dans les années 1970 comme dans les années 1950, il est toujours question de «maladie », de "souffrance », de «mortalité », mais les ambitions thérapeutiques sont plus modestes, plus réalistes : « Il faut bien, confie M. Roger Daoust à un journaliste, se garder au départ d'entretenir de faux espoirs chez les gens 405 ». Le travail consiste donc moins a " guérir » qu'à dépister et à prévenir et, à la recherche proprement clinique, on tend à substituer la recherche épidémiologique. Quant à la recherche, dont l'objectif ultime est de "trouver un moyen d'empêcher la multiplication des cellules ou de les détruire dans l'organisme », elle se poursuit, mais « lentement, péniblement jusqu'au jour $\mathrm{J}$ où les savants pourront crier victoire $406 »$.

\section{Développement disciplinaire et contraintes institutionnelles}

La prise en considération d'informations telles que les espaces occupés par l'Institut, les budgets de fonctionnement, le nombre de chercheurs ou le nombre de publications, donne de son développement l'image d'une évolution continue, progressive. Les locaux occupés par les laboratoires de recherche de l'I.C.M. représentent en effet successivement 1600 pi. ca. en 1950, 6300 pi. ca. en 1960 et 17000 pi. ca. en 1970. Le budget annuel, lui, a aussi augmenté d'une façon rapide : de $23000 \$$ qu'il était en 1950, il est passé à 95 000\$ en 1960 pour atteindre les 550 000 \$ en 1970. Enfin, le personnel qui en 1950 compte cinq personnes, s'est élargi en une vingtaine d'années à une équipe d'une quarantaine de personnes, dont 9

403 Propos de M. Roger Daoust reporté par Yvan Laprade, « Une longue histoire. L'Institut du cancer de Montréal », Journal de Montréal, 5 déc. 1978, p. 30.

404 Voir A. D. Kelly, The Cancer Movement in Canada, National Institute of Canada, pp. 20-23, non daté.

405 Hughette Roberge, « La recherche, ça donne quoi? », La Patrie, 29 août 1971, p. 8.

406 Ibid., p. 9. 
chercheurs, 7 étudiants diplômés, 2 stagiaires, 14 techniciens(nes) et 8 auxiliaires, et l'évolution de sa production - plus de trois cent soixante publications entre 1950 et 1975 - suit une courbe exponentielle. Bref, pendant ses vingt-cinq premières années, l'Institut «n'a cessé de se développer comme en font foi les accroissements de personnel, d'espaces, de subventions et d'activités scientifiques 407 ».

Mais aussi continue soit-elle, la progression des activités de l'I.C.M. ne parvient pas totalement à faire oublier que le début des années 1970 est le moment d'un «tournant», d'une crise, tant politico-administrative que scientifique, dont l'aboutissement est la venue à l'Institut du docteur René Simard, à titre de directeur scientifique. À la fois l'itinéraire que celui-ci a suivi et la position qu'il occupe dans les milieux scientifiques et politico-administratifs lui permettront de gérer les diverses tensions qui traversent l'Institut du cancer de Montréal et plus largement, le champ de la recherche en cancérologie. Médecin et scientifique (Ph.D.), formé au Canada (Faculté de médecine, Université de Montréal), aux États-Unis (au Mont Sinai Medical School of New York avec le docteur Hans Popper, spécialiste en pathologie) et en France (à l'Institut de recherches scientifiques sur le cancer à Villejuif sous la direction du docteur Wilhelm Bernhard), le docteur Simard (1936-) qui n'a, faut-il le préciser, aucun lien de parenté avec le fondateur de l'Institut, a déjà entrepris une carrière dans la recherche comme chercheur associé au Conseil de recherche médicale en 1974 et dans l'enseignement universitaire comme professeur au Département de biologie cellulaire de l'Université de Sherbrooke. Il occupe, au moment de sa nomination, le poste de président du Conseil de la recherche en santé du Québec. Quelques années plus tard, soit en 1978, le docteur René Simard accédera à la présidence du Conseil de la recherche médicale du Canada ${ }^{408}$. Non seulement ce spécialiste de la biologie cellulaire (transcription de l'ADN) est en mesure d'insuffler un nouveau dynamisme et d'imposer une nouvelle orientation à la recherche, mais aussi il réunit les qualités sociales - dont celle de l'ubiquité - pour diriger une équipe de recherche qui, localisée en un milieu hospitalier, doit développer, en les diversifiant, ses relations avec des organismes subventionnaires, des institutions universitaires et aussi des ministères et autres organismes gouvernementaux. Son

407 Roger Daoust, L'Institut du cancer de Montréal. Historique et revue des activités scientifiques, op. cit., p. 17.

408 Conseil de recherches médicales, Actualités-Newsletter, vol. 8, no 3, avril 1978, p. 1. 
arrivée est d'ailleurs marquée par un coup d'éclat : l'I.N.C. obtient une subvention de 210000 \$ pour le renouvellement des équipements, entre autres un microscope électronique.

Lorsqu'en 1976, l'Institut du cancer de Montréal fait la première page du Cancer Research (vol. 36, no 3, mars 1976), avec photographies de L.-C. Simard et d'A. Cantero, c'est la fin d'une époque, celle du «Montreal Group », petite équipe de chercheurs qui se sont distingués par leurs travaux en cancérogénèse chimique et pour qui Cancer Research, l'une des meilleures revues scientifiques consacrées au cancer, était un média important de diffusion et de consécration. C'est dans cette revue en effet qu'entre 1950 et 1981 les chercheurs publient le plus grand nombre d'articles (55, c'est-à-dire 19?) ${ }^{409}$.

409 La production totale de l'I.C.M. comprend entre 1950 et 1981, 466 publications dont 298 articles parus dans des revues scientifiques, 137 résumés (abstracts), 20 actes de congrès, 7 chapitres de livre et 4 publications non scientifiques. Le corpus sur lequel porte l'analyse ne concerne que les articles et les chapitres de livres publiés par l'un ou l'autre des 29 chercheurs permanents, à temps plein : soit un total de 292 publications. 


\section{Tableau 1}

Budgets annuels de l'I.C.M. selon les sources de subvention

\begin{tabular}{|c|c|c|c|c|c|c|c|c|c|}
\hline & $1972-1973$ & 1973-1974 & 1974-1975 & $1975-1976$ & 1976-1977 & 1977-1978 & 1978-1979 & 1979-1980 & 1980-1981 \\
\hline & $\$ \$$ & $\$$ & $\$$ & $\$$ & $\$$ & $\$$ & $\$$ & $\$$ & $\$$ \\
\hline Institut national du cancer & 253044 & 278363 & 319388 & $546093^{1}$ & 480025 & 555817 & 614926 & 488243 & 536083 \\
\hline Conseil de recherches médicales du Canada & 31900 & 38300 & 42260 & 94805 & 46600 & 132836 & 283790 & 243703 & 379347 \\
\hline Conseil de recherches médicales du Québec & 12000 & - & - & - & 56598 & 155597 & 100310 & 125350 & 145665 \\
\hline \multicolumn{10}{|l|}{ Conseil de recherches en santé du Québec } \\
\hline Ministère des Affaires sociales & - & 180953 & 228930 & 240346 & 365016 & 481319 & 660597 & 759243 & 754083 \\
\hline Ministère de l'Éducation & 3700 & 2800 & 2400 & 4500 & $10500^{2}$ & 8000 & 18000 & 19000 & 13000 \\
\hline Université de Montréal & 34630 & 20150 & 42260 & 48000 & 42448 & 104482 & 68580 & 85301 & 137834 \\
\hline Fonds divers & 15900 & 15000 & 18200 & 27500 & 27500 & 62133 & 68134 & 112175 & 70666 \\
\hline Autres & - & - & - & 11500 & $137148^{3}$ & $194902^{4}$ & 246255 & $372018^{5}$ & 198347 \\
\hline TOTAL & 361174 & 532566 & 627338 & 972744 & 1108231 & 1694086 & 2060622 & 2205681 & 2243267 \\
\hline
\end{tabular}


Source : $\quad$ I.C.M., Revue des activités de l'année, de 1972-1973 à 1980-1981.

1. Dont 210119 \$ en équipement de recherche pour R. Simard.

2. Première subvention du Fonds Formation des chercheurs et action concertée (FCAC).

3. Dont 28600 \$ de la Commission de contrôle de l'énergie atomique et 32000 \$ de l'Eldorado Nuclear.

4. Dont 30490 \$ du ministère de la Santé et du Bien-être social.

5. Dont Il 1095 \$ de l'Association des mines du Québec 
L'analyse de l'ensemble des articles publiés par les chercheurs permet de mesurer le degré et le mode d'insertion de l'I.C.M. dans les réseaux scientifiques internationaux et principalement américains : 93\% des articles sont rédigés en langue anglaise et pour la plupart (163) publiés dans des revues américaines. Parmi les cinq revues auxquelles ces chercheurs collaborent le plus fréquemment, une seule est québécoise : il s'agit de la Revue canadienne de biologie qui publie 15 articles. L'analyse des publications de l'I.C.M. permet enfin d'identifier, audelà des nombreuses et brèves fluctuations -deux ou trois ans -, trois périodes principales dans le développement de ce centre de recherche : une première qui correspond au démarrage de l'Institut (1950-1959) et qui se caractérise par l'augmentation croissante et assez rapide des publications, une seconde (19601974) pendant laquelle le nombre maximum de publications par année se maintient et une troisième (1975-1981) qui se traduit par une tendance à la hausse. Chacune de ces périodes se différencie aussi par la productivité des chercheurs (nombre d'articles par année divisé par le nombre de chercheurs). Après avoir connu une augmentation graduelle de sa productivité, l'Institut traverse dans les années 1960 une période de stabilité et connaît un léger fléchissement ; même si depuis le milieu des années 1970, il y a un redressement en ce qui a trait à la production, les effets de la réorganisation de l'Institut ne sont pas encore visibles d'une façon très nette. Non seulement l'équipe nouvelle est relativement jeune, mais aussi les recherches qu'elle entreprend prennent des orientations différentes et s'inscrivent dans des réseaux nouveaux, parfois plus concurrentiels, qui ne se limitent pas au seul champ de la cancérologie, comme c'était le cas pour la revue américaine Cancer Research, où I'I.C.M. publiait régulièrement des articles. En entrevue, un chercheur rappelle que :

Pour nous, le modèle qui était pratique, c'était la cancérogénèse chimique. Depuis ç'a changé, la technologie a évolué, la biologie moléculaire a avancé... Aujourd'hui, la cancérogénèse virologique apparaît un modèle plus efficace, rapide et moins cher.

Lorsque l'objectif de l'Institut était de «déterminer la cause et découvrir le traitement du cancer ", l'hypothèse qui dirigeait les recherches concernait le " défaut dans les mécanismes cellulaires qui contrôlent la croissance des tissus » et amenait le chercheur à réaliser des travaux ayant pour objet «l'étude des différentes facettes du métabolisme des acides nucléiques, des protéines et des glucides » par des méthodes biochimiques, histochimiques et physico-chimiques. 
Dans un document publié en 1966, les docteurs Simard et Cantero justifiaient le plan de recherche de l'Institut dans les termes suivants :

Il est logique de penser que les causes extérieures (agents chimiques, physiques, biologiques) produisent un même changement dans le métabolisme des cellules, changement qui serait la cause intérieure ou immédiate du cancer. C'est à déterminer la nature de cette altération dans le métabolisme cellulaire que s'appliquent surtout les chercheurs de notre centre [...].

Nous croyons que de telles études nous permettront un jour ou l'autre de mettre le doigt sur le (ou les) défaut(s) du métabolisme cellulaire représentant le mécanisme clé de la cancérisation. Il serait possible ensuite de contrôler la croissance cancéreuse par le rétablissement de l'équilibre chimique normal d'un tissu, c'est-à-dire apporter un traitement en cours 410 .

Les recherches de l'Institut portèrent ainsi sur des « tissus normaux, des tissus en voie de cancérisation et sur des tumeurs provoquées chez l'animal au moyen de substances chimiques cancérigènes » et permirent de mettre en lumière «plusieurs faits quant aux propriétés des tumeurs », par exemple la disparition de certains enzymes au cours de la transformation de cellules normales en cellules cancéreuses. L'importance du cobaye était alors telle que dans les plans élaborés en 1966, un étage complet, soit 7600 pi. ca., était consacré à l'animalerie et aux salles d'opération, les trois autres étages étant réservés à l'administration (aux bibliothèques et salles de conférence), à la biochimie et à la biologie. Quant aux spécialisations des chercheurs détenteurs d'un Ph.D., elles étaient, au milieu des années 1960, les suivantes: biochimie (G. de Lamirande et V. N. Nigam), histochimie (Roger Daoust), pathologie expérimentale (Bernard Messier), microscopie électronique (S. Karasaki) et physico-chimie (Claude Watters).

Lorsqu'en 1975, le docteur René Simard prend la direction scientifique de l'Institut, il « se donne des objectifs à la fois plus vastes et plus pertinents à la cancérologie humaine », tant en recherche fondamentale qu'en recherche clinique et préventive et constitue, dans une perspective multidisciplinaire, quatre groupes de recherche: le groupe de biologie cellulaire et moléculaire (étude de la régulation de l'activité génétique dans les cellules normales et cancéreuses), le

410 Texte rédigé (28 pages) par L.-C. Simard et A. Cantero, en 1966, pp. 6-7. 
groupe herpès (étude des relations étiologiques entre le virus herpès et le cancer du col utérin) et le groupe sur la carcinogénèse de l'environnement (identification des substances cancérigènes dans l'environnement humain) et le groupe de recherches cliniques (participation avec le Centre d'oncologie à l'élaboration de protocoles de traitement). La présentation graphique des interrelations entre ces divers groupes accorde une centralité au premier groupe et témoigne de l'importance que prend pour l'I.C.N. le développement de la biologie cellulaire et moléculaire 411 (voir le schéma 1).

\section{SCHÉMA I}

Groupes de recherches de l'I.C.M. en 1976

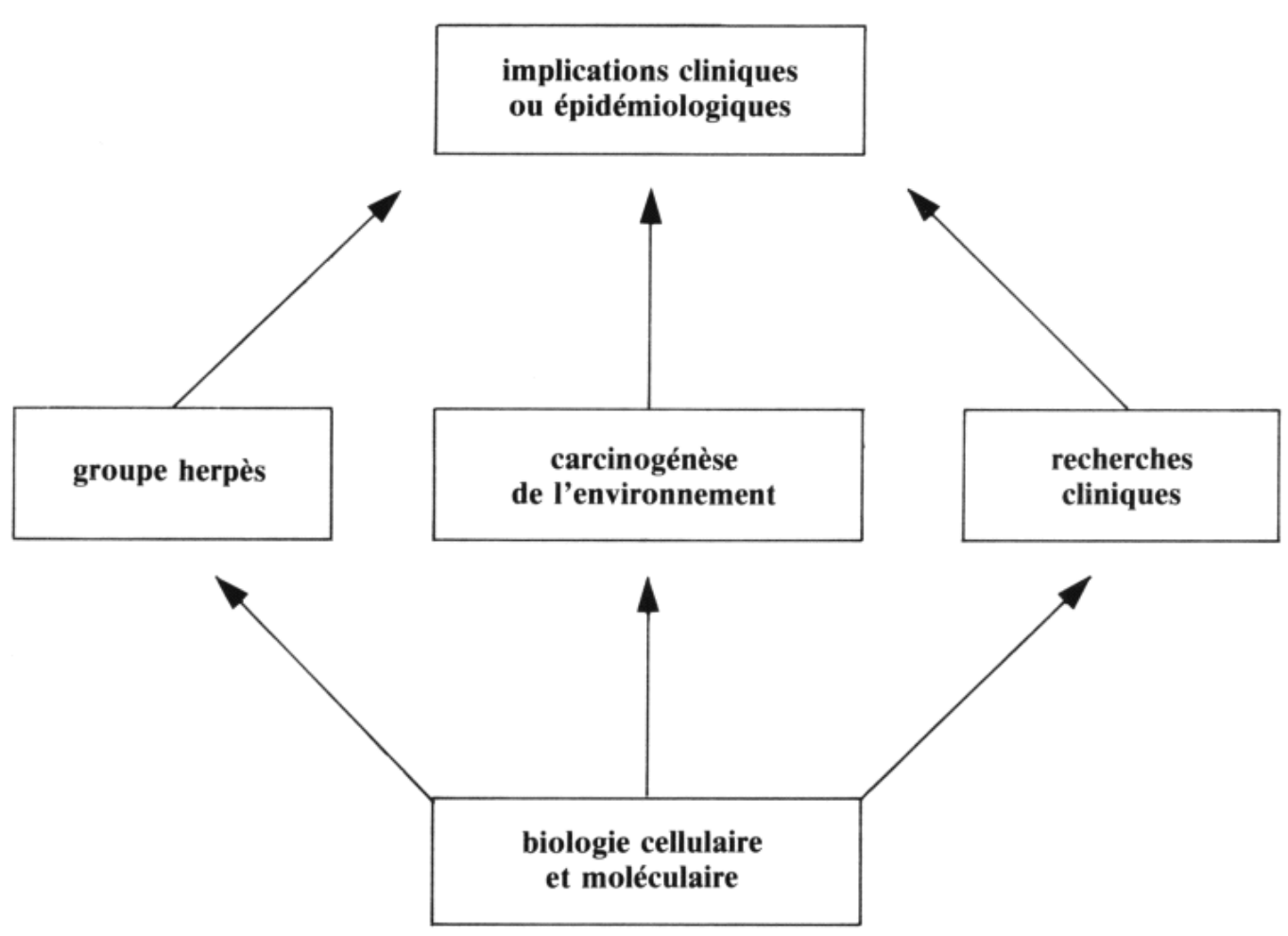

411 Institut du cancer de Montréal, Objectifs et programme scientifique, avril 1976, 11 pages (plus annexes). 
La réorientation de l'Institut du cancer de Montréal constitue une réponse, avec quelques années de retard, au « coup de théâtre » qui bouleverse la recherche en biologie moléculaire au début des années 1970. Ce « coup de théâtre » est la découverte de la «Reverse Transcriptase » qui, réalisée simultanément par des chercheurs américains, H. Temin et D. Baltimore, permet de copier ARN en ADN 412 . Tout en s'inscrivant dans le champ en pleine expansion de la biologie moléculaire, le nouvel objet que constitue la « Reverse Transcriptase » offre l'avantage « d'être suffisamment petit pour permettre des recherches intensives, d'être le lieu de découvertes potentielles dans le contrôle du cancer et, enfin, d'avoir une pertinence sur le plan politique 413 ». Cette découverte apportera à ses auteurs le Prix Nobel en 1975, provoquera une explosion des recherches et des publications et mobilisera les énergies de grands laboratoires américains, tel celui de M. Spiegelman à Columbia. L'importance de cette découverte oblige aussi les chercheurs canadiens à une véritable « conversion »; elle les amène à abandonner d'anciens modèles, d'anciennes méthodes et d'anciens instruments de recherche. Puisqu'il en va à la fois de connaissances théoriques, de compétences scientifiques et d'habiletés scientifiques, un tel changement ne peut pas se faire sans quelques résistances et il signifie souvent un renouvellement du personnel scientifique.

Si l'on fait exception des deux premiers chercheurs qui ont « fait carrière » à l'Institut, le personnel semble se renouveler assez fréquemment: la durée moyenne d'emploi de la trentaine de chercheurs associés à l'Institut entre 1950 et 1980 est de 5,4 années et correspond à l'ancienneté moyenne des chercheurs en poste en 1980 qui est de six ans. Avec son jeune personnel, l'Institut apparaît comme un lieu de formation et comme un «tremplin » pour de jeunes chercheurs ou des chercheurs d'origine étrangère. Cette « jeunesse » de l'Institut du cancer de

412 Au sujet de l'impact de cette découverte, voir K. E. Struber et D. L. Chubin, The Cancer Mission, Social Contexts and Biomedical Research, Sage Publications, Beverly Hills, 1980, Partie II, « Reverse Transcriptase », pp. 106-256. Jean Feunteun présente pour sa part cette découverte dans les termes suivants : "Les virus cancérogènes à RNA possèdent un enzyme, la " reverse transcriptase », qui permet de " copier » le RNA en DNA. Cette copie DNA peut alors s'intégrer normalement dans le DNA de l'hôte. On admettait jusqu'ici comme un dogme de la biologie moléculaire que seul le DNA pouvait être recopié en RNA et jamais l'inverse " «La cancérogénèse vitale », La recherche sur le cancer, Paris, Le Point, Éd. du Seuil, pp. 52-53.

413 K. E. Stuber et D. L. Chubin, The Cancer Mission, op. cit. 
Montréal tient tout autant à sa localisation géographique et institutionnelle centre de recherche en milieu francophone, absence de permanence pour les chercheurs, etc. - qu'à la réorganisation dont il est l'objet au milieu des années 1970.

Au moment de la venue du docteur René Simard, plusieurs nouveaux chercheurs sont effectivement recrutés : Martha Suh, Allegria Kessous-Elbaz, W. Edward Bradley, Eric Frost et autres. Cependant, seuls les deux premiers groupes de recherche (biologie cellulaire et herpès) apparaissent « fonctionnels ». Deux chercheurs déjà présents à l'Institut, l'un depuis 1966 et l'autre depuis 1968, sont aussi impliqués dans l'élaboration de nouveaux programmes. Il s'agit du docteur Réjean Morais, en carcinogénèse de l'environnement et Antoine Simard, en épidémiologie. Enfin, le secteur des recherches cliniques débutera bientôt ses opérations avec la venue en 1976 du docteur Pierre Band.

C'est donc dire qu'au milieu des années 1970, l'Institut du cancer de Montréal connaît un « second souffle ». D'ailleurs, entre 1975 et 1980, son budget passe de 973000 \$ à 2243 207\$, ce qui permet de regrouper une équipe plus nombreuse. En 1980, l'I.C.M. compte plus de quatre-vingts personnes, dont une vingtaine de chercheurs. Enfin, la diversification des sources de financement et la participation plus significative d'organismes québécois, dont le ministère des Affaires sociales et le Conseil de recherches en santé du Québec, permettent de réduire la dépendance de l'I.C.M. à l'égard de l'Institut national du cancer : déterminante au cours des années 1950 et 1960, la contribution financière de cet organisme devient, à la fin des années 1970, secondaire (moins de 30\%). D'une manière plus conséquente, l'action de l'État, d'abord provincial et aussi fédéral, par le biais du Conseil de recherches médicales du Canada, devient une condition au maintien et au développement de la recherche à l'I.C.M. (voir le tableau 1).

Toutefois, même si l'entente avec le ministère des Affaires sociales assure une stabilité à l'équipe de recherche - financement de douze postes de chercheur - et que la recherche s'oriente vers des secteurs "plus prometteurs » sur le plan scientifique - liaison de l'approche biochimique à une approche structurale dans l'étude du virus herpès, etc. - et à plus forte incidence sociale - recherches cliniques et épidémiologiques, etc. -, l'Institut du cancer de Montréal demeure confronté à divers problèmes qui sont largement liés à la position même qu'il 
occupe - entre l'hôpital et l'université - et aussi à ses relations financières et scientifiques avec l'Institut national du cancer.

En effet, si la subvention du M.A.S. contribue à doter l'équipe de recherche d'une relative stabilité, elle n'assure pas à chacun de ses membres la permanence, de la même façon que peut le faire une institution universitaire. Tout comme dans les années 1960, l'I.C.M. a perdu des chercheurs qui ont préféré poursuivre leur carrière en milieux universitaires - ce fut le cas de Claude Allard, de Georges Weber et d'autres. Encore récemment, il n'a pas su retenir les services d'un jeune biochimiste prometteur, Gordon Shore, maintenant à l'Université McGill. L'Institut n'a pas su non plus attirer des immunologistes. Le docteur Simard déplore lui-même qu'on ne reconnaisse pas de statut au professionnel de la recherche :

Il n'existe aucune reconnaissance dans quelque secteur que ce soit pour celui qui se définirait comme un professionnel de la recherche [...]. Ceux qui (dans les universités) portent le titre d'adjoint, agrégé ou titulaire de recherche, n'ont ni poste universitaire, ni rémunération universitaire, ni convention collective qui les protège, ni statut professionnel. Ils n'ont au surplus aucun «droit politique » dans les départements universitaires. Cette situation, ajoutée au fait que le recrutement dans les départements se fait en fonction de l'enseignement, non de la recherche, et que de toutes façons le nombre de postes a plutôt tendance à plafonner, n'est pas sans amener des répercussions sérieuses sur nos effectifs de recherche, la qualité des scientifiques que l'on voudrait recruter, le renouvellement ou l'addition de nouveaux chercheurs dans les secteurs prioritaires [...]. L'absence d'un statut de professionnel de la recherche rendra difficile la mise en oeuvre d'une politique scientifique, puisque le «savoir-faire » risque de faire défaut 414 !

Par ailleurs, les relations avec l'Université de Montréal demeurent toujours conflictuelles, non seulement au sujet du statut des chercheurs 415 mais aussi de

414 Dr René Simard, « La recherche sur la santé : problèmes et perspectives », Le Devoir, mercredi 14 décembre 1977, p. 32. Publié au moment où le gouvernement du Québec prépare un livre vert sur le développement culturel, ce texte est rédigé par le docteur Simard alors qu'en plus d'être directeur de l'I.C.M., il est aussi président du Conseil de la recherche en santé du Québec.

415 En 1978, il y a révision du contrat d'affiliation avec l'Université de Montréal : création d'un comité de liaison, mise sur pied d'une nouvelle procédure de nomination du directeur scientifique (avec participation du 
celui des étudiants. En raison de l'organisation de la Faculté de médecine, ces étudiants qui poursuivent des études supérieures sous la direction de chercheurs de l'Institut obtiennent jusqu'à tout récemment 416 Un Ph.D. non pas dans leur spécialité propre, en biochimie par exemple, mais en sciences cliniques. Le terme « recherches cliniques» demeure d'autant plus ambigu que sur la question des recherches cliniques, la relation de l'Institut et l'Hôpital demeure problématique : «Les activités purement cliniques sont du ressort du Centre d'oncologie de l'Hôpital Notre-Dame, mais la recherche clinique relève de l'Institut 417 ». Institutionnel, le conflit prendra, pendant les quelques années (1976-1980) où le docteur Pierre Band est à l'Institut, la dimension d'un « conflit de personnalité » et rendra difficile tout développement de ce secteur d'activités qui se situe à la frontière de la recherche scientifique et de la pratique médicale ${ }^{418}$. Avec l'orientation nouvelle qu'un autre chercheur, Antoine Simard, donne à ses travaux, l'I.C.M. développera beaucoup plus rapidement la recherche épidémiologique, et acquerra, auprès du public, une plus grande visibilité sociale : études auprès des travailleurs d'une fonderie de l'Est de Montréal et des travailleurs de l'amiante avec subvention de l'Association des mines d'amiante du Québec-, surveillance des mineurs de l'uranium, étude nationale sur le dépistage du cancer du sein, etc. Présente à l'origine de l'Institut, la dimension sociale réapparaît ainsi par le biais

Conseil de la Faculté de médecine), réaffirmation des obligations conjointes (collaboration de l'Institut à l'enseignement universitaire, etc.).

416 Cette « anomalie » a été corrigée tout récemment en 1984.

417 Procès-verbal du Conseil d'administration de l'I.C.M., 12 avril 1978, p. 8.

418 Préoccupée par le développement de l'oncologie comme spécialité médicale, la Corporation professionnelle des médecins du Québec crée un comité ad hoc pour "faire le bilan de l'exercice multidisciplinaire en oncologie et faire des recommandations à propos de la reconnaissance ou non de cette compétence ». Dans son rapport préliminaire, ce comité identifie les principaux centres ou organismes (Institut du cancer et Centre d'oncologie de l'Hôpital Notre-Dame, « McGill Cancer » créé en 1979 à l'Université McGill, le Laboratoire d'oncologie moléculaire dirigé à l'Hôtel-Dieu de Québec par le docteur Luc Bélanger, le Centre hospitalier universitaire de Sherbrooke), analyse la formation et les activités des médecins exerçant l'oncologie et en conclusion, suggère que l'appellation « oncologique » ne soit pas ajoutée à la désignation des spécialités actuelles, parce que l'oncologie médicale apparaît une « discipline horizontale » (La compétence en oncologie clinique, rapport préliminaire d'un comité ad hoc de la Corporation professionnelle des médecins du Québec, août 1981, 27 pages). 
des études épidémiologiques, mais elle ne détermine pas l'orientation scientifique des recherches menées par les divers groupes de chercheurs; l'action du groupe des pairs est toujours présente, en particulier par le biais de l'Institut national du cancer. 


\section{L'orientation de la recherche : régulation, coordination et autodétermination}

Bien qu'étroitement dépendantes du développement général des connaissances scientifiques et techniques, la définition des objets d'étude, l'élaboration des stratégies de recherche et l'organisation des activités scientifiques trouvent dans des contextes sociaux et institutionnels particuliers diverses contraintes et possibilités qui, tout au moins en ce qui regarde les modalités de réalisation, orientent la recherche.

L'action de l'Institut du cancer de Montréal s'inscrit manifestement dans la « grande lutte contre le cancer », qui réussit à mobiliser d'importantes ressources financières: depuis le début des années 1950, l'I.C.M. bénéficie de l'appui financier de l'Institut national du cancer, organisme de subvention à la recherche rattaché à la Société canadienne du cancer. Par les mécanismes d'évaluation qu'il instaure et par les efforts de planification et de coordination qu'il déploie autour de l'ensemble de la recherche sur le cancer au Canada, cet organisme exerce, même s'il n'est pas le seul organisme subventionnaire, un véritable pouvoir de régulation sur la recherche tant de l'I.C.M. que des autres centres. Même médiatisée par la participation de pairs - autres scientifiques, canadiens ou étrangers -, l'intervention de l'Institut national du cancer n'en apparaît pas moins « directive » : la réorientation que connaît la recherche à l'I.C.M. au milieu des années 1970 est une « réponse » au coup de théâtre » en biologie moléculaire des Temin et Baltimore, mais cette « réponse » est largement sollicitée par l'Institut national du cancer et ses groupes d'évaluateurs. Pour l'I.C.M., cette réorientation ne s'effectue pas sans difficultés ni résistance, puisqu'elle exige à la fois la « reconversion" - vers de nouvelles connaissances théoriques, de nouvelles techniques et de nouveaux instruments - et le renouvellement du personnel scientifique.

La « dépendance » des chercheurs à l'égard d'un organisme tel l'Institut national du cancer est d'autant plus grande que son action est source à la fois de crédibilité scientifique et de légitimité sociale. Même si l'Institut du cancer de Montréal bénéficie de subventions statutaires du gouvernement provincial et qu'il 
a réussi depuis la fin des années 1970 à diversifier ses sources de subventions, ses chercheurs demeurent l'objet d'évaluations (site visits) qu'effectue périodiquement - tous les trois ans - l'Institut national du cancer. Ces évaluations portent tout autant sur la qualité des recherches et la valeur des chercheurs - maîtrise de la littérature, habiletés techniques, esprit d'équipe, aptitude à identifier les problèmes importants et à évaluer les difficultés, etc. - que sur le fonctionnement général du centre de recherche - nature du leadership scientifique, diversité de l'expertise, structure d'âge du personnel scientifique, etc. Une grande insécurité caractérise les activités que mènent l'I.C.M. et ses différents chercheurs : tout en reconnaissant la valeur d'un tel système d'évaluation, les chercheurs manifestent une certaine anxiété et n'hésitent pas à formuler diverses critiques. Ces critiques portent d'une part sur la prédominance d'un groupe de spécialistes au sein de l'Institut national du cancer, celui des spécialistes en virologie et en biologie moléculaire, d'autre part sur les critères d'évaluation (importance du nombre de publications) et le mode d'attribution des subventions (d'une durée de deux ou trois ans) :

Deux ou trois ans, c'est, confie un chercheur, trop court, surtout lorsqu'on entreprend une nouvelle recherche. Le chercheur risque alors de faire des travaux uniquement pour publier indépendamment de l'intérêt scientifique [...]. Les idées originales sans publication ne passent pas. On refuse des projets risqués, surtout de la part de jeunes chercheurs.

L'I.N.C., c'est, remarque un autre chercheur, un outil qui permet de connaître le point de vue d'autres chercheurs [...]. Mais pour le chercheur, c'est dur. Souvent, ce qui est en cause, c'est leur poste, leur vie... Certes le système encourage l'élitisme: les meilleurs deviennent de plus en plus riches et les médiocres disparaissent. Certes il y a aussi des règlements de compte... Mais c'est le meilleur système que je connaisse. De la démocratie, Churchill ne disait-il pas : «C'est le pire des systèmes, mais on n'en connaît pas de meilleurs. »

La recherche est ainsi, non seulement de par les interactions entre les chercheurs, mais aussi sur le plan institutionnel, l'objet d'une «négociation permanente » : l'enjeu est d'autant plus grand qu'il s'agit pour les chercheurs non plus seulement d'accroître leur renommée et leur crédibilité scientifique, mais aussi de sauver leurs postes - et leur gagne-pain - et de s'assurer les conditions de poursuite d'une activité scientifique. Les stratégies que développent, plus ou moins consciemment, les chercheurs sont évidemment diverses : elles reposent le 
plus souvent sur des compromis - entre les préoccupations personnelles et les orientations privilégiées par l'Institut national du cancer - et peuvent donner lieu à des « ruses », tant sur le plan collectif qu'individuel - par exemple, participation de chacun des chercheurs à plus d'un projet de recherche, réalisation de travaux de recherche qui, au moment où les chances de réussite sont plus grandes, sont transformés en programme de recherche et soumis pour fin de subvention à l'I.N.C., etc. Pour l'Institut qui entend réunir une équipe de bons chercheurs, l'enjeu que constitue l'obtention de ces subventions est d'autant plus grand que sa position institutionnelle est précaire et que sa situation géographique apparaît quelque peu désavantageuse :

Le recrutement qui a été réalisé est très bon, note un des chercheurs. C'est réussi, compte tenu du contexte. Mais c'est fragile, surtout lorsqu'on recrute de bons chercheurs : s'il est bon, un chercheur est sollicité ailleurs. Pour des anglophones, il n'y a pas de problème à s'en aller dans un milieu anglophone, si on leur offre un avantage [...]. Il y a eu un Japonais, aussi un Indien, qui avait l'expertise dont l'Institut avait de besoin. Ce chercheur originaire de l'Inde est allé à l'Université de Sherbrooke où on lui offrait un poste permanent [...]. À trente ans la question de la permanence ne te préoccupe pas, à quarante ans, ça commence à te préoccuper et à quarantecinq, c'est un « must » surtout lorsque le chercheur est sur-spécialisé dans un petit domaine.

La double affiliation institutionnelle fournit à l'I.C.M. sa légitimité sociale : ses chercheurs participent en effet à la fois au milieu de la médecine et à celui de l'enseignement universitaire. Hier, les chercheurs de l'Institut pouvaient se présenter dans le contexte hospitalier et face au grand public, comme des « docteurs »; aujourd'hui, le directeur du centre est un scientifique qui a reçu luimême une formation médicale avancée. En même temps, cette double participation au monde de la médecine et au système universitaire met les chercheurs dans une position sociale particulière, ambiguë: le chercheurscientifique n'a le statut ni du médecin-clinicien ni du professeur d'université, mais il doit satisfaire à des exigences et à des demandes qui proviennent de ces différents milieux. Un tel contexte social et institutionnel amène le Centre de recherche et ses chercheurs à s'identifier et à s'intégrer aux différents milieux qui les entourent tout en cherchant à s'en différencier. Et même s'il a établi quelques relations avec le monde de l'industrie - par exemple avec la compagnie pharmaceutique Merck Sharp \& Dohme Canada pour l'organisation de 
conférences sur la cancérologie ou avec l'Association des mines d'amiante du Québec pour la réalisation de recherches épidémiologiques -, l'Institut du cancer de Montréal ne s'est pas transformé en une «industrie » (avec production d'analogues de substances naturelles ou la purification de substances naturelles). Les activités scientifiques des chercheurs demeurent, pour une part tout au moins, autodéterminées, c'est-à-dire qu'elles dépendent de leur compétence et des préoccupations des milieux scientifiques qu'ils fréquentent. Leurs énergies sont consacrées à la recherche et, pour une large part, à une recherche à caractère fondamental.

\section{Conclusion}

Dans le secteur biomédical, la recherche à caractère fondamental est toujours orientée en fonction d'autres activités ou préoccupations telles que l'enseignement médical, les soins et techniques thérapeutiques, la production industrielle d'analogues de substances naturelles, etc. Lorsqu'ils ne sont ni totalement intégrés au milieu hospitalier ni transformés en «industrie » et insérés dans un réseau industriel - industries pharmaceutiques, etc. -, les centres et les instituts qui mènent une telle recherche n'ont souvent, s'ils veulent conserver un caractère « fondamental » à leurs activités, d'autres choix que de se fondre dans le milieu universitaire. Au Québec, on a l'impression que la recherche scientifique a été, au cours des décennies précédentes, et demeure étroitement reliée au système universitaire, au point que cette recherche puisse être dite «académique » en raison de sa dépendance d'activités, d'enseignement et d'encadrement des étudiants ${ }^{419}$. Dans un pays dont la dépendance économique est plus marquée qu'ailleurs, l'université apparaît souvent comme le meilleur endroit pour développer des activités de recherche scientifique. Or, dans l'étude qu'elle a réalisée sur l'Institut Oswaldo Cruz au Brésil 420, Nancy Stepan montre qu'au contraire, la localisation de ce centre à l'extérieur de l'institution universitaire fut

419 Francine Descarries-Bélanger, Marcel Fournier, Louis Maheu et C. Richard, "La science du Québec francophone », The Canadian Review of Sociology and Anthropology, vol. 21, n' 3, août 1984, pp. 247-274.

420 Nancy Stepan, Beginnings of Brazilian Science, New York, Science History Publication, 1981. 
l'une des causes de son développement et des succès qu'il a obtenus. Tout en éliminant la tension souvent paralysante entre enseignement et recherche, la formule d'autres institutions - universitaires, médicales, etc. - selon laquelle est constitué un centre de recherche indépendant ou relativement autonome, permet de réunir un groupe de chercheurs qui, souvent de formation différente due à la multidisciplinarité, travaillent ensemble sur un ou plusieurs projets. De plus, côté enseignement universitaire, l'institut ou le centre de recherche offre l'avantage d'une plus grande flexibilité et d'un meilleur encadrement pour les étudiants orientés vers la recherche. Enfin, il est plus facile, dans ce cadre institutionnel, d'établir une relation entre la recherche et ses applications, et aussi de mettre en contact les chercheurs eux-mêmes avec les diverses populations qui utilisent les résultats de leurs recherches.

Il y aurait intérêt à analyser le développement d'autres centres de recherche qui, reliés au domaine biomédical, se sont consacrés à la recherche tout en se préoccupant de l'enseignement universitaire et du traitement : pensons à l'Institut de neurologie de Montréal, l'Institut de microbiologie et d'hygiène de Montréal, qui deviendra l'Institut Armand-Frappier, l'Institut de cardiologie, l'Institut de recherches cliniques de Montréal et bien d'autres.

Dans le cas de l'Institut du cancer de Montréal, comme dans celui d'autres centres de recherche, la relative autonomie institutionnelle apparaît aussi comme une condition à son maintien et à son développement, mais en autant qu'il a su acquérir une crédibilité scientifique et une légitimité sociale. Dès ses débuts, l'I.C.M. s'est trouvé, avec sa petite équipe de chercheurs et ses modestes budgets, dans une situation fort différente de celle d'autres grands centres américains qui, comme le Sloan-Kettering Institute, regroupait des centaines de chercheurs et disposait de grands budgets : les recherches de l'Institut du cancer de Montréal sont demeurées plus fondamentales et portèrent évidemment sur des cas moins nombreux. L'I.C.M. n'en a pas moins établi des contacts avec les milieux industriels et réussi à être en relation, d'une manière directe ou indirecte, avec les « malades » par l'observation et aussi avec le grand public grâce aux articles dans les journaux, aux conférences, à la mise sur pied d'un programme de dépistage du cancer du sein, entre autres.

Mais, en demeurant associé à une institution hospitalière, l'Institut du cancer de Montréal trouve - et révèle - l'une des conditions rendant possible la recherche 
biomédicale : entre le milieu médical et celui de la recherche scientifique, s'établit un « échange » dont chacun tire profit. Par leur localisation à l'Hôpital NotreDame, ce centre de recherche avec ses chercheurs acquièrent, du fait d'être impliqués dans la « lutte contre le cancer », une légitimité sociale. Même si leur tâche est de "comprendre ", celle-ci apparaît publiquement subordonnée au « souci de soigner » et à la " volonté de guérir ». Quant à l'« art de guérir » qu'est la médecine, elle retrouve, par son association avec la recherche scientifique, une nouvelle légitimité : en acquérant ainsi une dimension scientifique, la pratique médicale parvient, face à cette «maladie mystérieuse et malpropre » qu'est le cancer, à ne pas paraître totalement impuissante.

Fin du texte 